\title{
Title: An Isolable Mononuclear Palladium(I) Amido Complex
}

Authors: Jian Liu', Melissa M. Bollmeyer², Yujeong Kim ${ }^{3,4}$, Dengmengfei Xiao ${ }^{5}$, Samantha N. MacMillan $^{2}$, Qi Chen ${ }^{1}$, Xuebing Leng ${ }^{1}$, Sun Hee Kim ${ }^{3,4 *}$, Lili Zhao ${ }^{5 *}$, Kyle M. Lancaster ${ }^{2 *}$, and Liang Deng ${ }^{1 *}$.

\section{Affiliations:}

${ }^{1}$ State Key Laboratory of Organometallic Chemistry, Shanghai Institute of Organic Chemistry, University of Chinese Academy of Sciences, Chinese Academy of Sciences, 345 Lingling Road, Shanghai 200032, China.

${ }^{2}$ Department of Chemistry and Chemical Biology, Cornell University, Ithaca, NY, USA.

${ }^{3}$ Western Seoul Center, Korea Basic Science Institute (KBSI), Seoul 03759, Republic of Korea.

${ }^{4}$ Department of Chemistry and Nano Science, Ewha Womans University, Seoul 03760, Republic of Korea.

${ }^{5}$ Institute of Advanced Synthesis, School of Chemistry and Molecular Engineering, Nanjing Tech University, Nanjing 211816, China.

*Correspondence to: shkim7@kbsi.re.kr (S.H.K), ias_llzhao@njtech.edu.cn (L.Z.), km1236@cornell.edu (K.M.L.), deng@sioc.ac.cn (L.D.).

\section{Abstract:}

Mononuclear $\mathrm{Pd}(\mathrm{I})$ species are putative intermediates in $\mathrm{Pd}$-catalyzed reactions, but our knowledge about them is limited due to difficulties in accessing them. Herein, we report the isolation of a $\mathrm{Pd}(\mathrm{I})$ amido complex, [(BINAP)Pd(NHAr $\left.{ }^{\text {Trip }}\right)$ ] (BINAP $=2,2^{\prime}-$ bis(diphenylphosphino)-1,1'-binaphthalene, $\operatorname{Ar}^{\text {Trip }}=2,6$-bis(2',4',6'-triisopropylphenyl)phenyl), from the reaction of (BINAP)PdCl 2 with $\mathrm{LiNHAr}^{\text {Trip }}$. This $\mathrm{Pd}(\mathrm{I})$ amido species has been characterized by X-ray crystallography, electron paramagnetic resonance, and multi-edge Pd Xray absorption spectroscopy. Theoretical study revealed that, while the 3 -electron-2-center $\pi$ interaction between $\mathrm{Pd}$ and $\mathrm{N}$ in the $\mathrm{Pd}(\mathrm{I})$ complex imposes severe Pauli repulsion in its $\mathrm{Pd}-\mathrm{N}$ bond, pronounced attractive inter-ligand dispersion force aids its stabilization. In accord with its electronic features, reactions of homolytic $\mathrm{Pd}-\mathrm{N}$ bond cleavage and deprotonation of primary amines are observed on the $\mathrm{Pd}(\mathrm{I})$ amido complex.

\section{One Sentence Summary:}

30 An isolable $\mathrm{Pd}(\mathrm{I})$ amido complex was prepared and its electronic structure and reactivity properties characterized.

\section{Main Text:}

Palladium is a frequently used metal in the modern molecular chemists' catalyst arsenal, and can be found in a variety of useful organic reactions, such as Wacker oxidations, crosscouplings, $\mathrm{C}-\mathrm{H}$ bond functionalization and hydrogenation reactions (1). Underlying the broad utility of Pd are the multiple oxidation states accessible, which suit them well to the formation and cleavage of covalent bonds. Pd compounds most commonly occur as diamagnetic, closedshell $\mathrm{Pd}(0), \operatorname{Pd}(\mathrm{II})$ and $\mathrm{Pd}(\mathrm{IV})$ complexes. Paramagnetic, open-shell Pd compounds are far less prevalent, but are now receiving increased attention (2-5). Paramagnetic $\operatorname{Pd}(\mathrm{I})$ species, for example, are implicated as intermediates in some Pd-catalyzed reactions, but sparse data are 
available concerning their electronic structures and reactivity. In $\mathrm{Pd}$-catalyzed $\mathrm{C}-\mathrm{C}$ bondforming reactions, $\mathrm{Pd}(\mathrm{I})$ halide species $\mathrm{L}_{n} \mathrm{Pd}^{\mathrm{I}} \mathrm{X}(\mathrm{L}=$ phosphine; $\mathrm{X}=\mathrm{Br}$, I) are proposed to form via single-electron transfer reactions of photo-excited $\mathrm{Pd}(0)$ phosphine complexes with organic halides (6-8), as well as in the reactions of $\operatorname{Pd}(0)$ phosphine complexes with fluoroalkyl halides (9) (Fig. 1A). In the reactions of $\mathrm{Pd}(0)$ species with dioxygen, which is a key step in $\mathrm{Pd}-$ catalyzed aerobic oxidation reactions, $\mathrm{Pd}(\mathrm{I})$ superoxide species $\mathrm{L}_{\mathrm{n}} \mathrm{Pd}^{\mathrm{I}}\left(\eta^{1}-\mathrm{OO}^{\circ}\right)$ are proposed as intermediates en route to $\mathrm{Pd}(\mathrm{II})$ peroxides $\mathrm{L}_{\mathrm{n}} \mathrm{Pd}^{\mathrm{II}}\left(\eta^{2}-\mathrm{O}_{2}\right)(10)$ (Fig. 1A). The formation of the $\mathrm{Pd}(\mathrm{I})$ intermediates has also been envisaged in thermolysis or photolysis of $\mathrm{Pd}(\mathrm{II})$ compounds. For example, photolysis-induced decomposition of (PNP)Pd(II) alkyl (PNP = phosphine-amidophosphine) complexes was proposed to proceed through (PNP)Pd(I) intermediates that dimerized to yield diamagnetic, dinuclear $\mathrm{Pd}(\mathrm{I})$ complexes (11) (Fig. 1A).
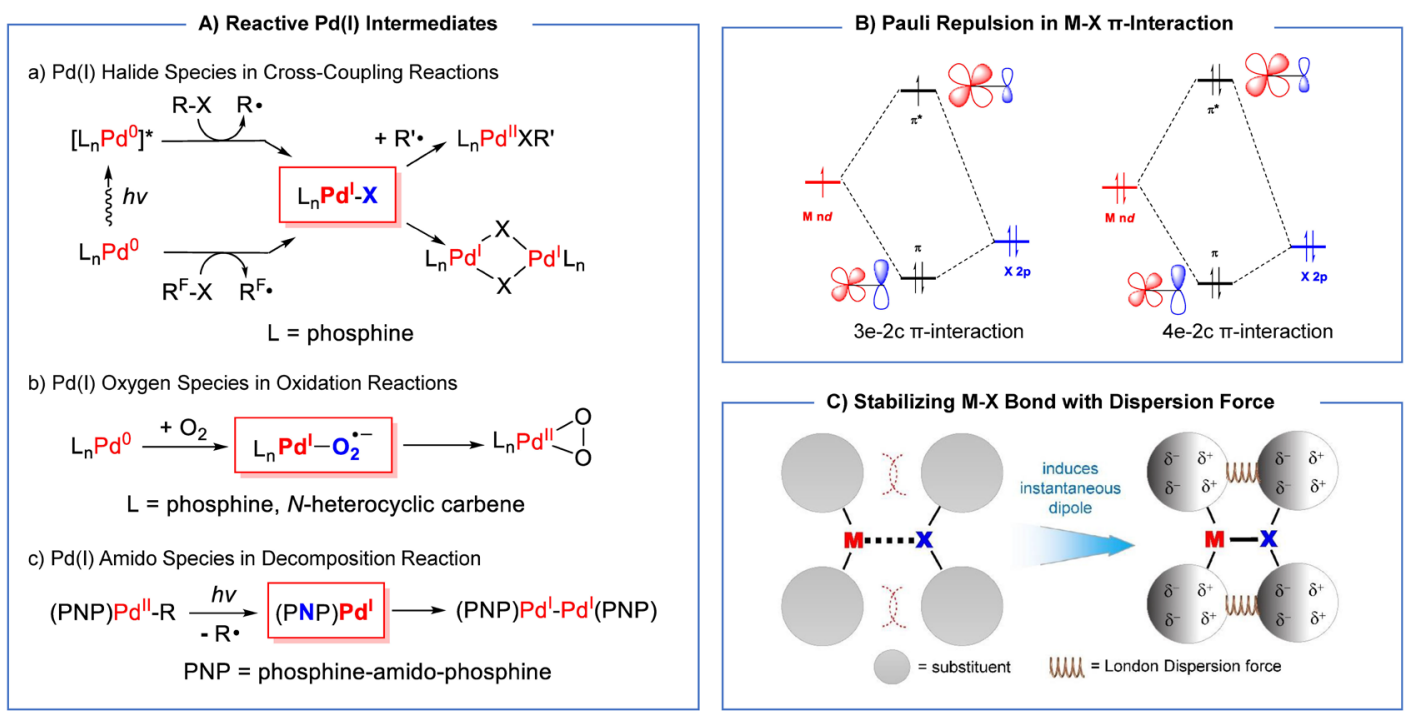

Fig. 1. Research background on Pd(I) species bearing $\pi$-donating ligands. (A) Examples of reactive $\mathrm{Pd}(\mathrm{I})$ intermediates containing $\pi$-donating ligands. (B) Pauli repulsion in metal-ligand $\pi$ interaction. (C) A cartoon illustrating how London dispersion forces stabilize an $\mathrm{M}-\mathrm{X}$ bond.

A common feature of the aforementioned reactive $\mathrm{Pd}(\mathrm{I})$ intermediates is the presence of $\pi$ donors-ligands whose coordinating atoms bear non-bonding lone pairs, e.g. halides, superoxide, and amido in the aforementioned cases - within Pd's inner coordination sphere. Such mononuclear $\mathrm{Pd}(\mathrm{I})$ species reported to date are exceedingly reactive and have only been observed using spectroscopic methods in $\gamma$-ray irradiated $\mathrm{Pd}(\mathrm{II}) \mathrm{Cl}_{2}$ and $\mathrm{Pd}(\mathrm{II})(\mathrm{acac})_{2}$ and thermalized $\mathrm{Pd}(\mathrm{II})$-exchanged zeolites (12-14), where their stability is conferred by immobilization within the lattice framework. Certain $\operatorname{Pd}(0)$ and $\operatorname{Pd}(\mathrm{II})$ complexes are reported to undergo chemical and electrochemical redox reactions to produce mononuclear paramagnetic $\mathrm{Pd}(\mathrm{I})$ complexes (15-19). These include three isolable complexes $\left[\left(\mathrm{PBu}_{3}^{t}\right)_{2} \mathrm{Pd}\right] \mathrm{X}\left(\mathrm{X}=\mathrm{PF}_{6}\right.$, $\left.\mathrm{CB}_{11} \mathrm{Cl}_{11} \mathrm{H}\right)(18,19)$ and $\left[\left(\mathrm{PBu}_{3}^{t}\right)_{2} \mathrm{Pd}(\mathrm{NCMe})\right]\left(\mathrm{CB}_{11} \mathrm{Cl}_{11} \mathrm{H}\right)(19)$. These mononuclear $\mathrm{Pd}(\mathrm{I})$ complexes, however, are not supported by $\pi$-donating ligands. To our knowledge, isolable $\mathrm{Pd}(\mathrm{I})$ complexes bearing $\pi$-donating ligand have remained elusive. The challenge of accessing mononuclear $\mathrm{Pd}(\mathrm{I})$ complexes bearing $\pi$-donating ligands likely originates from severe Pauli repulsion: conventional wisdom dictates that $\pi$-interactions between the $n d$ orbitals of low-valent platinum-group metals (Ru, Rh, Pd, Os, Ir, Pt) and the lone pairs of $\pi$-donors (Fig. 1B) should enforce severe Pauli repulsion $(20,21)$, leading to the destabilization of the metal-ligand 
multiple bond. Pauli repulsion has been used to explain the high reactivity of low-valent platinum-group metal amido, alkoxide, imido, oxo, and nitride species (22-24). So far, lowvalent platinum-group metal complexes containing $\pi$-donor ligands are restricted to the $n \mathrm{~d}^{6}-n \mathrm{~d}^{8}$ metal ions (25-27). Analogous isolable complexes containing a $n \mathrm{~d}^{9}$-platinum-group metal center are unknown.

Herein we report the first $n \mathrm{~d}^{9}$ platinum-group metal terminal amido complex, namely the $\mathrm{Pd}(\mathrm{I})$ complex [(BINAP)Pd(NHAr $\left.{ }^{\text {Trip }}\right)$ ] (BINAP = 2,2'-bis(diphenylphosphino)-1,1'-binaphthalene, $\operatorname{Ar}^{\text {Trip }}=2,6$-bis $\left(2^{\prime}, 4^{\prime}, 6^{\prime}\right.$-triisopropylphenyl)phenyl). The $\mathrm{Pd}(\mathrm{I})$ amido complex is isolated from the reaction of (BINAP) $\mathrm{PdCl}_{2}$ with $\mathrm{LiNHAr}^{\text {Trip }}$ and has been characterized by single-crystal X-ray diffraction, electron paramagnetic resonance spectroscopy, and multi-edge Pd X-ray absorption spectroscopy. Electronic structure calculations indicate that the $\operatorname{Pd}(\mathrm{I})$ amido complex is $S=1 / 2$ with a three-electron two-center $\pi$-interaction between the $\mathrm{Pd}$ and $\mathrm{N}$ atoms, and that the $\mathrm{Pd}-\mathrm{N}$ bond indeed present severe destabilizing Pauli repulsion. However, dispersion forces (28) (Fig. 1C) between BINAP and the bulky amido ligand aids the stabilization of the complex. Further reactivity studies evaluate the lability of the $\mathrm{Pd}-\mathrm{N}$ bond. When subjected to thermolysis, photoirradiation, or coordination of exogenous ligands, the $\mathrm{Pd}(\mathrm{I})$ amido complex undergoes homolytic $\mathrm{Pd}-\mathrm{N}$ bond cleavage to release the aminyl radical [NHAr $\left.{ }^{\text {Trip }}\right]^{\circ}$. In addition, the amido ligand in the $\operatorname{Pd}(\mathrm{I})$ complex exhibits high basicity as it can deprotonate primary alkyl and aryl amines. These observations showcase the unique reactivity of low-valent, odd-electron platinum-groupmetal amido complexes.

Synthesis and Molecular Structure of [(BINAP)Pd(NHAr $\left.\left.{ }^{\text {Trip }}\right)\right]$. The $\operatorname{Pd}(\mathrm{I})$ amido complex [(BINAP)Pd(NHAr $\left.\left.{ }^{\text {Trip }}\right)\right]$ (1) was obtained via the reaction of (BINAP) $\mathrm{PdCl}_{2}$ with two equivalents of LiNHAr ${ }^{\text {Trip }}$. Mixing the two reagents in toluene at $-78{ }^{\circ} \mathrm{C}$ produced a blue solution, whose ${ }^{31} \mathrm{P}$ NMR spectrum features two signals with an $A B$-splitting pattern, suggesting the formation of a $\mathrm{Pd}(\mathrm{II})$ monoamido intermediate, presumably (BINAP)Pd(NHAr $\left.{ }^{\text {Trip }}\right) \mathrm{Cl}$ (A). When warmed to room temperature, the solution turned green. Recrystallization led to the isolation of the $\mathrm{Pd}(\mathrm{I})$ amido complex 1 as a green crystalline solid in 51\% yield (Fig. 2A). The composition of 1 is supported by elemental analysis $(\mathrm{C}, \mathrm{H}, \mathrm{N})$, cold electrospray mass spectroscopy (Fig. S6), and its structure has been confirmed by single-crystal X-ray diffraction (Fig. 2B). The infrared spectrum

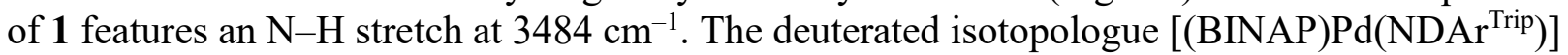
(1-d) shows the N-D stretch at $2641 \mathrm{~cm}^{-1}$ (Fig. S5). In addition to 1, three amine byproducts, the amino-imine 2, the aniline featuring an alkene side arm 3, and the free aniline 4 (Fig. 2A), are observed. These amines are likely formed from the decomposition reactions of the aminyl radical [NHAr $\left.{ }^{\text {Trip }}\right]^{\bullet}$. Consequently, $\mathbf{1}$ is proposed to form via a homolytic $\mathrm{Pd}-\mathrm{N}$ bond cleavage reaction of a $\mathrm{Pd}(\mathrm{II})$ bisamido intermediate, (BINAP)Pd(NHAr $\left.{ }^{\text {Trip }}\right)_{2}$, that can be produced by the interaction of A with LiNHAr ${ }^{\text {Trip }}$ (Fig. 2C). 


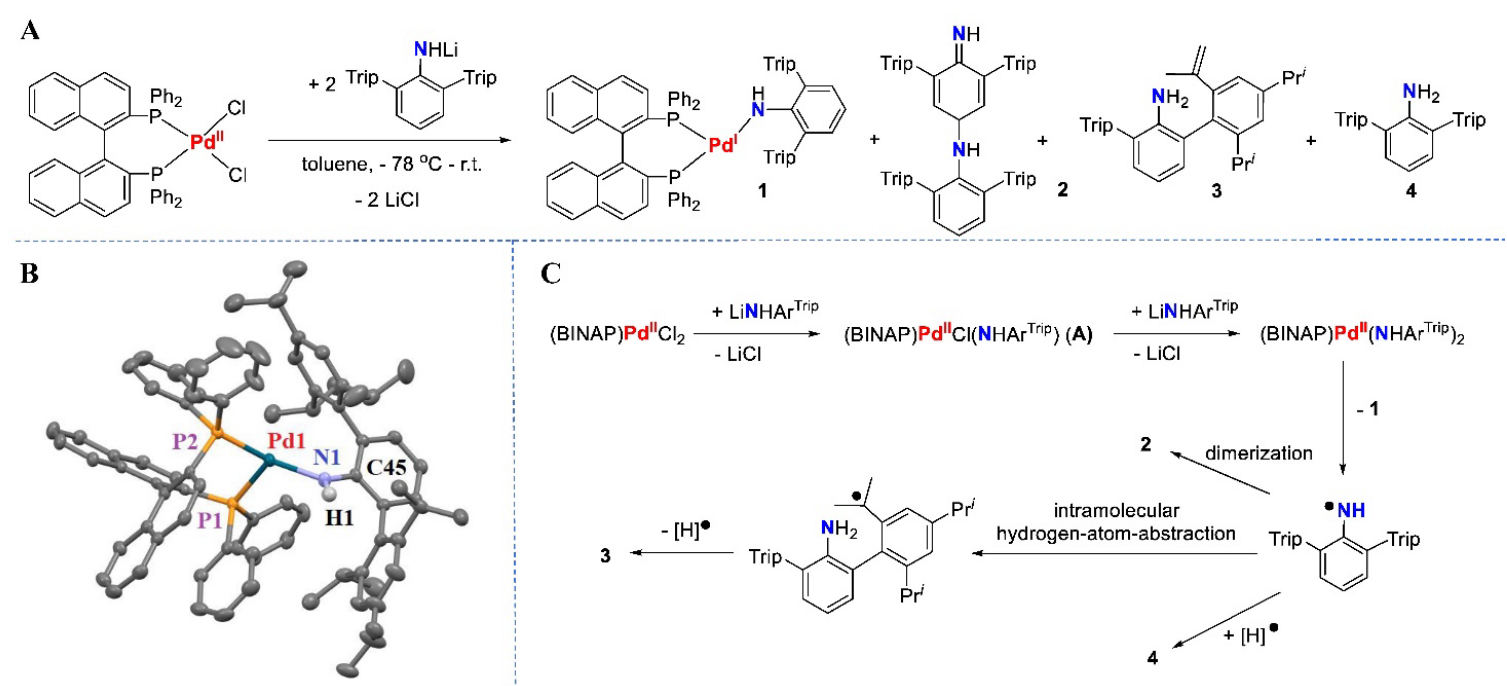

Fig. 2. Synthetic route to the $P d(I)$ amido complex and its molecular structure. (A) The reaction giving $\mathrm{Pd}(\mathrm{I})$ amido complex [(BINAP)Pd(NHAr $\left.{ }^{\text {Trip }}\right)$ ] (1) and the byproducts 2-4. (B) Molecular structure of $\mathbf{1}$, showing one of the two crystallographically independent molecules in the unit cell with $30 \%$ displacement ellipsoids and a partial atom numbering scheme. Hydrogen atoms, except the one on N1, are omitted for clarity. Selected distances $(\AA)$ and angles (deg): Pd1-N1 2.063(2), Pd1-P1 2.3314(7), Pd1-P2 2.2883(7), N1-C45 1.377(3), P2-Pd1-P1 92.20(2), N1-Pd1-P1 108.06(6), N1-Pd1-P2 154.04(6), C45-N1-Pd1 135.29(18). (C) A proposed route for the formation of 1 and the byproducts $2-4$.

Single crystals of 1 were obtained by cooling a diethyl ether solution at $-30{ }^{\circ} \mathrm{C}$ for two days. $\mathrm{X}$-ray diffraction revealed that there are two crystallographically independent molecules in the unit cell, with similar structure metrics. As the representative, Fig. 1B depicts the structure of one of the molecules. The three-coordinate $\mathrm{Pd}(\mathrm{I})$ complex has a $\mathrm{P}-\mathrm{Pd}-\mathrm{P}$ angle of $92.20(2)^{\circ}$ and two unequal $\mathrm{P}-\mathrm{Pd}-\mathrm{N}$ angles of $108.06(6)^{\circ}$ and $154.04(6)^{\circ}$. While the sum of the three angles $\left(354.3^{\circ}\right)$ indicates an idealized planar geometry for the Pd center, the presence of two unequal P$\mathrm{Pd}-\mathrm{N}$ angles differentiates 1 from trigonal-planar three-coordinate $\mathrm{Pd}(0)$ complexes $\left(\mathrm{Pr}_{2}^{i} \mathrm{PCH}_{2} \mathrm{CH}_{2} \mathrm{CH}_{2} \mathrm{PPr}_{2}{ }_{2}\right) \mathrm{Pd}\left(\mathrm{PCy}_{3}\right)(29)$ and $\mathrm{Pd}\left(\mathrm{PPh}_{3}\right)_{3}$ (30) and T-shaped three-coordinate $\mathrm{Pd}(\mathrm{II})$ complexes $\left(\mathrm{PBu}^{\mathrm{t}}\right) \mathrm{Pd}\left(\mathrm{C}_{6} \mathrm{H}_{4}-4-\mathrm{OCH}_{3}\right)\left(\mathrm{N}_{(}\left(\mathrm{C}_{6} \mathrm{H}_{3}-3,5-\left(\mathrm{CF}_{3}\right)_{2}\right)_{2}\right)(31)$ and $(\mathrm{IPr}) \mathrm{Pd}(3-m e t h y l n o r b o r n-2-$ $\mathrm{yl})\left(\mathrm{NHC}_{6} \mathrm{H}_{4}-4-\mathrm{CH}_{3}\right)(\mathrm{IPr}=1,3$-bis (2',6'-diisopropylphenyl)imidazole-2-ylidene) (32). The $\mathrm{Pd}-\mathrm{N}$ bond distance in 1 is 2.063(2) $\AA$, which is slightly longer than those of the three-coordinate $\mathrm{Pd}(\mathrm{II})$ amido complexes (sIPr) $\mathrm{Pd}\left(3\right.$-methylnorborn-2-yl) $\left(\mathrm{NHC}_{6} \mathrm{H}_{4}-4-\mathrm{OCH}_{3}\right)(\mathrm{sIPr}=1,3-$ bis(2',6'-diisopropylphenyl)imidazolin-2-ylidene) (2.037(3) $\AA$ ) and (IPr)Pd(3-methylnorborn-2$\mathrm{yl})\left(\mathrm{NHC}_{6} \mathrm{H}_{4}-4-\mathrm{CH}_{3}\right)(2.011(3) \AA)(32)$. Counter to the knowledge that the trans influence of the amido ligand would elongate the transoid Pd-P bond, the 2.2883(7) $\AA$ Pd1-P2 bond is shorter than the 2.3314(7) $\AA \mathrm{Pd} 1-\mathrm{P} 1$ bond. The shortening of the Pd-P bond distance might be caused by attractive dispersion forces between the phenyl groups on the $\mathrm{P}$ atom and the proximal 2,4,6triisopropylphenyl group on the amido ligand (vide infra). In addition, the bond distances within the amido ligand of $\mathbf{1}$ itself are typical of anilido ligands in metal complexes $(31,32)$, and are different from those of the parent phenylaminyl radical [NHPh] ${ }^{\circ}(33)$ and the arylaminyl complexes (34-37) (Table S1), which hints at the monoanionic nature of [NHAr $\left.{ }^{\text {Trip }}\right]^{1-}$ in $\mathbf{1}$.

Spectroscopic and Electronic Structure Features of [(BINAP)Pd(NHAr $\left.{ }^{\text {Trip }}\right)$ ]. Complex 1 features an $S=1 / 2$ ground spin-state as indicated by the measured magnetic moment of 2.1(1) $\mu_{\mathrm{B}}$. 
Continuous wave (CW) and field-swept echo-detected (FSE) EPR were obtained for 1 (Figs. 3A$3 \mathrm{C}$, and S73). The X-band (9 GHz) CW-EPR spectrum obtained at room temperature shows a four-line pattern centered at $g_{\text {iso }} c a .2 .052$ with $A_{\text {iso }}\left({ }^{31} \mathrm{P} 1\right)=202 \mathrm{G}(567 \mathrm{MHz})$ and $A_{\text {iso }}\left({ }^{31} \mathrm{P} 2\right)=80$ $\mathrm{G}(225 \mathrm{MHz})$ (Fig. S73). The anisotropy of the $g$-values and the ${ }^{31} \mathrm{P} A$-values were resolved at low temperatures by obtaining spectra at X-, Q- (35 GHz), and W-band (94 GHz). Figs. 3A-3C shows the frozen-solution multifrequency EPR spectra obtained for $\mathbf{1}$ along with simulations using globally-fit spin Hamiltonian parameters. The g-values obtained are $g_{1}=2.0085, g_{2}=$ 2.0350, and $g_{3}=2.1115$. The small g-value is consistent with the DFT-calculated electronic structure, as discussed below (Table 2), but is deviation from $g_{\mathrm{e}}(2.002)$ is unusual among the few known $\operatorname{Pd}(\mathrm{I})$ complexes. For example, the spectra of the $\operatorname{Pd}(\mathrm{I})$ species generated by $\gamma$-ray irradiation on $\mathrm{Pd}(\mathrm{II})$ compounds have their $g_{\perp}$ values in the range 2.0 to 2.1 and $g_{/ /}$values in the range 2.1 to $2.6(38)$, the spectrum of $\left[\left(\mathrm{PBu}_{3}^{t}\right)_{2} \mathrm{Pd}\right]\left[\mathrm{CB}_{11} \mathrm{Cl}_{11} \mathrm{H}\right]$ has the g-values of $g_{\perp}=2.338$, $g_{/ /}$ $=1.971(19)$, and that of $\left[\left(\mathrm{PBu}_{3}^{t}\right)_{2} \mathrm{Pd}(\mathrm{NCMe})\right]\left[\mathrm{CB}_{11} \mathrm{Cl}_{11} \mathrm{H}\right]$ shows $g_{\perp}=2.088, g_{/ /}=2.314(19)$. The ${ }^{31} \mathrm{P}$ hyperfine constant values (HFCs) determined by globally fitting the frozen-solution EPR spectra of 1 for ${ }^{31} \mathrm{P} 1$ are: $\mathrm{A}_{1}=535, \mathrm{~A}_{2}=535$, and $\mathrm{A}_{3}=631 \mathrm{MHz}$. The values for ${ }^{31} \mathrm{P} 2$ are $\mathrm{A}_{1}=$ $205, A_{2}=210$, and $A_{3}=260 \mathrm{MHz}$. Deduction of atomic spin density from the isotropic $\left(\mathrm{A}_{\text {iso }}\right)$ and dipolar (T) contributions to the HFCs (39) yields a spin density of $13.0 \%$ on P1, of which $4.3 \%$ resides in the $3 \mathrm{~s}$ orbital and $8.7 \%$ in a $3 \mathrm{p}$ orbital, and a spin density on $\mathrm{P} 2$ is $6.4 \%$, where $1.7 \%$ resides in the $3 \mathrm{~s}$ orbital and $4.7 \%$ in the $3 \mathrm{p}$ orbital. Thus, total spin density on two $\mathrm{P}$ nuclei is $c a .20 \%$ based on the EPR experiments. $A\left({ }^{105} \mathrm{Pd}\right)$ and $A\left({ }^{14} \mathrm{~N}\right)$ contributions to the spectra could not be resolved.

A

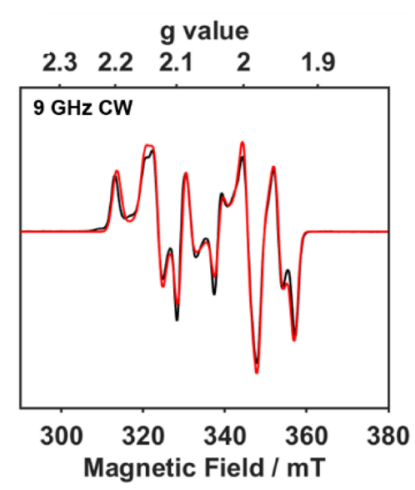

D

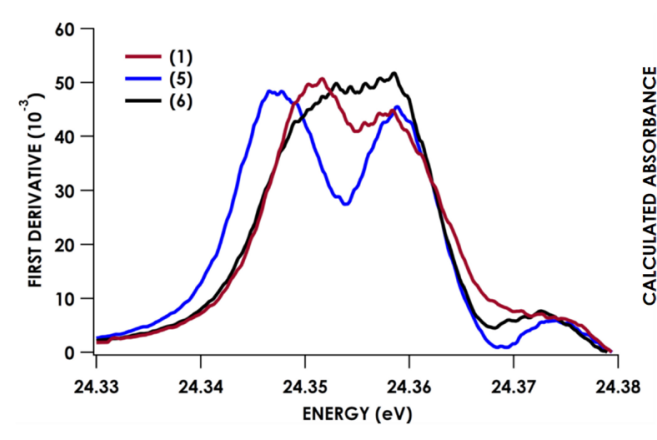

$\mathbf{E}$
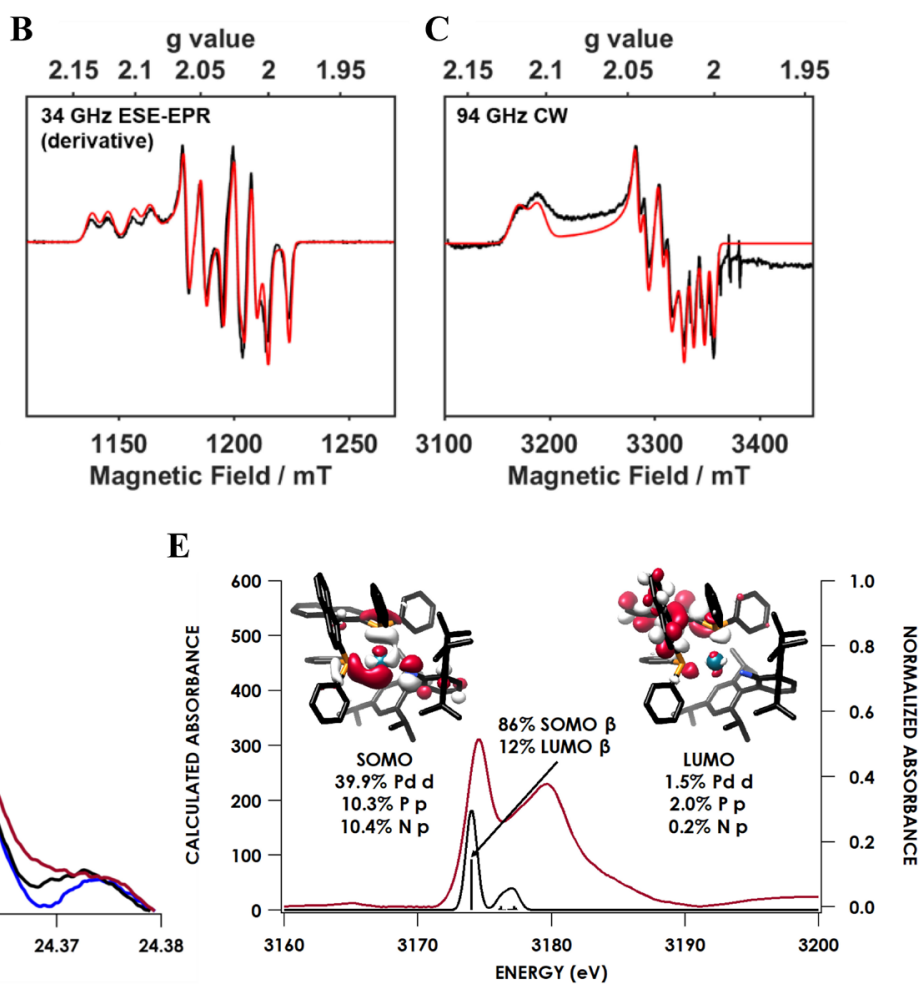

Fig. 3. Spectroscopic data of Pd complexes. (A-C) EPR spectra of 1 (black line) and simulations (red line) at $9 \mathrm{GHz} \mathrm{CW}, 34 \mathrm{GHz}$ electron spin echo fieldsweep (derivative), and 94 $\mathrm{GHz} \mathrm{CW}$ EPR. (D) Overlay of the smoothed second derivatives of Pd K-edge XAS spectra of $\mathrm{Pd}^{0}(\operatorname{IPr})_{2}(\mathbf{5}$, blue $), 1$ (red), and (BINAP)Pd ${ }^{\mathrm{II}}(\mathrm{OAc})_{2}(\mathbf{6}$, black). (E) Experimental (red) and 
TDDFT calculated (black) Pd L $\mathrm{L}_{3}$-edge XAS spectra of $\mathbf{1}$. The B3LYP functional and SARCZORA basis set was used for Pd, with ZORA-def2-TZVP(-f) used for all other atoms. Contributions of individual orbitals were obtained from Löwdin population analysis of the QROs. Orbitals are plotted at an isovalue of 0.03 au with hydrogen atoms removed for clarity.

Table 1. Experimental Pd K-Edge and $\mathrm{L}_{2,3}$-Edge Energies.

\begin{tabular}{ccccc}
\hline Compound & $\begin{array}{c}\text { K-edge } \\
(\mathrm{eV})\end{array}$ & $\begin{array}{c}\mathrm{L}_{3} \text { pre-edge } \\
\text { max }(\mathrm{eV})\end{array}$ & $\begin{array}{c}\mathrm{L}_{2} \text { pre-edge } \\
\text { max }(\mathrm{eV})\end{array}$ & $\begin{array}{c}\text { Total } \mathrm{L}_{3}+\mathrm{L}_{2} \\
\text { Mainline Area }\end{array}$ \\
\hline $\mathrm{Pd}^{0}\left(\mathrm{IPr}_{2}(\mathbf{5})\right.$ & 24347 & nd & nd & nd \\
$\left(\mathrm{BINAP}^{\prime} \mathrm{Pd}^{\mathrm{I}}\left(\mathrm{Ar} r^{\text {Trip }}\right)(\mathbf{1})\right.$ & 24351 & 3174.5 & 3331.7 & $1.66(0.03)$ \\
$\left(\mathrm{BINAP}^{\mathrm{P}} \mathrm{Pd}^{\mathrm{II}}(\mathrm{OAc})_{2}(\mathbf{6})\right.$ & 24353 & 3176.4 & 3333.6 & $4.02(0.16)$ \\
\hline
\end{tabular}

To probe the electronics of the Pd center in 1, Pd K- and L-edge XAS data for 1, the $\operatorname{Pd}(0)$ complex $\left[\mathrm{Pd}^{0}(\mathrm{IPr})_{2}\right](\mathbf{5})$, and the $\mathrm{Pd}(\mathrm{II})$ complex [(BINAP)Pd $\left.\mathrm{Pd}^{\mathrm{II}}(\mathrm{OAc})_{2}\right](\mathbf{6})$ were collected. As shown in Figs. S74 and 3D, and Table 1, the rising-edge energies obtained from K-edge (1s $\rightarrow$ valence/continuum) for the series of compounds shift toward higher energies with increasing formal oxidation state, though it has been noted that factors such as coordination environment and ligand identity can shift rising-edge energies to degrees similar to shifts caused by oxidation state changes (40). Pre-edge features arising from the metal $1 \mathrm{~s} \rightarrow n \mathrm{~d}$ transitions are also conventionally used to assess physical oxidation states. Such excitations are not expected for the $\operatorname{Pd}(0)$ complexes because of their $d^{10}$ configuration, but will occur in the case of formally $\operatorname{Pd}(\mathrm{I})$ and Pd(II) complexes. Such features are not resolved in the experimental Pd K-edge spectra likely owing to the weak intensity of these quadrupole allowed but dipole forbidden transitions as well as the core-hole lifetime broadening endemic to $2^{\text {nd }}$ and $3^{\text {rd }}$ row metal K-edge XAS.

To complement the K-edge data, the $\mathrm{Pd} \mathrm{L}_{2,3}$-edge ( $2 \mathrm{p} \rightarrow$ valence/continuum) XAS data were obtained, where dipole-allowed $\mathrm{Pd} 2 \mathrm{p} \rightarrow 4 \mathrm{~d}$ transitions gives rise to intense features that probe the energetics and covalency of the Pd ligand field (41). Experimental $\mathrm{Pd} \mathrm{L}_{2,3}$-edge spectra are shown in Figs. 3E and S75-S77 for 1 and $6 . \mathrm{L}_{3}$ and $\mathrm{L}_{2}$ mainlines in these spectra can be assigned to excitations from the Pd $2 p$ orbitals into singly or unoccupied Pd $4 d$ orbitals. Satellite features at higher energies relative to the mainline result from transitions into higher lying levels of primarily ligand character (vide infra). The $\mathrm{L}_{3}$ and $\mathrm{L}_{2}$ mainlines for $\mathbf{1}$ are shifted by $c a .2 \mathrm{eV}$ to lower energy relative to $\mathbf{6}$ (Table 1 ). Areas of $\mathrm{L}_{2,3}$-edge mainlines can be used to quantify metal nd character in valence acceptor orbitals, providing a direct probe of covalency and physical oxidation state (40). This approach has been applied to $\mathrm{Pd} \mathrm{L}_{2,3}$-edges, where an increase in the $\mathrm{L}_{2,3}$-edge area of $\mathrm{PdAl}_{3}$ and $\mathrm{PdCl}_{2}$ compared to Pd metal was attributed to $d$-count depletion (42). In the present case, the total $\mathrm{L}_{2,3}$-edge mainline area of $\mathbf{1}$ is $c a$. half that of $\mathbf{6}$, consistent with Pdlocalized reduction.

Hybrid density functional theory (DFT) calculations were carried out to interrogate the electronic structure of $\mathbf{1}$. All calculations used the dispersion-corrected B3LYP-D3 hybrid density functional (43) (44) with the segmented all-electron relativistically contracted (SARC)ZORA basis on Pd (45) and ZORA-def2-TZVP(-f) basis set on all other atoms. All calculations used crystallographic coordinates.

Table 2. Experimental and DFT-calculated EPR parameters for 1. 


\begin{tabular}{ccc}
\hline $\mathrm{g}$ tensor & {$[2.0085,2.0350,2.1115]$} & {$[2.0216,2.0408,2.1065]$} \\
$A\left({ }^{31} \mathrm{P} 1\right) / \mathrm{MHz}$ & {$[205,210,260]$} & {$[237,242,298]$} \\
$A\left({ }^{31} \mathrm{P} 2\right) / \mathrm{MHz}$ & {$[535,535,631]$} & {$[535,537,650]$} \\
$A\left({ }^{105} \mathrm{Pd}\right) / \mathrm{MHz}$ & $\mathrm{NR}$ & {$[105,31.1,80.8]$} \\
$A\left({ }^{14} \mathrm{~N}\right) / \mathrm{MHz}$ & $\mathrm{NR}$ & {$[2.6,3.3,24.7]$} \\
\hline
\end{tabular}

${ }^{a}$ Calculations used crystallographic coordinates with the B3LYP hybrid density function, D3 correction for dispersion, the SARC-ZORA basis set on Pd, and the ZORA-def2-TZVP(-f) basis set on all other atoms.

Veracity of the electronic structure calculations was judged by comparison of calculated spectroscopic parameters to experiment. Spin-Hamiltonian parameters calculated for $\mathbf{1}$ agree well with experiment (Table 2). Specifically, the $g$-values as well as the magnitudes and asymmetry of the ${ }^{31} \mathrm{P}$ HFCs are effectively reproduced by experiment. Calculated Mulliken spin densities comprise $9.5 \% 3 \mathrm{p}$ and $3.9 \% 3 \mathrm{~s}$ on P1 and $5.7 \% 3 \mathrm{p}$ and $2.7 \% 3 \mathrm{~s}$ on P2, in splendid agreement with analysis of the experimentally-obtained HFCs (vide supra). The calculation yielded low ${ }^{14} \mathrm{~N}$ and ${ }^{105} \mathrm{Pd}$ HFC values, consistent with the fact that these features are unresolved in the EPR data.

The single-point DFT solutions were used as starting points for time-dependent DFT (TDDFT) calculations of the XAS data obtained for $\mathbf{1}$ and $\mathbf{6}$. TDDFT has been used previously to calculate $\mathrm{L}_{2,3}$-edge XAS spectra for second-row transition metals and was shown to adequately reproduce the structure of experimental $\mathrm{L}_{3}$-edges without including the contributions from spinorbit coupling that yield the $\mathrm{L}_{3}-\mathrm{L}_{2}$ splitting (46). TDDFT reproduced the overall envelope of $\mathrm{L}_{3}$ features in the experimental spectra (Figs. 3E and S79). The satellite features to higher energy of the $\mathrm{L}_{3}$ mainlines comprise transitions into ligand-localized molecular orbitals with minimal $\mathrm{Pd}$ $4 d$ character. The mainline transition in 1 primarily comprises the $\mathrm{Pd} 2 p \rightarrow \mathrm{SOMO}$ excitation, while for (BINAP) $\mathrm{Pd}^{\mathrm{II}}(\mathrm{OAc})_{2}$ the mainline consisted of the Pd $2 p$ LUMO excitation as well as transitions to two additional low-lying MOs with ca. $10 \%$ contributions from Pd $4 d$ orbitals. Calculated total $\mathrm{Pd} 4 d$ character in all acceptor orbital holes against summed $\mathrm{L}_{3}$ and $\mathrm{L}_{2}$ mainline areas gives a correlation with $\mathrm{R}^{2}=0.97$ (Fig. S81). Formally $\mathrm{Pd}^{\mathrm{I}}$ complex $\mathbf{1}$ exhibits $30 \%$ lower overall $\mathrm{d}$ vacancy than the $\mathrm{Pd}^{\mathrm{II}}$ complex, providing further support for metal-centered reduction relative to formally $\mathrm{Pd}^{\mathrm{II}}$-containing 6.

The experimentally-validated DFT calculations indicate that $\mathbf{1}$ bears a three-electron twocenter $\mathrm{Pd}-\mathrm{N} \pi$-bond, and its electronic configuration of can be described as $\left(\pi_{d_{\mathrm{xy}}+p_{\mathrm{N}}}\right)^{2}\left(d_{\mathrm{z} 2}, d_{\mathrm{xz}}, d_{\mathrm{z} 2}, d_{\mathrm{x} 2-\mathrm{y} 2}\right)^{8}\left(\pi^{*} d_{\mathrm{xy}-p_{\mathrm{N}}}\right)^{1}$. Löwdin orbital populations show that the SOMO is highly delocalized, although there is a substantial (40\%) Pd $4 d$ contribution consistent with the observed anisotropy in $g$-values obtained for 1 (Fig. 4A). Major contributors to the SOMO come from the P-donors $(10.3 \% 3 \mathrm{p})$ and the amide $(10.4 \% \mathrm{~N} 2 \mathrm{p})$. The sum of the spin density on the NHAr ${ }^{\text {Trip }}$ fragment, 0.22 , precludes description of $\mathbf{1}$ as an aminyl radical complex. Relevant comparisons include the aminyl radical species [(bipy) $\left.\mathrm{Rh}\left(\mathrm{N}(\mathrm{Trop})_{2}\right)\right][\mathrm{OTf}](0.56$, bipy $=$ bipyridine, Trop $=$ $5 H$-dibenzo[a,d ]cyclohepten-5-yl) (26), [( $\left.\left.\mathrm{Ph}_{2} \mathrm{~B}\left(\mathrm{CH}_{2} \mathrm{PBu}_{2}^{t}\right)_{2}\right) \mathrm{Cu}\left(\mathrm{N}(\text { tolyl-p })_{2}\right)\right]$ (0.69) (36), $\left[\left(\mathrm{Me}_{3} \mathrm{NN}\right) \mathrm{Cu}\left(\mathrm{NPh}_{2}\right)\right]\left(0.58, \mathrm{Me}_{3} \mathrm{NN}=2,4\right.$-bis(2,4,6-trimethylphenylimido)pentyl) (37), [(PNP)NiCl][OTf] (0.69) (35), and [(PNP)Re(CO) 3$][\mathrm{OTf}](0.83)(34)$ that feature higher spin density on their N-ligands. To gain insight into the nature of the Pd-N bond in $\mathbf{1}$ and its unusual 
stability, we further did bonding analysis by using the state-of-the-art energy decomposition analysis (EDA) (47) with the natural orbitals for chemical valency (NOCV) approach (48-50) (see SI for details). The most important numerical results are provided in Figure 4B, while the more detailed information can be found in Table S3 and Figs. S83-S87. The interacting neutral fragments of (BINAP) $\mathrm{Pd}^{0}$ and NHAr ${ }^{\text {Trip }}$ has comparable orbital energy (i.e., $\Delta E_{\text {orb }}=-72.0$ $\mathrm{kcal} / \mathrm{mol}$ ) with that of the ionic fragments of [(BINAP)Pd $]^{+}$and [NHAr $\left.{ }^{\text {Trip }}\right]^{-}$(i.e., $\Delta E_{\text {orb }}=-73.7$ $\mathrm{kcal} / \mathrm{mol}$ ), implying the two resonant structures exist for the complex 1 but the neutral fragments are slightly favored because of the smaller orbital energy (see Figure S87a). This also agrees very well with the spectroscopic data and spin density analysis as shown in Figure S83b. It revealed that there is significant Pauli repulsion (i.e., $\Delta E_{\text {Pauli }}=123.1 \mathrm{kcal} / \mathrm{mol}$ ) within the $\mathrm{Pd}-\mathrm{N}$ interaction by using the neutral interacting fragments. Nonetheless, the favorable attractive interactions, including the electrostatic energy $\left(\Delta E_{\text {elstat }}=-92.3 \mathrm{kcal} / \mathrm{mol}\right)$ and orbital interaction energy $\left(\Delta E_{\text {orb }}=-72.0 \mathrm{kcal} / \mathrm{mol}\right)$, can compensate and even exceeds the Pauli repulsion $\Delta E_{\text {Pauli }}$ by $41.2 \mathrm{kcal} / \mathrm{mol}$. It should be emphasized that the dispersion energy (i.e., $\Delta E_{\text {disp }}=-31.3 \mathrm{kcal} / \mathrm{mol}$ ), contributing $16 \%$ of total attractive forces, leads to a summed bond dissociation energy $\left(D_{\mathrm{e}}\right)$ of $50.9 \mathrm{kcal} / \mathrm{mol}$ - help to stabilize the $\mathrm{Pd}(\mathrm{I})$ amido species at ambient temperature. The dispersion forces can be discerned from the short inter-ligand $\mathrm{H} \cdot \bullet \cdot \mathrm{H}$ contacts between BINAP and NHAr ${ }^{\text {Trip }}$ in the optimized structure of 1 (Fig. 4C). The ionic interacting fragments has similar Pauli repulsion and orbital energies but with a significant strong electrostatic energy $\left(\Delta E_{\text {elstat }}=-163.5\right.$ $\mathrm{kcal} / \mathrm{mol})$, which is understandable between the cation [(BINAP) $\left.\mathrm{Pd}^{\mathrm{I}}\right]^{+}$and anion $\left[\mathrm{NHAr}^{\mathrm{Trip}}\right]^{-}$ fragments and thus leads to more larger intrinsic energy $\Delta E_{\text {int }}$ of $-139.0 \mathrm{kcal} / \mathrm{mol}$ and bond dissociation energy $\left(D_{\mathrm{e}}\right)$ of $121.3 \mathrm{kcal} / \mathrm{mol}$.

A

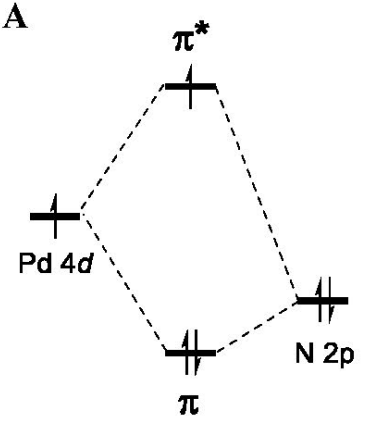

\begin{tabular}{|c|c|c|}
\hline Fragments & $\begin{array}{c}{\left[\text { (BINAP)Pd }{ }^{0}\right](\mathrm{S})} \\
+ \\
{\left[\begin{array}{c}{\left[^{2} H A r^{T r i p}\right]^{0}} \\
(D)\end{array}\right.}\end{array}$ & 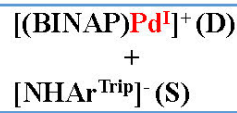 \\
\hline$\Delta \mathbf{E}_{\text {int }}$ & -72.4 & -139.0 \\
\hline$\Delta \mathbf{E}_{\text {Pauli }}$ & 123.1 & 129.5 \\
\hline$\Delta \mathbf{E}_{\text {disp }}$ & $-31.3(16.0 \%)$ & $-31.3(11.7 \%)$ \\
\hline$\Delta \mathbf{E}_{\text {elstat }}$ & $-92.3(47.2 \%)$ & $-163.5(60.9 \%)$ \\
\hline$\Delta \mathbf{E}_{\text {orb }}$ & $-72.0(36.8 \%)$ & $-73.7(27.4 \%)$ \\
\hline$\Delta \mathbf{E}_{\text {rest }}$ & $-11.9(16.6 \%)$ & $-26.7(36.2 \%)$ \\
\hline$\Delta \mathbf{E}_{\text {prep }}$ & 21.5 & 17.7 \\
\hline$\Delta \mathbf{E}=-\mathbf{D}_{\mathrm{e}}$ & -50.9 & -121.3 \\
\hline
\end{tabular}

SOMO-1
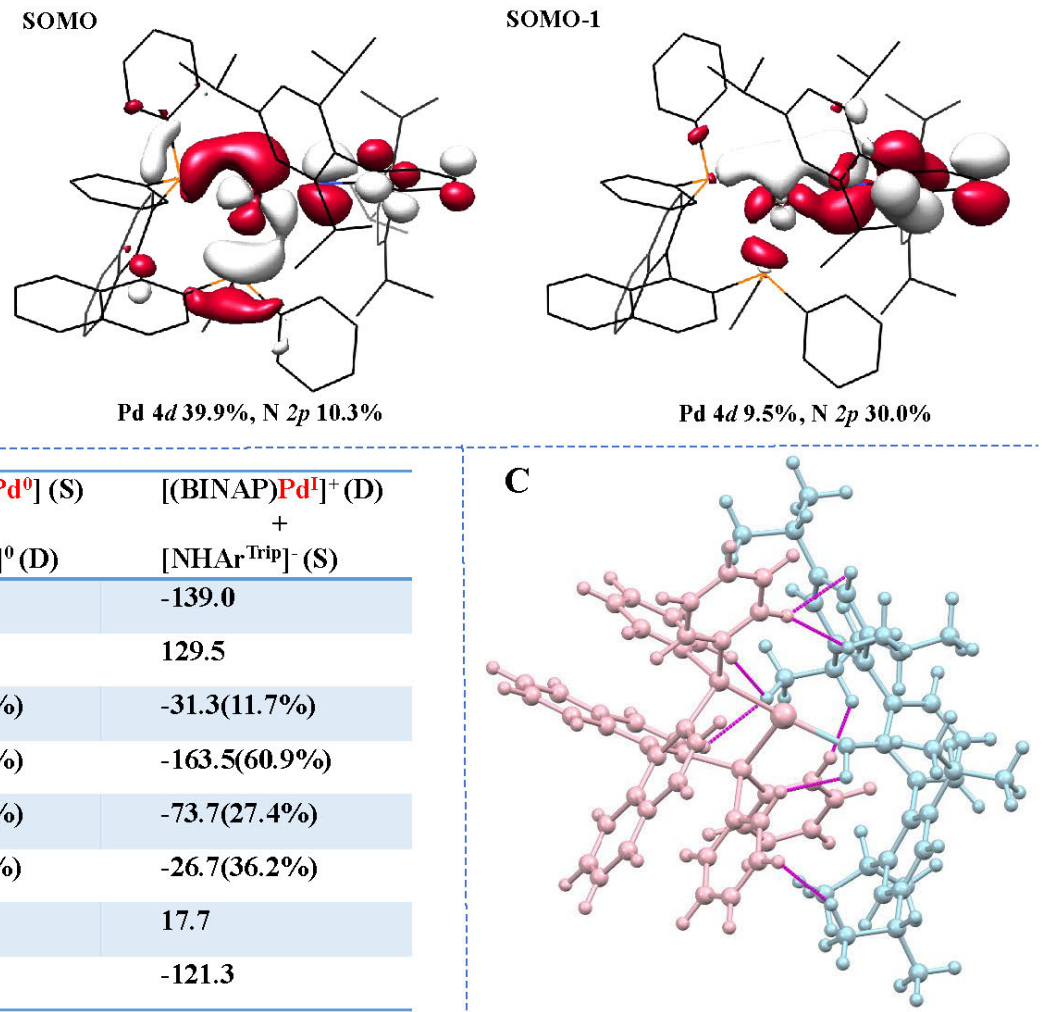

Fig. 4. DFT calculations of Pd(I) amido complex. (A) Selected molecular orbitals of $\mathbf{1}$, hydrogen atoms on ligands were omitted. (B) EDA-NOCV results (in $\mathrm{kcal} / \mathrm{mol}$ ). Fragments of 
(BINAP)Pd and NHAr ${ }^{\text {Trip }}$ are given on table in singlet (S) or doublet (D) electronic states. (C) Short inter-ligand $\mathrm{H} \bullet \bullet H$ contacts with the distances less than $2.4 \AA$ (purple lines).

Reactivity of [(BINAP)Pd(NHAr $\left.\left.{ }^{\text {Trip }}\right)\right]$. Complex 1 is the first isolable $d^{9}$ platinum-groupmetal complex bearing a $\pi$-donating ligand. Being different from the aforementioned fleeting $\mathrm{Pd}(\mathrm{I})$ species, it is stable at ambient temperature, which facilitates studies of its reactivity. When 1 is subjected to thermolysis, light-irradiation, or coordination with exogenous ligands, it undergoes $\mathrm{Pd}-\mathrm{N}$ bond homolytic cleavage reactions to yield anilines and $\mathrm{Pd}(0)$ species (Fig. 5A). In these reactions, the arylaminyl radical dimerization product $\mathbf{2}$, the alkane-chain dehydrogenation product 3 and the aniline $\mathrm{NH}_{2} \mathrm{Ar}^{\text {Trip }}(\mathbf{4})$ are observed, implicating the radical intermediate [NHAr $\left.{ }^{\text {Trip }}\right]^{\cdot}$ in these reactions (Fig. S19). In addition, two $\mathrm{Pd}(0)$ complexes, [(BINAP) $\left.\mathrm{Pd}\left(2,6-\left(\mathrm{CH}_{3}\right)_{2}-\mathrm{C}_{6} \mathrm{H}_{3} \mathrm{NC}\right)_{2}\right](7)$ and [(BINAP) $\left.\mathrm{Pd}\left(\eta^{2}-3,5-\left(\mathrm{CF}_{3}\right)_{2}-\mathrm{C}_{6} \mathrm{H}_{3} \mathrm{CH}=\mathrm{CH}_{2}\right)\right](8)$, have been isolated in the corresponding reaction and structurally authenticated by $\mathrm{X}$-ray diffraction studies (Figs. S29 and S34). The decomposition reaction of 1 under white lightirradiation (6 W LED) at room temperature shows zero-order kinetics with a kinetic constant $k_{\text {irri }}$ $=1.6 \times 10^{-8} \mathrm{~mol} \cdot \mathrm{L}^{-1} \bullet \mathrm{s}^{-1}$ (Fig. S23), whereas the thermal decomposition reaction at $348 \mathrm{~K}$ is a first-order reaction with a rate constant $k_{\text {therm }}=1.1 \times 10^{-4} \mathrm{~s}^{-1}$ (Fig. S27). The thermal and lightirradiation-induced decomposition reactions of 1 might result from amido-to-palladium(I) electron-transfer to form (BINAP) $\mathrm{Pd}^{0}\left(\mathrm{NHAr}^{\text {Trip }}\right)^{\circ}$. The absorption spectrum of $\mathbf{1}$ in toluene shows an intense feature at $808 \mathrm{~nm}\left(7300 \mathrm{~mol}^{-1} \cdot \mathrm{L} \cdot \mathrm{cm}^{-1}\right)$. TDDFT calculations suggest that the band principally arises due to a charge transfer $(\mathrm{CT})$ transition comprising transfer of an electron from the nitrogen lone-pair on [NHAr $\left.{ }^{\text {Trip }}\right]^{1-}$ and from $\mathrm{Pd}_{4} \mathrm{~d}_{\mathrm{z} 2}$ to the SOMO of 1 (Fig. S78). Either transition fully populates the $\mathrm{Pd}-\mathrm{N}$ antibonding $\mathrm{MO}$ and thus promotes bond cleavage. Kinetics obtained under pseudo-first-order conditions involving both the concentrations of 1 and the alkene 3,5-bis(trifluromethyl)styrene of the ligand-coordination-induced-decomposition reactions of 1 with an excess amount of 3,5-bis(trifluromethyl)styrene in benzene at $30{ }^{\circ} \mathrm{C}$ suggest an associative mechanism (Figs. S41-S47).

A
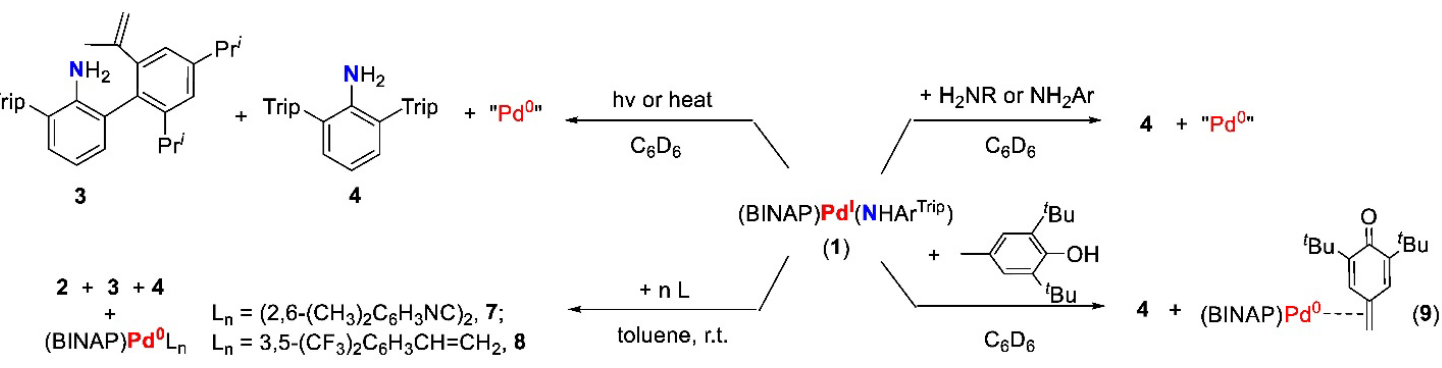

B

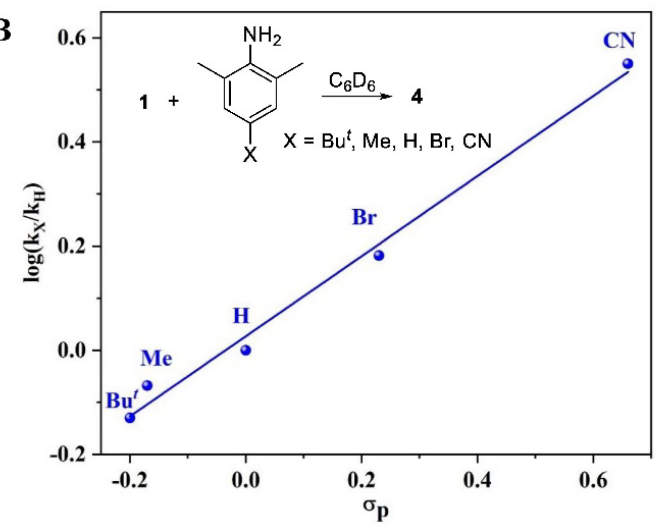

C

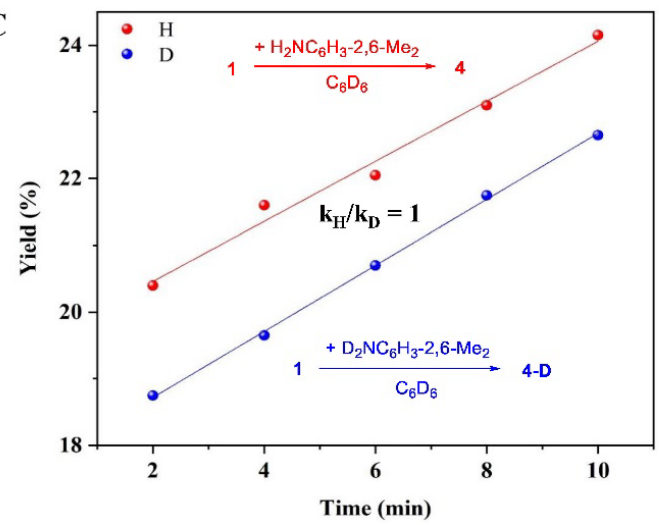


Fig. 5. Reactivity of 1. (A) Thermolysis-, light irradiation, and ligand-coordination-induced decomposition reactions of $\mathbf{1}$, as well as its reactions with primary amines and a phenol. (B) The Hammett plot with para-substituted 2,6-dimethylaniline $\left(k_{\mathrm{X}} / k_{\mathrm{H}}=\right.$ relative rate constants for para$\mathrm{X}$ substituted 2,6-dimethylanilines versus 2,6-dimethylaniline; $\sigma_{\mathrm{p}}=$ Hammett substituent constant, $\rho=$ reaction constant). (C) The kinetic isotope effect $k_{\mathrm{H}} / k_{\mathrm{D}}$ for the reactions of $\mathbf{1}$ with 2,6-dimethylaniline.

The amido ligand in $\mathbf{1}$ is highly basic in accord with the severe Pauli repulsion in the $\mathrm{Pd}-\mathrm{N} \pi-$ bonding. When 1 is treated with phenols and amines, e.g. 2,6-di(tert-butyl)-4-methylphenol, 2,6di(isopropyl)aniline, 2,6-dimethylaniline, $n$-butyl amine, and $n$-octyl amine, the free aniline $\mathrm{NH}_{2} \mathrm{Ar}^{\text {Trip }}$ (4) was formed in high yields. The reaction with the phenol allows the isolation of a $\operatorname{Pd}(0)$ complex (2,6-di-tert-butyl-4-methylenecyclohexa-2,5-dienone)palladium(0) complex (9) in $67 \%$ yield (Fig. 5A), whose structure has been confirmed by X-ray diffraction (Figs. S48 and $\mathrm{S} 49$ ). The reactions with amines produced blue-purple mixtures and the attempts to isolate palladium-containing species from the mixture were unsuccessful. These reactions likely start with a proton-transfer step between the basic amido ligand in $\mathbf{1}$ and the $\mathrm{H}-\mathrm{X}(\mathrm{X}=\mathrm{O}, \mathrm{N})$ bonds in phenols and amines, rather than a hydrogen-atom-abstraction mechanism as i) a linear Hammett plot with a positive reaction constant $\rho=+0.77$ was obtained for the reactions of 1 with anilines bearing different para-substituents (Fig. 5B), ii) no obvious kinetic isotope effect was observed in the reactions 1 with 2,6- $\mathrm{Me}_{2} \mathrm{C}_{6} \mathrm{H}_{3} \mathrm{NH}_{2}$ and 2,6- $\mathrm{Me}_{2} \mathrm{C}_{6} \mathrm{H}_{3} \mathrm{ND}_{2}$ (Fig. 5C), iii) no reaction took place when 1 was treated with substrates bearing weak $\mathrm{C}-\mathrm{H}$ bonds, e.g. xanthene $(73.3 \mathrm{kcal} / \mathrm{mol}$ in DMSO) and cyclohexa-1,4-diene (67 kcal/mol in gas phase), whose $\mathrm{C}-\mathrm{H}$ bond dissociation energies are much lower than those of the $\mathrm{O}-\mathrm{H}$ bond of 2,6-di(tert-butyl)-4-methylphenol (78 $\mathrm{kcal} / \mathrm{mol}$ in DMSO) and the N-H bonds of amines ( $\geq 89 \mathrm{kcal} / \mathrm{mol}$ in DMSO) (51). Thus, the formation of the $\operatorname{Pd}(0)$ complex 9 can be explained by the sequential steps of proton-transfer followed by electron-transfer and hydrogen-atom abstraction reactions (Fig. S55). Notably, as anilido anions are generally less basic than aliphatic amido anions (51), the capability of $\mathbf{1}$ to react with the aliphatic amines has well-demonstrated the super-basicity of its amido ligand, which is a consequence of Pauli repulsion in the $4 d^{9}$ metal amido complex.

In summary, the first isolable, room-temperature stable $\mathrm{Pd}(\mathrm{I})$ complex bearing an $\pi$-donating ligand [(BINAP)Pd(NHAr $\left.\left.{ }^{\text {Trip }}\right)\right]$, which also represents the first platinum-group-metal amido complex with a n $d^{9}$ electronic configuration, has been synthesized from the salt elimination reaction of (BINAP) $\mathrm{PdCl}_{2}$ with $\mathrm{LiNHAr}{ }^{\text {Trip }}$. The $\mathrm{Pd}(\mathrm{I})$ amido complex features a long $\mathrm{Pd}-\mathrm{N}$ bond and inequivalent N-Pd-P angles. EPR and XAS spectroscopies indicate that $\mathrm{Pd}-\mathrm{N}$ bond in the $\mathrm{Pd}(\mathrm{I})$ amido complex is highly covalent. Theoretical studies accord with the spectroscopic data and further revealed that pronounced dispersion forces between the BINAP and the bulky amido ligand $\mathrm{NHAr}^{\text {Trip }}$ are likely responsible for the unusual stability of this complex. Reactivity studies revealed that the $\mathrm{Pd}-\mathrm{N}$ bond in [(BINAP)Pd(NHAr $\left.{ }^{\text {Trip }}\right)$ ] can undergo homolytic cleavage reaction to release the aminyl radical [NHAr $\left.{ }^{\text {Trip }}\right]^{\cdot}$ when the complex is subjected to heat, lightirradiation, or ligand-coordination. As a consequence of the severe Pauli repulsion, the anilido ligand in the $\operatorname{Pd}(\mathrm{I})$ complex exhibits strong basicity, and can even deprotonate aliphatic amines. The reactivity profile of the $\operatorname{Pd}(\mathrm{I})$ amido complex points out the potential synthetic utility of lowvalent platinum-group-metal species bearing $\pi$-donating ligands for the design of new reactions.

\section{References and Notes:}

1. M. Hartings, Reactions coupled to palladium. Nat. Chem. 4, 764 (2012).

2. D. C. Powers, T. Ritter, Palladium(III) in synthesis and catalysis. Top Organomet Chem 503, 129-156 (2011). 
3. Q. Liu, X. Dong, J. Li, J. Xiao, Y. Dong, H. Liu, Recent advances on palladium radical involved reactions. ACS Catal. 5, 6111-6137 (2015).

4. K. J. Bonney, F. Proutiere, F. Schoenebeck, Dinuclear Pd(I) complexes-solely precatalysts? Demonstration of direct reactivity of a Pd(I) dimer with an aryl iodide. Chem. Sci., 4, 4434-4439 (2013).

5. P. Cui, V. M. Iluc, Redox-induced umpolung of transition metal carbenes. Chem. Sci., 6, 7343-7354 (2015).

6. M. Parasram, P. Chuentragool, D. Sarkar, V. Gevorgyan, Photoinduced formation of hybrid aryl Pd-radical species capable of 1,5-HAT: Selective catalytic oxidation of silyl ethers into silyl enol ethers. J. Am. Chem. Soc., 138, 63406343 (2016).

7. B. Zhao, R. Shang, G.-Z. Wang, S. Wang, H. Chen, Y. Fu, Palladium-catalyzed dual ligand-enabled alkylation of silyl enol ether and enamide under irradiation: Scope, mechanism, and theoretical elucidation of hybrid alkyl $\operatorname{Pd}(\mathrm{I})-$ radical species. ACS Catal. 10, 1334-1343 (2019).

8. G. M. Torres, Y. Liu, B. A. Arndtsen, A dual light-driven palladium catalyst: Breaking the barriers in carbonylation reactions. Science, 368, 318-323 (2020).

9. Q.-Y. Chen, Z.-Y. Yang, C.-X. Zhao, Z.-M. Qiu, Studies on fluoroalkylation and fluoroalkoxylation. Part 28. Palladium(0)-induced addition of fluoroalkyl iodides to alkenes: an electron transfer process. J. Chem. Soc., Perkin Trans. 1, 563-567 (1988).

10. J. N. Jaworski, S. D. McCann, I. A. Guzei, S. S. Stahl, Detection of palladium(I) in aerobic oxidation catalysis. Angew. Chem., Int. Ed., 56, 3605-3610 (2017).

11. C. M. Fafard, D. Adhikari, B. M. Foxman, D. J. Mindiola, O. V. Ozerov, Addition of ammonia, water, and dihydrogen across a single Pd-Pd bond. J. Am. Chem. Soc., 129, 10318-10319 (2007).

12. S. Fujiwara, M. Nakamura, Electron spin resonance of Pd(I). I. $\gamma$-irradiated bis(acetylacetonato)palladium(II). $J$. Chem. Phys. 52, 6299-6301 (1970).

13. S. Fujiwara, M. Nakamura, Electron spin resonance of Pd(I). II. $\gamma$-irradiated single crystals of $\mathrm{K}_{2} \mathrm{PdCl}_{4}$ and $\left(\mathrm{NH}_{4}\right)_{2} \mathrm{PdCl}_{4}$. J. Chem. Phys. 54, 3378-3380 (1971).

14. Y. B. Taarit, J. C. Vedrine, J. F. Dutel, C. Naccache, Epr investigation of structure and reactivity of Pd(I) species generated in synthetic mordenite-type zeolite. J Magn Reson 31, 251-257 (1978).

15. G. A. Lane, W. E. Geiger, N. G. Connelly, Palladium(I) .pi.-radicals. Electrochemical preparation and study of their reaction pathways. J. Am. Chem. Soc., 109, $402-407$ (1987).

16. J. Luo, G. N. Tran, N. P. Rath, L. M. Mirica, Detection and characterization of mononuclear Pd(I) complexes supported by N2S2 and N4 tetradentate ligands. Inorg Chem, 15659-15669 (2020).

17. A. J. Blake, R. O. Gould, T. I. Hyde, M. Schröder, Stabilisation of monovalent palladium by tetra-aza macrocycles. J. Chem. Soc., Chem. Commun. 0, 431-433 (1987).

18. T. Troadec, S. Y. Tan, C. J. Wedge, J. P. Rourke, P. R. Unwin, A. B. Chaplin, One-electron oxidation of $\left.\left[\mathrm{M}^{2}\left(\mathrm{P}^{t} \mathrm{Bu}\right)_{2}\right)_{2}\right]$ $(\mathrm{M}=\mathrm{Pd}, \mathrm{Pt})$ : Isolation of monomeric $\left[\mathrm{Pd}\left(\mathrm{P}^{t} \mathrm{Bu}_{3}\right)_{2}\right]^{+}$and redox-promoted $\mathrm{C}-\mathrm{H}$ Bond cyclometalation. . Angew. Chem., Int. Ed., 55, 3754-3757 (2016).

19. M. C. MacInnis, J. C. DeMott, E. M. Zolnhofer, J. Zhou, K. Meyer, R. P. Hughes, O. V. Ozerov, Cationic twocoordinate complexes of $\mathrm{Pd}(\mathrm{I})$ and $\mathrm{Pt}(\mathrm{I})$ have longer metal-ligand bonds than their neutral counterparts. Chem 1, 902-920 (2016).

20. F. M. Bickelhaupt, E. Jan Baerends, Kohn-Sham density functional theory: Predicting and understanding chemistry. Rev. Comput. Chem. 15, 1-86 (2000).

21. K. G. Caulton, The influence of Pi-stabilized unsaturation and filled repulsions in transition-metal chemistry. . New J. Chem. 18, 25-41 (1994).

22. H. E. Bryndza, W. Tam, Monomeric metal hydroxides, alkoxides, and amides of the late transition metals: synthesis, reactions, and thermochemistry. Chem. Rev. 88, 1163-1188 (1988).

23. J. R. Fulton, A. W. Holland, D. J. Fox, R. G. Bergman, Formation, reactivity, and properties of nondative late transition metal-oxygen and-nitrogen bonds. Acc. Chem. Res. 35, 44-56 (2002).

24. T. B. Gunnoe, Reactivity of ruthenium(II) and copper(I) complexes that possess anionic heteroatomic ligands: Synthetic exploitation of nucleophilicity and basicity of amido, hydroxo, alkoxo, and aryloxo ligands for the activation of substrates that possess polar bonds as well as nonpolar $\mathrm{C}-\mathrm{H}$ and $\mathrm{H}-\mathrm{H}$ bonds. Eur. J. Inorg. Chem., 1185-1203 (2007).

25. M. D. Fryzuk, C. D. Montgomery, Amides of the platinum group metals. Coord. Chem. Rev. 95, 1-40 (1989).

26. T. Buttner, J. Geier, G. Frison, J. Harmer, C. Calle, A. Schweiger, H. Schonberg, H. Grutzmacher, A stable aminyl radical metal complex. Science, 307, 235-238 (2005).

27. M. S. Driver, J. F. Hartwig, A rare, low-valent alkylamido complex, a diphenylamido complex, and their reductive elimination of amines by three-coordinate intermediates. J. Am. Chem. Soc., 117, 4708-4709 (1995).

28. D. J. Liptrot, P. P. Power, London dispersion forces in sterically crowded inorganic and organometallic molecules. 
Nat. Rev. Chem. 1, (2017).

29. P. J. Perez, J. C. Calabrese, E. E. Bunel, Synthesis, characterization, and reactivity of $\left[\left(\left({ }^{i} \mathrm{Pr}\right)_{2} \mathrm{P}\left(\mathrm{CH}_{2}\right)_{3} \mathrm{P}\left({ }^{i} \mathrm{Pr}\right)_{2}\right)(\mathrm{PCy}) \mathrm{PdH}\right][\mathrm{OR}]$. Organometallics 20, 337-345 (2001).

30. C. Tejel, L. Asensio, M. P. del Rio, B. de Bruin, J. A. Lopez, M. A. Ciriano, Developing synthetic approaches with non-innocent metalloligands: easy access to $\operatorname{Ir}(\mathrm{I}) / \mathrm{Pd}(0)$ and $\operatorname{Ir}(\mathrm{I}) / \operatorname{Pd}(0) / \operatorname{Ir}(\mathrm{I})$ cores. Angew. Chem., Int. Ed., 50, 8839$8843(2011)$.

31. M. Yamashita, J. F. Hartwig, Synthesis, structure, and reductive elimination chemistry of three-coordinate arylpalladium amido complexes. J. Am. Chem. Soc., 126, 5344-5345 (2004).

32. P. S. Hanley, S. L. Marquard, T. R. Cundari, J. F. Hartwig, Reductive elimination of alkylamines from low-valent, alkylpalladium(II) amido complexes. J. Am. Chem. Soc., 134, 15281-15284 (2012).

33. F. N. Penkert, T. Weyhermüller, E. Bill, P. Hildebrandt, S. Lecomte, K. Wieghardt, Anilino radical complexes of cobalt(III) and manganese(IV) and comparison with their phenoxyl analogues. J. Am. Chem. Soc., 122, 9663-9673 (2000).

34. A. T. Radosevich, J. G. Melnick, S. A. Stoian, D. Bacciu, C. H. Chen, B. M. Foxman, O. V. Ozerov, D. G. Nocera, Ligand reactivity in diarylamido/bis(phosphine) PNP complexes of $\mathrm{Mn}(\mathrm{CO})_{3}$ and $\operatorname{Re}(\mathrm{CO})_{3}$. Inorg. Chem. 48, 92149221 (2009)

35. D. Adhikari, S. Mossin, F. Basuli, J. C. Huffman, R. K. Szilagyi, K. Meyer, D. J. Mindiola, Structural, spectroscopic, and theoretical elucidation of a redox-active pincer-type ancillary applied in catalysis. J. Am. Chem. Soc., 130, 3676-3682 (2008).

36. N. P. Mankad, W. E. Antholine, R. K. Szilagyi, J. C. Peters, Three-coordinate copper(I) amido and aminyl radical complexes. J. Am. Chem. Soc., 131, 3878-3880 (2009).

37. S. Wiese, Y. M. Badiei, R. T. Gephart, S. Mossin, M. S. Varonka, M. M. Melzer, K. Meyer, T. R. Cundari, T. H. Warren, Catalytic C-H amination with unactivated amines through copper(II) amides. Angew. Chem., Int. Ed., 49, 8850-8855 (2010).

38. M. Nakamura, S. Fujiwara, Electron spin resonance of Pd(I). III* The nature of the metal-ligand bonds in square planar complexes of palladium(I). J. Coord. Chem., 1, 221-227 (1972).

39. J. R. Morton, K. F. Preston, Atomic parameters for paramagnetic resonance data. J Magn Reson 30, 577-582 (1978).

40. S. N. MacMillan, K. M. Lancaster, X-ray spectroscopic interrogation of transition-metal-mediated homogeneous catalysis: Primer and case studies. ACS Catal. 7, 1776-1791 (2017).

41. R. B. Boysen, R. K. Szilagyi, Development of palladium L-edge X-ray absorption spectroscopy and its application for chloropalladium complexes. Inorg. Chim. Acta 361, 1047-1058 (2008).

42. T. K. Sham, L-edge x-ray-absorption spectra of $\mathrm{PdAl}_{3}$ and $\mathrm{PdCl}_{2}$ : A study of charge redistribution in compounds of an element with a nearly full 4d shell. Phys. Rev. B. 31, 1903-1908 (1985).

43. M. Elstner, P. Hobza, T. Frauenheim, S. Suhai, E. Kaxiras, Hydrogen bonding and stacking interactions of nucleic acid base pairs: A density-functional-theory based treatment. J. Chem. Phys. 114, 5149-5155 (2001).

44. S. Grimme, J. Antony, S. Ehrlich, H. Krieg, A consistent and accurate ab initio parametrization of density functional dispersion correction (DFT-D) for the 94 elements H-Pu. J. Chem. Phys. 132, 154104 (2010).

45. J. D. Rolfes, F. Neese, D. A. Pantazis, All-electron scalar relativistic basis sets for the elements Rb-Xe. J. Comput. Chem. 41, 1842-1849 (2020).

46. W. He, P. Kennepohl, Direct experimental evaluation of ligand-induced backbonding in nickel metallacyclic complexes. Faraday Discuss 220, 133-143 (2019).

47. T. Ziegler, A. Rauk, On the calculation of bonding energies by the Hartree Fock Slater method. Theoret. Chim. Acta 46, 1-10 (1977).

48. M. Mitoraj, A. Michalak, Donor-acceptor properties of ligands from the natural orbitals for chemical valence. Organometallics 26, 6576-6580 (2007).

49. M. Mitoraj, A. Michalak, Applications of natural orbitals for chemical valence in a description of bonding in conjugated molecules. J Mol Model 14, 681-687 (2008).

50. M. P. Mitoraj, A. Michalak, T. Ziegler, A combined charge and energy decomposition scheme for bond analysis. J. Chem. Theory Comput. 5, 962-975 (2009).

51. J. J. Warren, T. A. Tronic, J. M. Mayer, Thermochemistry of proton-coupled electron transfer reagents and its implications. Chem Rev 110, 6961-7001 (2010).

52. T. Hayashi, Y. Matsumoto, Y. Ito, Palladium-catalyzed asymmetric 1,4-disilylation of $a, b$-unsaturated ketones: Catalytic asymmetric synthesis of $b$-hydroxy ketones. J. Am. Chem. Soc., 110, 5579-5581 (1988).

53. B. Twamley, C.-S. Hwang, N. J. Hardman, P. P. Power, Sterically encumbered terphenyl substituted primary pnictanes $\mathrm{ArEH}_{2}$ and their metallated derivatives $\mathrm{ArE}(\mathrm{H}) \mathrm{Li}\left(\mathrm{Ar}=-\mathrm{C}_{6} \mathrm{H}_{3}-2,6\right.$-Trip 2 ; Trip = 2,4,6-triisopropylphenyl; $\mathrm{E}=\mathrm{N}, \mathrm{P}, \mathrm{As}, \mathrm{Sb})$. J. Organomet. Chem. 609, 152-160 (2000). 
54. M. Virant, M. Mihelac, M. Gazvoda, A. E. Cotman, A. Frantar, B. Pinter, J. Kosmrlj, Pyridine wingtip in [Pd(PytzNHC) $\left.)_{2}\right]^{2+}$ complex is a proton shuttle in the catalytic hydroamination of alkynes. Org. Lett. 22, 2157-2161 (2020).

55. D. P. Hruszkewycz, J. Wu, N. Hazari, C. D. Incarvito, Palladium(I)-bridging allyl dimers for the catalytic functionalization of $\mathrm{CO}_{2}$. J. Am. Chem. Soc., 133, 3280-3283 (2011).

56. D. F. Evans, The determination of the paramagnetic susceptibility of substances in solution by nuclear magnetic resonance. J. Chem. Soc., 2003-2005 (1959).

57. C. Adamo, R. Subra, A. Di Matteo, V. Barone, Structure and magnetic properties of benzyl, anilino, and phenoxyl radicals by density functional computations. J. Chem. Phys. 109, 10244-10254 (1998).

58. G. M. Sheldrick, SADABS: Program for empirical absorption correction of area detector data; University of Göttingen: Germany, 1996.

59. G. M. Sheldrick, SHELXTL 5.10 for Windows NT: Structure determination software programs; Bruker analytical X-ray systems, Inc.: Madison, Wisconsin, USA, 1997.

60. S. Stoll, A. Schweiger, EasySpin, a comprehensive software package for spectral simulation and analysis in EPR. J. Magn. Reson. 178, 42-55 (2006).

61. S. Webb, Sixpack: Sam's interface for XAS package.

62. V. A. Solé, E. Papillon, M. Cotte, P. Walter, J. Susini, A multiplatform code for the analysis of energy-dispersive X-ray fluorescence spectra. Spectrochim. Acta, Part B 62, 63-68 (2007).

63. M. Morháč, V. Matoušek, Peak clipping algorithms for background estimation in spectroscopic data. Appl. Spectrosc. 62, 91-106 (2008).

64. F. Neese, The ORCA program system. WIREs Comput. Mol. Sci., 2, 73-78 (2012).

65. A. D. Becke, Density-functional thermochemistry. III. The role of exact exchange. J. Chem. Phys. 98, 5648-5652 (1993).

66. C. Lee, W. Yang, R. G. Parr, Development of the Colle-Salvetti correlation-energy formula into a functional of the electron density. Phys Rev B Condens Matter 37, 785-789 (1988).

67. L. W. S. H. Vosko, M. Nusair,, Accurate spin-dependent electron liquid correlation energies for local spin density calculations: a critical analysis. Can. J. Phys. 58, 1200-1211 (1980).

68. P. J. Stephens, F. J. Devlin, C. F. Chabalowski, M. J. Frisch, Ab initio calculation of vibrational absorption and circular dichroism spectra using density functional force fields. J.Phys.Chem. 98, 11623-11627 (1994).

69. F. Neese, F. Wennmohs, A. Hansen, U. Becker, Efficient, approximate and parallel Hartree-Fock and hybrid DFT calculations. A 'chain-of-spheres' algorithm for the Hartree-Fock exchange. Chem. Phys. 356, 98-109 (2009).

70. G. L. Stoychev, A. A. Auer, F. Neese, Automatic generation of auxiliary basis sets. J. Chem. Theory. Comput. 13, 554-562 (2017).

71. J. D. Rolfes, F. Neese, D. A. Pantazis, All-electron scalar relativistic basis sets for the elements Rb-Xe. J. Comput. Chem. 41, 1842-1849 (2020).

72. F. Weigend, R. Ahlrichs, Balanced basis sets of split valence, triple zeta valence and quadruple zeta valence quality for H to Rn: Design and assessment of accuracy. Phys. Chem. Chem. Phys. 7, 3297-3305 (2005).

73. E. van Lenthe, A. van der Avoird, P. E. S. Wormer, Density functional calculations of molecular hyperfine interactions in the zero order regular approximation for relativistic effects. J. Chem. Phys. 108, 4783-4796 (1998).

74. S. Grimme, S. Ehrlich, L. Goerigk, Effect of the damping function in dispersion corrected density functional theory. J Comput Chem 32, 1456-1465 (2011).

75. A. Klamt, G. Schüürmann, COSMO: a new approach to dielectric screening in solvents with explicit expressions for the screening energy and its gradient. J. Chem. Soc., Perkin Trans., 799-805 (1993).

76. J. P. Perdew, Density-functional approximation for the correlation energy of the inhomogeneous electron gas. Phys. Rev.B 33, 8822-8824 (1986).

77. A. D. Becke, Density-functional exchange-energy approximation with correct asymptotic behavior. Phys. Rev. A: At. Mol. Opt. Phys. 38, 3098-3100 (1988).

78. A. Schäfer, H. Horn, R. Ahlrichs, Fully optimized contracted Gaussian basis sets for atoms Li to Kr. J. Chem. Phys. 97, 2571-2577 (1992).

79. B. M. Day, T. Pugh, D. Hendriks, C. F. Guerra, D. J. Evans, F. M. Bickelhaupt, R. A. Layfield, Normal-to-abnormal rearrangement and NHC activation in three-coordinate iron(II) carbene complexes. J. Am. Chem. Soc., 135, 1333813341 (2013).

80. X. Cong, F. Fan, P. Ma, M. Luo, H. Chen, X. Zeng, Low-valent, high-spin Chromium-catalyzed cleavage of aromatic carbon-nitrogen bonds at room temperature: A combined experimental and theoretical study. J. Am. Chem. Soc. 139, 15182-15190 (2017).

55 81. G. Frenking, F. M. Bickelhaupt, The Chemical Bond 1. Fundamental Aspects of Chemical Bonding. G. Frenking and S. Shaik (editors), 121-158. Wiley-VCH: Weinheim, 2014. 
82. L. Zhao, M. von Hopffgarten, D. M. Andrada, G. Frenking, Energy decomposition analysis. WIREs Comput. Mol. Sci., 8, e1345 (2018).

83. L. Zhao, M. Hermann, W. H. E. Schwarz, G. Frenking, The Lewis electron-pair bonding model: modern energy decomposition analysis. Nat. Rev. Chem. 3, 48-63 (2019).

Acknowledgments: We thank Mr. Chenglu Lu for the cold electron spray mass spectrometry measurements, and Mr. Jianfeng Zhang for elemental analysis. Funding: L.D. thanks the financial support from the National Natural Science Foundation of China (grants 21725104, 21690062, 22061160464, 21821002, 21833011, and 21873103), the Science and Technology Commission of Shanghai Municipality (grant 19XD1424800), and K. C. Wong Education Foundation. K.M.L. thanks the NSF for support of this research via CHE-1954515. M.M.B is an NSF Graduate Research Fellow. XAS data were obtained at SSRL, which is supported by the DOE, Office of Science, Office of Basic Energy Sciences under Contract No. DE-AC0276SF00515. The SSRL Structural Molecular Biology Program is supported by the US DOE Office of Biological and Environmental Research, and by NIH/HIGMS (including P41GM103393). S.H.K. thanks the NRF of Korea for support of this research (NRF2017M3D1A1039380). L.Z. thanks the financial support from National Natural Science Foundation of China (Grant No. 21973044), the State Key Laboratory of Materials-oriented Chemical Engineering (project No. KL19-11), and the high performance center of Nanjing Tech University for supporting the computational resources. Author contributions: J.L., M.M.B., Y.K., and D.X.: Investigation, Validation, Formal analysis, Writing - original draft, and Visualization. S.N.M.: Writing - original draft, Writing - review \& editing, Formal analysis and Visualization. Q.C. and X.L.: Investigation, Validation, and Formal analysis. K.M.L., S.H.K., and L.Z.: Writing original draft, Writing - review \& editing, Visualization, and Supervision. L.D.: Conceptualization, Writing - original draft, Writing - review \& editing, Visualization, Supervision, and Project administration. Competing interests: Authors declare no competing interests. Data and materials availability: X-ray data are available free of charge from the Cambridge Crystallographic Data Centre under reference numbers CCDC 2059309 (1), 2059310 (2), $2070924\left(6 \cdot \mathrm{CH}_{2} \mathrm{Cl}_{2}\right), 2059311$ (7), $2059312(\mathbf{8} \bullet 0.5 n$-hexane) and 2059313 (9). All other experimental, spectroscopic crystallographic, and computational data are included in the supplementary materials.

\section{Supplementary Materials:}

Materials and Methods

Figures S1-S86

Tables S1-S3

References (52-83)

Data S1 


\section{Supplementary Materials for}

\section{An Isolable Mononuclear Palladium(I) Amido Complex}

Jian Liu ${ }^{1}$, Melissa M. Bollmeyer ${ }^{2}$, Yujeong Kim ${ }^{3,4}$, Dengmengfei Xiao ${ }^{5}$, Samantha N. MacMillan ${ }^{2}$, Qi Chen ${ }^{1}$, Xuebing Leng ${ }^{1}$, Sun Hee Kim ${ }^{3,4 *}$, Lili Zhao ${ }^{5 *}$, Kyle M. Lancaster ${ }^{2 *}$, and Liang Deng ${ }^{1 *}$

*Corresponding author. Email: shkim7@kbsi.re.kr (S.H.K), ias_llzhao@njtech.edu.cn (L.Z.),kml236@cornell.edu (K.M.L.), deng@sioc.ac.cn (L.D.).

This PDF file includes:

Materials and Methods

Supplementary Text

Figs. S1 to S86

Tables S1 to S3

Caption for Data $\mathrm{S} 1$

References

Other Supplementary Materials for this manuscript include the following:

Data S1 (.xyz) 


\section{Materials and Methods}

General Procedures. All experiments were performed either under an atmosphere of dry dinitrogen with the rigid exclusion of air and moisture using standard Schlenk techniques or in a glovebox. Organic solvents were dried with a solvent purification system (Innovative Technology) and bubbled with dry $\mathrm{N}_{2}$ gas prior to use. (BINAP) $\mathrm{PdCl}_{2} \quad(\mathrm{BINAP}=$ 2,2'-bis(diphenylphosphino)-1,1'-binaphthalene) (52), $\quad$ LiNHAr ${ }^{\text {Trip }} \quad\left(\operatorname{Ar}^{\text {Trip }}=\right.$ 2,6-bis(2',4',6'-triisopropylphenyl)pheny) (53), N,N'-dideuterium-2,6-dimethylaniline (54), and $\operatorname{Pd}(\operatorname{IPr})_{2}(55)$ were synthesized according to literature procedures. Chemicals were purchased from chemical vendors and used as received unless otherwise noted. ${ }^{1} \mathrm{H},{ }^{13} \mathrm{C},{ }^{19} \mathrm{~F}$, and ${ }^{31} \mathrm{P}$ NMR spectra were recorded with Agilent $400 \mathrm{MHz}$ or Bruker $400 \mathrm{MHz}$ or JEOL 600MHz NMR spectrometer. All chemical shifts were reported in units of ppm with references to the residue of the deuterated solvents for proton and carbon chemical shifts, to external $85 \%$ phosphoric acid solution for phosphorous chemical shifts, to $\mathrm{CF}_{3} \mathrm{COOH}$ for fluorine chemical shifts, and to $\mathrm{CDCl}_{3}$ for deuterium chemical shifts. Elemental analysis was performed by the Analytical Laboratory of Shanghai Institute of Organic Chemistry (CAS). Magnetic moments were measured by the method originally described by Evans with stock and experimental solutions containing a known amount of a $\left(\mathrm{CH}_{3}\right)_{3} \mathrm{SiOSi}\left(\mathrm{CH}_{3}\right)_{3}$ standard (56). Absorption spectra were recorded with a Shimadzu UV-3600 UV-vis-NIR spectrophotometer. IR spectra were recorded with NICOLET AVATAR 330 FT-IR spectrophotometer and Bruker ALPHA II Sample Compartment RT-DLaTGS. The photoreactors used in this research were bought from GeAo Chem (white LEDs, luminous flux $\geq 110 \mathrm{~lm}$, beam angle $=120^{\circ}$, current intensity $\geq 350 \mathrm{~mA}, 1 \mathrm{~W}$ for every light bulb; every Schlenk tube was irradiated by 6 light bulbs from the side. 


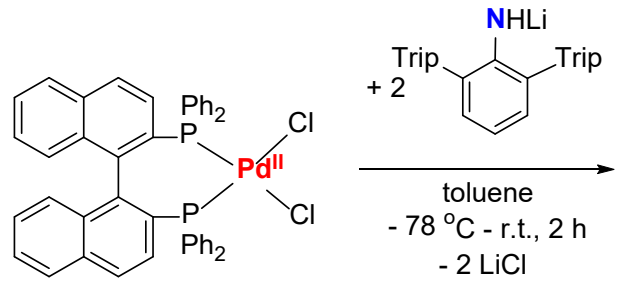

Trip: 2,4,6-triisopropylphenyl

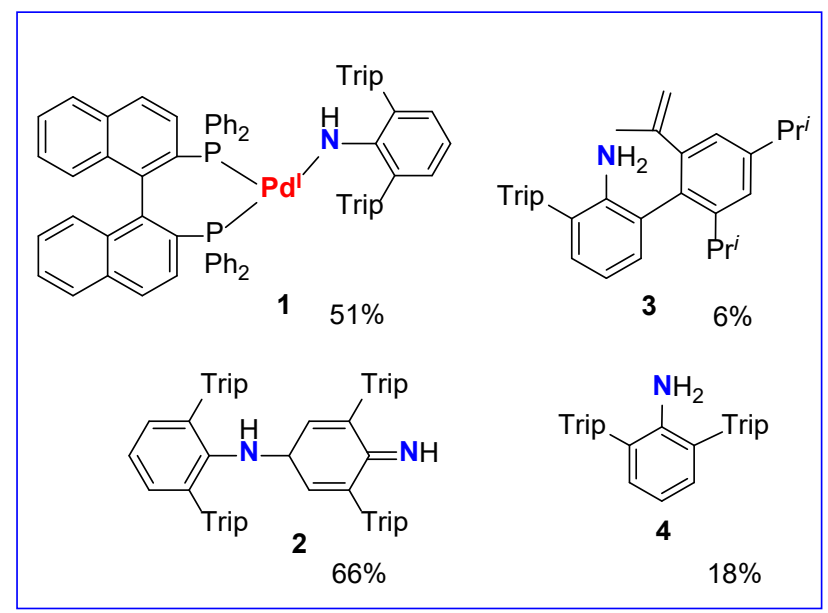

Preparation of [(BINAP)Pd(NHAr $\left.\left.{ }^{\text {Trip }}\right)\right]$ (1). To an orange suspension of (BINAP) $\mathrm{PdCl}_{2}(200$ $\mathrm{mg}, 0.25 \mathrm{mmol})$ in toluene $(20 \mathrm{~mL})$ was added LiNHAr ${ }^{\text {Trip }}(277 \mathrm{mg}, 0.55 \mathrm{mmol})$ at $-78^{\circ} \mathrm{C}$. The color of the reaction mixture changed to blue immediately. The mixture was slowly warmed to room temperature and then kept stirring for $2 \mathrm{~h}$. During the course, the color of the reaction mixture changed to green gradually. The resultant mixture was filtered through diatomaceous earth, and the filtrate was concentrated under vacuum to leave a green residue. The residue was dissolved by diethyl ether $(5 \mathrm{~mL})$. The ether solution was concentrated and kept at $-30{ }^{\circ} \mathrm{C}$ for days to yield green crystals. The green crystals were collected by filtration, and a single-crystal X-ray diffraction study confirmed its identity as the palladium(I) amido complex 1 (156 mg, 51\%). After collecting of 1 by filtration, the filtrate was concentrated under vacuum to leave a residue. The residue was dissolved in $\mathrm{C}_{6} \mathrm{D}_{6}(500 \mu \mathrm{L})$ and 1,3,5-trimethoxybenzene $(2.5 \mathrm{mg}, 0.015 \mathrm{mmol})$ was added as an internal standard for NMR quantification, which indicates the NMR yields of 2, 3 and 4 in $66 \%, 6 \%$ and 18\%, respectively (Fig. S8.). The isolation and characterization of $\mathbf{2}, \mathbf{3}$ and $\mathbf{4}$ can be independently achieved (vide infra). For [(BINAP)Pd(NHAr ${ }^{\text {Trip })] ~(1): ~ A n a l . ~ C a l c d ~ f o r ~} \mathrm{C}_{80} \mathrm{H}_{82} \mathrm{P}_{2} \mathrm{PdN}$ : C, 78.38; $\mathrm{H}$, 6.74; N, 1.14; Found: C, 78.58; H, 6.97; N, 1.18. Magnetic susceptibility $\left(\mathrm{C}_{6} \mathrm{D}_{6}, 294 \mathrm{~K}\right): \mu_{\mathrm{eff}}=2.1(1)$ $\mu_{\mathrm{B}}$. Absorption spectrum (toluene): $\lambda_{\max }, \mathrm{nm}\left(\varepsilon, \mathrm{M}^{-1} \mathrm{~cm}^{-1}\right)=300$ (12000), 390 (6000), 800 (7300). IR $\left(\mathrm{KBr}, \mathrm{cm}^{-1}\right): v=3478(\mathrm{w}), 3379(\mathrm{w}), 3303(\mathrm{w}), 3051(\mathrm{~m}), 2957(\mathrm{~s}), 2925(\mathrm{~s}), 2864(\mathrm{~m}), 1605(\mathrm{~m})$, 1575 (m), 1459 (m), 1435(s), 1398 (m), 1380 (m), 1360 (m), 1311 (m), 1098 (m), 1071 (m), 876 (m), $814(\mathrm{~m}), 745(\mathrm{~s}), 696(\mathrm{~s}), 523(\mathrm{~m}), 504(\mathrm{~s})$. 


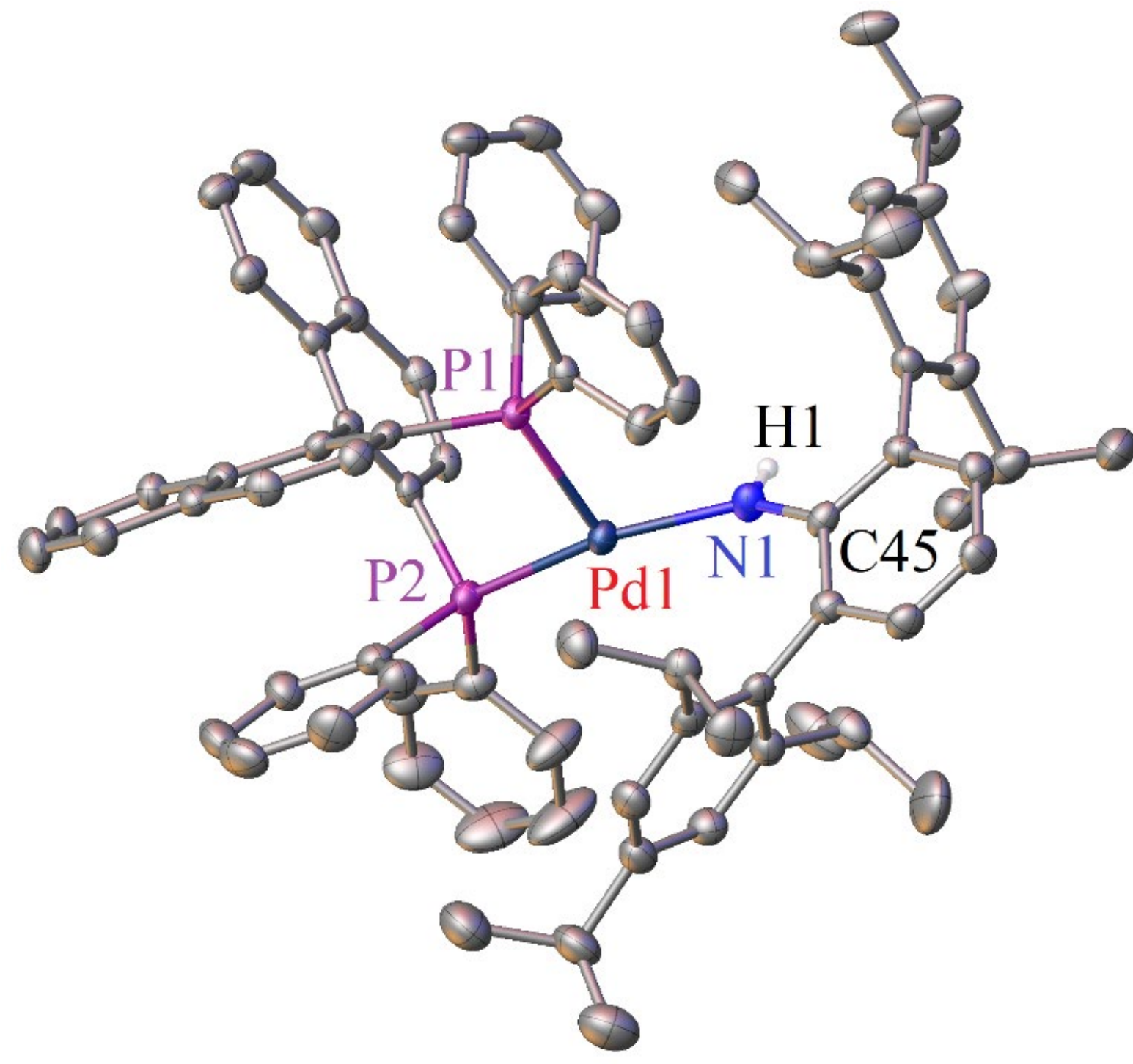

Fig. S1. Molecular structure of 1a, showing one of the two crystallographically independent molecules in the unit cell with $30 \%$ probability ellipsoids and the partial atoms numbering scheme. Hydrogen atoms, except the one on N1, are omitted for clarity. Selected distances $(\AA)$ and angles (deg): Pd1-N1 2.063(2), Pd1-P1 2.3314(7), Pd1-P2 2.2883(7), N1-C45 1.377(3), P2-Pd1-P1 92.20(2), N1-Pd1-P1 108.06(6), N1-Pd1-P2 154.04(6), Pd1-N1-H1 112.4, C45-N1-Pd1 135.29(18), C45-N1-H1 112.3. 


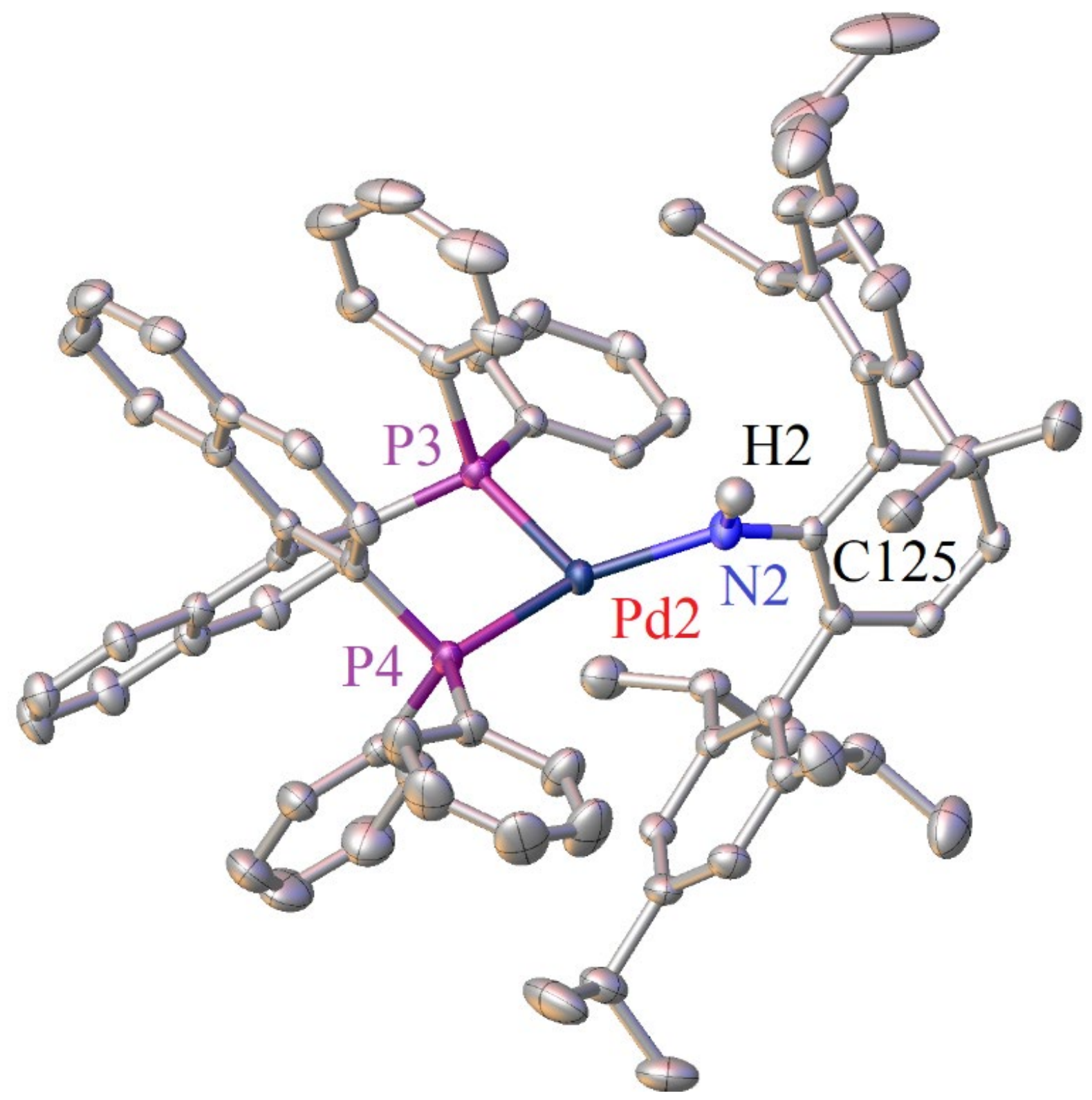

Fig. S2. Molecular structure of $\mathbf{1 b}$, showing another one of the two crystallographically independent molecules in the unit cell with $30 \%$ probability ellipsoids and the partial atoms numbering scheme. Hydrogen atoms, except the one on N2, are omitted for clarity. Selected distances $(\AA)$ and angles (deg): Pd2-N2 2.063(2), Pd2-P3 2.3211(7), Pd2-P4 2.2841(7), N2-C125 1.371(3), P3-Pd2-P4 92.04(2), N2-Pd2-P3 114.39(6), N2-Pd2-P4 149.54(6), Pd2-N2-H2 110.0, C125-N2-Pd2 139.98(18), C125-N2-H2 110.0. 


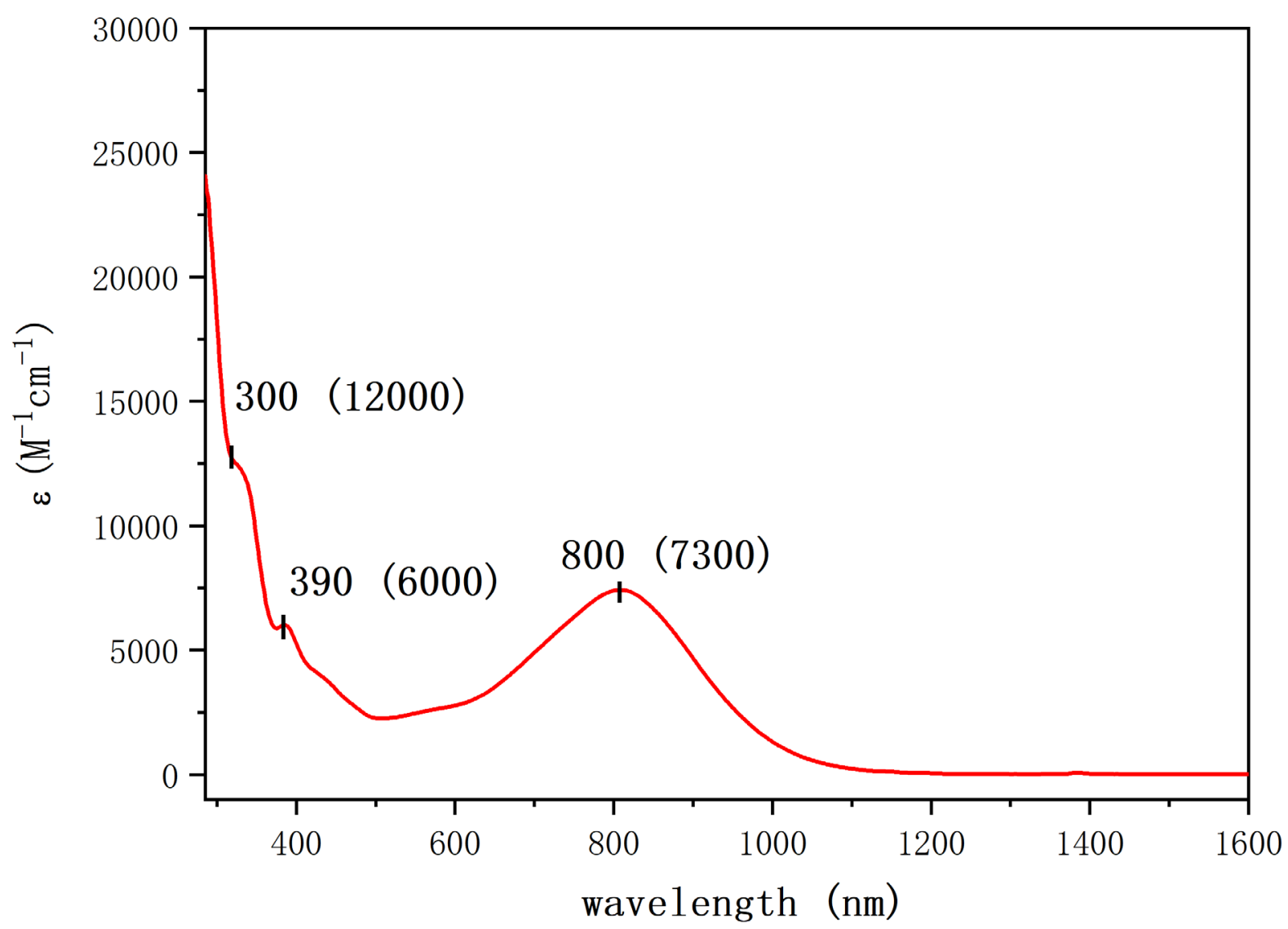

Fig. S3. UV-vis absorption spectrum in toluene of $\mathbf{1}$ recorded at room temperature. 


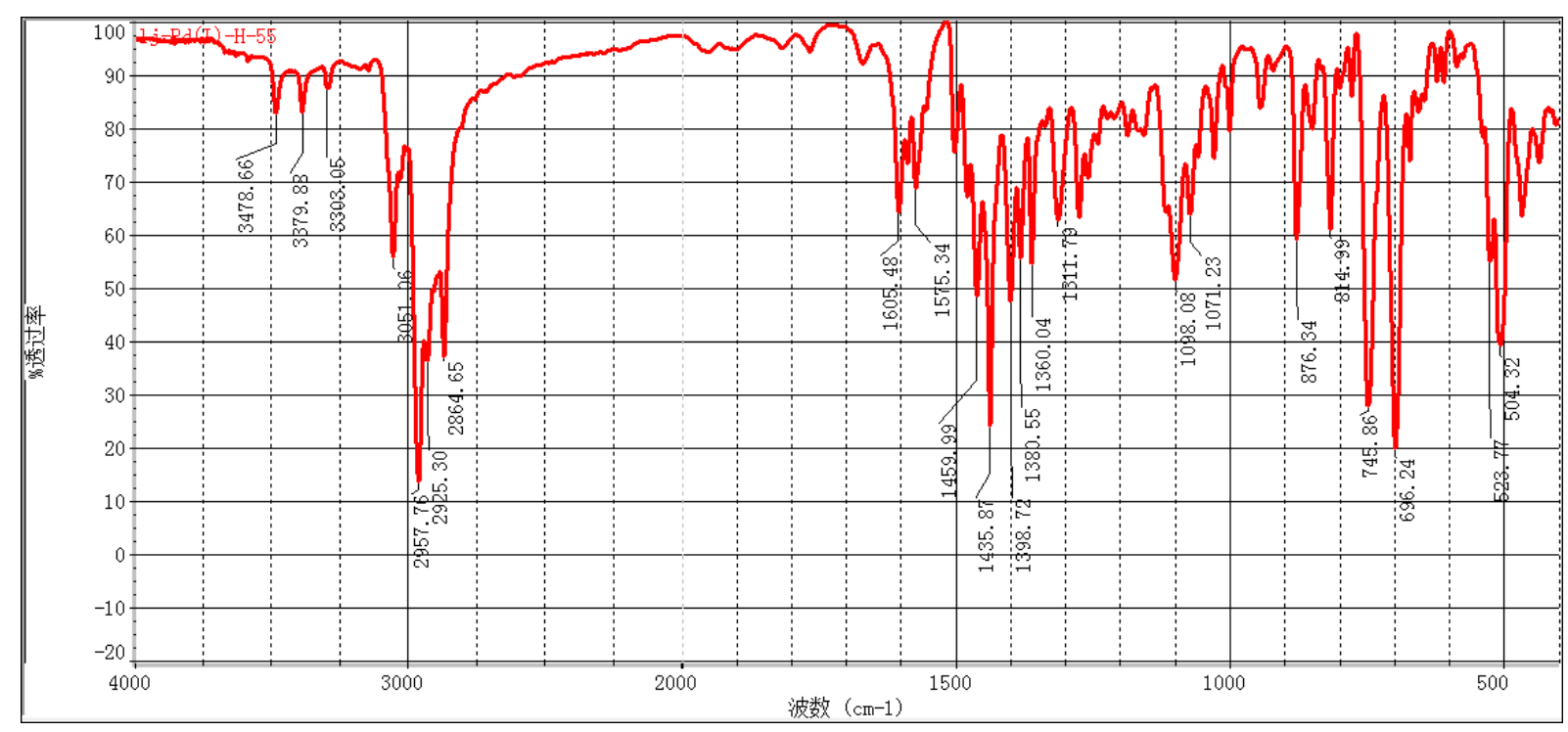

Fig. S4. IR spectrum of 1 . 


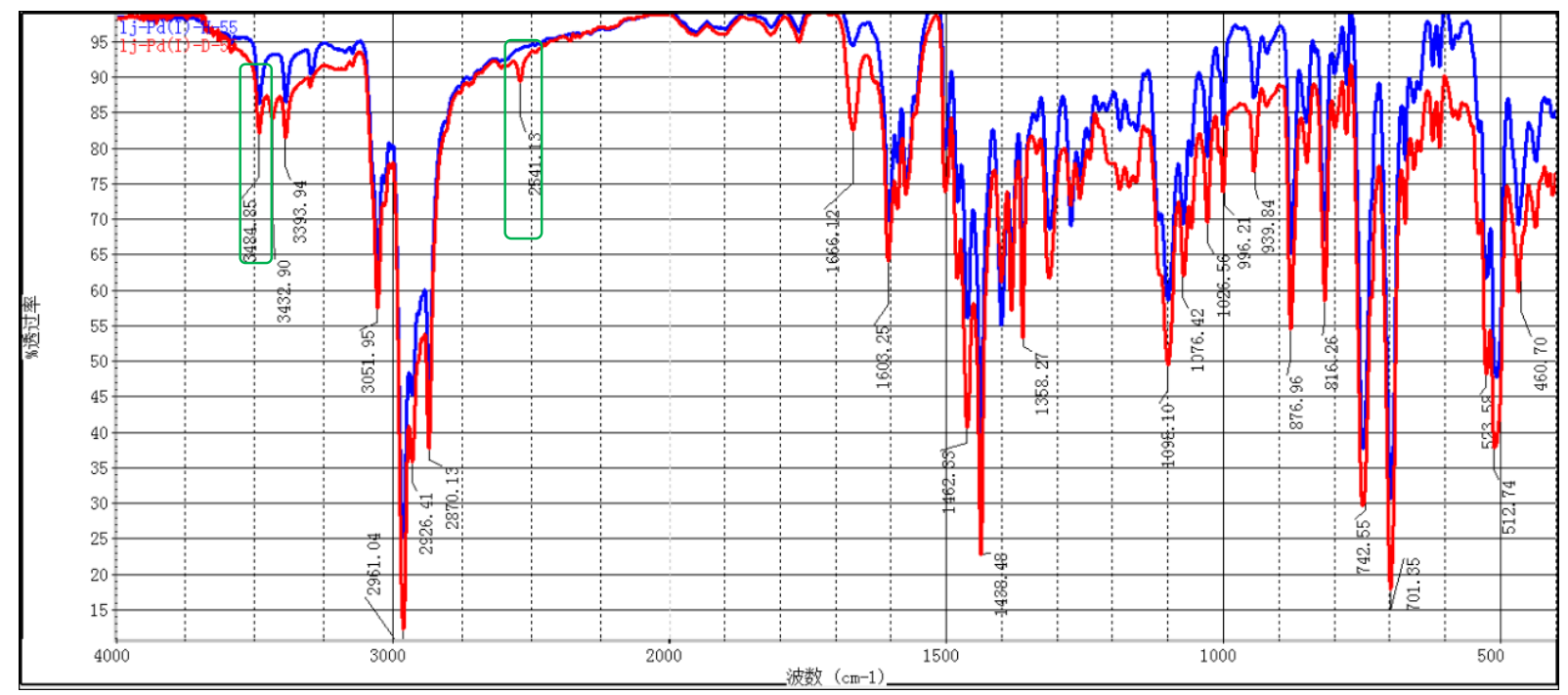

Fig. S5. Comparison of IR spectra of $\left[(\mathrm{BINAP}) \mathrm{Pd}\left(\mathrm{NHAr}^{\text {Trip }}\right)\right] \quad(\mathbf{1}$, red line $)$ and [(BINAP)Pd(NDAr ${ }^{\text {Trip })}$ ] (1-d, blue line) $\left(3484 \mathrm{~cm}^{-1}\right.$ is the characteristic peak of N-H bond, 2641 $\mathrm{cm}^{-1}$ is the characteristic peak of N-D bond). 

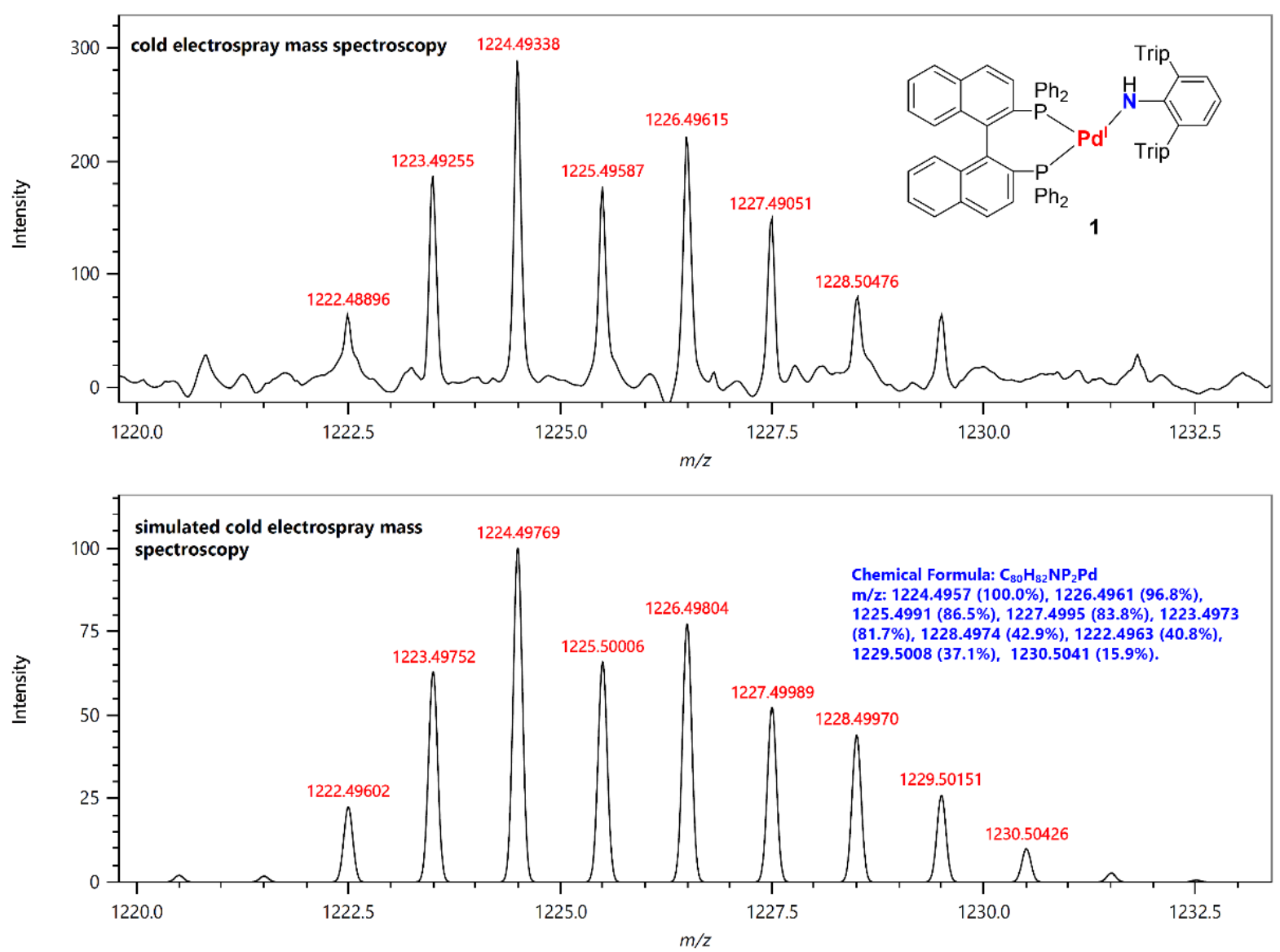

Fig. S6. Mass spectrum of 1 (top) and its simulated spectrum (bottom). 

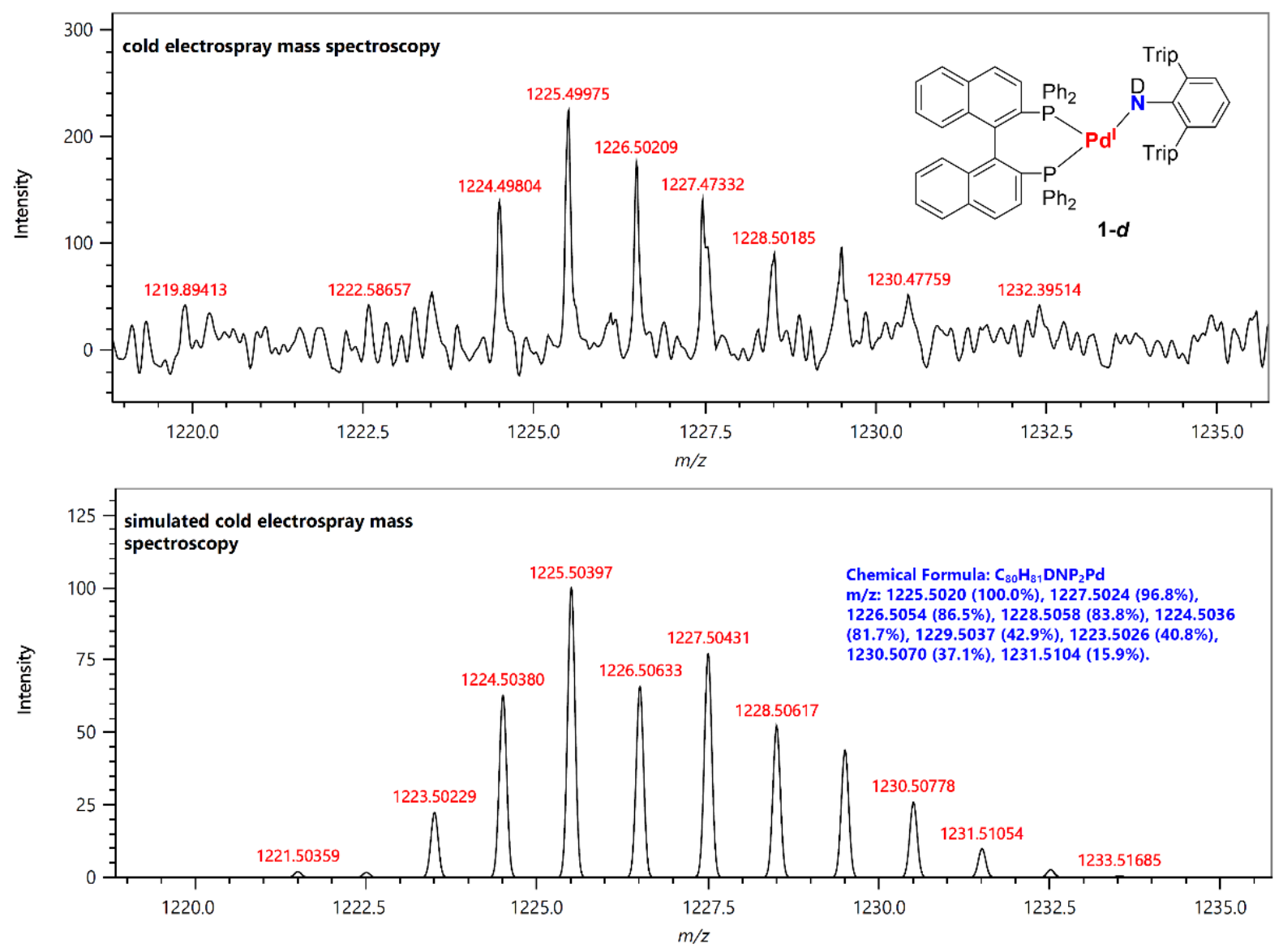

Fig. S7. Mass spectrum of [(BINAP)Pd(NDAr $\left.\left.{ }^{\text {Trip }}\right)\right]$ (1-d, top) and its simulated spectrum (bottom). 


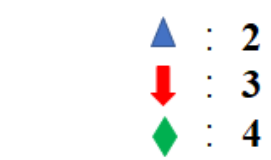

${ }^{1} \mathrm{H}$ NMR, $400 \mathrm{MHz}, \mathrm{C}_{6} \mathrm{D}_{6}$

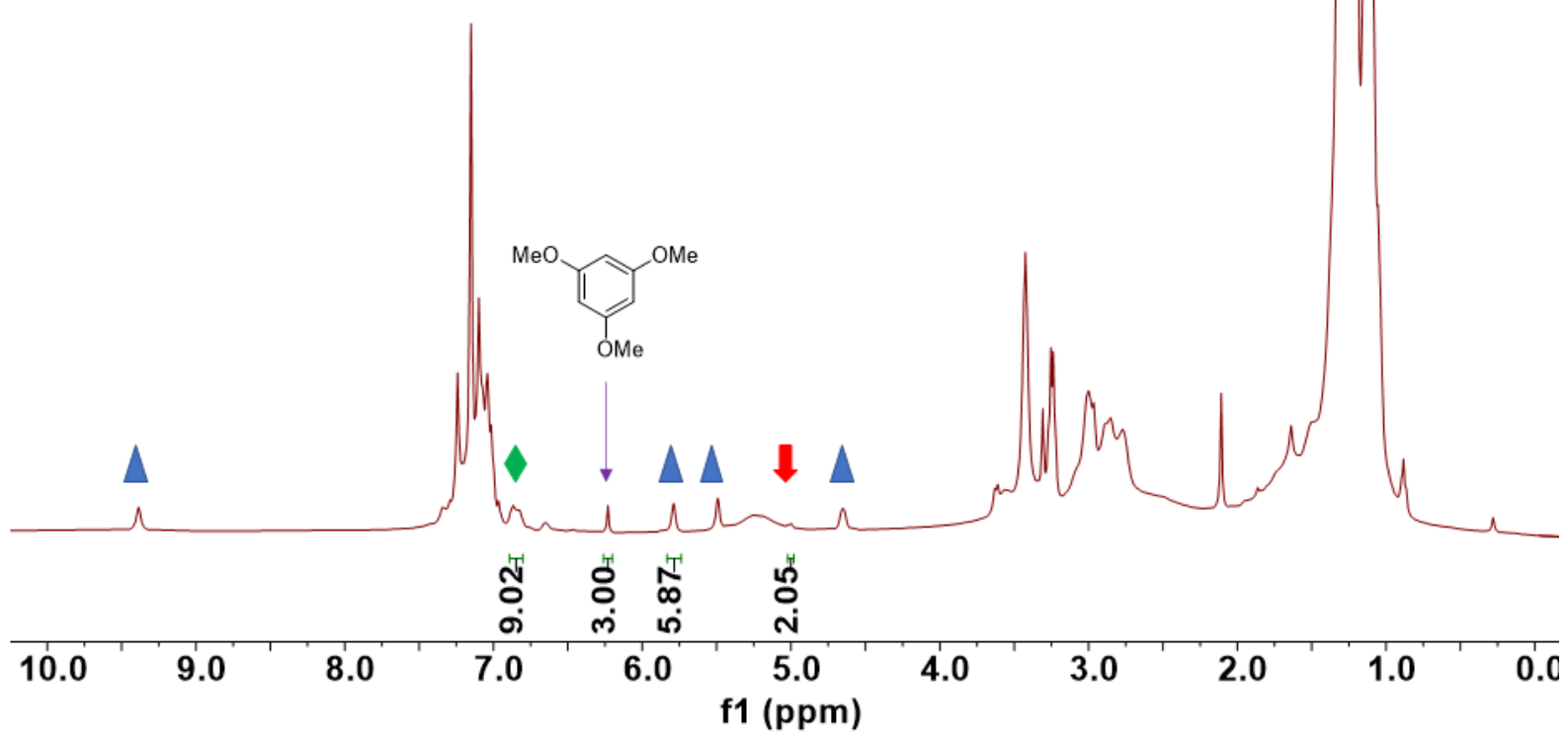

Fig. S8. The ${ }^{1} \mathrm{H}$ NMR spectrum of the mixture of $\mathbf{2 , 3}$ and $\mathbf{4}$ formed in the preparation of $\mathbf{1}$. 
Isolation and Characterization of 2. To an orange suspension of (BINAP) $\mathrm{PdCl}_{2}(200 \mathrm{mg}, 0.25$ $\mathrm{mmol})$ in toluene $(20 \mathrm{~mL})$ was added LiNHAr ${ }^{\text {Trip }}(277 \mathrm{mg}, 0.55 \mathrm{mmol})$ at $-78{ }^{\circ} \mathrm{C}$. The reaction mixture was then warmed to room temperature and kept stirring for $2 \mathrm{~h}$. The resultant mixture was filtered through diatomaceous earth, and the filtrate was concentrated under vacuum to leave a green residue. The residue was extracted with $n$-hexane $(5 \mathrm{~mL} \times 3)$, and the $n$-hexane solution was combined and concentrated. Standing the $n$-hexane solution at room temperature afforded $\mathbf{2}$ as white crystals (49 mg, 39\%). For 2: ${ }^{1} \mathrm{H}$ NMR (400 MHz, $\left.\mathrm{C}_{6} \mathrm{D}_{6}, 296 \mathrm{~K}\right)$ : $\delta$ (ppm) 9.42 (s, 1H), 7.14-7.02 (m, $10 \mathrm{H}), 6.88(\mathrm{t}, J=7.5 \mathrm{~Hz}, 1 \mathrm{H}), 5.80(\mathrm{~s}, 1 \mathrm{H}), 5.51(\mathrm{~s}, 1 \mathrm{H}), 4.67(\mathrm{~s}, 1 \mathrm{H}), 3.64(\mathrm{~d}, J=8.2 \mathrm{~Hz}, 1 \mathrm{H})$, 3.17-2.69 (m, 12H), 1.39 (d, $J=6.8 \mathrm{~Hz}, 3 \mathrm{H}), 1.32$ (d, $J=6.9 \mathrm{~Hz}, 3 \mathrm{H}), 1.28-1.20$ (m, 30H), 1.18-1.03 (m, 36H). ${ }^{13} \mathrm{C}$ NMR (101 MHz, $\left.\mathrm{C}_{6} \mathrm{D}_{6}, 296 \mathrm{~K}\right): \delta$ (ppm) 166.34, 149.30, 149.01, 147.88, 147.73, $147.64,147.38,147.28,146.58,146.38,145.90$, 139.02, 138.96, 137.44, 136.21, 134.86, 133.99, $131.81,131.29,130.48,121.90,121.88,121.20,121.16,120.91,120.39,120.26,56.38,34.80,34.73$, $34.57,31.46,31.27,31.25,31.05,30.87,25.97,25.92,25.10,24.99,24.79$, 24.67, 24.55, 24.40, 24.37, 24.28, 24.26, 24.22, 24.17, 24.14, 24.07, 23.09, 23.07. HRMS (ESI): calcd for $\mathrm{C}_{72} \mathrm{H}_{101} \mathrm{~N}_{2}$ $\left[(\mathrm{M}+\mathrm{H})^{+}\right], 993.7959 ;$ Found, 993.7941. IR (thin film, $\left.\mathrm{cm}^{-1}\right): v=3341$ (m), 2960 (s), 2976 (s), 2867 (s), $1765(\mathrm{w}), 1656$ (m), 1606 (m), 1564 (s), 1461 (s), 1433 (s), 1414 (s), 1382 (m), 1361 (m), 1325 (m), 1266 (m), 1248 (m), 1229 (m), 1170 (m), 1103 (m), 1077 (m), 1054 (m), 1001 (m), 955 (m), 942 (m), 919 (m), $877(\mathrm{~m}), 858(\mathrm{~m}), 804(\mathrm{~m}), 765$ (m), $713(\mathrm{~m}), 651(\mathrm{~m}), 582(\mathrm{w}), 563(\mathrm{w}), 487(\mathrm{w})$. 


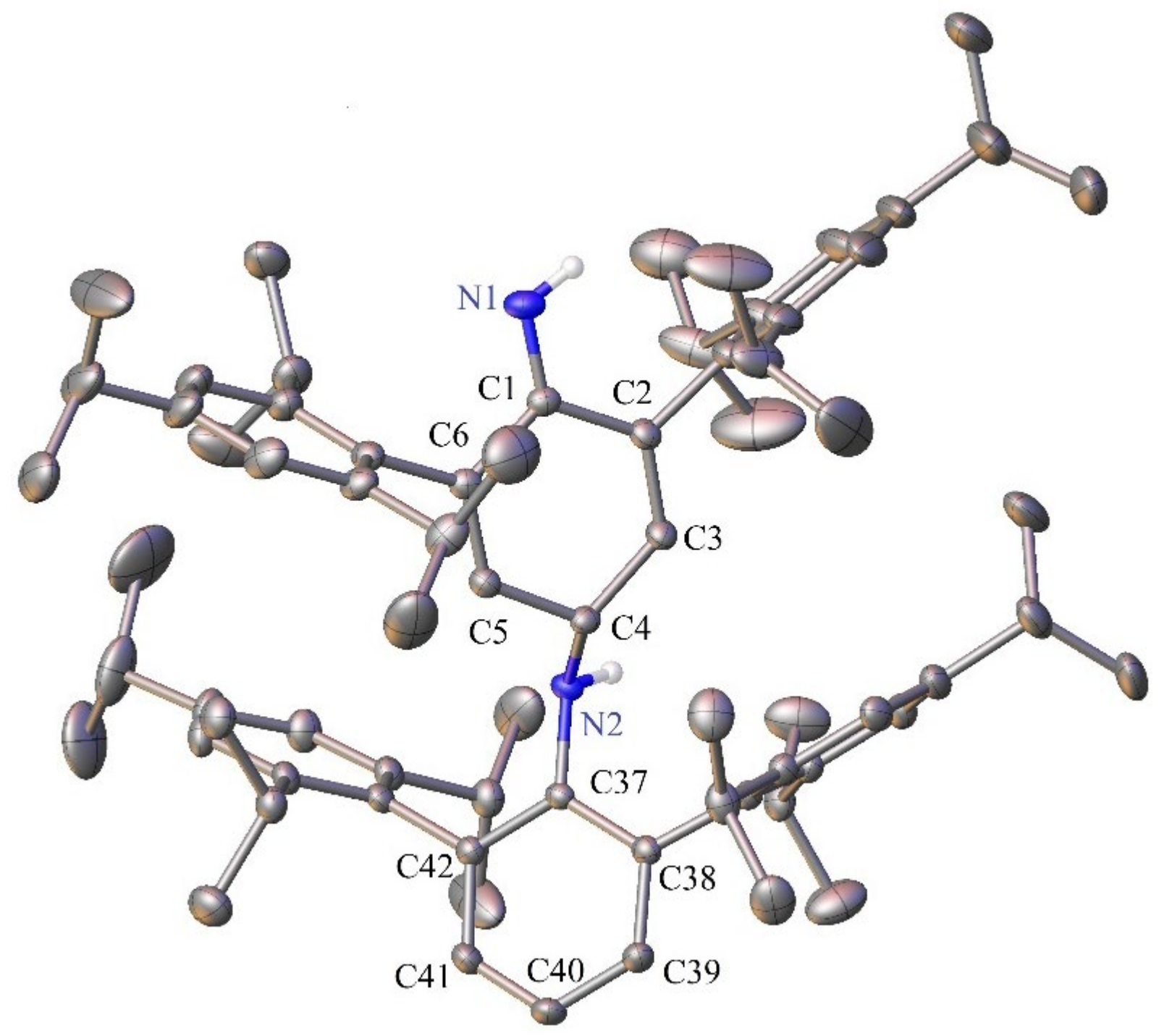

Fig. S9. Molecular structure of 2 , showing $30 \%$ probability ellipsoids and the partial atoms numbering scheme, hydrogen atoms were omitted (except on N). Selected distances $(\AA)$ and angles (deg) of 2: N1-C1 1.287(3), C1-C2 1.487(3), C2-C3 1.335(3), C3-C4 1.489(3), C5-C4 1.487(3), C5-C6 1.334(3), C1-C6 1.482(3), N2-C4 1.481(3), N2-C37 1.415(3), C37-C38 1.417(3), C38-C39 1.388(3), C39-C40 1.385(4), C40-C41 1.376(4), C41-C42 1.393(3), C42-C37 1.405(3). 

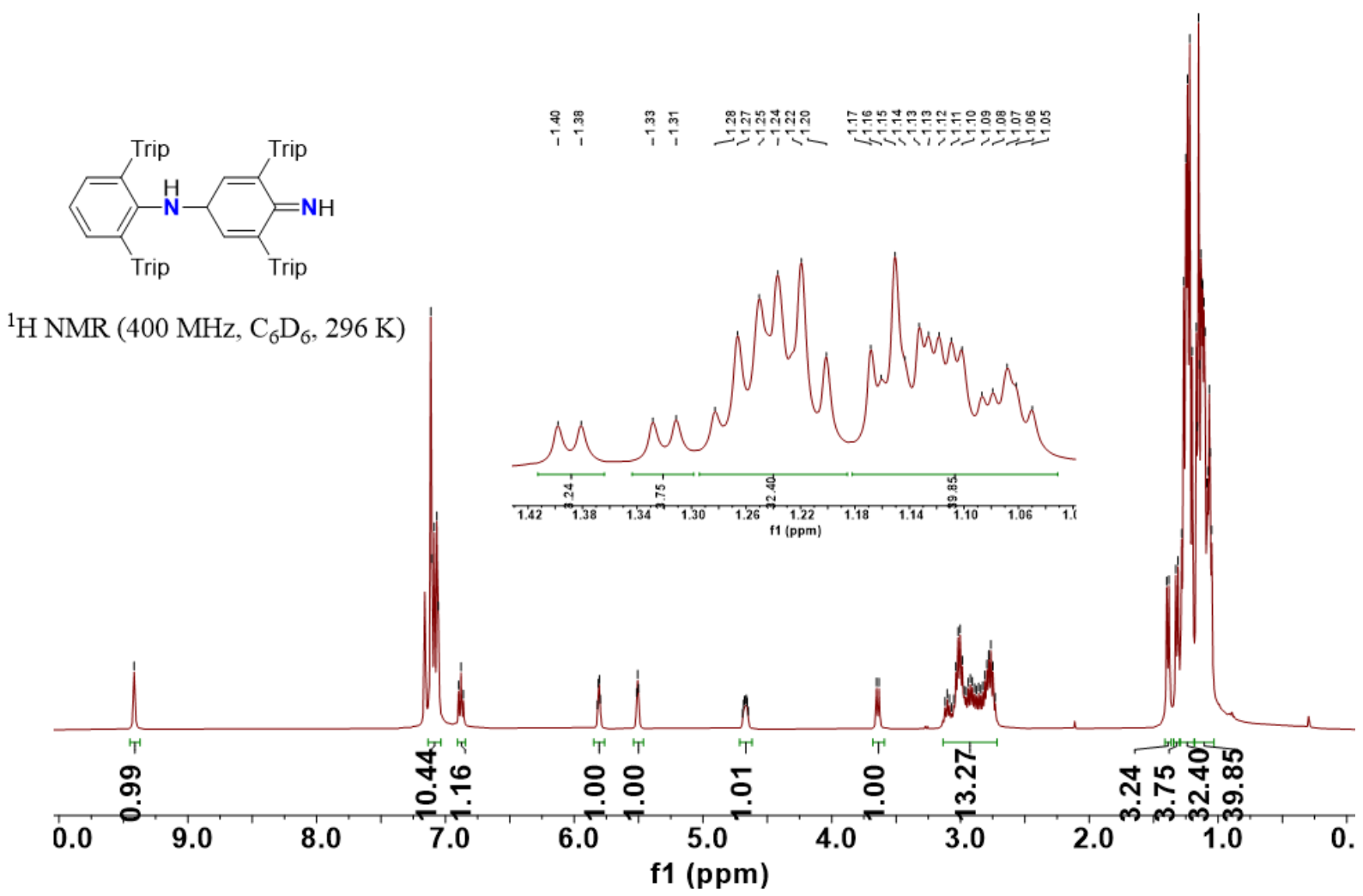

Fig. S10. ${ }^{1} \mathrm{H}$ NMR spectrum of $\mathbf{2}$ (Inset: expanded region of ${ }^{1} \mathrm{H}$ NMR spectrum of $\mathbf{2}$ from 1.42 to 1.0 ppm). 


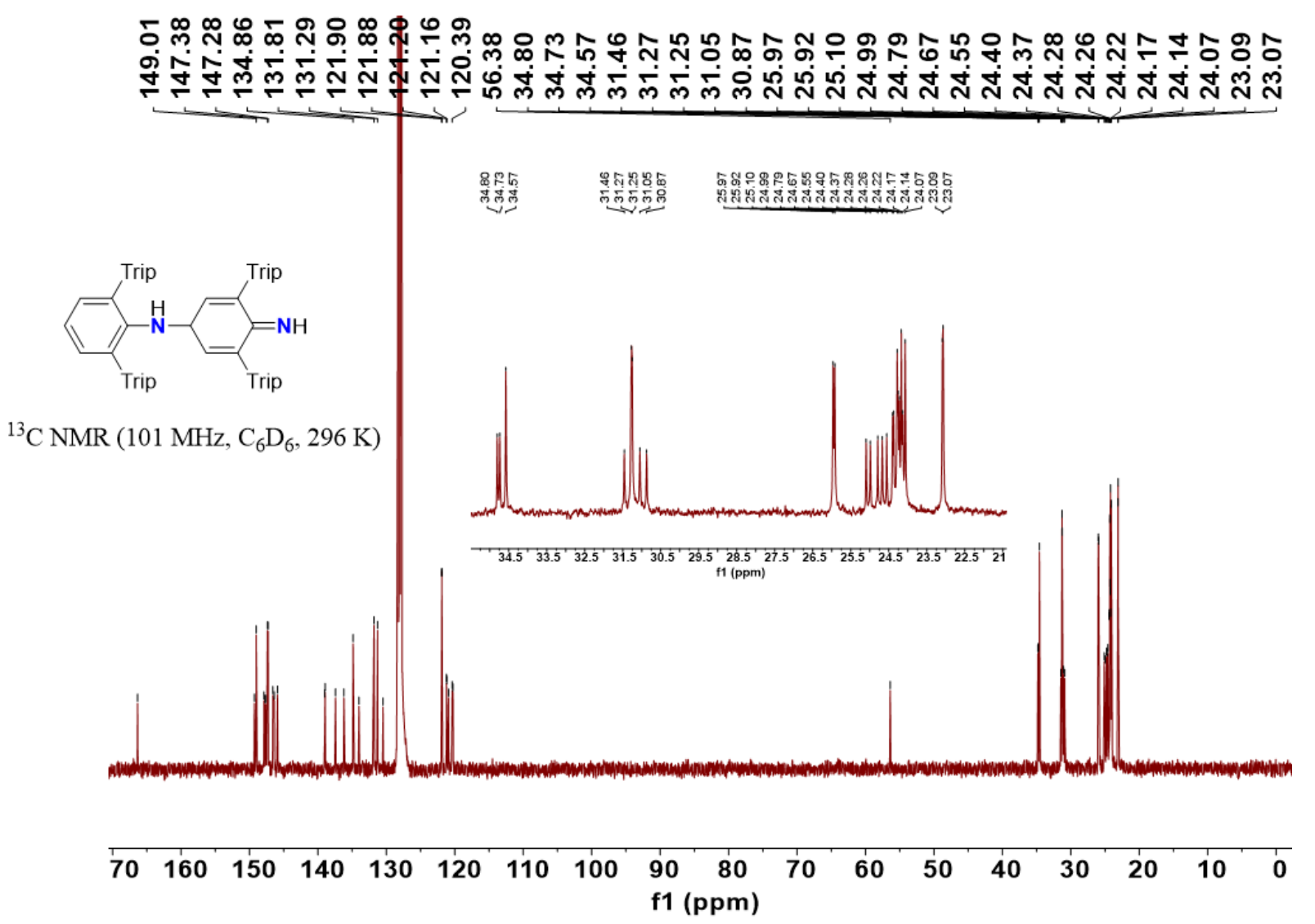

Fig. S11. ${ }^{13} \mathrm{C}$ NMR spectrum of 2 (Inset: expanded region of ${ }^{13} \mathrm{C}$ NMR spectrum of 2 from 35.0 to $21.0 \mathrm{ppm}$ ). 


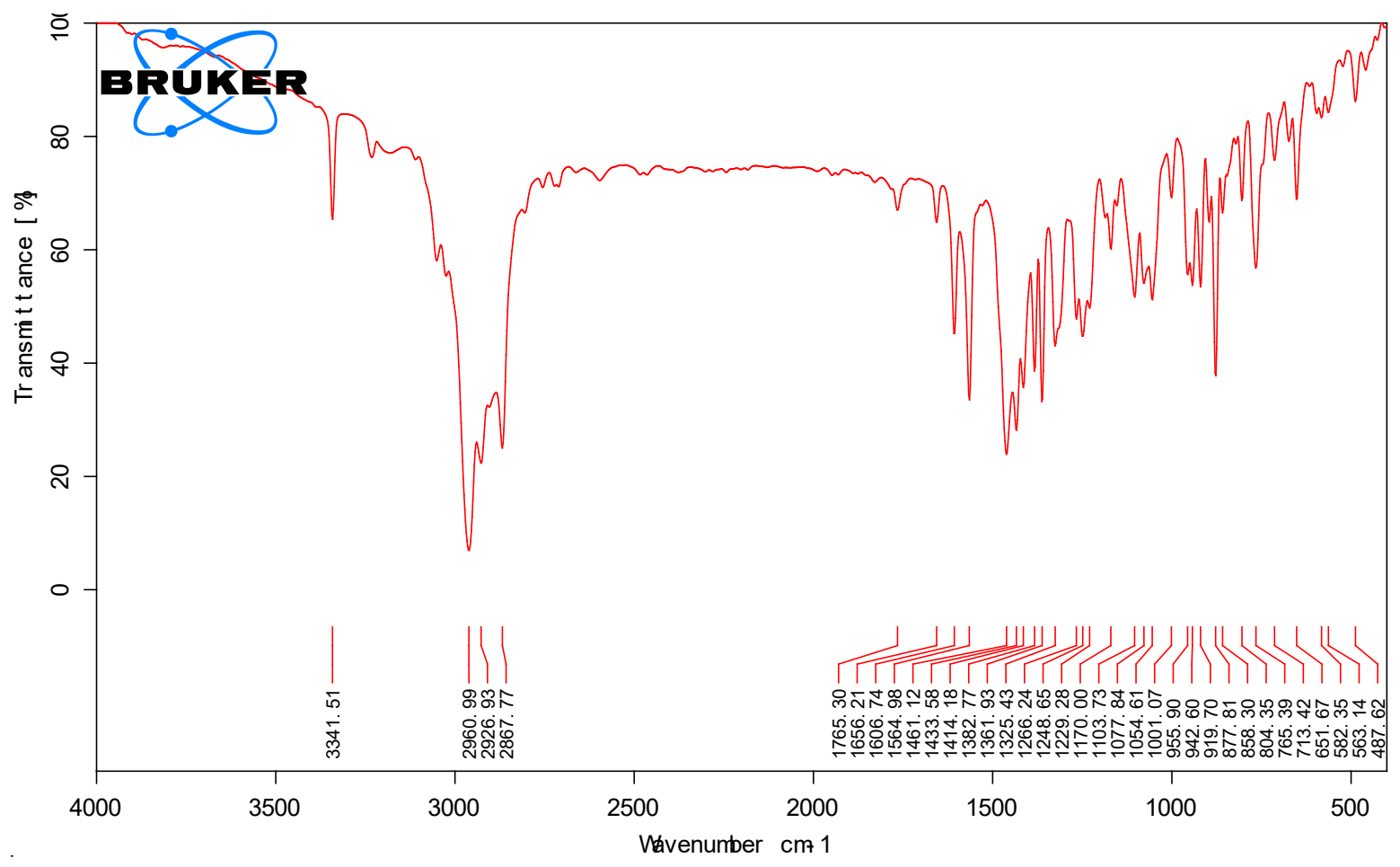

Fig. S12. IR spectrum of 2. 
Isolation and Characterization of 3 and 4. To an orange suspension of (BINAP) $\mathrm{PdCl}_{2}(800$ $\mathrm{mg}, 1.00 \mathrm{mmol})$ in toluene $(80 \mathrm{~mL})$ was added LiNHAr Trip $(1117 \mathrm{mg}, 2.20 \mathrm{mmol})$ at $-78{ }^{\circ} \mathrm{C}$. The reaction mixture was then warmed to room temperature and kept stirring for $2 \mathrm{~h}$. The resultant mixture was filtered through diatomaceous earth, and the filtrate was concentrated under vacuum to leave a green residue. The residue was extracted with $n$-hexane $(5 \mathrm{~mL} \times 3)$, and the $n$-hexane solution was combined and concentrated under vacuum to leave a residue. The residue was purified by flash column chromatography (silica gel, $n$-hexane as elute) to give $\mathbf{3}$ and $\mathbf{4}$ as white solid. For $\mathbf{3}$ : 20 mg, 4\%. ${ }^{1} \mathrm{H}$ NMR (400 MHz, $\left.\mathrm{C}_{6} \mathrm{D}_{6}, 296 \mathrm{~K}\right): \delta$ (ppm) 7.32-7.20 (m, 4H), 7.07-6.96 (m, 2H), 6.79 $(\mathrm{t}, J=7.5 \mathrm{~Hz}, 1 \mathrm{H}), 5.02(\mathrm{~s}, 2 \mathrm{H}), 3.18-2.77(\mathrm{~m}, 7 \mathrm{H}), 1.88(\mathrm{~s}, 3 \mathrm{H}), 1.36-1.14(\mathrm{~m}, 30 \mathrm{H}) .{ }^{13} \mathrm{C}$ NMR $(101$ $\left.\mathrm{MHz}, \mathrm{C}_{6} \mathrm{D}_{6}, 296 \mathrm{~K}\right): \delta$ (ppm) 148.86, 148.62, 148.44, 148.26, 148.02, 147.47, 145.04, 142.87, 133.92 , 133.06, 130.31, 129.76, 125.62, 125.33, 124.86, 122.89, 121.53, 121.44, 117.63, 114.88, $34.85,34.56,31.00,30.71,30.43,24.96,24.71,24.47,24.40,24.29,24.25,24.10,24.05$. HRMS (ESI): calcd for $\mathrm{C}_{36} \mathrm{H}_{50} \mathrm{~N}\left[(\mathrm{M}+\mathrm{H})^{+}\right], 496.3938$; Found, 496.3939. IR (thin film, $\mathrm{cm}^{-1}$ ): $v=3476(w)$, 3380 (w), 3049 (w), 2957 (s), 2923 (m), 2866 (m), 1600 (m), 1568(w), 1445 (m), 1365 (m), 1309 (w), $1258(\mathrm{~m}), 1208(\mathrm{w}), 1168(\mathrm{w}), 1062$ (m), 880 (m), 796 (m), 748 (m), 650 (w), 476 (w). For 4: $263 \mathrm{mg}, 53 \%$. The isolated yield of 4 is higher than that of the NMR yield, which might be due to the decomposition of $\mathbf{2}$ during column chromatography. The latter reaction could also produce 4 . ${ }^{1} \mathrm{H}$ NMR (400 MHz, $\left.\mathrm{C}_{6} \mathrm{D}_{6}, 296 \mathrm{~K}\right): \delta(\mathrm{ppm}) 7.26$ (s, 4H), 7.04 (d, J=7.4 Hz, 2H), 6.83 (t, J= 7.4 Hz, 1H), 3.08-2.99 (m, 4H), $2.97(\mathrm{~s}, 2 \mathrm{H}), 2.92-2.81(\mathrm{~m}, 2 \mathrm{H}), 1.31-1.25(\mathrm{~m}, 24 \mathrm{H}), 1.22(\mathrm{~d}, J=6.9 \mathrm{~Hz}$, 12H) (Fig. S16.). The NMR data of $\mathbf{4}$ are identical to those reported in the literature (53). 


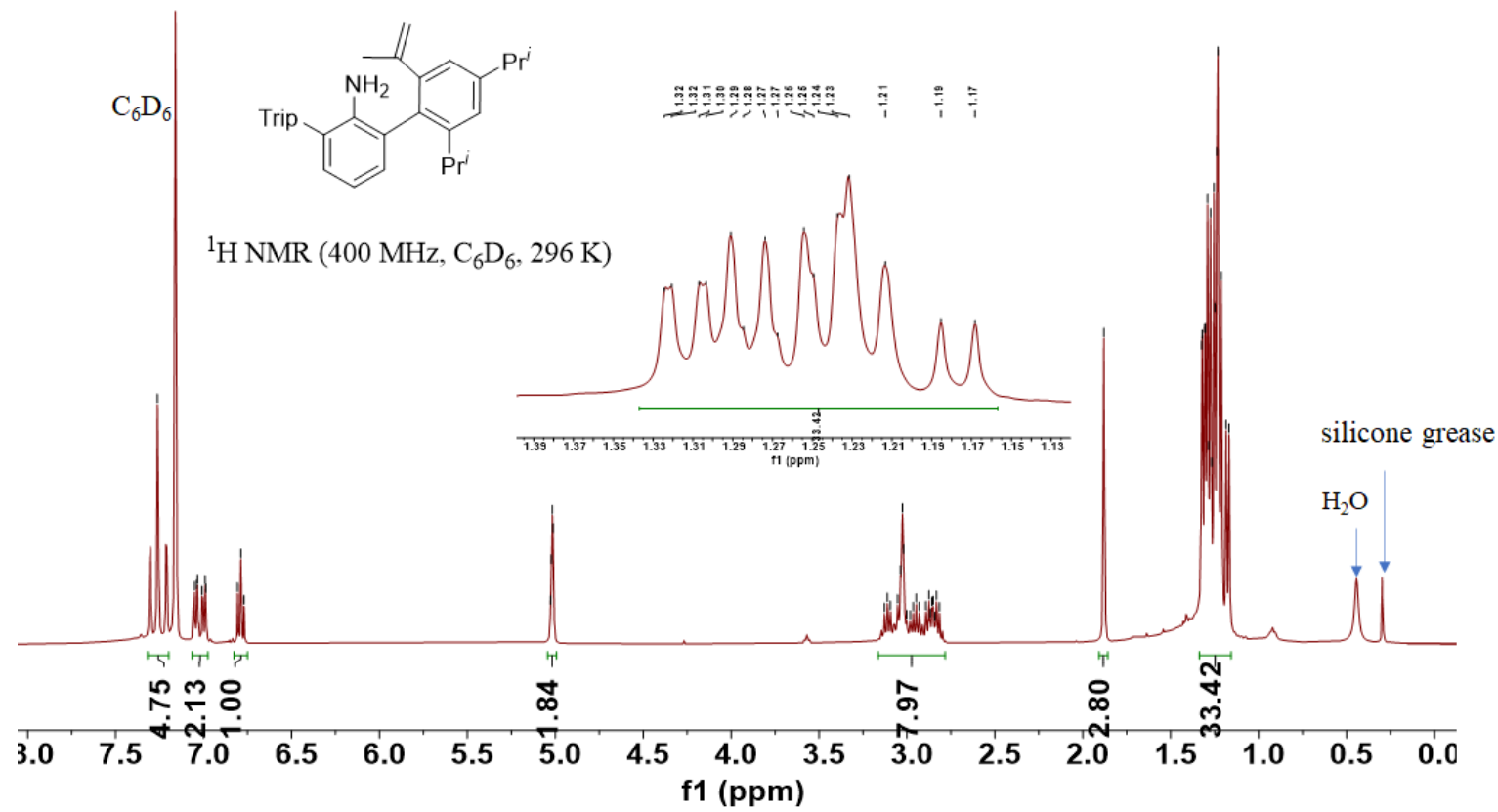

Fig. S13. ${ }^{1} \mathrm{H}$ NMR spectrum of 3 (Inset: expanded region of ${ }^{1} \mathrm{H}$ NMR spectrum of 3 from 1.40 to $1.13 \mathrm{ppm})$. 


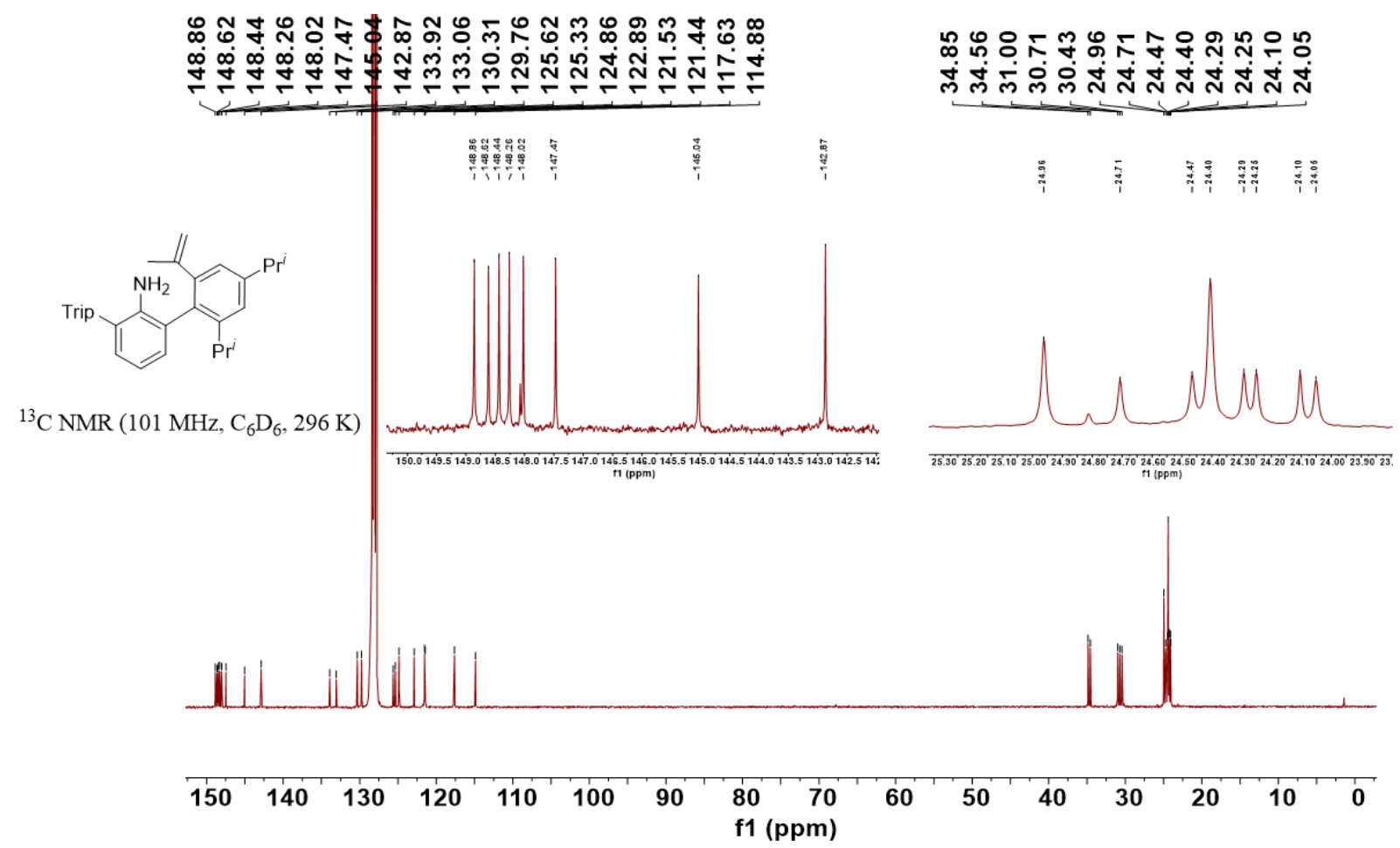

Fig. S14. ${ }^{13} \mathrm{C}$ NMR spectrum of $\mathbf{3}$ (Inset: expanded region of ${ }^{13} \mathrm{C}$ NMR spectrum of $\mathbf{3}$ from 150.0 to $142.5 \mathrm{ppm}$ and from 25.2 to $23.5 \mathrm{ppm}$ ). 


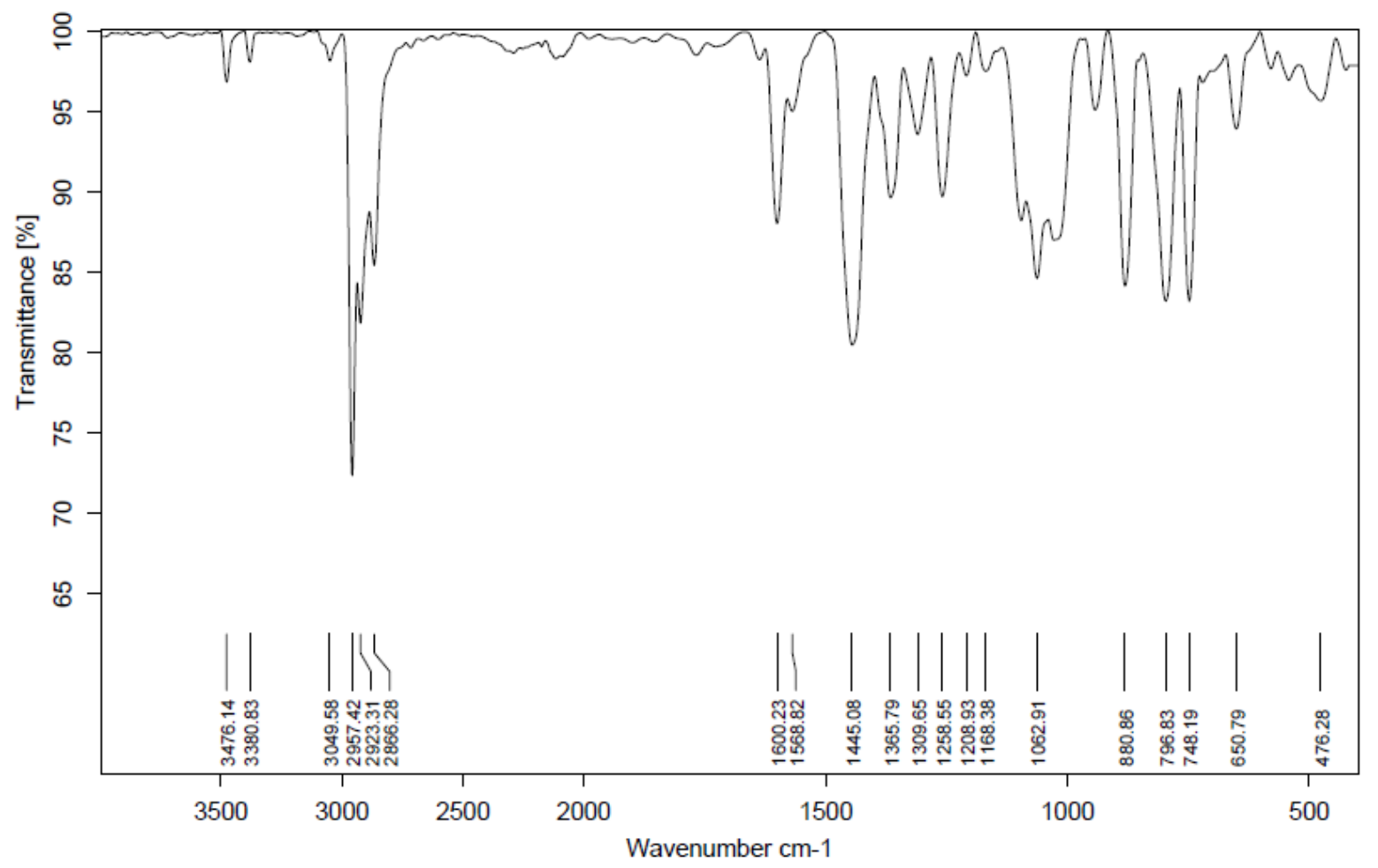

Fig. S15. IR spectrum of 3. 


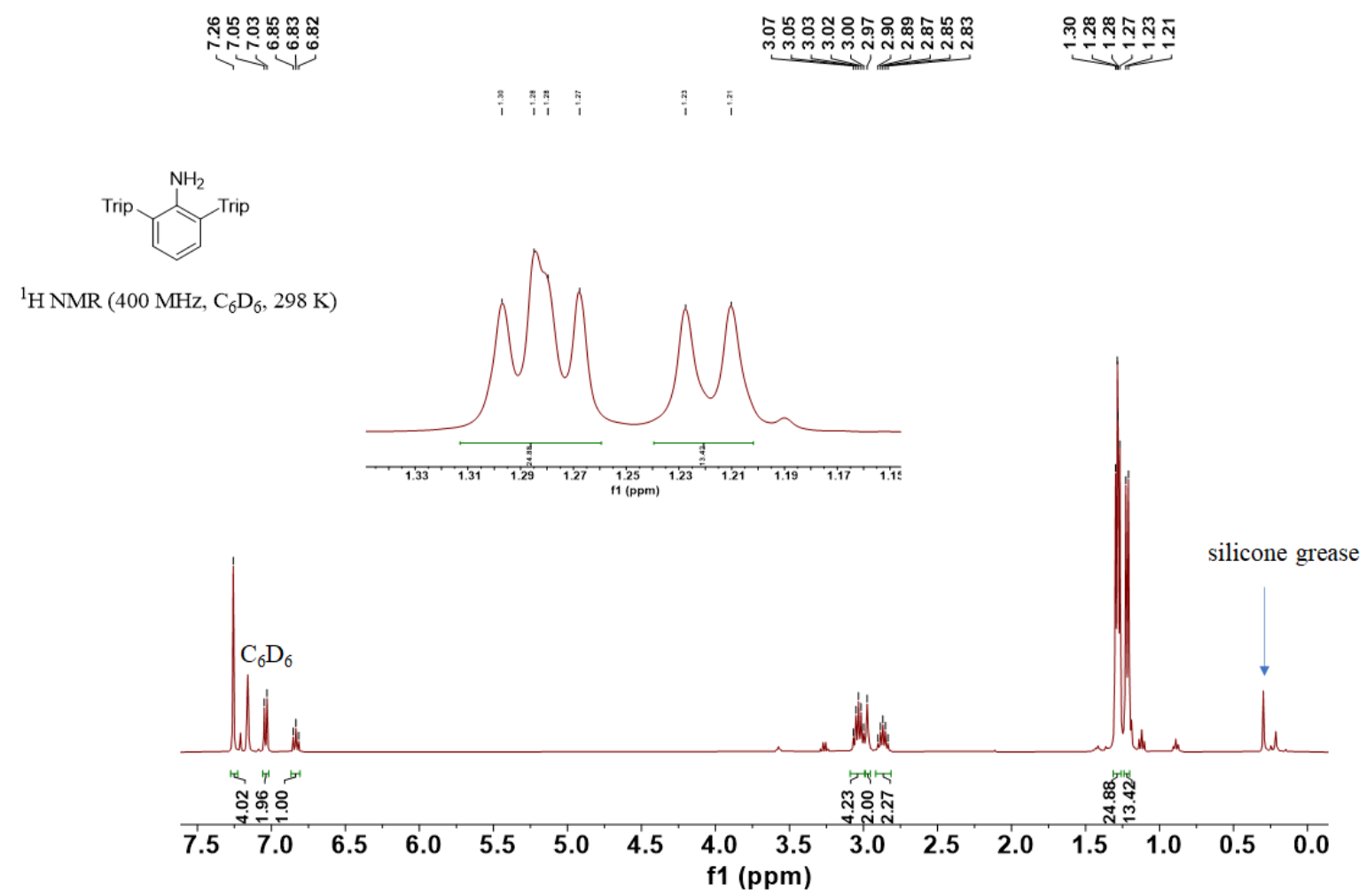

Fig. S16. ${ }^{1} \mathrm{H}$ NMR spectrum of 4 (Inset: expanded region of ${ }^{1} \mathrm{H}$ NMR spectrum of 4 from 1.35 to $1.15 \mathrm{ppm})$. 


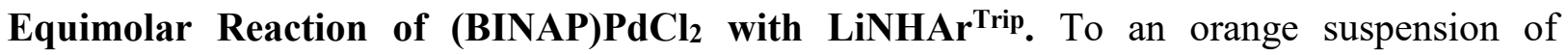
(BINAP)PdCl 2 (640 mg, $0.8 \mathrm{mmol})$ in toluene $(30 \mathrm{~mL})$ was added LiNHAr Trip $(440 \mathrm{mg}, 0.88 \mathrm{mmol})$ at $-78{ }^{\circ} \mathrm{C}$. The reaction mixture was then warmed to room temperature and kept stirring for $2 \mathrm{~h}$. The mixture changed into a blue suspension that was filtered to afford a blue solid. The solid was then washed with toluene $(3 \times 2 \mathrm{~mL})$ and dried under vacuum. The resultant solid is slightly soluble in $\mathrm{C}_{6} \mathrm{D}_{6}$. The ${ }^{1} \mathrm{H}$ NMR and ${ }^{31} \mathrm{P}$ NMR analyses indicate the solid might contain (BINAP)PdCl(NHAr ${ }^{\text {Trip }}$ ) (A) (Figs. S17 and S18). However, our attempts to isolate the desired complex upon recrystallization were unsuccessful. 


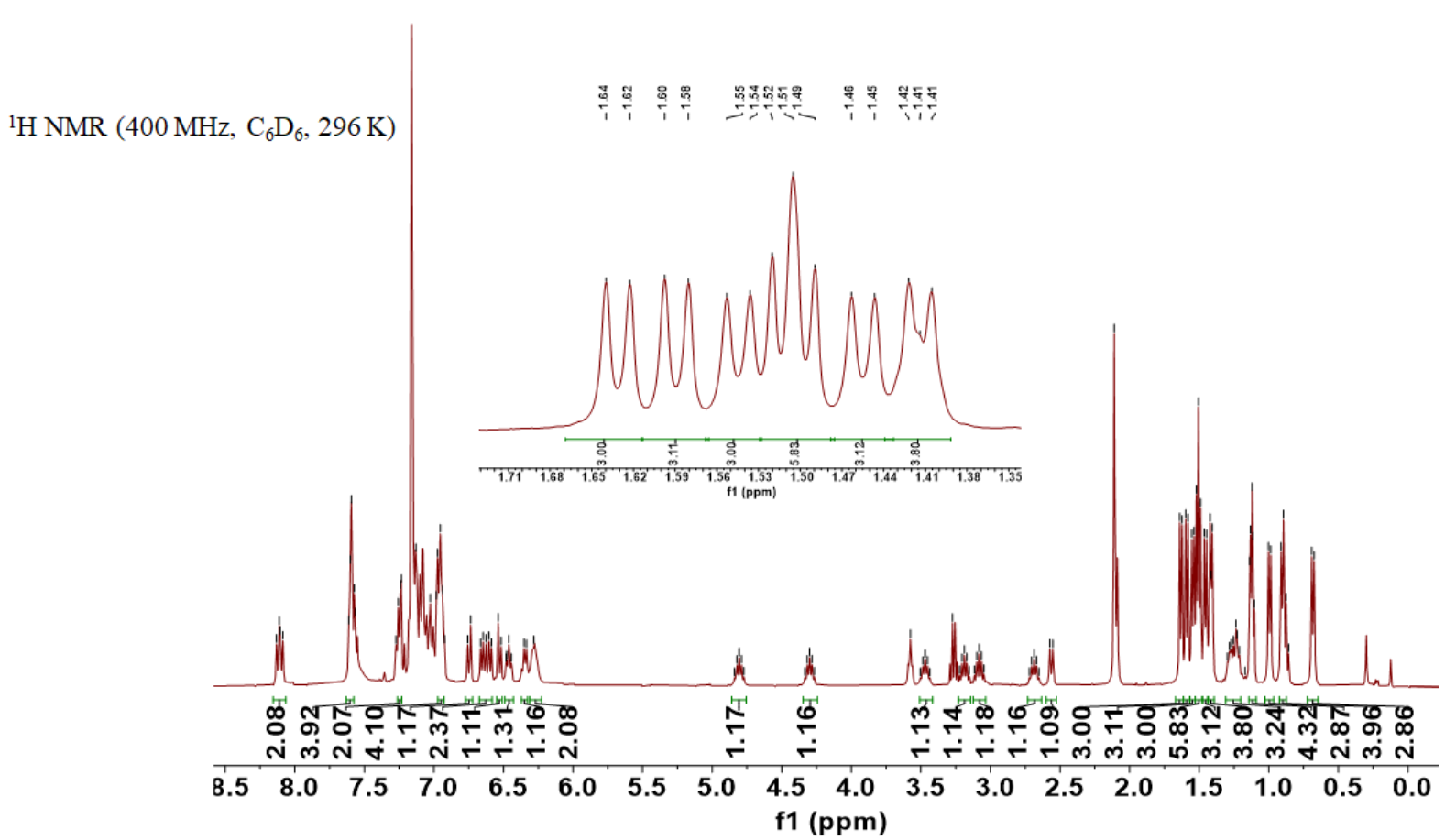

Fig. S17. The ${ }^{1} \mathrm{H}$ NMR spectrum of the mixture formed from equimolar reaction of (BINAP) $\mathrm{PdCl}_{2}$ with LiNHAr ${ }^{\text {Trip }}$ (Inset: expanded region of ${ }^{1} \mathrm{H}$ NMR spectrum of reaction mixture from 1.71 to 1.35 ppm). 
${ }^{31} \mathrm{P}$ NMR $\left(162 \mathrm{MHz}, \mathrm{C}_{6} \mathrm{D}_{6}, 296 \mathrm{~K}\right)$

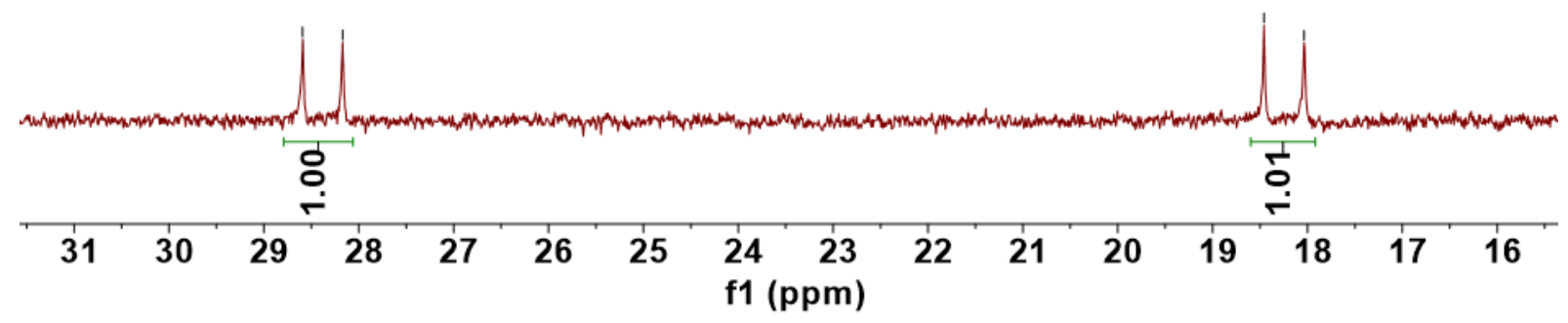

Fig. S18. The ${ }^{31} \mathrm{P}$ NMR spectrum of the mixture formed from equimolar reaction of (BINAP) $\mathrm{PdCl}_{2}$ with LiNHAr ${ }^{\text {Trip }}$. 

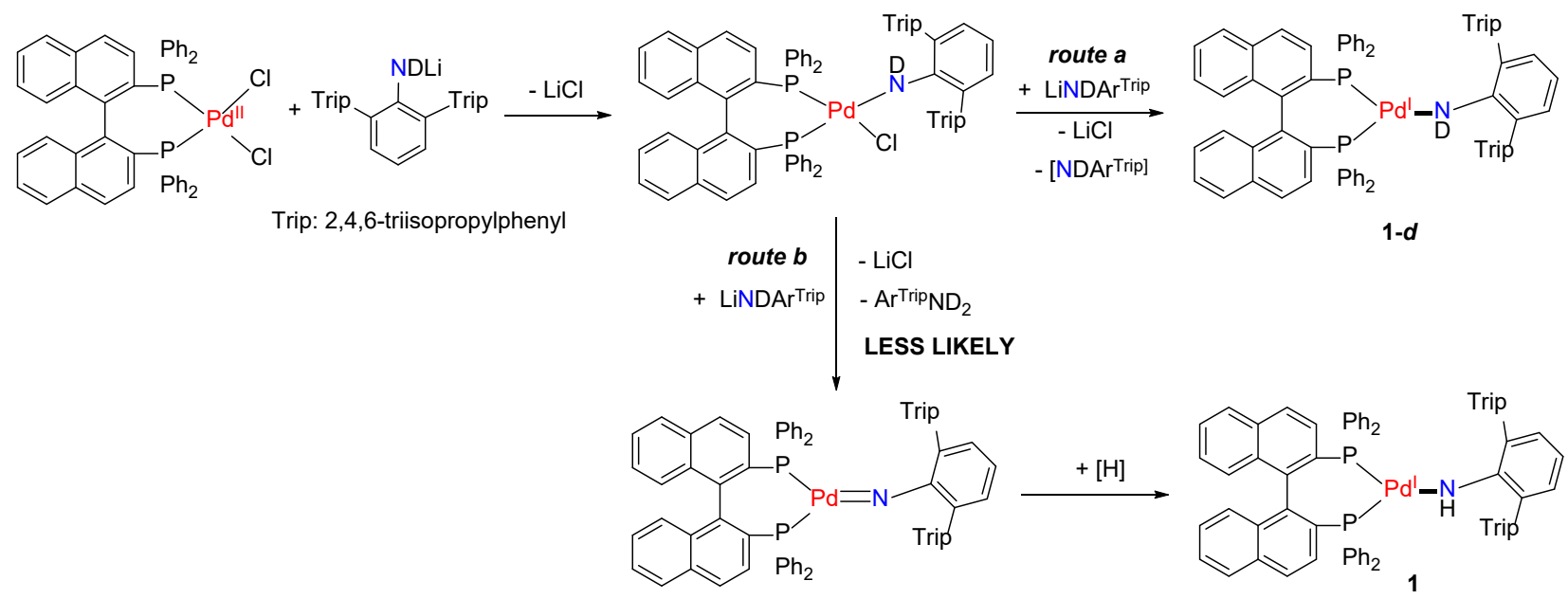

Fig. S19. Possible route for the reaction of (BINAP) $\mathrm{PdCl}_{2}$ with $\mathrm{LiNDAr}^{\text {Trip }}$. 
Table S1. Selected interatomic distances $(\AA)$ of the NHAr moieties in PhNH (B) (57), some metal anilido complex (C) (32) and the aminyl radical complexes D-F (34-36).

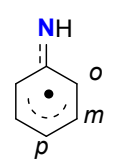

B

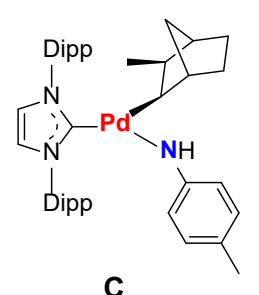

C

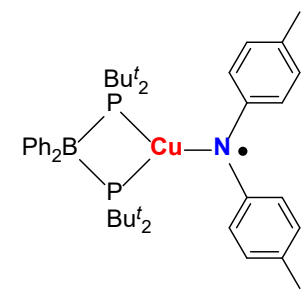

D

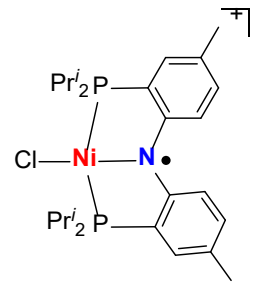

E

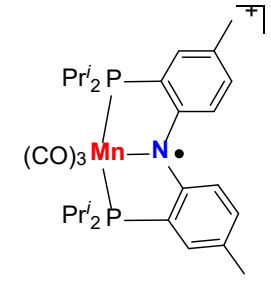

F

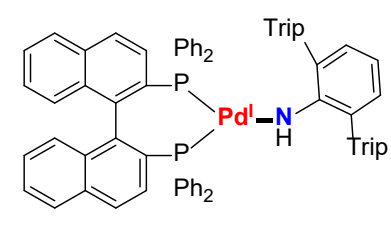

1

\begin{tabular}{lllll}
\hline & $\mathrm{N}-\mathrm{C}$ & $\mathrm{C}-\mathrm{C}^{o}$ & $\mathrm{C}^{o}-\mathrm{C}^{m}$ & $\mathrm{C}^{m}-\mathrm{C}^{p}$ \\
\hline $\mathbf{B}$ & 1.341 & $1.435 / 1.434$ & $1.384 / 1.383$ & $1.405 / 1.405$ \\
$\mathbf{C}$ & $1.376(5)$ & $1.404(5) / 1.406(5)$ & $1.389(5) / 1.391(5)$ & $1.389(6) / 1.392(6)$ \\
$\mathbf{D}$ & $1.382(3)$ & $1.419(3) / 1.409(3)$ & $1.389(4) / 1.386(4)$ & $1.394(3) / 1.393(3)$ \\
& $1.390(3)$ & $1.410(4) / 1.416(3)$ & $1.388(3) / 1.391(3)$ & $1.388(3) / 1.399(4)$ \\
$\mathbf{E}$ & $1.407(3)$ & $1.406(3) / 1.402(3)$ & $1.391(3) / 1.383(3)$ & $1.398(3) / 1.397(3)$ \\
& $1.397(3)$ & $1.403(3) / 1.402(3)$ & $1.382(3) / 1.385(3)$ & $1.398(3) / 1.394(3)$ \\
$\mathbf{F}$ & $1.391(3)$ & $1.420(3) / 1.408(4)$ & $1.391(3) / 1.381(3)$ & $1.400(4) / 1.400(3)$ \\
& $1.401(3)$ & $1.414(3) / 1.403(4)$ & $1.399(3) / 1.386(3)$ & $1.403(4) / 1.403(3)$ \\
$\mathbf{1}$ & $1.377(3)$ & $1.431(4) / 1.421(4)$ & $1.391(4) / 1.393(4)$ & $1.379(4) / 1.378(4)$ \\
\hline
\end{tabular}


Reactivity of [(BINAP)Pd(NHAr $\left.\left.{ }^{\text {Trip }}\right)\right]$ (1)<smiles>Pc1ccccc1NC[Pb](Pc1ccccc1)P(c1ccccc1)c1ccc2ccccc2c1-c1ccccc1</smiles>

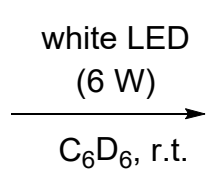<smiles>C=C(C)c1cc(PCC)cc(P)c1-c1ccccc1OCC</smiles><smiles>Nc1c([18O])cccc1Br</smiles>

Decomposition Reaction of 1 under White LED Irradiation. White LED-irradiation on the $\mathrm{C}_{6} \mathrm{D}_{6}$ solution of $\mathbf{1}$ can induce its decomposition to yield $\mathbf{3}$ and $\mathbf{4}$ in comparable yields, along with diamagnetic palladium phosphine complexes as indicated by ${ }^{1} \mathrm{H}$ and ${ }^{31} \mathrm{P}$ NMR spectra (Figs. S20 and S21). Adding dodecane as an internal standard, the yields of $\mathbf{3}$ and $\mathbf{4}$ were also confirmed by GC (Fig. S22.). The attempts to isolate the palladium-containing products were unsuccessful. Kinetic study on the decomposition reaction has been performed. The kinetic study monitors the increase of the characteristic ${ }^{1} \mathrm{H}$ NMR signal of 3 at $\delta=5.02 \mathrm{ppm}$ formed in the reaction with 1,3,5-trimethoxybenzene as internal standard. The procedure is as following: To a J-Young tube were added 1 (15 mg, $0.010 \mathrm{mmol})$, 1,3,5-trimethoxybenzene $(6.3 \mathrm{mg}, 0.037 \mathrm{mmol})$ and $\mathrm{C}_{6} \mathrm{D}_{6}(500$ $\mu \mathrm{L})$, then J-Young tube is illuminated by white LED ( 2 × $3 \mathrm{~W}$ white LEDs). The plot of yield vs time is shown in Fig. S23. 


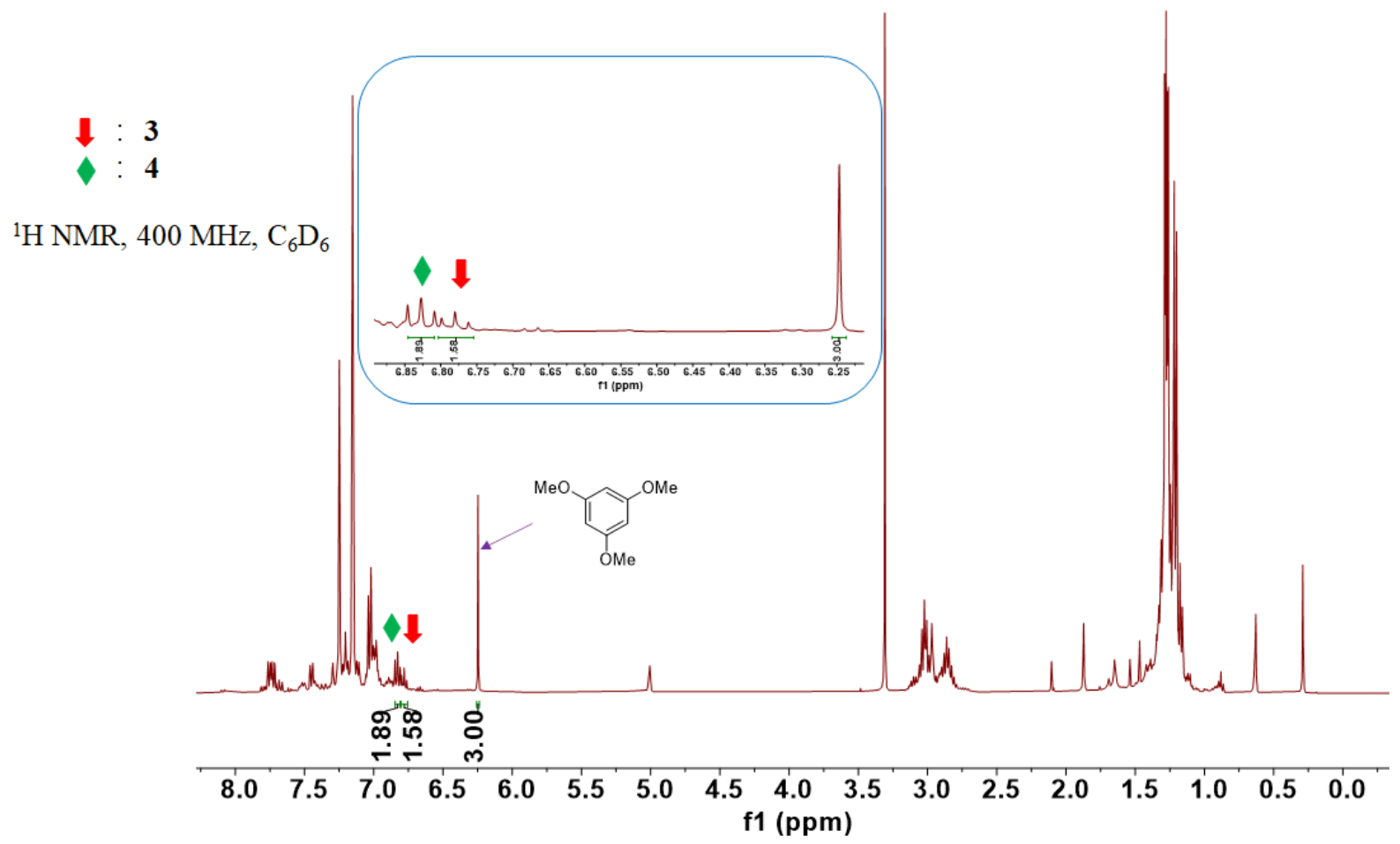

Fig. S20. ${ }^{1} \mathrm{H}$ NMR spectrum of the mixture formed from exposing the $\mathrm{C}_{6} \mathrm{D}_{6}$ solution of $\mathbf{1}$ under white LED for $90 \mathrm{~h}$ (Inset: expanded region of ${ }^{1} \mathrm{H}$ NMR spectrum of reaction mixture from 6.85 to $6.25 \mathrm{ppm})$. 


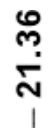

${ }^{31} \mathrm{P} \mathrm{NMR}, 162 \mathrm{MHz}, \mathrm{C}_{6} \mathrm{D}_{6}$

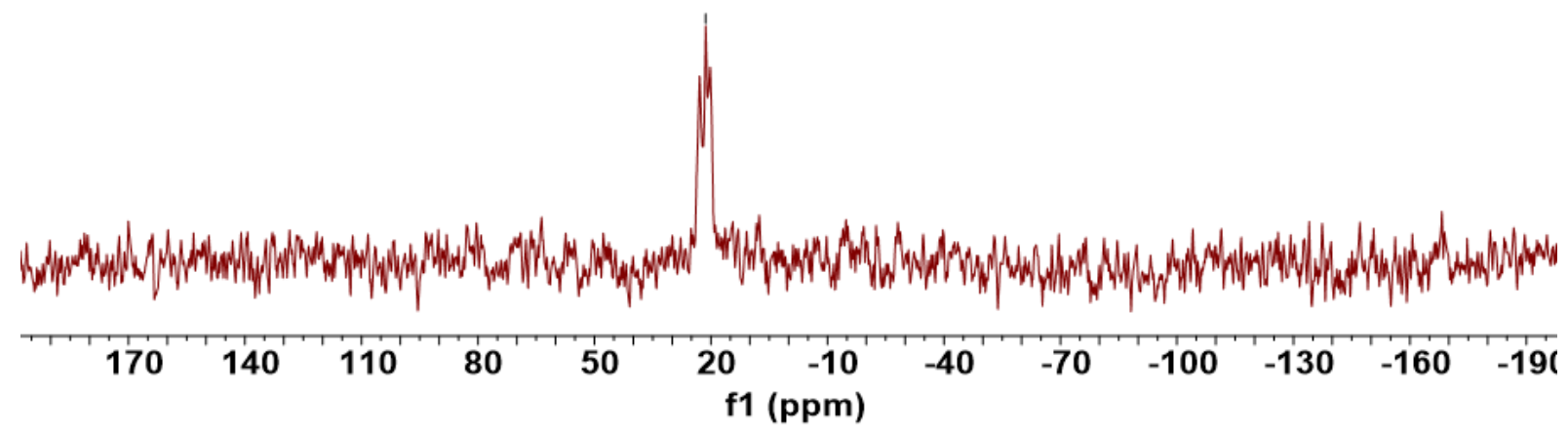

Fig. S21. ${ }^{31} \mathrm{P}$ NMR spectrum of the mixture formed from exposing the $\mathrm{C}_{6} \mathrm{D}_{6}$ solution of $\mathbf{1}$ under white LED for $90 \mathrm{~h}$. 


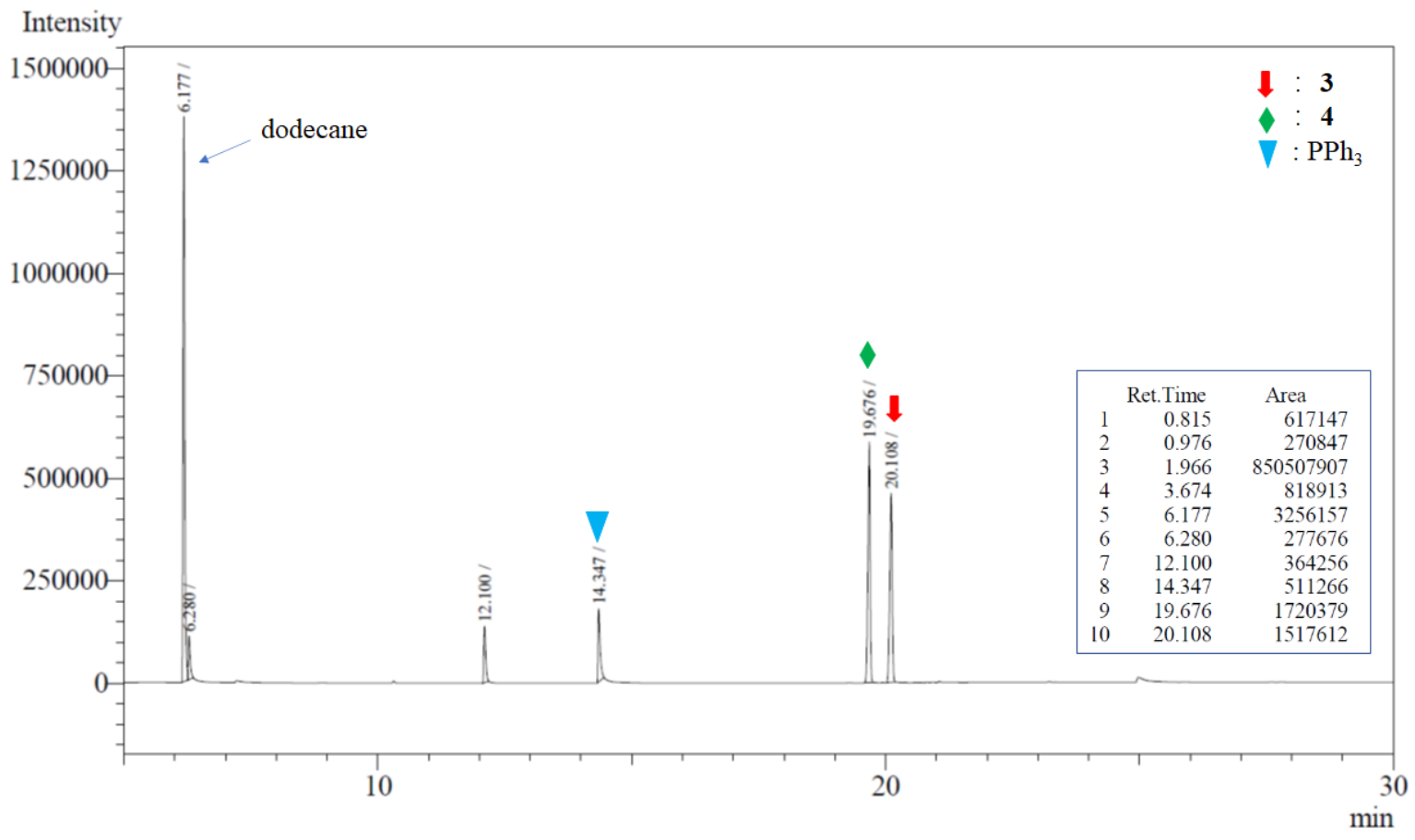

Fig. S22. GC graph of the sample obtained from exposing the $\mathrm{C}_{6} \mathrm{D}_{6}$ solution of 1 under white LED for $90 \mathrm{~h}$. 


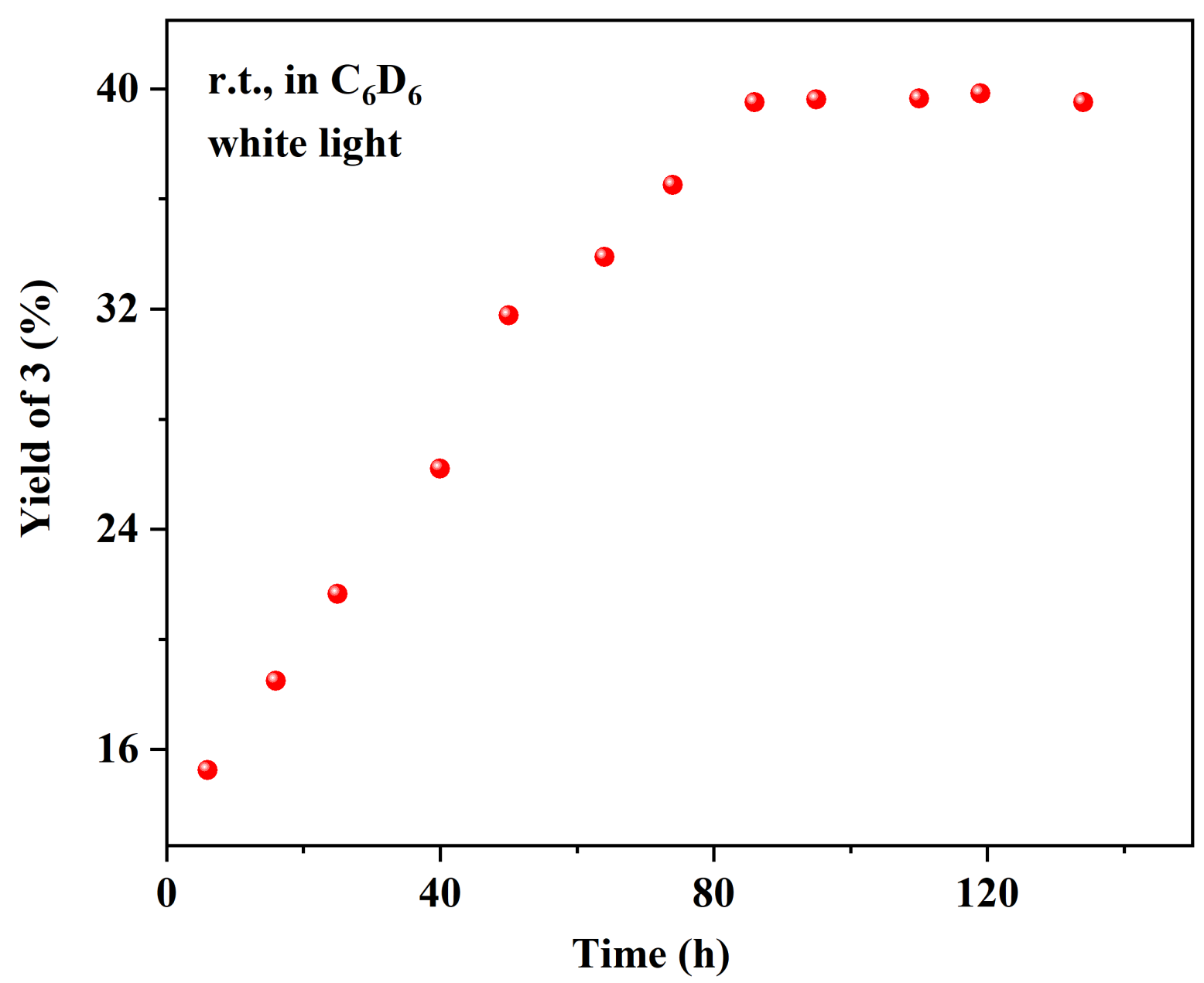

Fig. S23. Plot of yield of 3 (based on the full amount of NHAr ${ }^{\text {Trip }}$ in 1) versus time for the decomposition reaction of $\mathbf{1}$ under white LED at room temperature. In $90 \mathrm{~h}$, the yield of $\mathbf{3}$ achieved $40 \%$ that suggests the conversion of 1 of $80 \%$ as merely half of the NHAr ${ }^{\text {Trip }}$ is converted to 3 . 


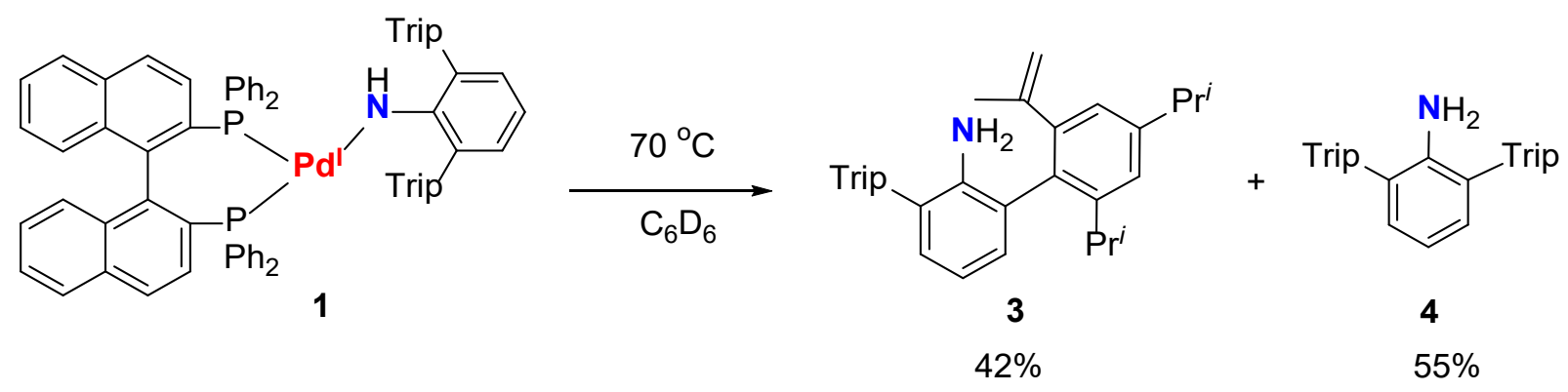

Decomposition of 1 under Thermolysis. 1 is heat-sensitive. Its decomposition in $\mathrm{C}_{6} \mathrm{D}_{6}$ at 70 ${ }^{\circ} \mathrm{C}$ yields 3 and 4 in comparable yields, along with unidentified diamagnetic palladium phosphine species as indicated by ${ }^{1} \mathrm{H}$ and ${ }^{31} \mathrm{P}$ NMR spectra (Figs. S24 and S25). Adding dodecane as an internal standard, the yields of $\mathbf{3}$ and $\mathbf{4}$ were also confirmed by GC (Fig. S26.). The kinetic studies on the thermolysis-induced decomposition reaction of 1 monitor the increase of the characteristic ${ }^{1} \mathrm{H}$ NMR signal of 3 at $\delta=5.02 \mathrm{ppm}$ formed in the reaction at $70{ }^{\circ} \mathrm{C}$ with $1,3,5$-trimethoxybenzene as internal standard. The procedure is as following: To a J-Young tube was added $\mathbf{1}(10 \mathrm{mg}, 0.008 \mathrm{mmol})$, 1,3,5-trimethoxybenzene $\left(0.10 \mathrm{M}\right.$ in $\left.\mathrm{C}_{6} \mathrm{D}_{6}, 100 \mu \mathrm{L}\right)$. Then the reaction mixture was diluted with $\mathrm{C}_{6} \mathrm{D}_{6}$ to $500 \mu \mathrm{L}$. The mixture was warmed to $70{ }^{\circ} \mathrm{C}$ and monitored by ${ }^{1} \mathrm{H}$ NMR. The plot of yields of 3 versus time is shown in Fig. S27. By observing the change in half-life, the thermal decomposition reaction at $70{ }^{\circ} \mathrm{C}$ is a first-order reaction. 


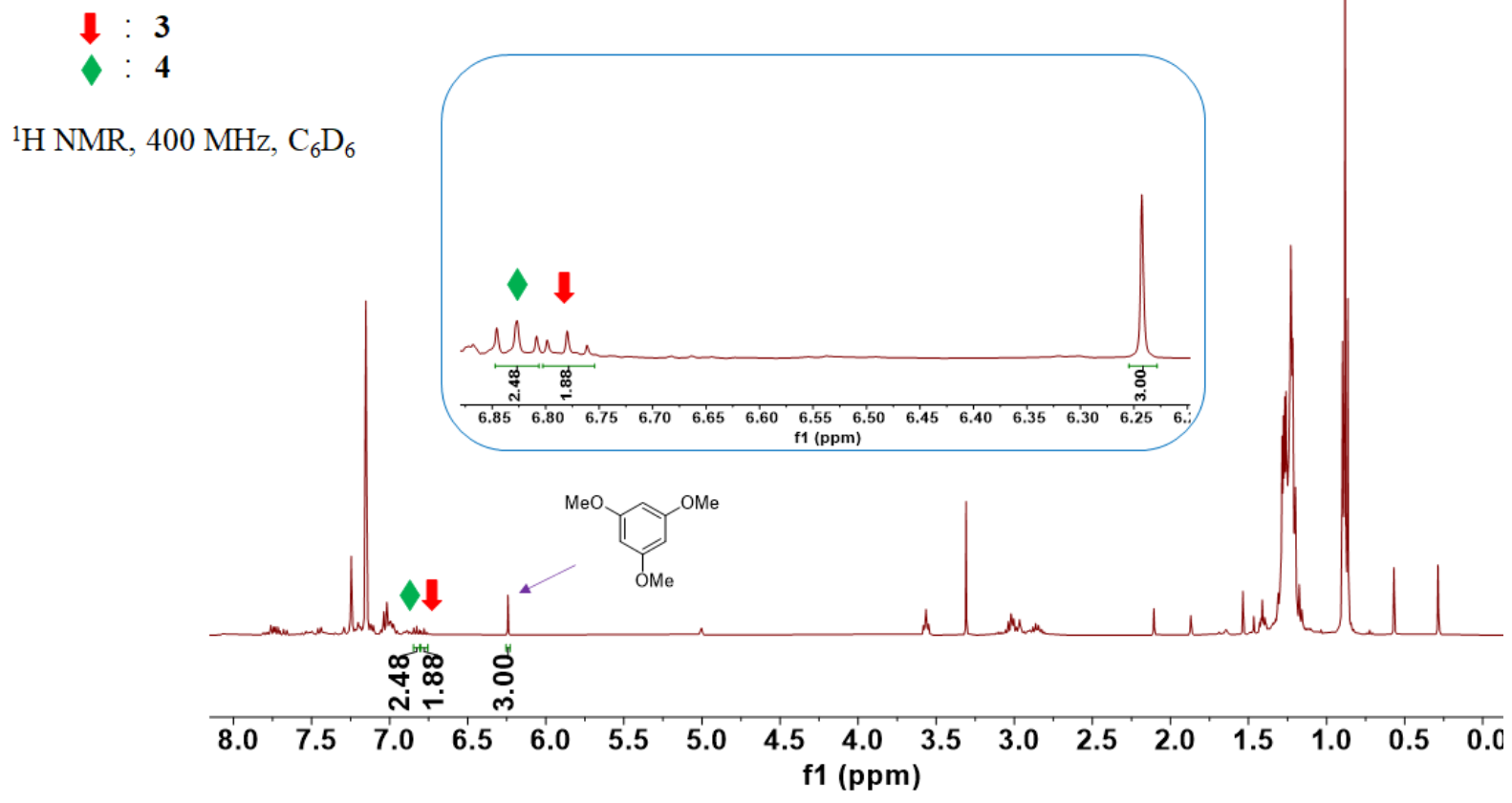

Fig. S24. ${ }^{1} \mathrm{H}$ NMR spectrum of the mixture formed from heating the $\mathrm{C}_{6} \mathrm{D}_{6}$ solution of 1 under $70{ }^{\circ} \mathrm{C}$ for $14 \mathrm{~h}$ (Inset: expanded region of ${ }^{1} \mathrm{H}$ NMR spectrum of reaction mixture from 6.85 to $6.25 \mathrm{ppm}$ ). 


\section{$\stackrel{m}{\frac{m}{n}}$}

${ }^{31} \mathrm{P} \mathrm{NMR}, 162 \mathrm{MHz}, \mathrm{C}_{6} \mathrm{D}_{6}$

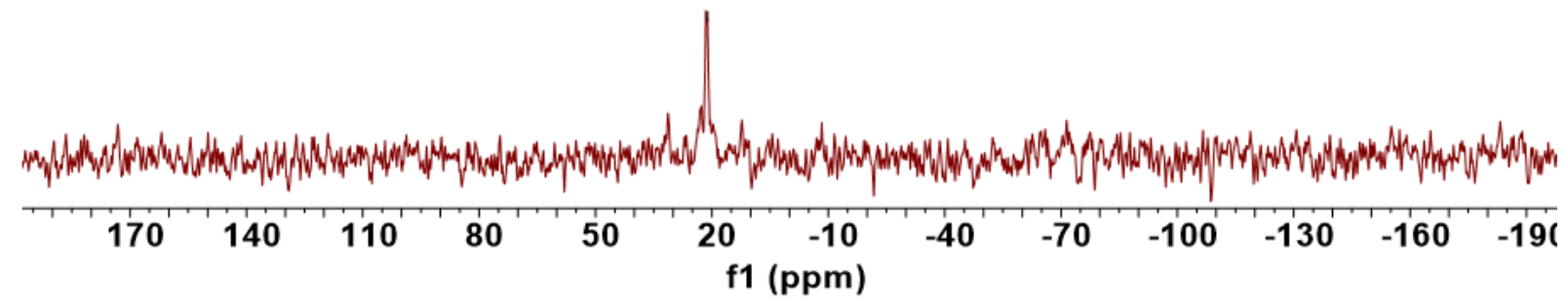

Fig. S25. ${ }^{31} \mathrm{P}$ NMR spectrum of the mixture formed from heating the $\mathrm{C}_{6} \mathrm{D}_{6}$ solution of 1 under $70{ }^{\circ} \mathrm{C}$ for $14 \mathrm{~h}$. 


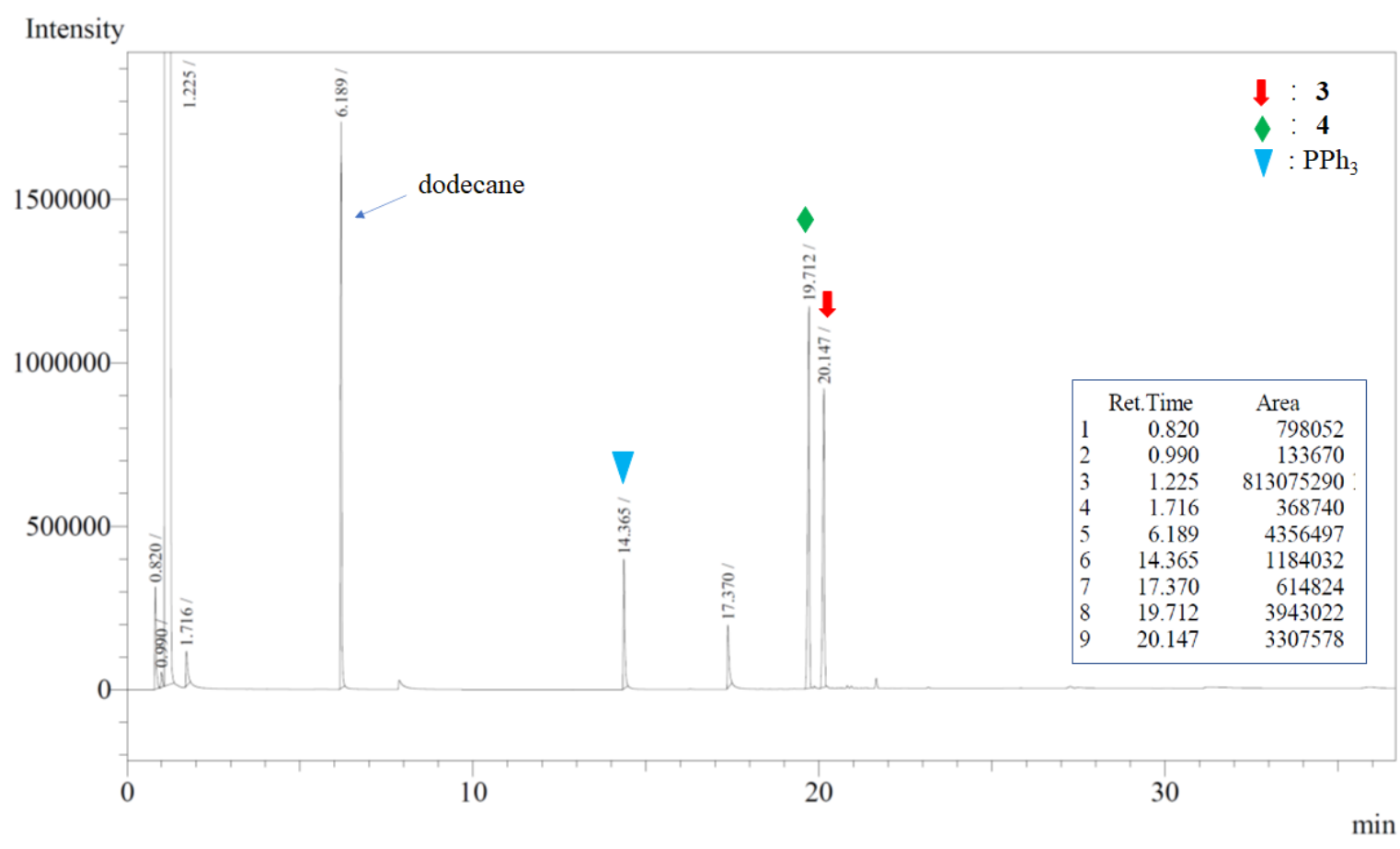

Fig. S26. GC graph of the sample obtained from heating the $\mathrm{C}_{6} \mathrm{D}_{6}$ solution of 1 under $70{ }^{\circ} \mathrm{C}$ for $14 \mathrm{~h}$. 


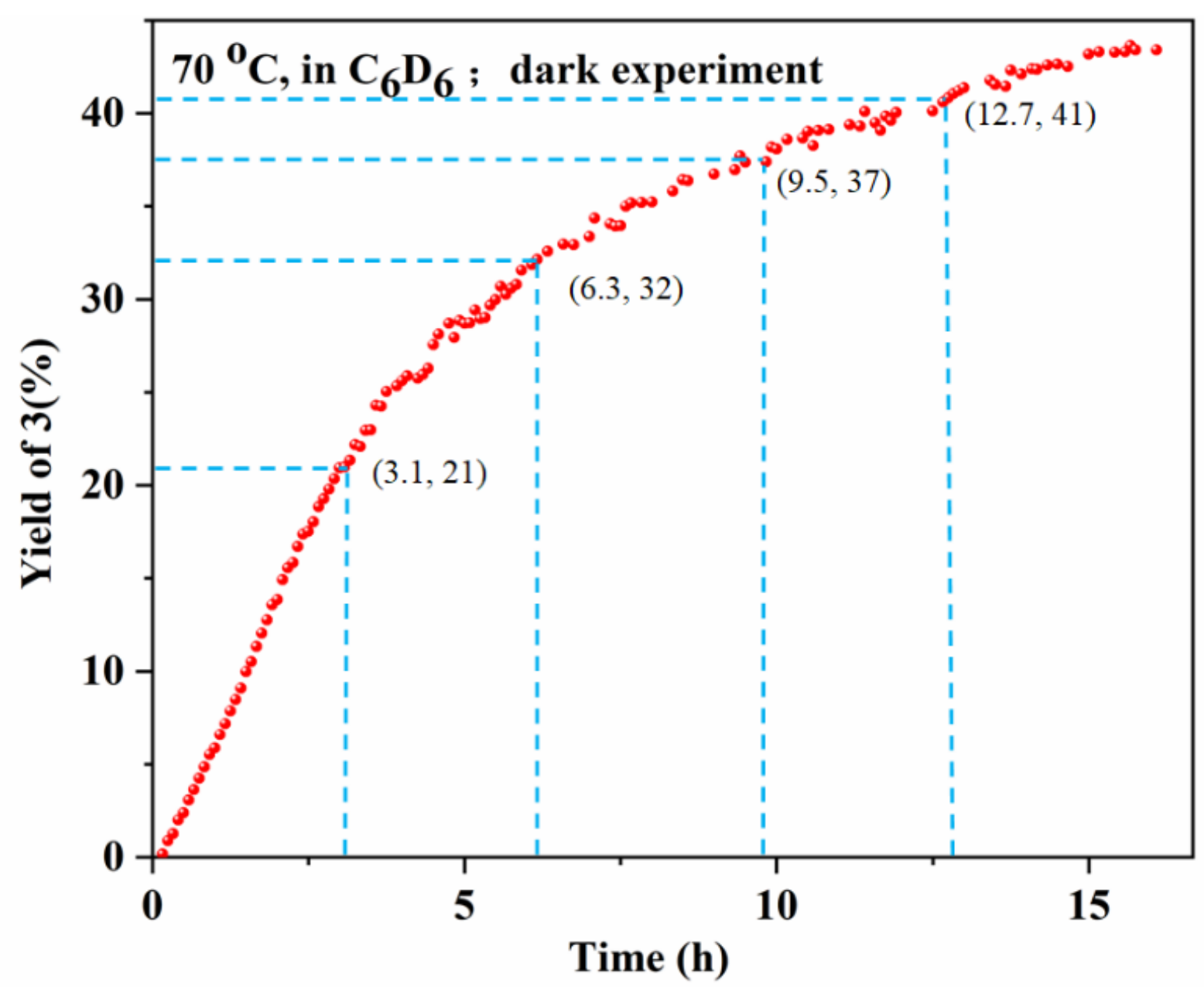

Fig. S27. Plot of yield of 3 (based on the full amount of NHAr Trip in 1) versus time for decomposition reaction of 1 under $70{ }^{\circ} \mathrm{C}$. In $14 \mathrm{~h}$, the yield of 3 achieved $40 \%$ that suggests the conversion of 1 of $80 \%$ as merely half of the NHAr ${ }^{\text {Trip }}$ is converted to 3 . The half-life is $t_{1 / 2}=3.1 \mathrm{~h}$. 


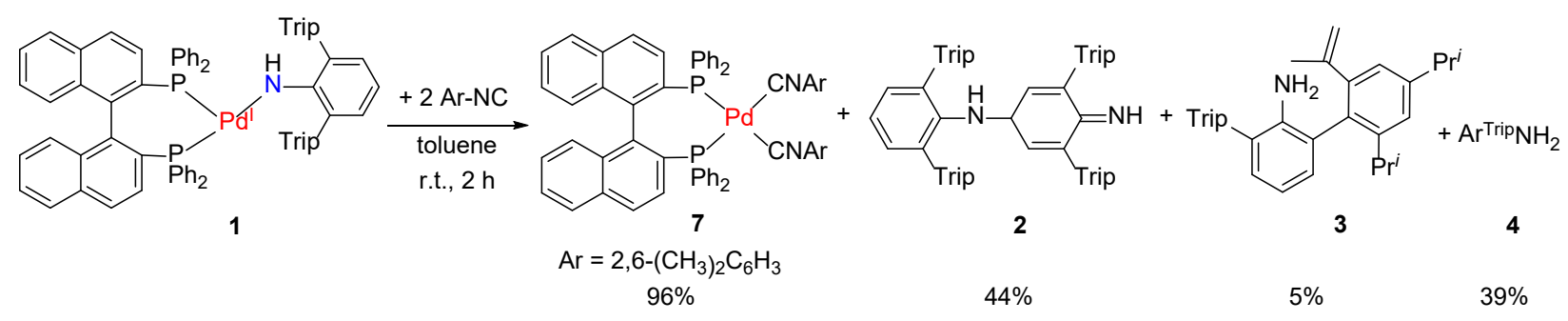

Reaction of 1 with 2,6-dimethylphenylisocyanide. To a solution of $\mathbf{1}$ (200 mg, $0.16 \mathrm{mmol}$ ) in toluene $(20 \mathrm{~mL})$ was added 2,6-dimethylphenylisocyanide (43 $\mathrm{mg}, 0.33 \mathrm{mmol})$ at room temperature. The color of the solution changed from green to red immediately. After stirring for $2 \mathrm{~h}$, the red precipitate was collected by filtration. The resultant red solid was then washed with toluene $(3 \times 2$ $\mathrm{mL})$ and dried under vacuum, which leaves [(BINAP)Pd(2,6-( $\left.\left.\left(\mathrm{CH}_{3}\right)_{2} \mathrm{C}_{6} \mathrm{H}_{3} \mathrm{NC}\right)_{2}\right]$ (7) as a red powder (156 mg, 96\%). Single crystals of 7 suitable for X-ray diffraction were grown by diffusion of a toluene solution of 2,6-dimethylphenylisocyanide into a concentrated toluene solution of $\mathbf{1}$ at $-30{ }^{\circ} \mathrm{C}$ for days. Anal. Calcd for $\mathrm{C}_{62} \mathrm{H}_{50} \mathrm{P}_{2} \mathrm{PdN}_{2}$ : C, 75.11; H, 5.08; N, 2.83; Found: C, 75.06; H, 5.45; N, 2.31. Absorption spectrum (THF): $\lambda_{\max }, \mathrm{nm}\left(\varepsilon, \mathrm{M}^{-1} \mathrm{~cm}^{-1}\right)=350(8800), 520$ (3500). IR $\left(\mathrm{KBr}, \mathrm{cm}^{-1}\right): v$ $=3048(\mathrm{~s}), 3000(\mathrm{~m}), 2944(\mathrm{~m}), 2860$ (w), 2062 (s), 2029 (s), 1841 (w), 1614 (w), 1587 (s), 1499 (m), 1468 (s), 1432 (s), 1379 (w), 1303 (m), 1186 (m), 1085 (s), 1027 (m), 812 (s), 774 (s), 741 (s), $502(\mathrm{~s}), 457(\mathrm{~m})$. After the collection of 7 by filtration, the filtrate was concentrated under vacuum to leave a residue. The residue was dissolved in $\mathrm{C}_{6} \mathrm{D}_{6}(500 \mu \mathrm{L})$ and 1,3,5-trimethoxybenzene $(12.1 \mathrm{mg}$, $0.072 \mathrm{mmol}$ ) was added as an internal standard for NMR quantification, which indicates the NMR yields of 2, 3 and 4 in 44\%, 5\% and 39\%, respectively (Fig. S28.). 


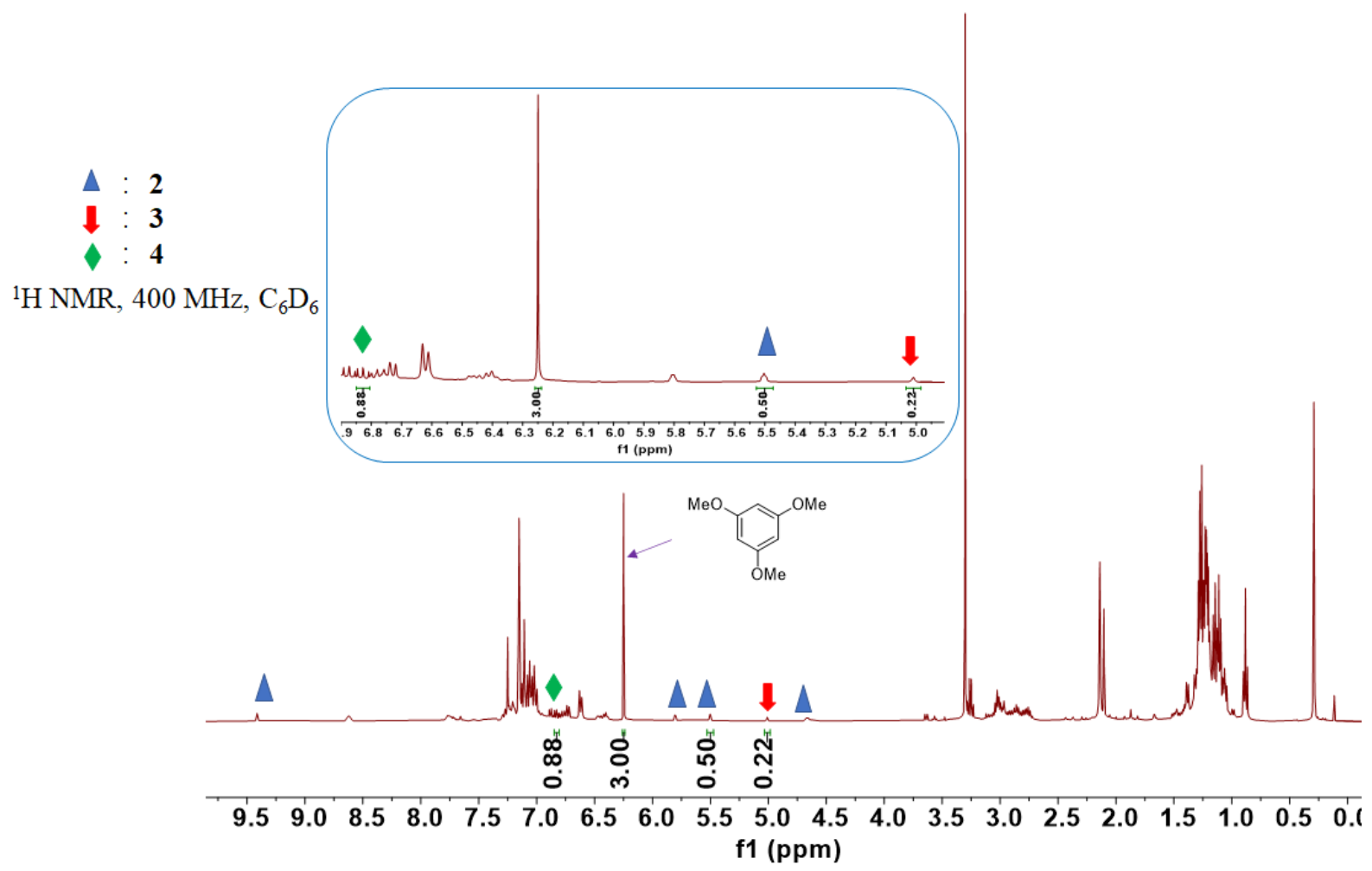

Fig. S28. The ${ }^{1} \mathrm{H}$ NMR spectrum of the mixture formed from the reaction of 1 with two equiv. of 2,6-dimethylphenylisocyanide (Inset: expanded region of ${ }^{1} \mathrm{H}$ NMR spectrum of reaction mixture from 6.9 to $5.0 \mathrm{ppm})$. 


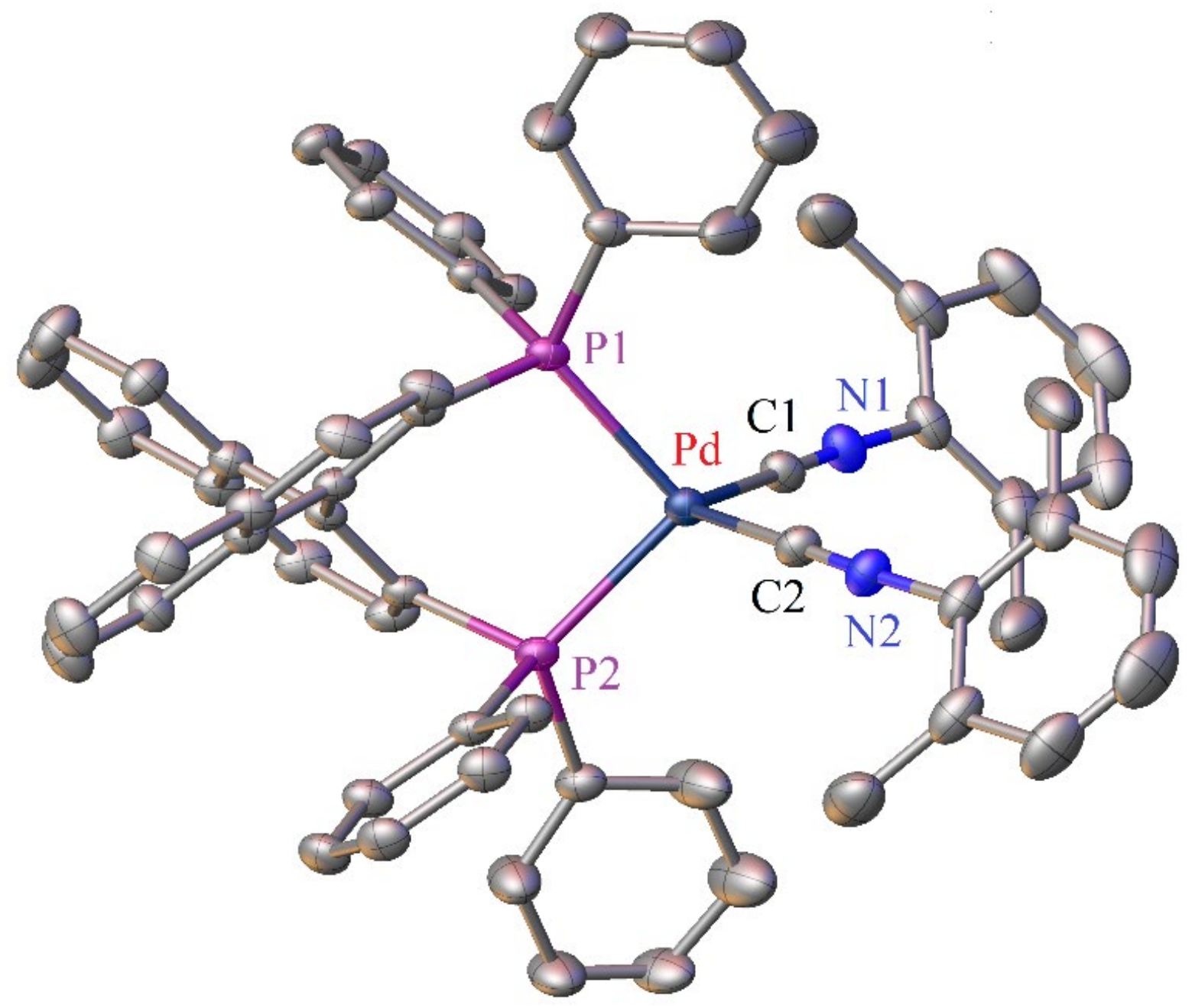

Fig. S29. Molecular structure of 7 , showing $30 \%$ probability ellipsoids and the partial atoms numbering scheme. Selected distances $(\AA)$ and angles (deg): Pd-C1 2.004(3), Pd-P1 2.3493(8), N1-C1 1.156(4), C1-Pd1-I 86.45(6), C1-Pd-P1 112.17(9), C1-Pd-P2 114.82(9), P1-Pd-P2 94.00(4), C2-Pd-P1 114.82(9), C2-Pd-P2 112.18(9). 


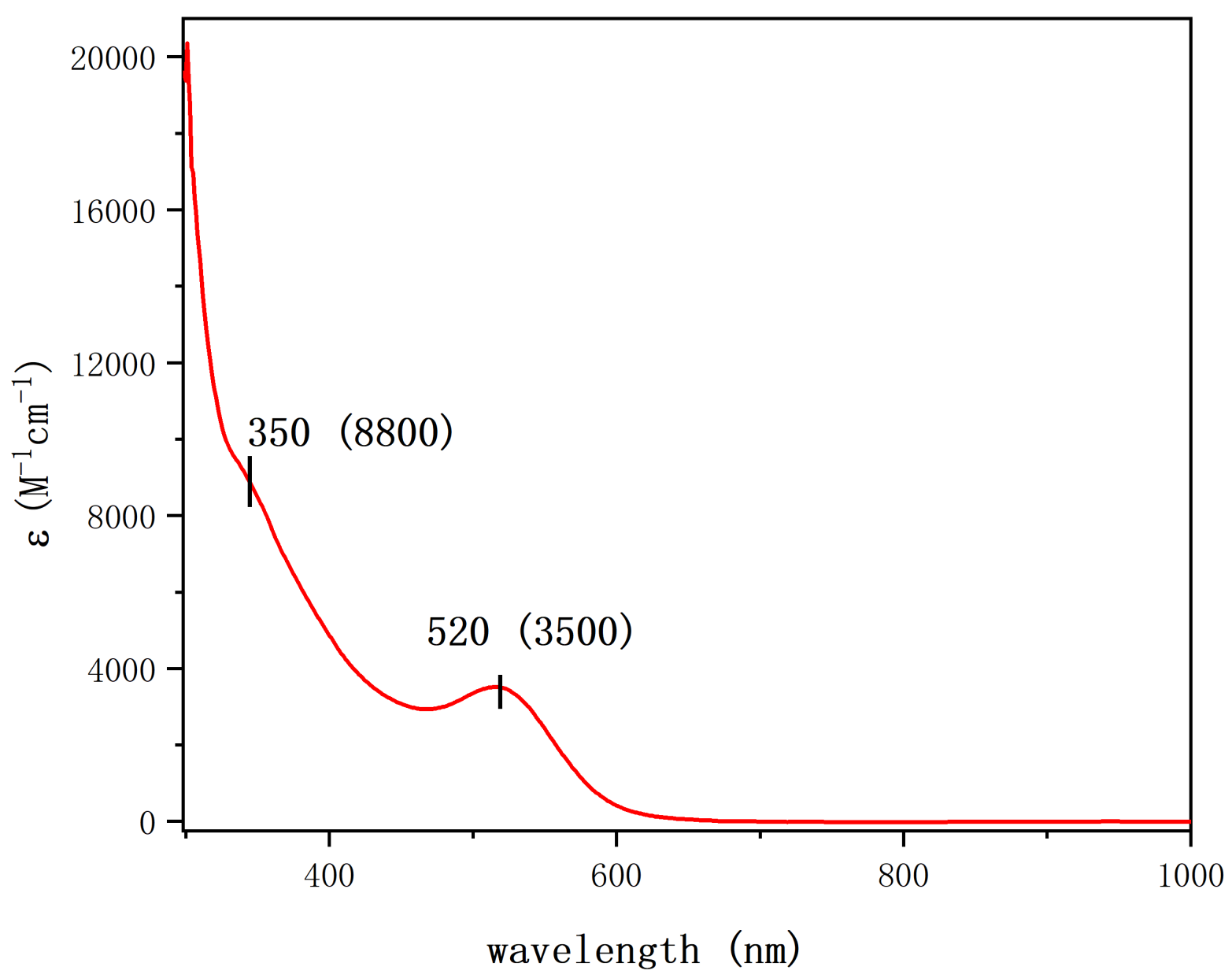

Fig. S30. UV-vis absorption spectrum in THF of 7 recorded at room temperature. 


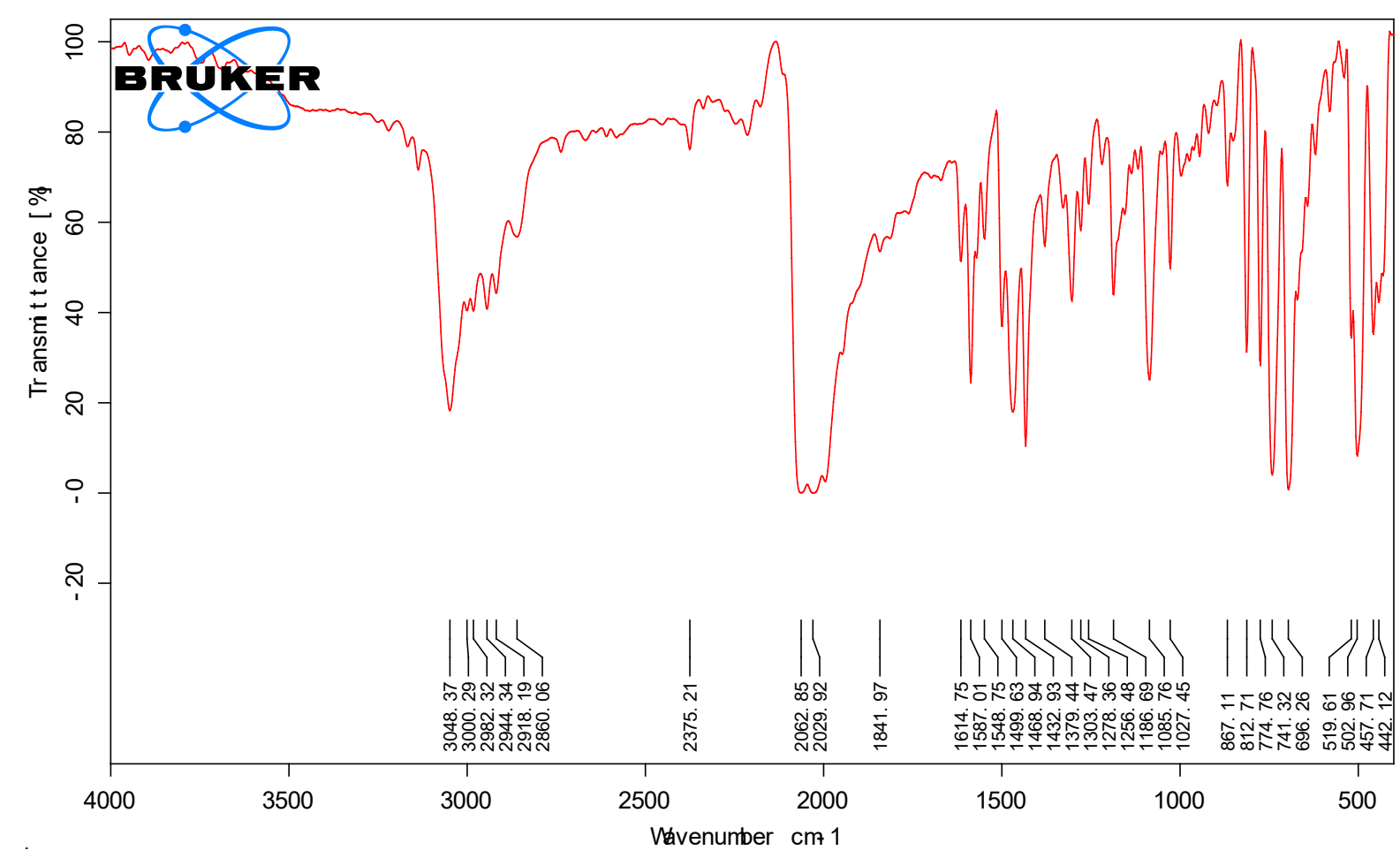

Fig. S31. IR spectrum of 7. 


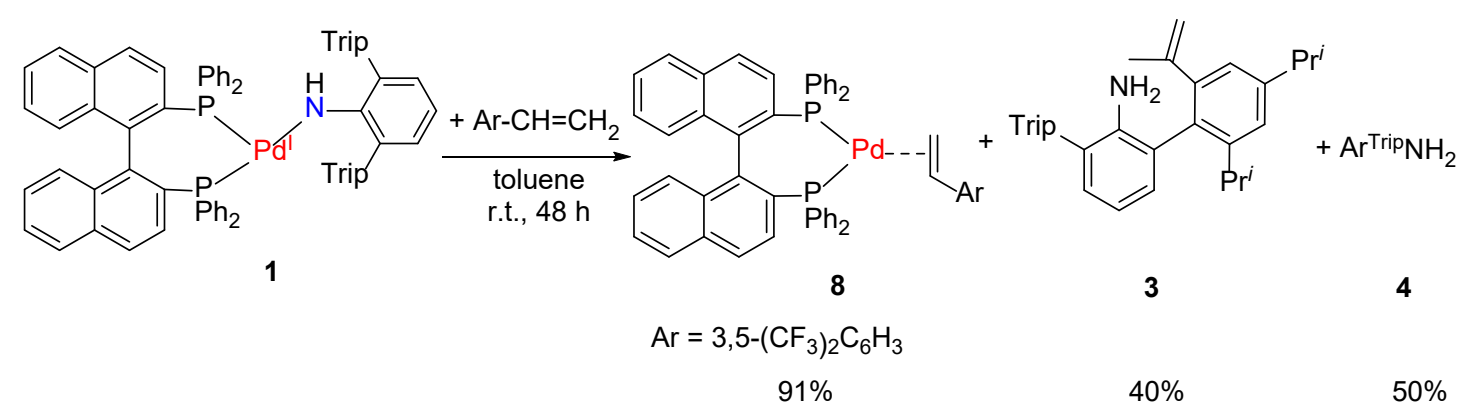

Reaction of 1 with 3,5-di(trifluoromethyl)styrene: To a solution of 1 (250 mg, $0.20 \mathrm{mmol})$ in toluene $(20 \mathrm{~mL})$ was added 3,5-di(trifluoromethyl)styrene $(73 \mathrm{mg}, 0.30 \mathrm{mmol})$ at room temperature. The color of the solution changed from green to yellow gradually. After stirring for $48 \mathrm{~h}$, the mixture was concentrated under vacuum to leave a yellow residue. The resultant yellow solid was then washed with $n$-hexane $(3 \times 2 \mathrm{~mL})$ and dried under vacuum, which leaves [(BINAP)Pd $\left.\left(\eta^{2}-\mathrm{H}_{2} \mathrm{C}=\mathrm{CHC}_{6} \mathrm{H}_{3}-3,5-\left(\mathrm{CF}_{3}\right)_{2}\right)\right](8)$ as a yellow powder $(180 \mathrm{mg}, 91 \%)$. Single crystals of 8 suitable for X-ray diffraction were grown by diffusion of a $n$-hexane solution of 3,5-di(trifluoromethyl)styrene into a concentrated toluene solution of $\mathbf{1}$ at room temperature for days. Anal. Calcd for $\mathrm{C}_{54} \mathrm{H}_{38} \mathrm{P}_{2} \mathrm{PdF}_{6}$ : C, 66.92; H, 3.95; Found: C, 66.93; H, 4.18. Absorption spectrum (THF): $\lambda_{\max }, \mathrm{nm}\left(\varepsilon, \mathrm{M}^{-1} \mathrm{~cm}^{-1}\right)=340(12300), 400(7400) . \mathrm{IR}\left(\mathrm{KBr}, \mathrm{cm}^{-1}\right): v=3053(\mathrm{~m}), 2995(\mathrm{w})$, 1604 (m), 1585 (m), 1497 (m), 1435 (m), 1394 (m), 1352 (w), 1306 (w), 1277 (s), 1220 (w), 1164 (s), $1128(\mathrm{~s}), 1100$ (m), 890 (m), 873 (m), 814 (w), 743 (s), 694 (s), 521 (m), 504 (s), 463 (m), 432 (w). The ${ }^{19} \mathrm{~F}$ and ${ }^{31} \mathrm{P}$ NMR data indicate the presence of two isomers of $\mathbf{8}$ with the ratio of $1: 2.4$, probably related to the different orientation of the styrene ligand toward the (BINAP)Pd unit that has $C_{2}$-symmetry. ${ }^{1} \mathrm{H}$ NMR (400 MHz, $\left.\mathrm{C}_{6} \mathrm{D}_{6}, 296 \mathrm{~K}\right): \delta(\mathrm{ppm})$ 8.15-8.03 (m), 7.84-7.75 (m), $7.52(\mathrm{~s})$, 7.48-7.35 (m), 7.33-7.18 (m), 7.15-7.07 (m), 7.05-6.91 (m), 6.84-6.76 (m), 6.74-6.67 (m), 6.65-6.56 (m), 6.47-6.40 (m), 6.39-6.30 (m), 6.27-6.20 (m), 4.80-4.68 (m), 4.59-4.45 (m), 3.65-3.52 (m), 3.50-3.39 (m), 3.22-3.13 (m), ${ }^{13} \mathrm{C}$ NMR (101 MHz, C6 $\left.\mathrm{D}_{6}, 296 \mathrm{~K}\right): \delta$ (ppm) 150.03, 149.35, 149.33, 149.28, 149.26, 138.49, 138.46, 138.32, 138.05, 138.01, 137.90, 137.29, 137.20, 137.04, 136.96, $136.87,136.68,136.61,136.39$, 136.30, 136.06, 135.26, 135.09, 135.02, 134.92, 134.88, 134.84, $134.81,134.78,134.75,134.70,134.63,134.54,134.27,134.25,134.17,134.12,134.10,134.05$, $133.76,133.59,133.31,133.24,133.20,132.49,132.43,132.20,132.14,131.77,131.48,131.40$, $131.38,131.16,131.08,131.06,130.84,130.06$, 129.91, 129.87, 129.76, 129.37, 129.34, 128.87, $128.84,128.77,128.74,128.67,128.65,128.63,128.56,128.50,128.30,127.93,127.82,127.67$, 
$127.57,127.54,127.50,127.45,127.21,127.15,127.10,127.04,127.00,126.95,126.85,126.05$, 126.02, 125.97, 125.90, 125.84, 125.70, 124.29, 123.26, 123.13, 115.19, 67.23, 67.19, 67.02, 66.97, 63.38, 63.21, 46.72, 46.65, 45.46, 45.41, 45.21, 45.16. ${ }^{31} \mathrm{P}$ NMR (162 MHz, C6 $\left.\mathrm{D}_{6}, 296 \mathrm{~K}\right): \delta$ (ppm) $30.01(\mathrm{~d}, J=22.1 \mathrm{~Hz}), 29.73(\mathrm{~d}, J=23.0 \mathrm{~Hz}), 25.10(\mathrm{~d}, J=22.9 \mathrm{~Hz}), 20.93(\mathrm{~d}, J=22.1 \mathrm{~Hz}) .{ }^{19} \mathrm{~F}$ NMR (377 MHz, $\left.\mathrm{C}_{6} \mathrm{D}_{6}, 296 \mathrm{~K}\right): \delta$ (ppm) -62.39, -62.71. After the collection of 8 by filtration, the filtrate was concentrated under vacuum to leave a residue. The residue was dissolved in $\mathrm{C}_{6} \mathrm{D}_{6}(500$ $\mu \mathrm{L})$ and 1,3,5-trimethoxybenzene (28 $\mathrm{mg}, 0.17 \mathrm{mmol}$ ) was added as an internal standard for NMR quantification, which indicates the NMR yields of 3 and 4 in 40\% and 50\%, respectively (Fig. S32.). The yields of $\mathbf{3}$ and $\mathbf{4}$ were also confirmed by GC. Adding dodecane as an internal standard (93 mg, $0.55 \mathrm{mmol}$ ), which indicates the GC yields of 3 and $\mathbf{4}$ in $31 \%$ and $51 \%$, respectively (Fig. S33.). 


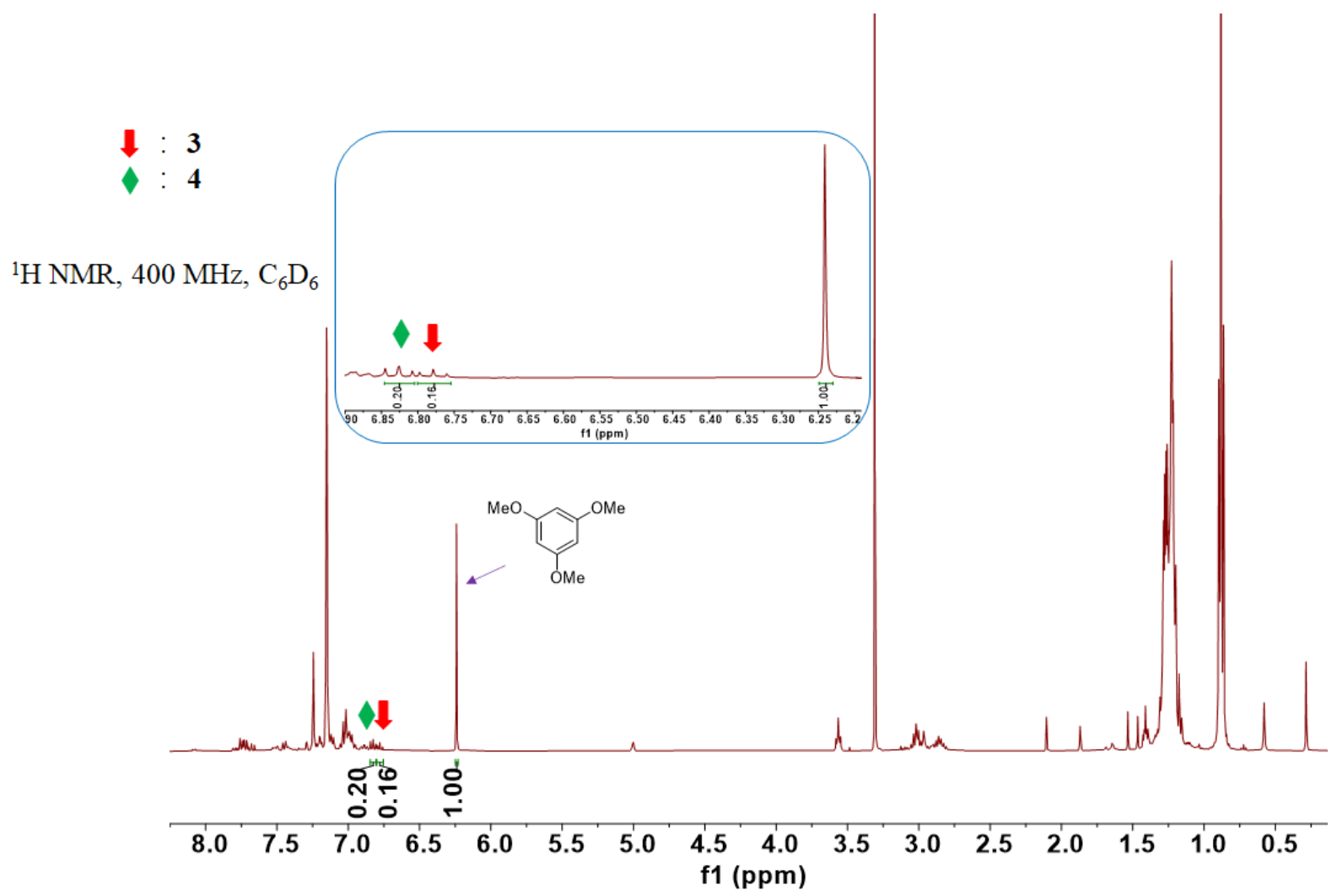

Fig. S32. The ${ }^{1} \mathrm{H}$ NMR spectrum of the mixture formed from the reaction of 1 with 3,5-di(trifluoromethyl)styrene in $48 \mathrm{~h}$ (Inset: expanded region of ${ }^{1} \mathrm{H}$ NMR spectrum of reaction mixture from 6.9 to $6.2 \mathrm{ppm})$. 


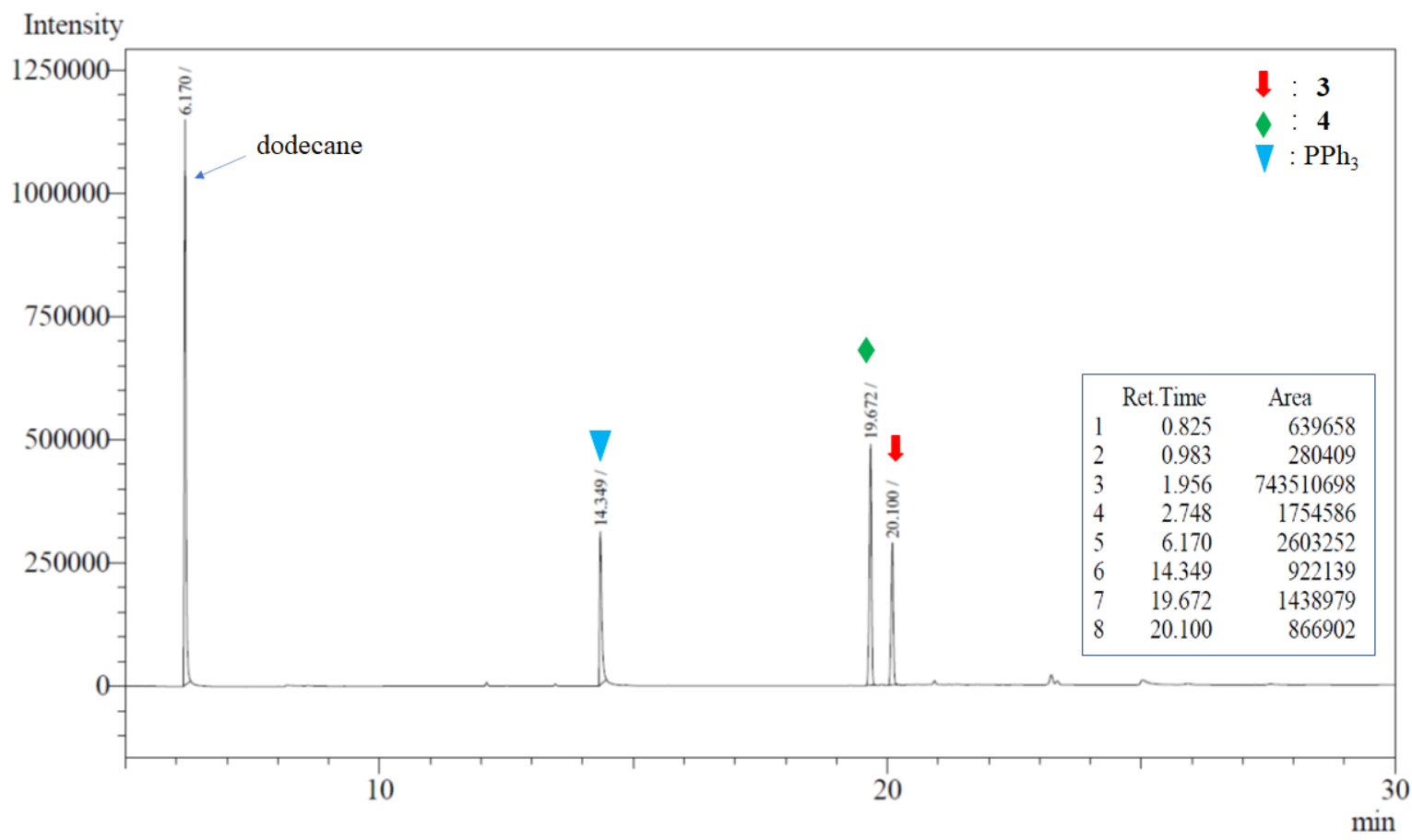

Fig. S33. GC graph of the sample obtained from the reaction of 1 with 3,5-di(trifluoromethyl)styrene in $48 \mathrm{~h}$. 


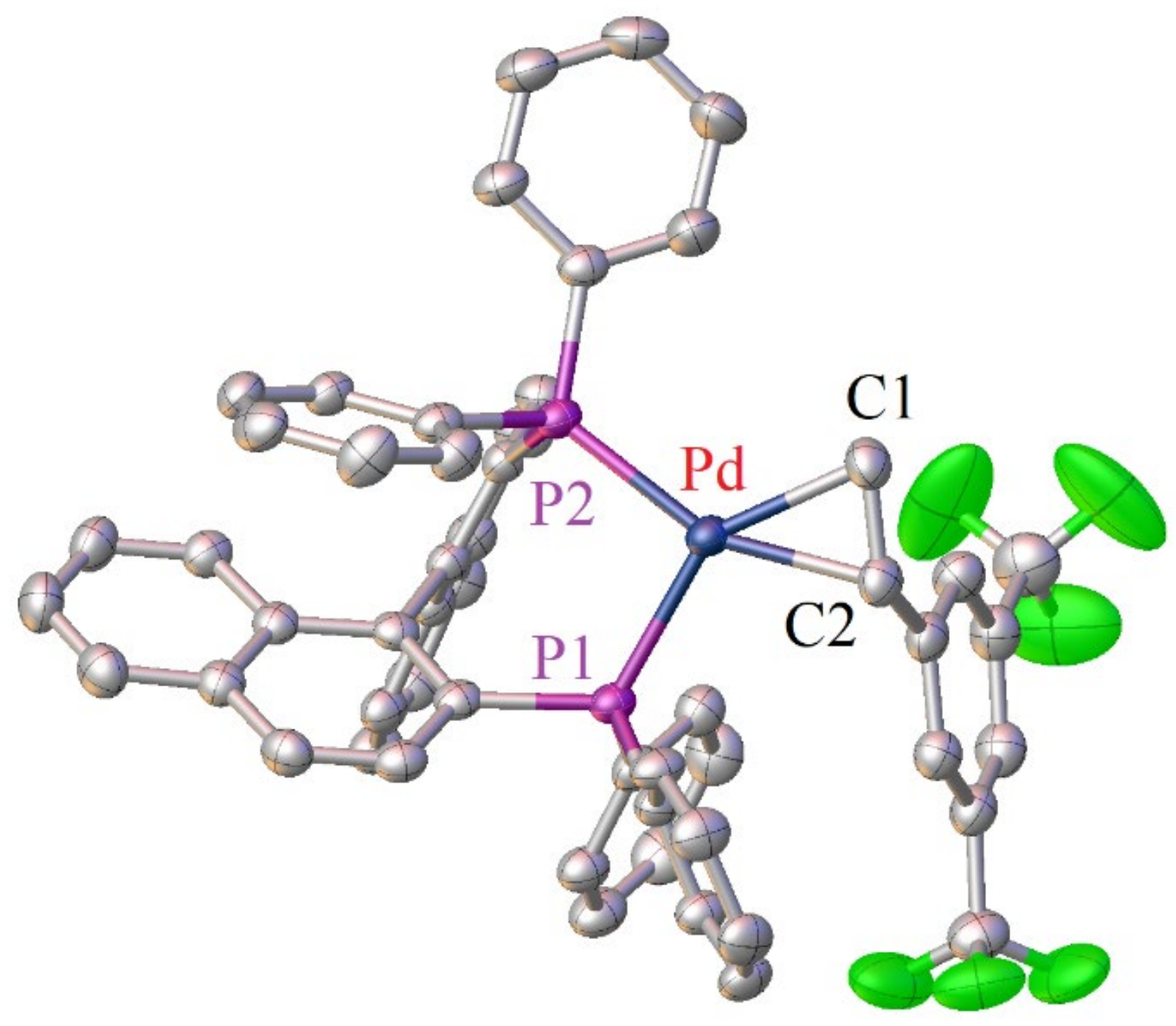

Fig. S34. Molecular structure of $\mathbf{8}$, showing $30 \%$ probability ellipsoids and the partial atoms numbering scheme. Selected distances $(\AA)$ and angles (deg): Pd-C1 2.146(4), Pd-C2 2.143(3), Pd-P1 2.3218(9), Pd-P2 2.2954(9), C1-Pd1-C2 38.29(14), C1-Pd-P1 145.01(10), C1-Pd-P2 118.92(10), P1-Pd-C2 106.76(10), P1-Pd-P2 96.07(3), P2-Pd-C2 156.98(10). 


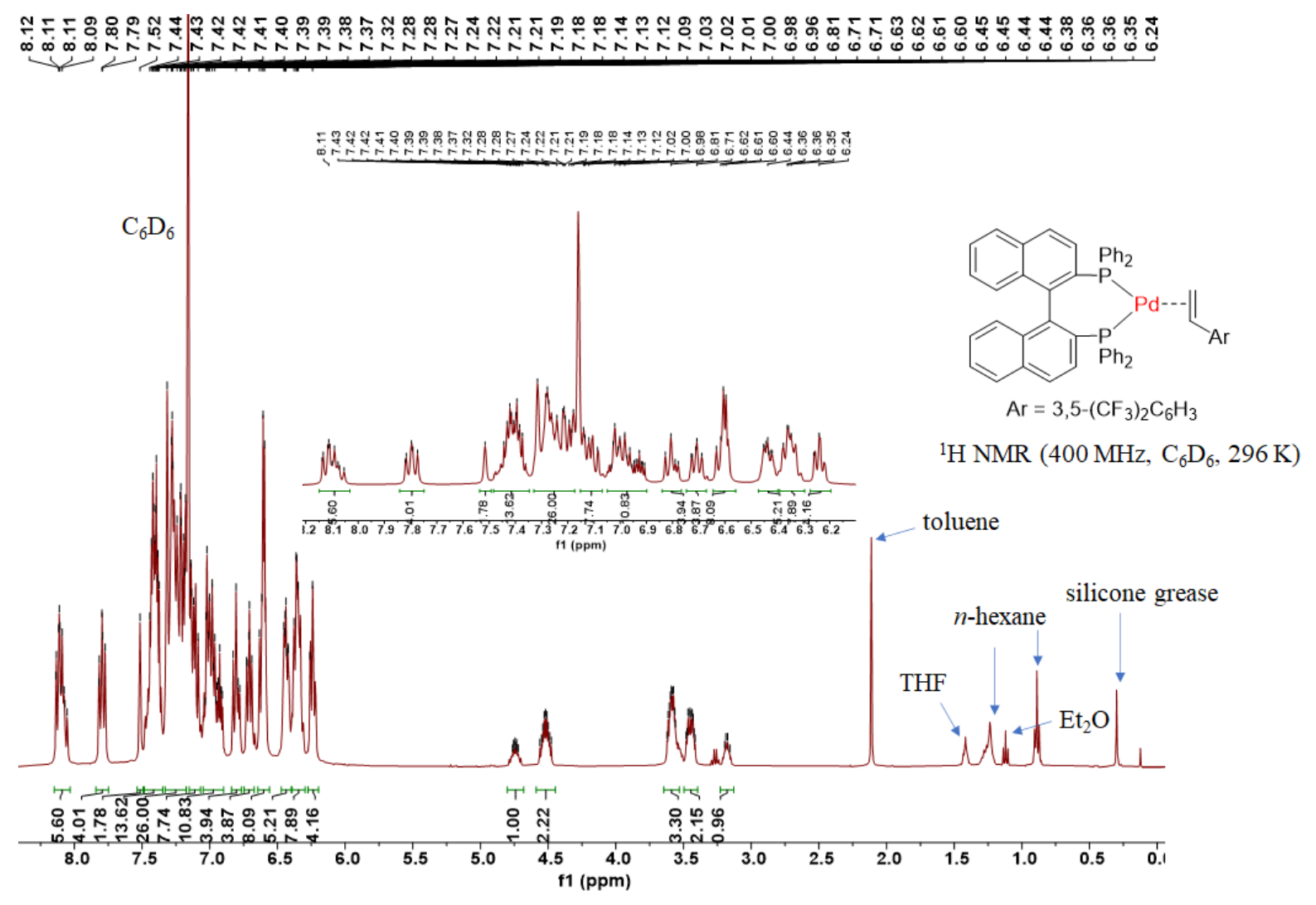

Fig. S35. ${ }^{1} \mathrm{H}$ NMR spectrum of $\mathbf{8}$ (Inset: expanded region of ${ }^{1} \mathrm{H}$ NMR spectrum of $\mathbf{8}$ from 8.2 to 6.2 ppm). 


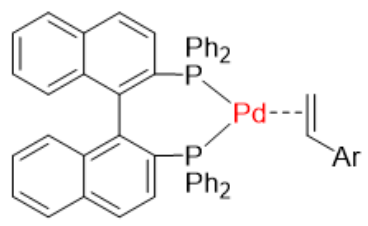

$\mathrm{Ar}=3,5-\left(\mathrm{CF}_{3}\right)_{2} \mathrm{C}_{6} \mathrm{H}_{3}$

${ }^{13} \mathrm{C}$ NMR $\left(101 \mathrm{MHz}, \mathrm{C}_{6} \mathrm{D}_{6}, 296 \mathrm{~K}\right)$

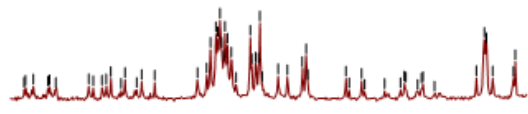

$\begin{array}{lllllllllll}138 & 137 & 136 & 135 & 134 & 133 & 132 & 131 & 130\end{array}$

f1 (ppm)

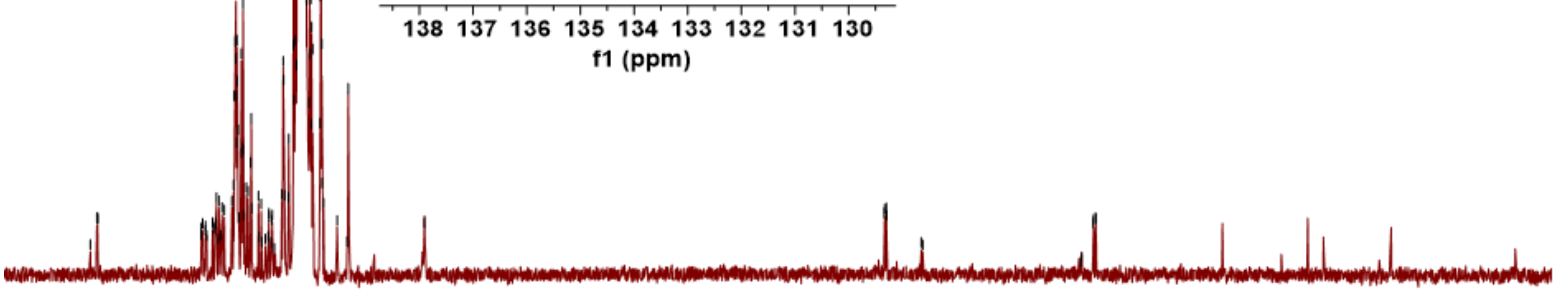

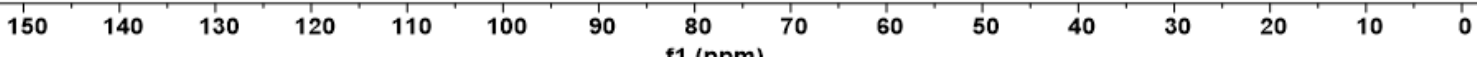

Fig. S36. ${ }^{13} \mathrm{C}$ NMR spectrum of 8 (Inset: expanded region of ${ }^{13} \mathrm{C}$ NMR spectrum of 8 from 138 to $130 \mathrm{ppm})$. 


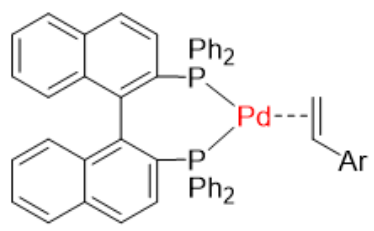

$\mathrm{Ar}=3,5-\left(\mathrm{CF}_{3}\right)_{2} \mathrm{C}_{6} \mathrm{H}_{3}$

${ }^{31} \mathrm{P}$ NMR $\left(162 \mathrm{MHz}, \mathrm{C}_{6} \mathrm{D}_{6}, 296 \mathrm{~K}\right)$

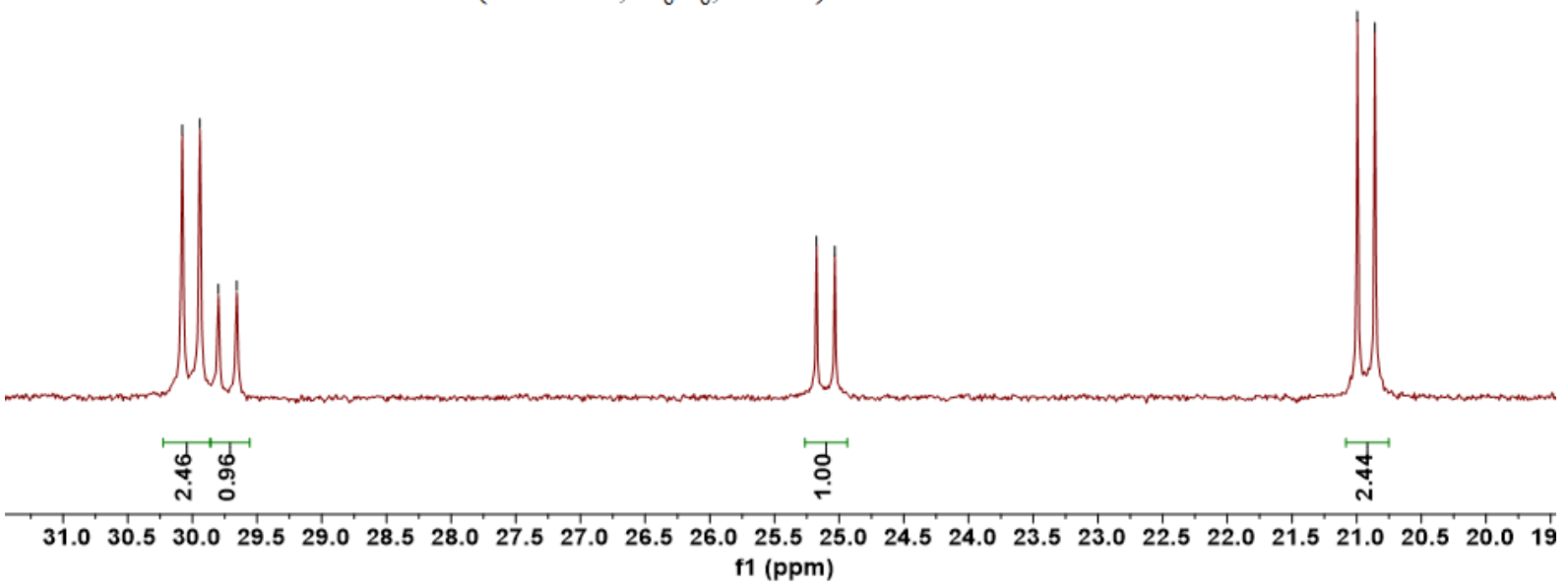

Fig. S37. ${ }^{31} \mathrm{P}$ NMR spectrum of $\mathbf{8}$. The NMR data indicate the presence of two isomers of $\mathbf{8}$ with the ratio of $1: 2.4$, probably related to the different orientation of the styrene ligand toward the (BINAP)Pd unit that has $C_{2}$-symmetry. 


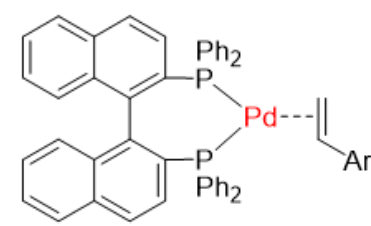

$\mathrm{Ar}=3,5-\left(\mathrm{CF}_{3}\right)_{2} \mathrm{C}_{6} \mathrm{H}_{3}$

${ }^{19} \mathrm{~F}$ NMR $\left(377 \mathrm{MHz}, \mathrm{C}_{6} \mathrm{D}_{6}, 296 \mathrm{~K}\right)$

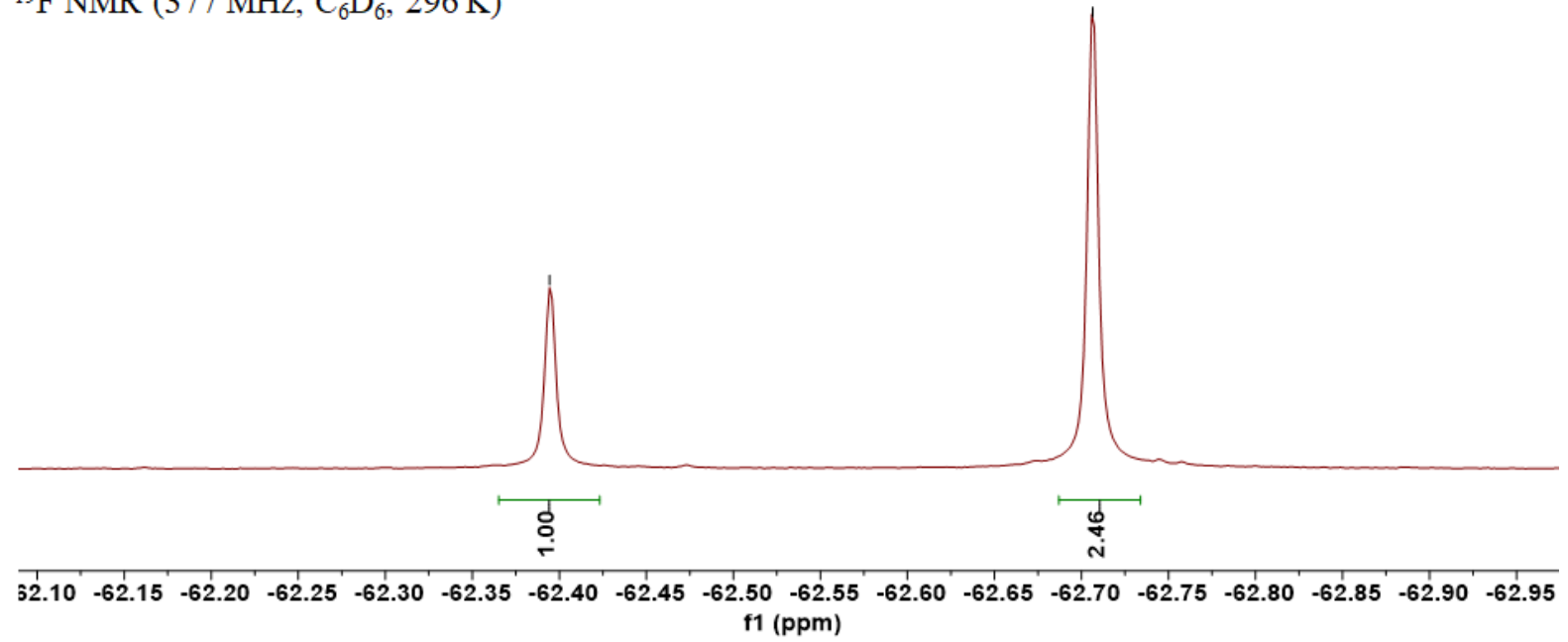

Fig. S38. ${ }^{19} \mathrm{~F}$ NMR spectrum of $\mathbf{8}$. The NMR data indicate the presence of two isomers of $\mathbf{8}$ with the ratio of $1: 2.5$, probably related to the different orientation of the styrene ligand toward the (BINAP)Pd unit that has $C_{2}$-symmetry. 


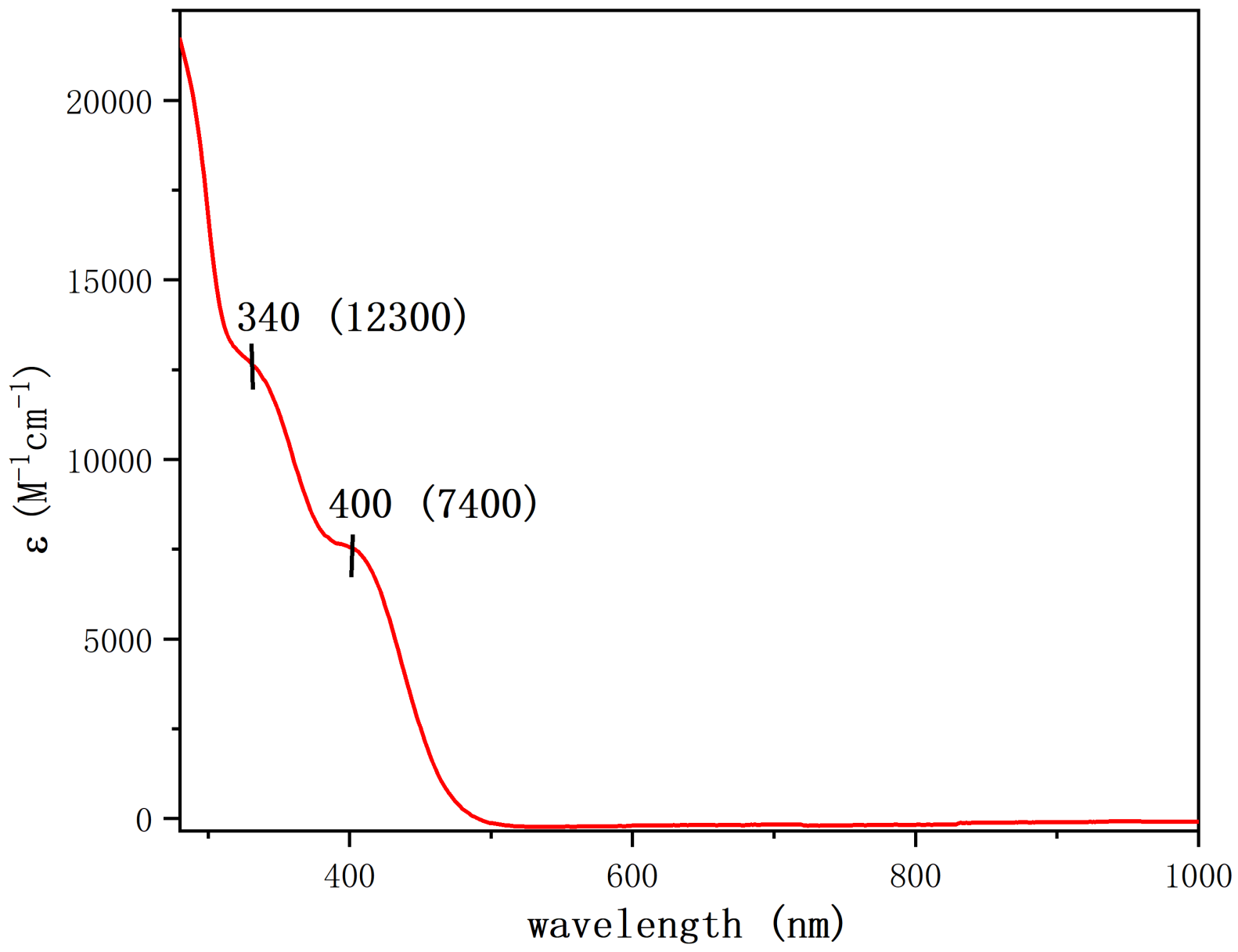

Fig. S39. UV-vis absorption spectrum in THF of $\mathbf{8}$ recorded at room temperature. 


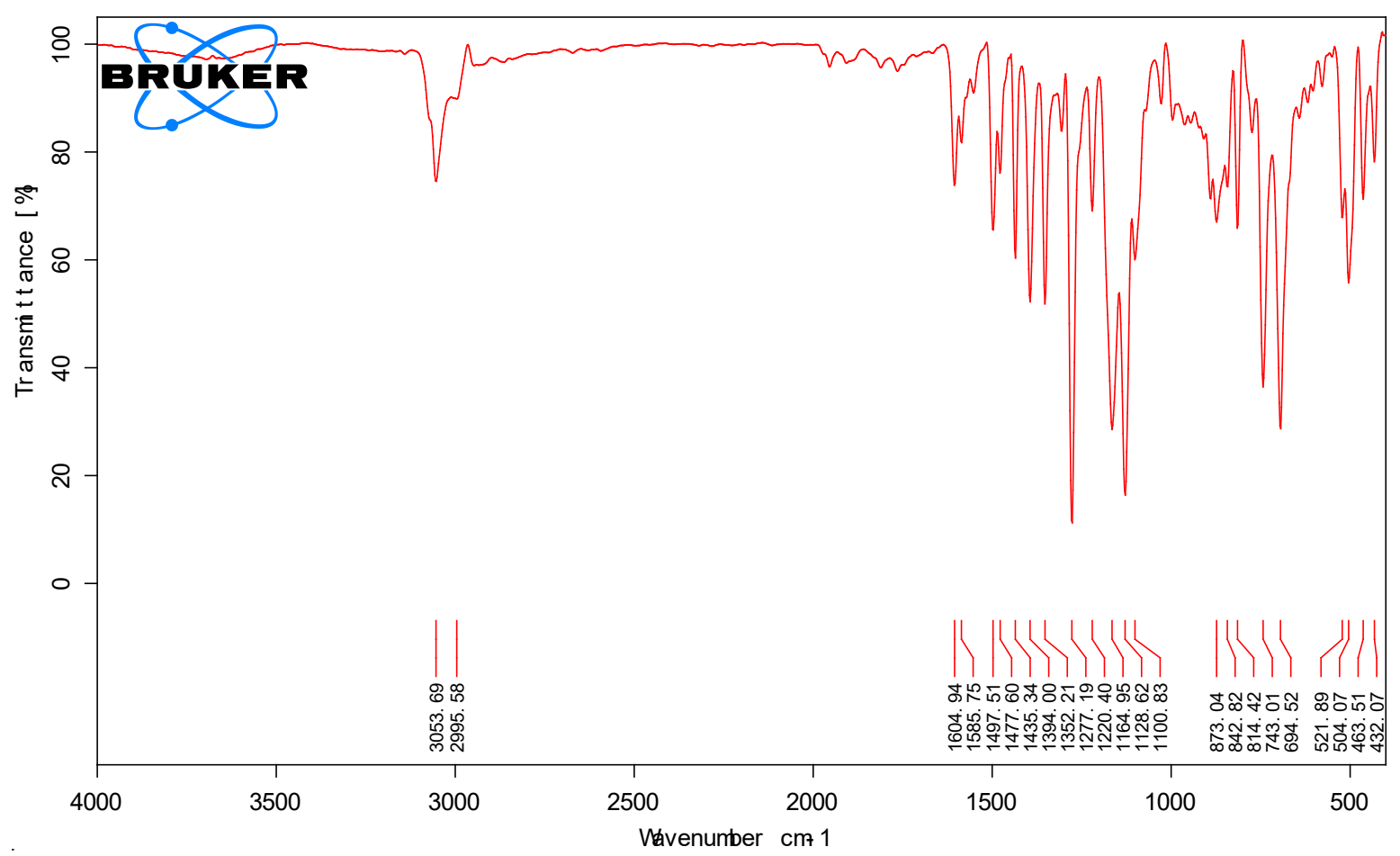

Fig. S40. IR spectrum of 8 . 
Kinetic Studies on the Reaction of 1 with 3,5-di(trifluoromethyl)styrene. The kinetic studies monitor the increase of the characteristic ${ }^{1} \mathrm{H}$ NMR signal of 8 at $\delta=7.84-7.75 \mathrm{ppm}$ formed in the reaction of 1 with excess amount of 3,5-bis(trifluoromethyl)styrene (20-40 equiv.) with 1,3,5-trimethoxybenzene as internal standard. Reactions were conducted with general procedure as follows: To a J-Young tube were added 1 (10 mg, $0.008 \mathrm{mmol}), 1,3,5$-trimethoxybenzene (2 $\mathrm{mg}$, $0.01 \mathrm{mmol}$ ) and a certain amount of 3,5-bis(trifluoromethyl)styrene (39, 49, 59, 69, and $79 \mathrm{mg})$, respectively. Then the reaction mixtures were diluted with $\mathrm{C}_{6} \mathrm{D}_{6}$ to $500 \mu \mathrm{L}$. The mixtures were kept at $30{ }^{\circ} \mathrm{C}$ and monitored by ${ }^{1} \mathrm{H}$ NMR continuously. For a given reaction, the formation of $\mathbf{8}$ shows a constant half-life, e.g. $t_{1 / 2}=24 \mathrm{~min}$ for the reaction of $1(0.016 \mathrm{~mol} / \mathrm{L})$ with 3,5-bis(trifluoromethyl)styrene $(0.325 \mathrm{~mol} / \mathrm{L})$ at $30{ }^{\circ} \mathrm{C}$, which indicates a pseudo-first-order kinetics for the concentration of the $\mathbf{1}$ (Fig. S41.). The profile of the reaction indicates a pseudo-first-order kinetics for the concentration of the alkene (Figs. S42-S47). 


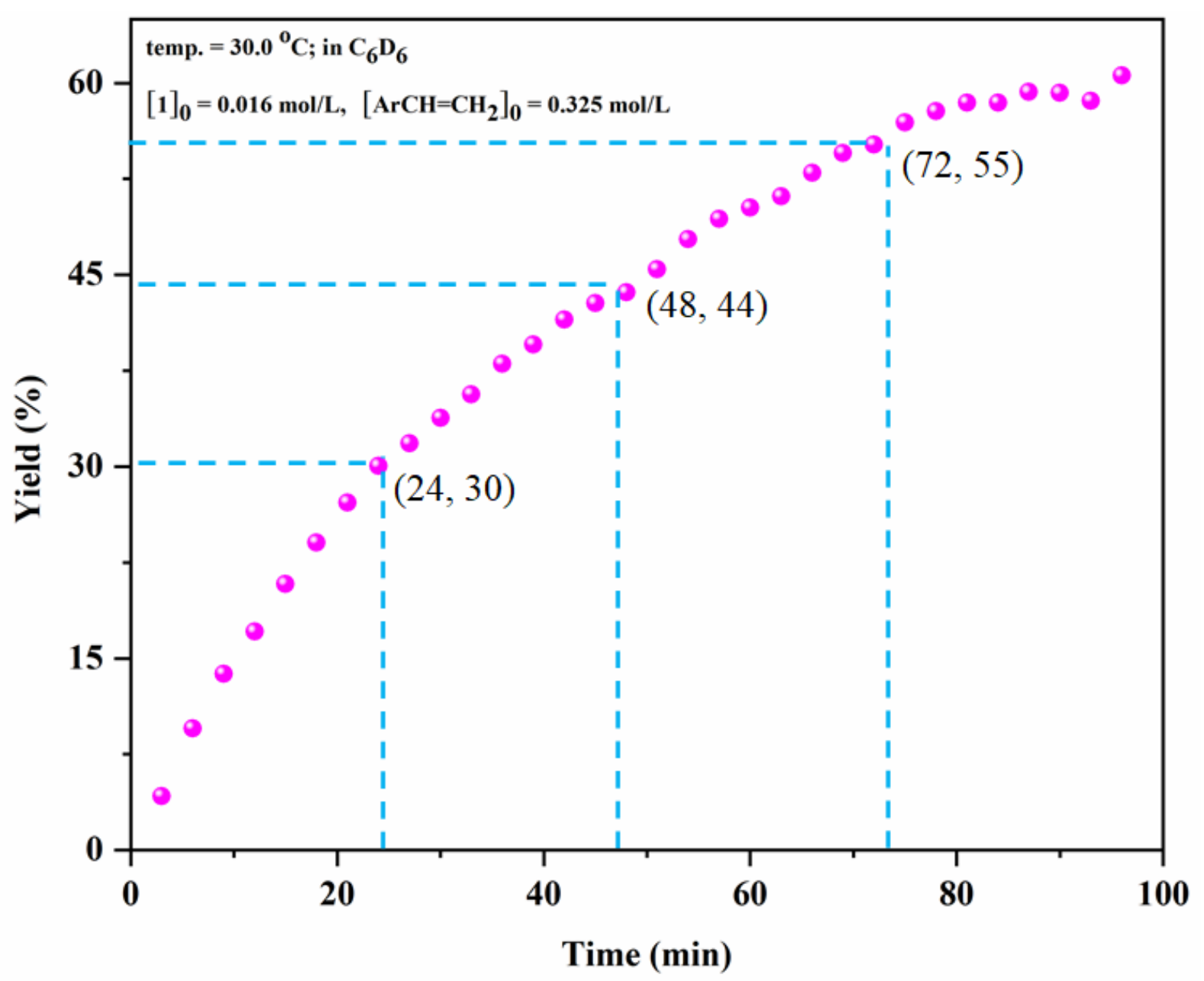

Fig. S41. A representative plot for the change of the yield of the product 8 versus time for the reaction of 1 with 3,5-bis(trifluoromethyl)-styrene in $\mathrm{C}_{6} \mathrm{D}_{6}$ at $30^{\circ} \mathrm{C}$. The half-life is $t_{1 / 2}=24$ min. 


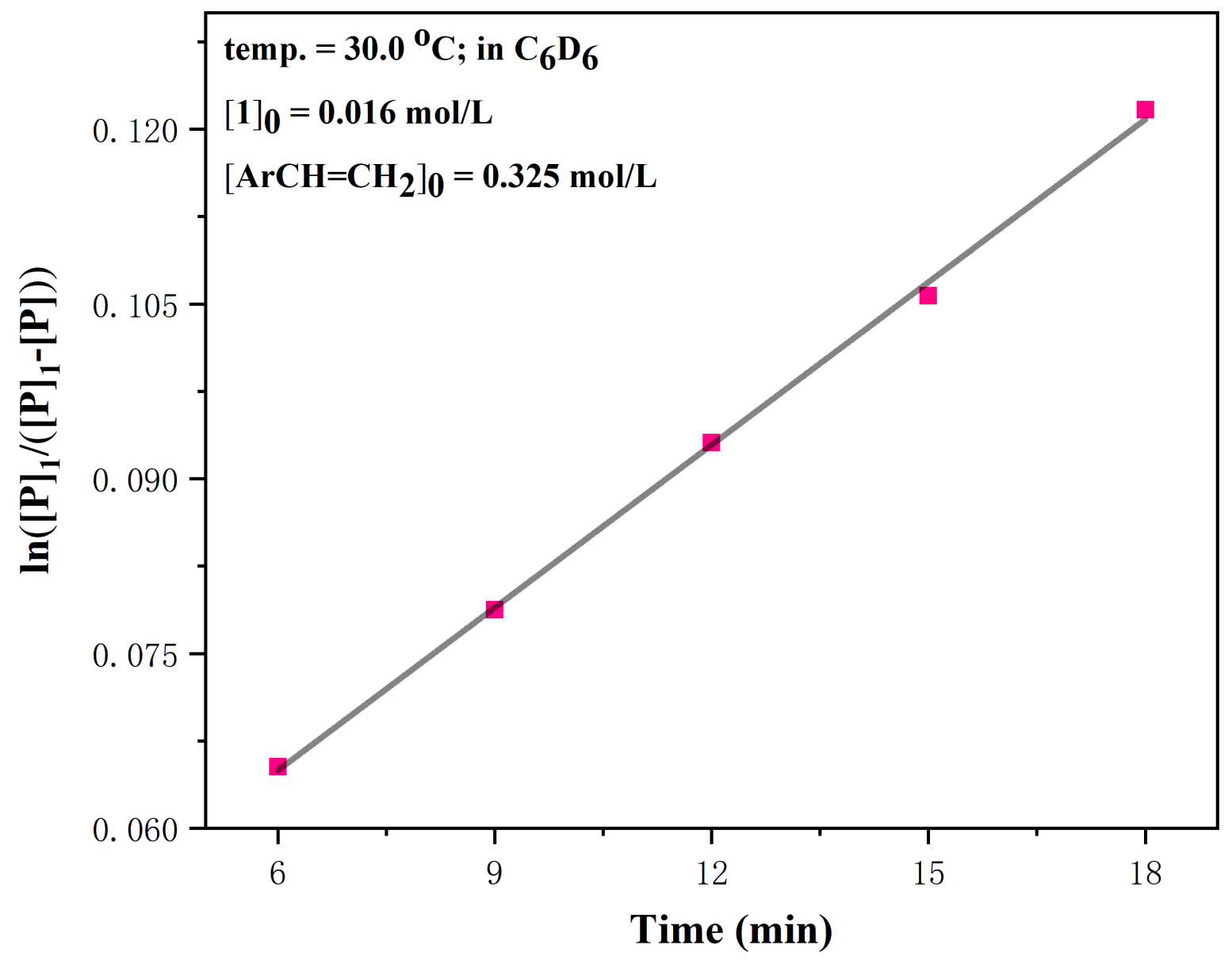

Fig. S42. Plot of $\ln \left([\mathrm{P}]_{1} /\left([\mathrm{P}]_{1}-[\mathrm{P}]\right)\right)$ vs time for the reaction of 1 with 3,5-bis(trifluoromethyl)styrene (20 equiv.) at $30^{\circ} \mathrm{C}$. 


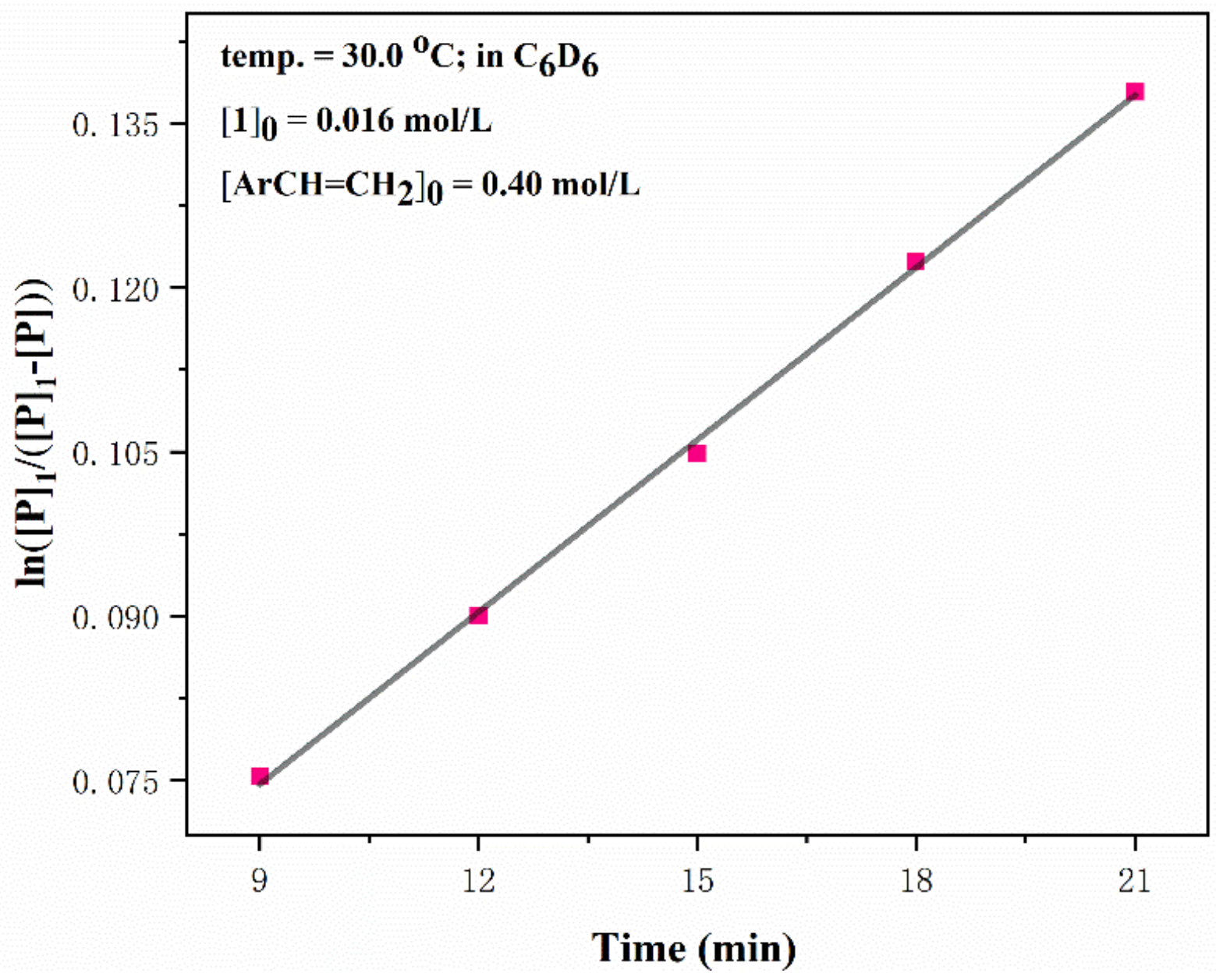

Fig. S43. Plot of $\ln \left([\mathrm{P}]_{1} /\left([\mathrm{P}]_{1}-[\mathrm{P}]\right)\right)$ vs time for the reaction of 1 with 3,5-bis(trifluoromethyl)styrene (25 equiv.) at $30^{\circ} \mathrm{C}$. 


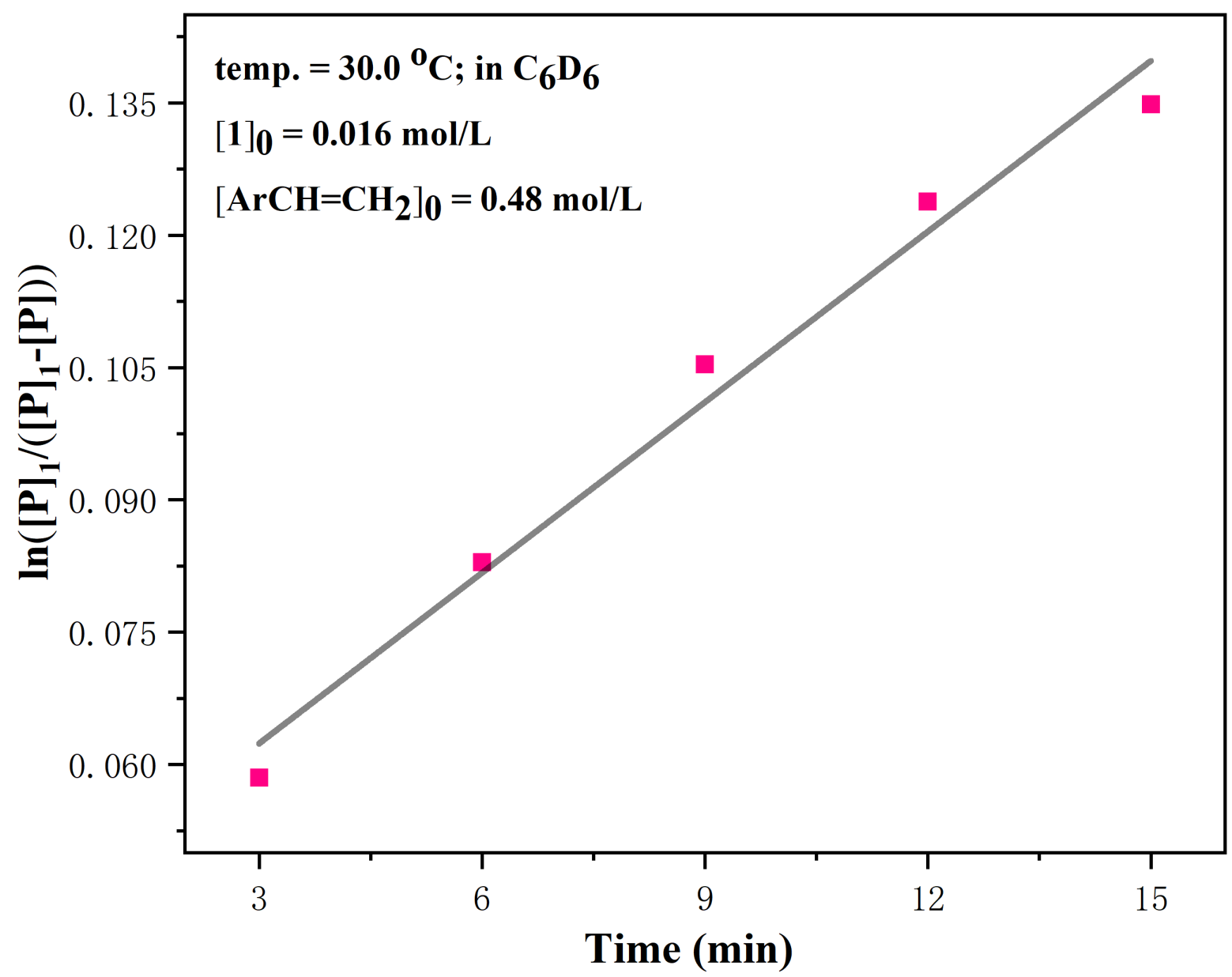

Fig. S44. Plot of $\ln \left([\mathrm{P}]_{1} /\left([\mathrm{P}]_{1}-[\mathrm{P}]\right)\right)$ vs time for the reaction of 1 with 3,5-bis(trifluoromethyl)styrene (30 equiv.) at $30{ }^{\circ} \mathrm{C}$. 


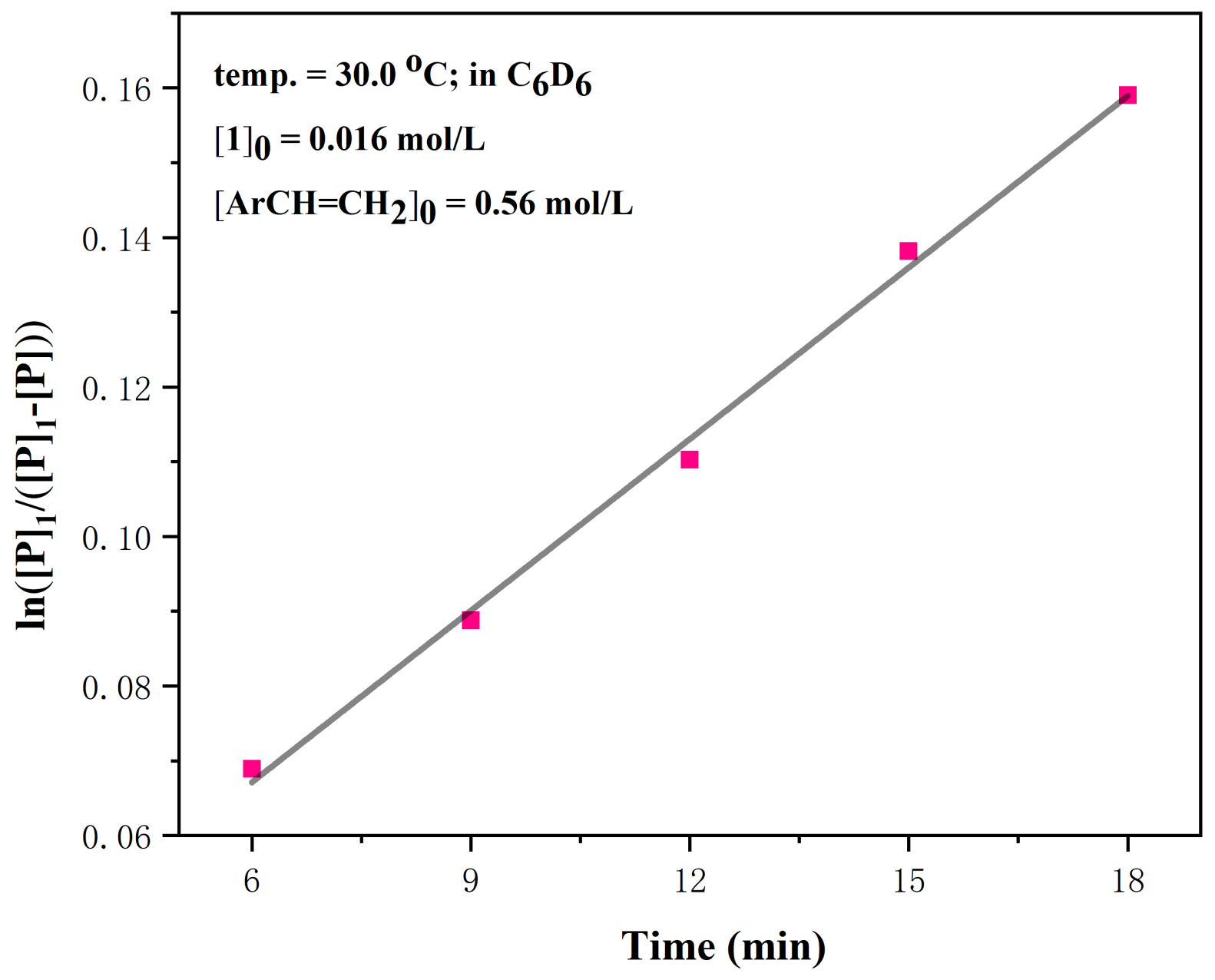

Fig. S45. Plot of $\ln \left([\mathrm{P}]_{1} /\left([\mathrm{P}]_{1}-[\mathrm{P}]\right)\right)$ vs time for the reaction of 1 with 3,5-bis(trifluoromethyl)styrene (35 equiv.) at $30^{\circ} \mathrm{C}$. 


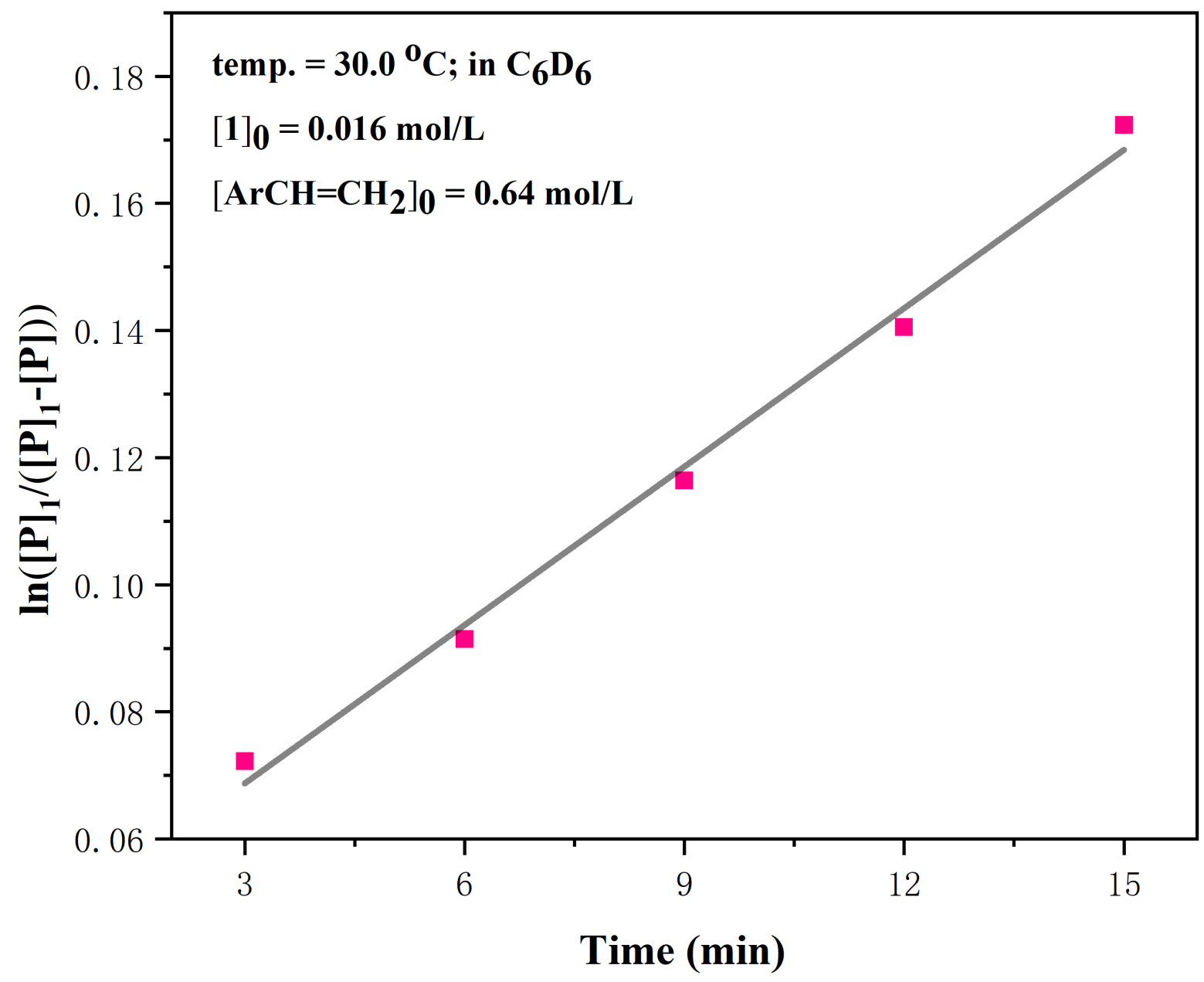

Fig. S46. Plot of $\ln \left([\mathrm{P}]_{1} /\left([\mathrm{P}]_{1}-[\mathrm{P}]\right)\right)$ vs time for the reaction of 1 with 3,5-bis(trifluoromethyl)styrene (40 equiv.) at $30^{\circ} \mathrm{C}$. 


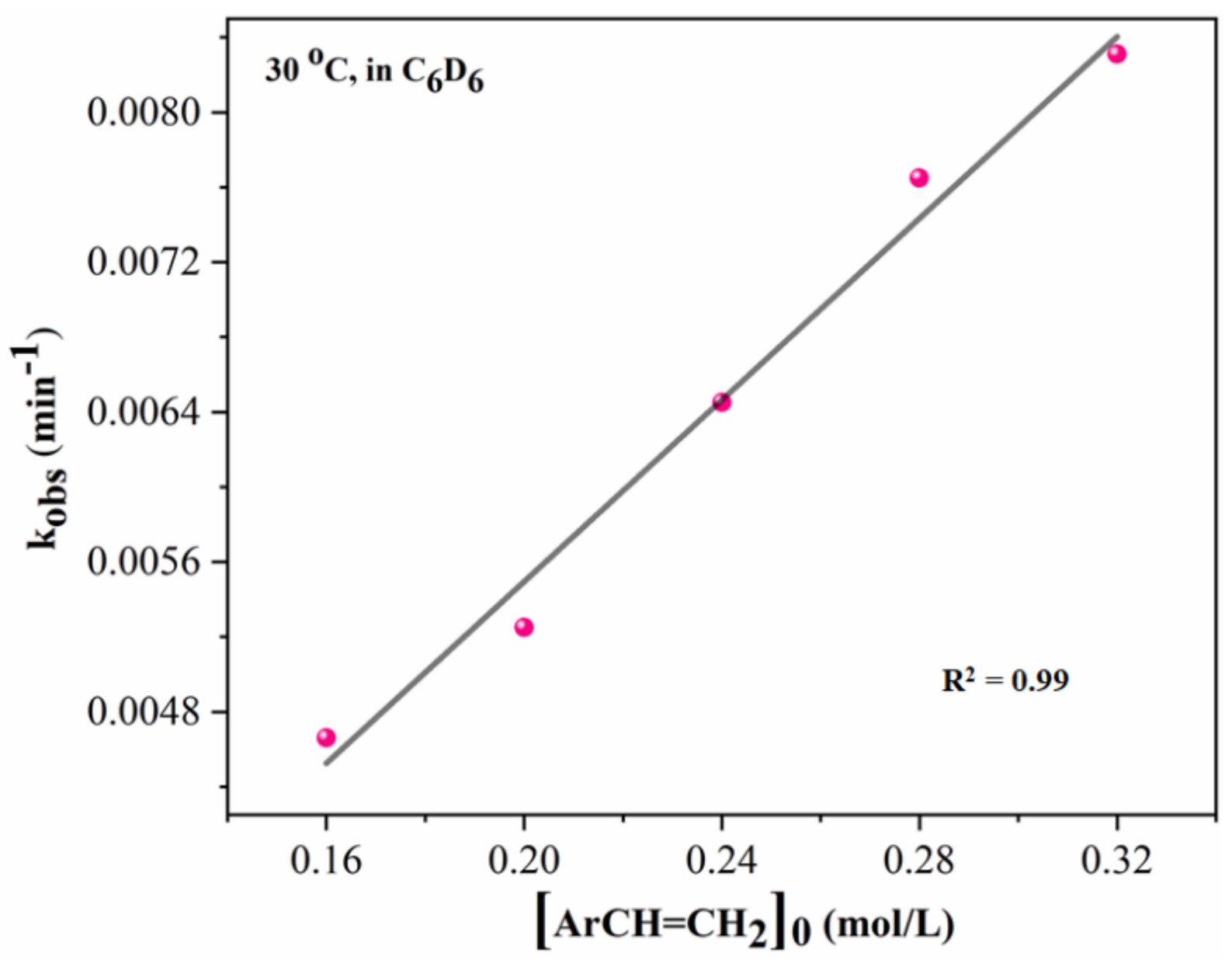

Fig. S47. The linear dependence of the observed pseudo-first-order rate constants, $k_{\mathrm{obs}}$, versus alkene concentration. 


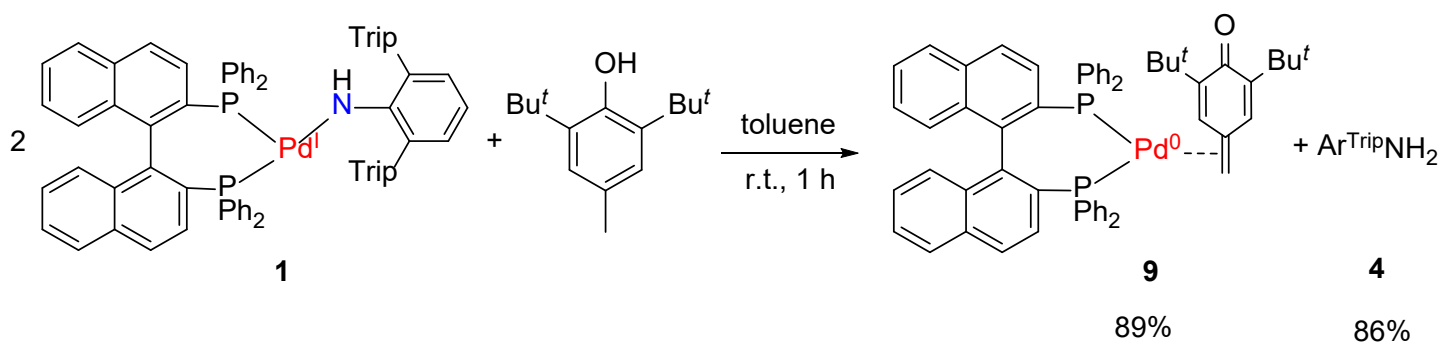

Reaction of 1 with 2,6-di(tert-butyl)-4-methylphenol: To a solution of 1 (200 mg, 0.16 $\mathrm{mmol})$ in toluene $(20 \mathrm{~mL})$ was added 2,6-di(tert-butyl)-4-methylphenol $(18 \mathrm{mg}, 0.08 \mathrm{mmol})$ at room temperature. The color of the solution changed from green to red immediately. After stirring for $1 \mathrm{~h}$, the mixture was concentrated under vacuum to leave a red residue. The resultant red solid was then washed with $n$-hexane $(3 \times 2 \mathrm{~mL})$ and dried under vacuum, which leaves 9 as a red powder $(135 \mathrm{mg}$, $89 \%$ ). Single crystals of 9 suitable for X-ray diffraction were grown from liquid diffusion of $n$-pentane solution of 2,6-di(tert-butyl)-4-methylphenol into a concentrated toluene solution of 1 at $-30{ }^{\circ} \mathrm{C}$ for days. For 9: Anal. Calcd for $\mathrm{C}_{59} \mathrm{H}_{54} \mathrm{P}_{2} \mathrm{PdO}$ : C, 74.80; H, 5.75; Found: C, 74.84; H, 5.81 . Absorption spectrum (THF): $\lambda_{\max }, \mathrm{nm}\left(\varepsilon, \mathrm{M}^{-1} \mathrm{~cm}^{-1}\right)=400$ (5600), 450 (9600). IR (KBr, $\left.\mathrm{cm}^{-1}\right): v=$ 3053 (m), 2949 (m), 2913 (m), 2878 (m), 1602 (s), 1560 (s), 1480 (m), 1435 (s), 1383 (m), 1350 (m), 1308 (m), 1225 (s), 1091 (m), 923 (m), 909 (m), 815 (m), 744 (s), 694 (s), 522 (m), 504 (s), 461 (m). ${ }^{1} \mathrm{H}$ NMR (400 MHz, THF-d8, $\left.298 \mathrm{~K}\right): \delta 7.72$ (t, $\left.J=9.0 \mathrm{~Hz}, 2 \mathrm{H}\right), 7.58-7.44(\mathrm{~m}, 6 \mathrm{H}), 7.42-6.98$ (m, $16 \mathrm{H}), 6.96-6.88(\mathrm{~m}, 2 \mathrm{H}), 6.75-6.69(\mathrm{~m}, 1 \mathrm{H}), 6.68-6.59(\mathrm{~m}, 3 \mathrm{H}), 6.58-6.50(\mathrm{~m}, 2 \mathrm{H}), 6.41-6.32(\mathrm{~m}$, 2H), $2.96(\mathrm{~s}, 1 \mathrm{H}), 2.24(\mathrm{~s}, 1 \mathrm{H}), 1.27$ (d, $J=30.2 \mathrm{~Hz}, 18 \mathrm{H}) .{ }^{13} \mathrm{C}$ NMR (101 MHz, THF- $\left.d_{8}, 298 \mathrm{~K}\right): \delta$ (ppm) 184.35, 184.32, 142.56, 142.53, 141.36, 141.33, 140.42, 140.41, 140.27, 138.25, 137.61, $137.54,137.37,137.33,137.28,137.23,136.43,136.41,136.36,135.81,135.61,135.54,135.50$, $135.47,135.45,134.95,134.78,134.77,134.74,134.70,134.59,134.35,134.23,134.17,134.01$, $133.99,133.83,133.45,133.12,130.42,130.38,130.36,130.20,130.18,130.14,130.04,129.76$, $129.74,129.48,129.16,129.07,128.95,128.93,128.71,128.70,128.63,128.52,128.43,128.36$, $128.23,128.07,127.99,127.89,127.77,127.73,127.66,127.09,127.03,126.98,126.79,126.60$, 126.43, 125.84, 83.86, 83.81, 83.74, 83.69, 54.47, 54.18, 35.44, 35.42, 35.37, 35.35, 29.97, 29.78. ${ }^{31} \mathrm{P}$ NMR (162 MHz, THF-d8, $\left.298 \mathrm{~K}\right): \delta$ (ppm) 32.03 (d, $\left.J=9.9 \mathrm{~Hz}\right), 29.41$ (d, $\left.J=10.0 \mathrm{~Hz}\right)$. The $n$-hexane solutions were combined and concentrated under vacuum to leave a residue that was further purified by flash column chromatography (silica gel, $n$-hexane as elute) to give $\mathbf{4}$ as white solid (70 mg, 86\%). 


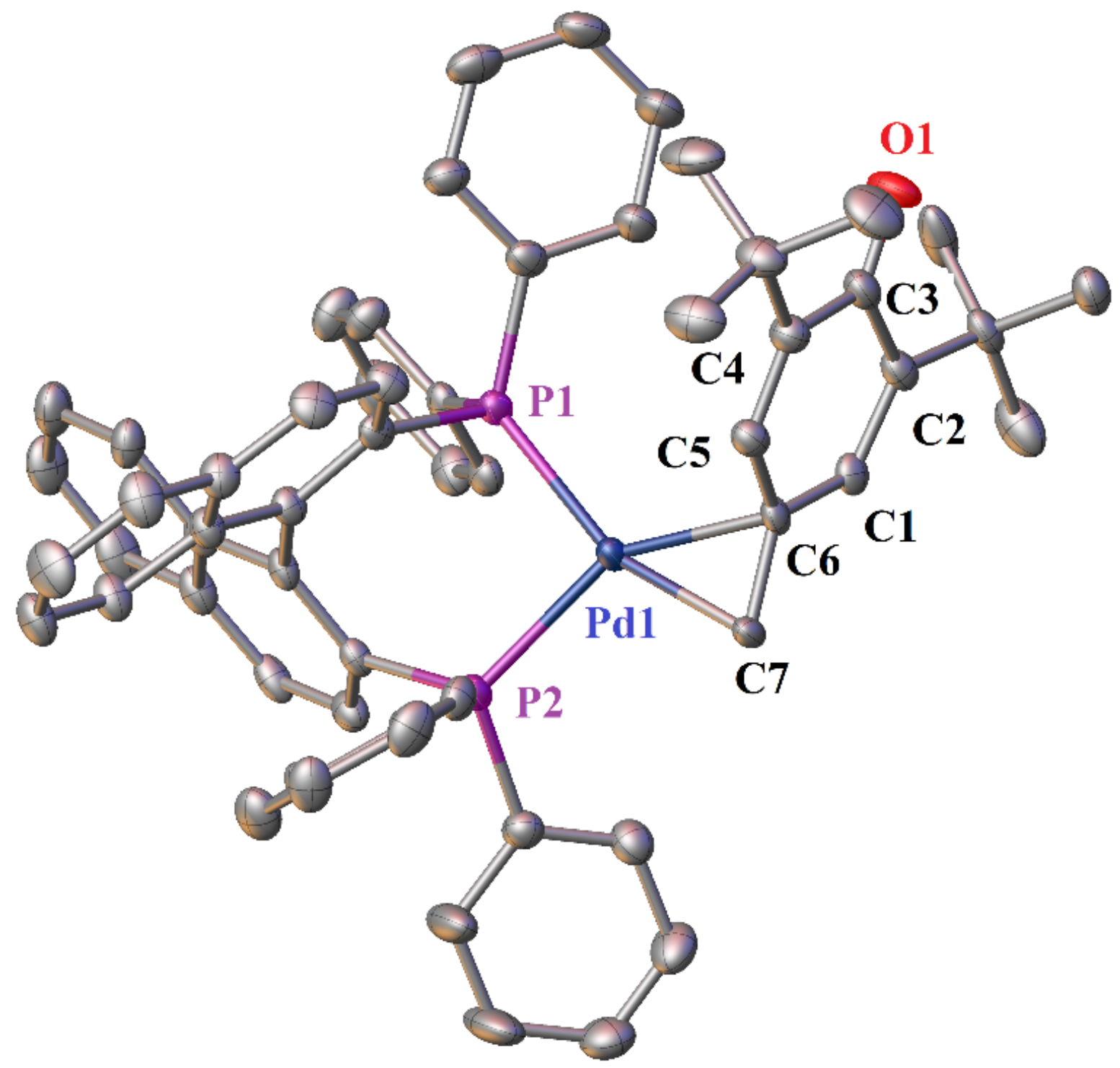

Fig. S48. Molecular structure of 9a, showing one of the two crystallographically independent molecules in the unit cell with $30 \%$ probability ellipsoids and the partial atoms numbering scheme. Selected distances $(\AA)$ and angles (deg): Pd1-C7 2.111(5), Pd1-C6 2.199(6), Pd1-P1 2.3174(13), Pd1-P2 2.3202(14), O1-C3 1.247(6), C1-C2 1.363(7), C1-C6 1.445(7), C3-C2 1.500(7), C3-C4 1.471(7), C4-C5 1.332(7), C5-C6 1.437(7), C7-C6 1.421(7), C7-Pd1-C6 38.43(18), C7-Pd1-P1 156.71(14), C7-Pd1-P2 105.74(13), P1-Pd1-C6 119.31(13), P1-Pd1-P2 94.83(5), P2-Pd1-C6 $143.55(13)$. 


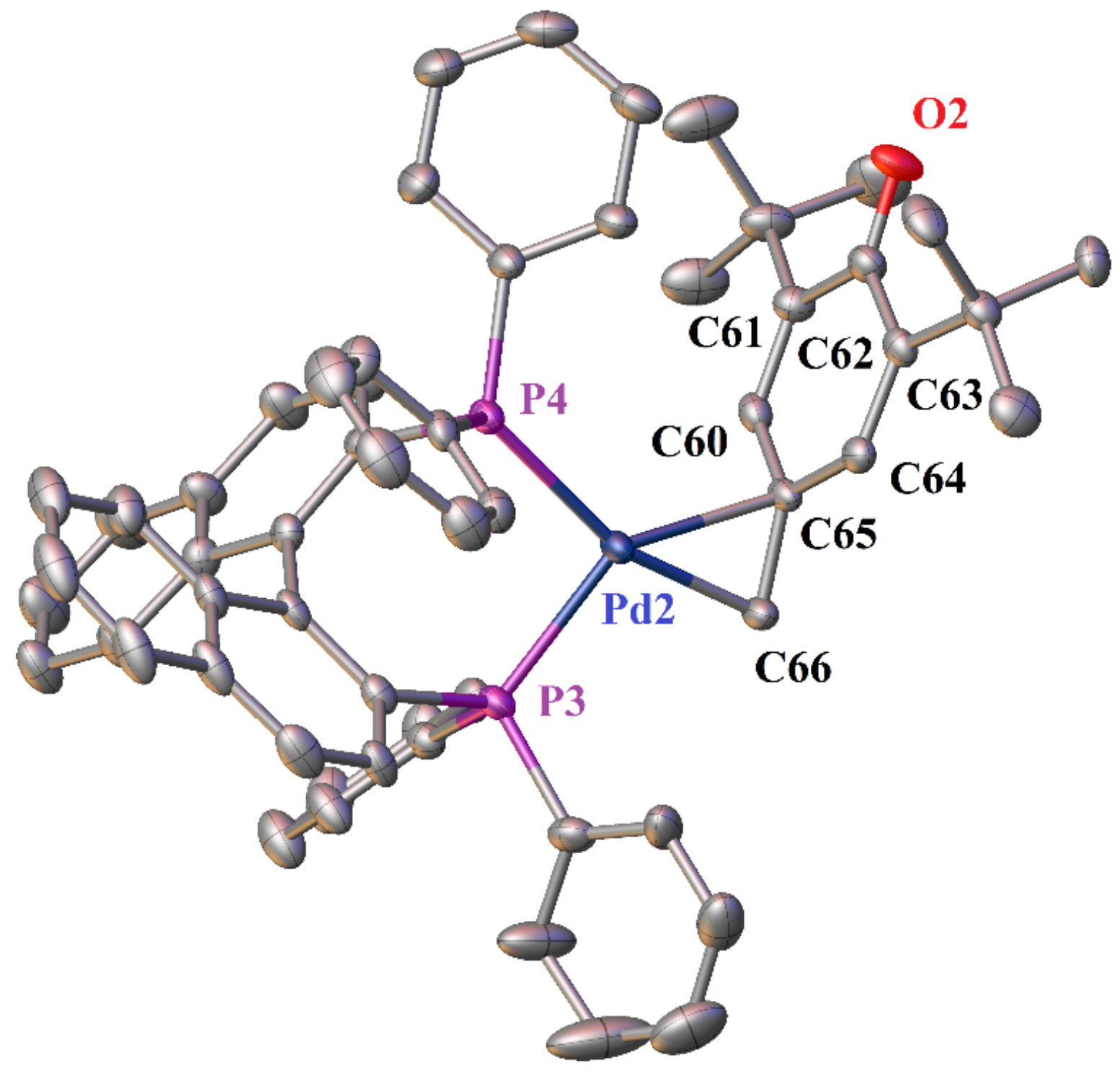

Fig. S49. Molecular structure of 9b, showing another one of the two crystallographically independent molecules in the unit cell with $30 \%$ probability ellipsoids and the partial atoms numbering scheme. Selected distances ( $\AA$ ) and angles (deg): Pd2-C66 2.108(5), Pd2-C65 2.214(6), Pd2-P3 2.3053(14), Pd2-P4 2.3164(13), O2-C62 1.238(6), C60-C61 1.361(7), C61-C62 1.467(7), C62-C63 1.488(7), C63-C64 1.343(7), C64-C65 1.430(7), C65-C66 1.434(7), C66-Pd2-C65 38.66(17), C66-Pd2-P3 102.13(13), C66-Pd2-P4 160.67(14), P3-Pd2-C65 140.62(13), P3-Pd2-P4 95.93(5), P4-Pd2-C65 122.59(13). 


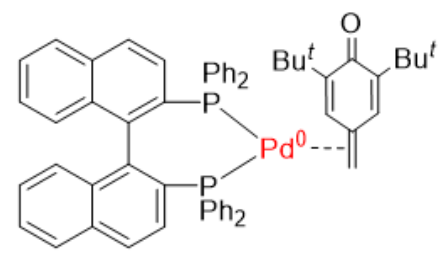

${ }^{1} \mathrm{H}$ NMR $\left(400 \mathrm{MHz}, \mathrm{THF}-d_{8}, 298 \mathrm{~K}\right)$

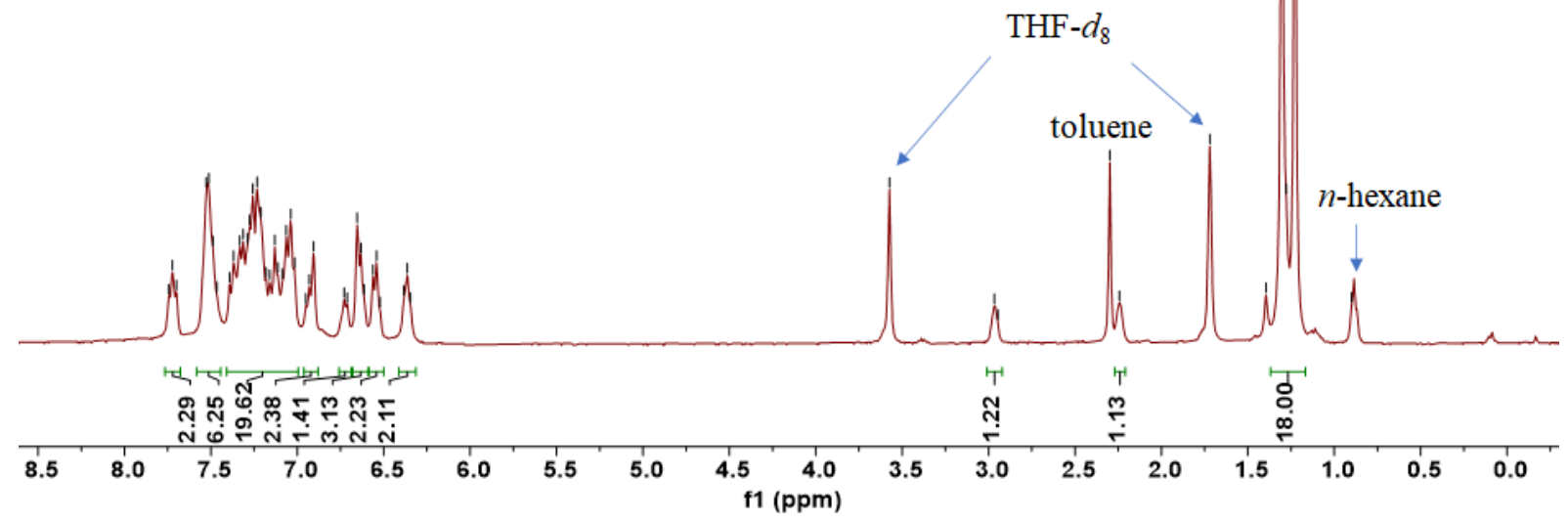

Fig. S50. ${ }^{1} \mathrm{H}$ NMR spectrum of 9. 


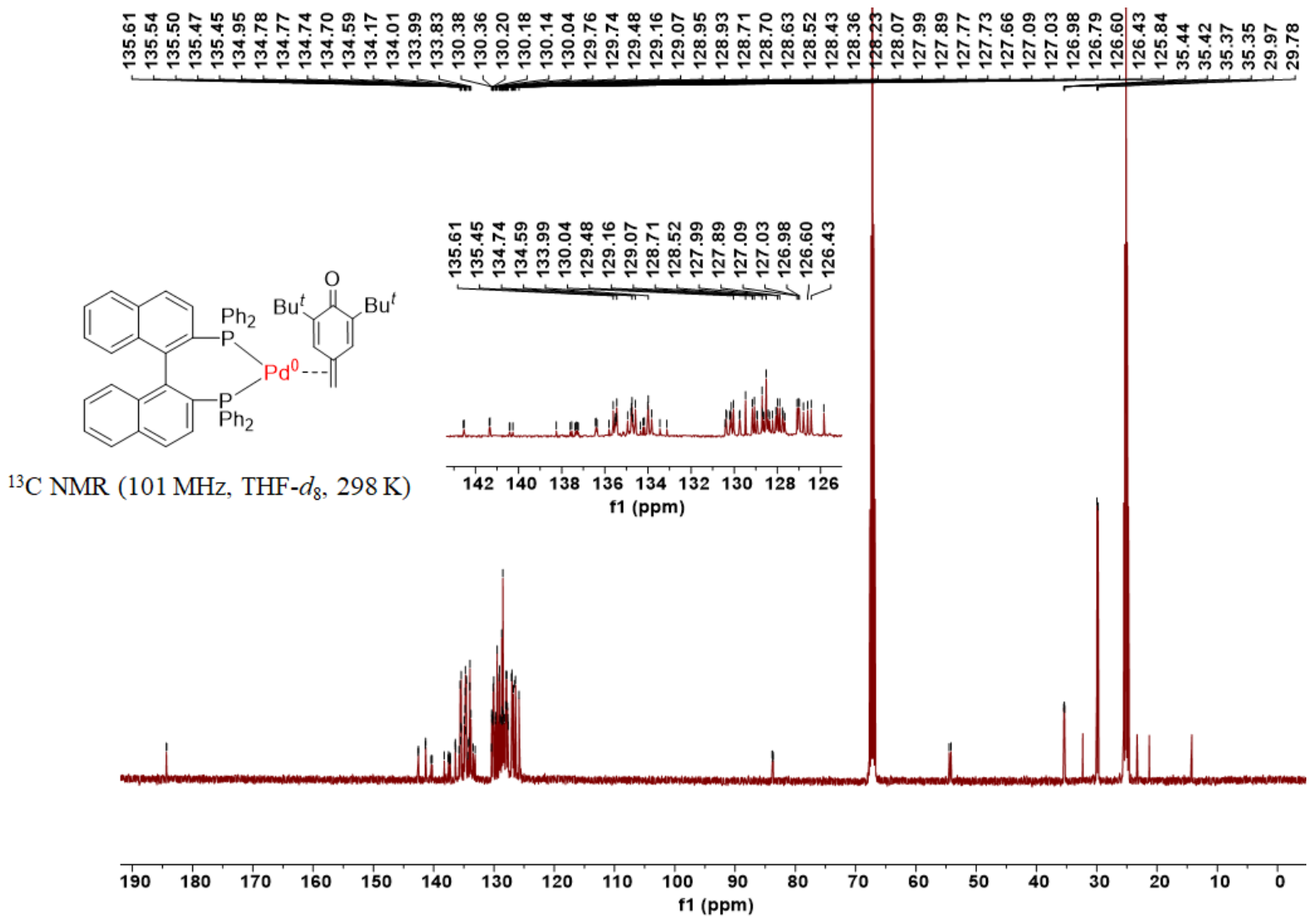

Fig. S51. ${ }^{13} \mathrm{C}$ NMR spectrum of 9. (Inset: expanded region of ${ }^{13} \mathrm{C}$ NMR spectrum of 9 from 142 to $126 \mathrm{ppm})$ 


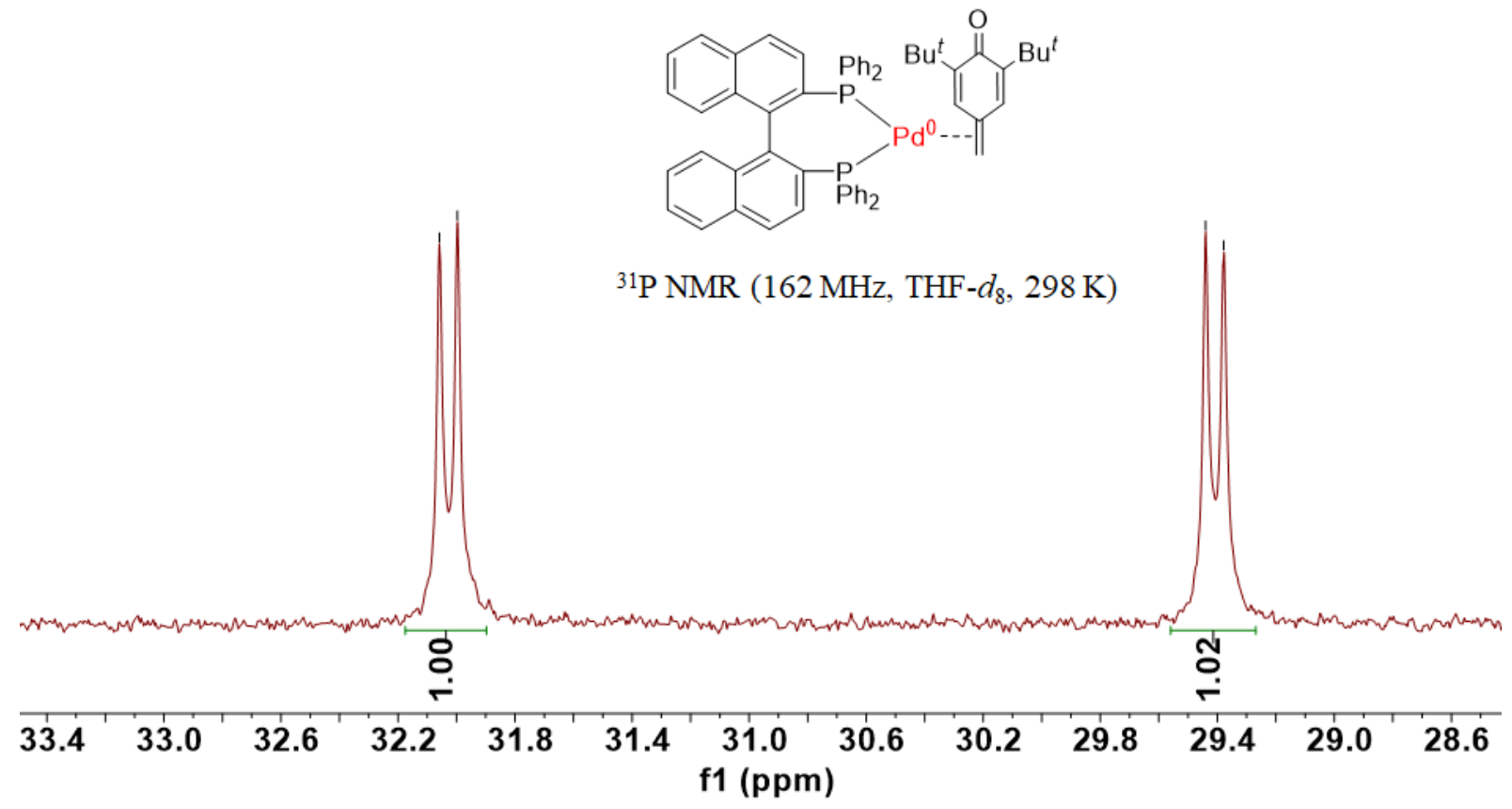

Fig. S52. ${ }^{31} \mathrm{P}$ NMR spectrum of 9 . 


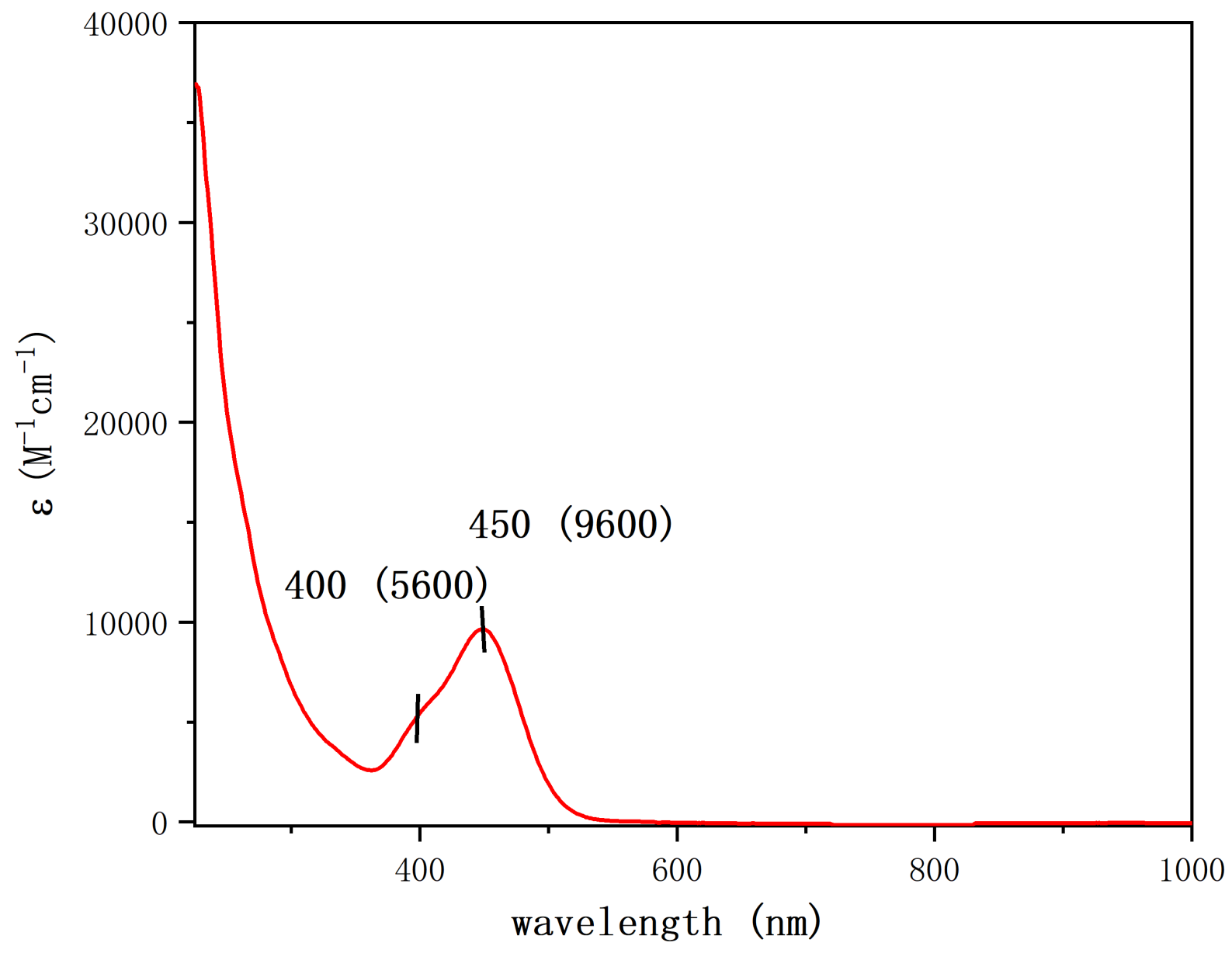

Fig. S53. UV-vis absorption spectrum in THF of 9 recorded at room temperature. 


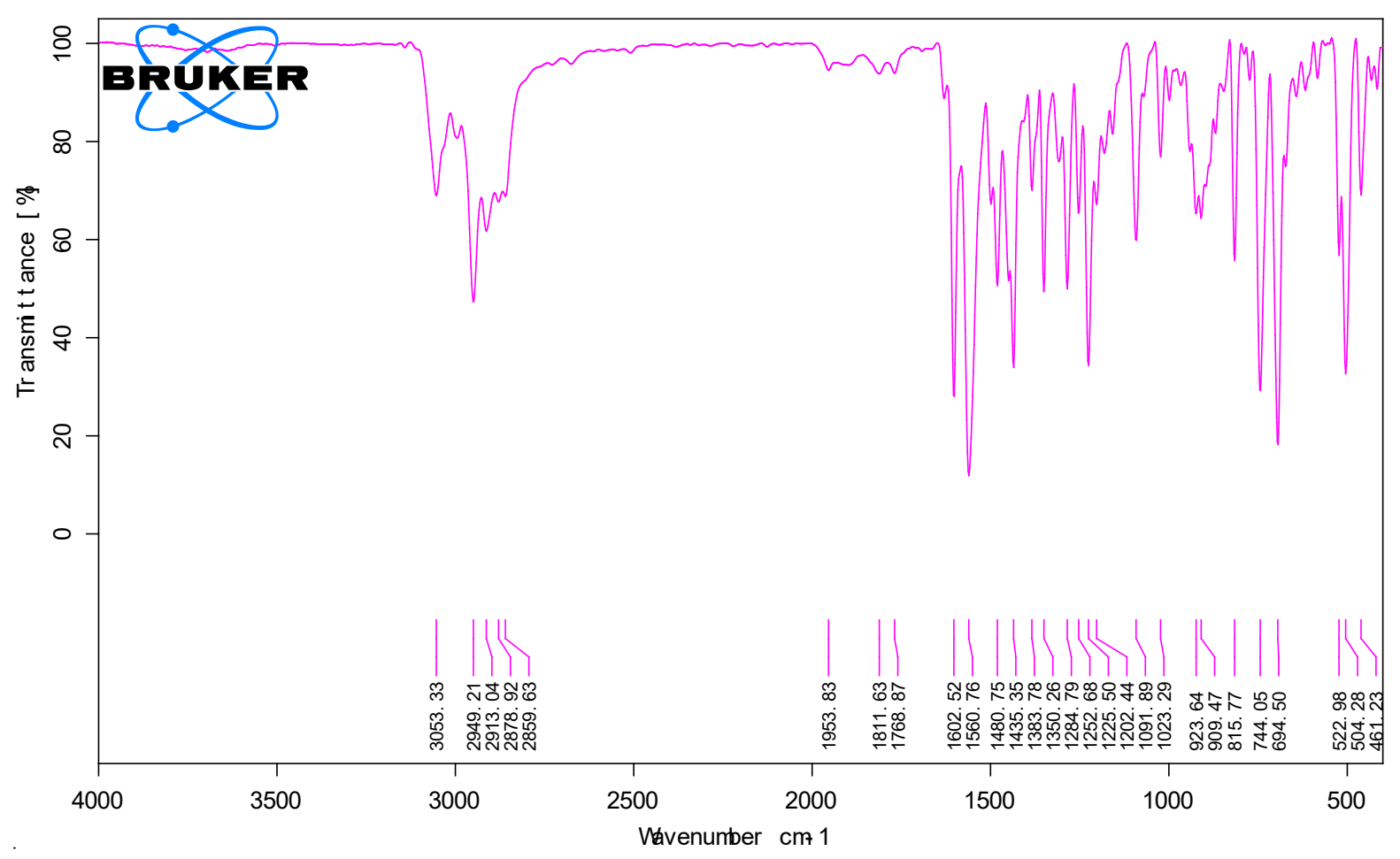

Fig. S54. IR spectrum of 9. 

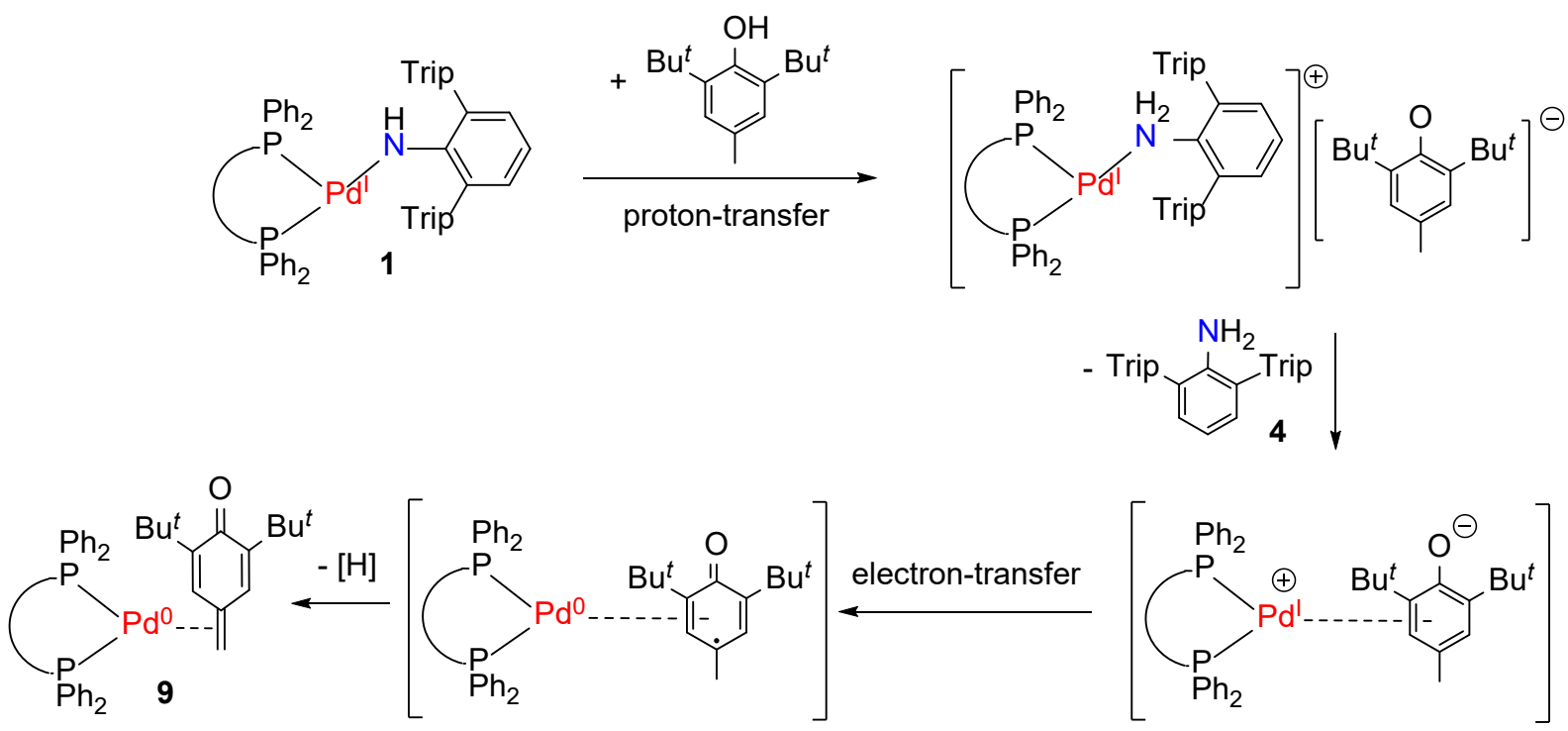

Fig. S55. A probable mechanism for the reaction of 1 with 2,6-di(tert-butyl)-4-methylphenol. 


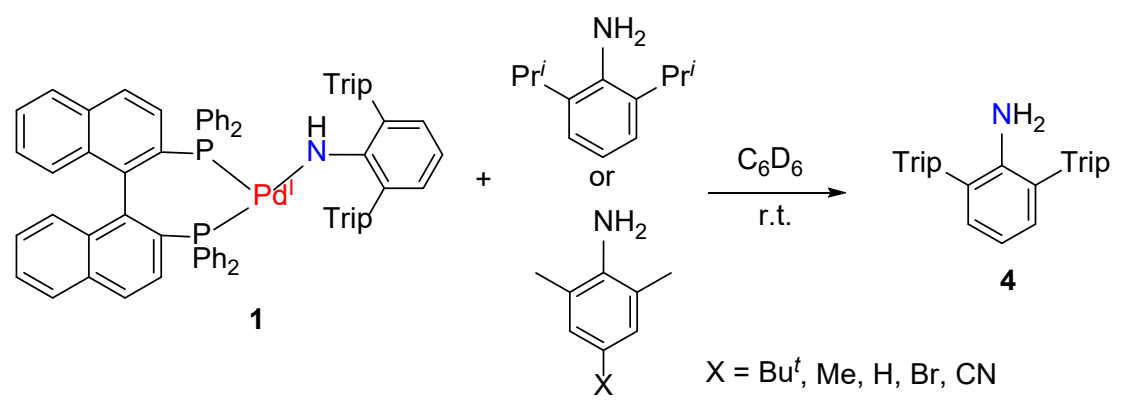

Reactions of 1 with Anilines. The interaction of 1 with primary anilines, e.g. 2,6-di(isopropyl)aniline and para-substituted 2,6-dimethylanilines, in $\mathrm{C}_{6} \mathrm{D}_{6}$ led to the production of the free amine $\mathrm{Ar}^{\mathrm{Trip}} \mathrm{NH}_{2}$ (4) as indicated by ${ }^{1} \mathrm{H}$ NMR spectrum (Figs. S56-S61). These reactions were conducted with general procedure as follows: To a J-Young tube were added 1, 1,3,5-trimethoxybenzene and anilines. Then the reaction mixture was diluted with $\mathrm{C}_{6} \mathrm{D}_{6}$ to $500 \mu \mathrm{L}$. The reactions produced 4 instantly as indicated by the observation of its characteristic ${ }^{1} \mathrm{H}$ NMR signals in the range 3.08 to $2.99 \mathrm{ppm}$. Aiming to probe the outcome of the anilines and palladium species, the reaction of 2,6-dimethylanilines $(4.3 \mathrm{mg}, 0.0035 \mathrm{mmol})$ with 1 (43.5 $\mathrm{mg}, 0.035 \mathrm{mmol})$ was examined in detail. When the production of 4 stopped in $1 \mathrm{~h}$, analyzing the ${ }^{31} \mathrm{P}$ NMR spectrum with $\mathrm{OPPh}_{3}(4.5 \mathrm{mg}, 0.016 \mathrm{mmol})$ as an internal standard indicated the formation of diamagnetic phosphine-containing species in $71 \%$ yield (Fig. S62.). The exact identity of the phosphine-palladium species is unclear. The reaction mixture is quenched with a drop of water, analyzing the ${ }^{1} \mathrm{H}$ NMR spectrum with 1,3,5-trimethoxybenzene $\left(0.10 \mathrm{M}\right.$ in $\left.\mathrm{C}_{6} \mathrm{D}_{6}, 100 \mu \mathrm{L}\right)$ as an internal standard indicated the formation of 2,6-dimethylaniline in 93\% yield (Fig. S63.). 


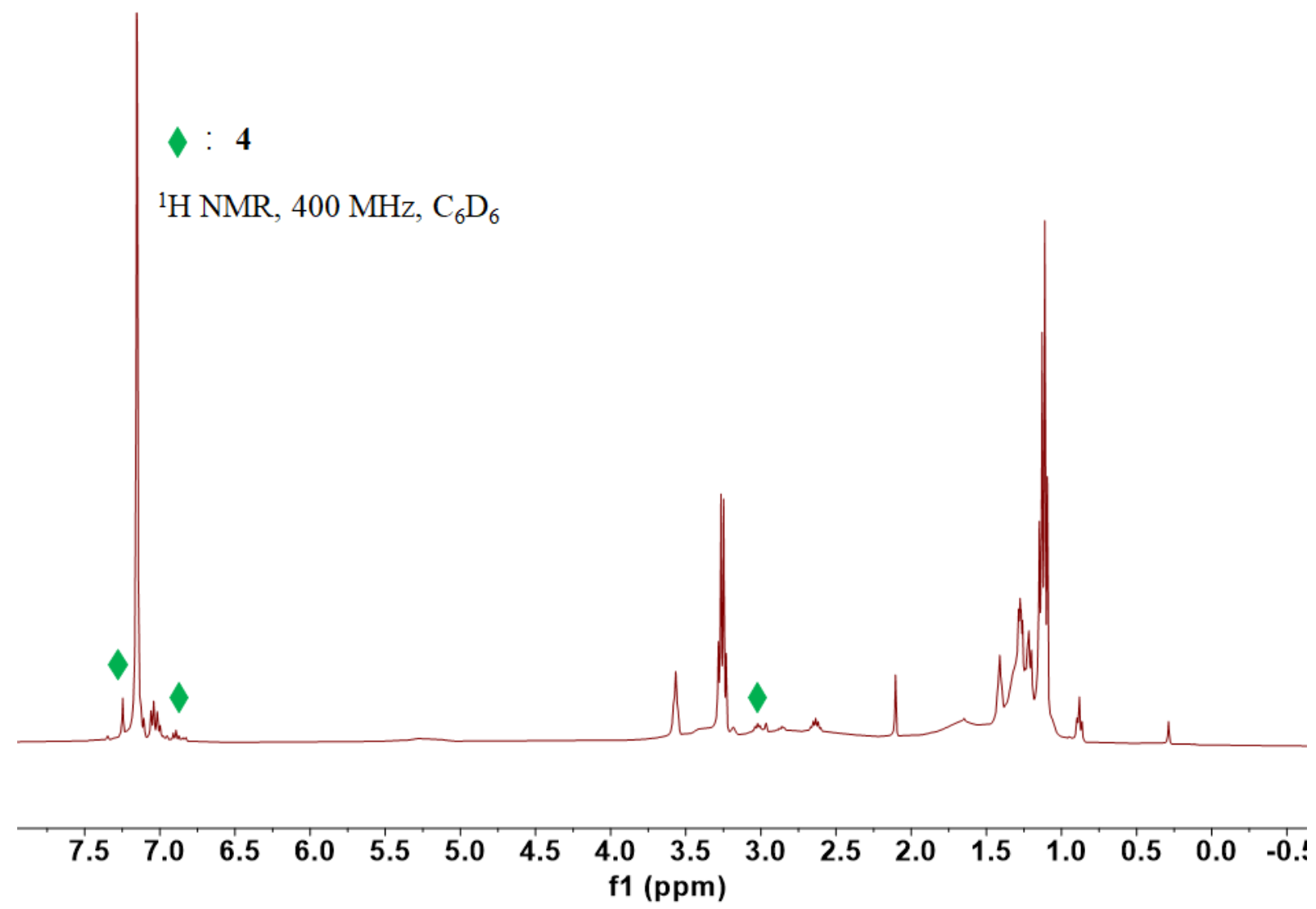

Fig. S56. The ${ }^{1} \mathrm{H}$ NMR spectrum of the mixture of the reaction of 1 with one equiv. of 2,6-di(isopropyl)aniline in $1 \mathrm{~h}$. 


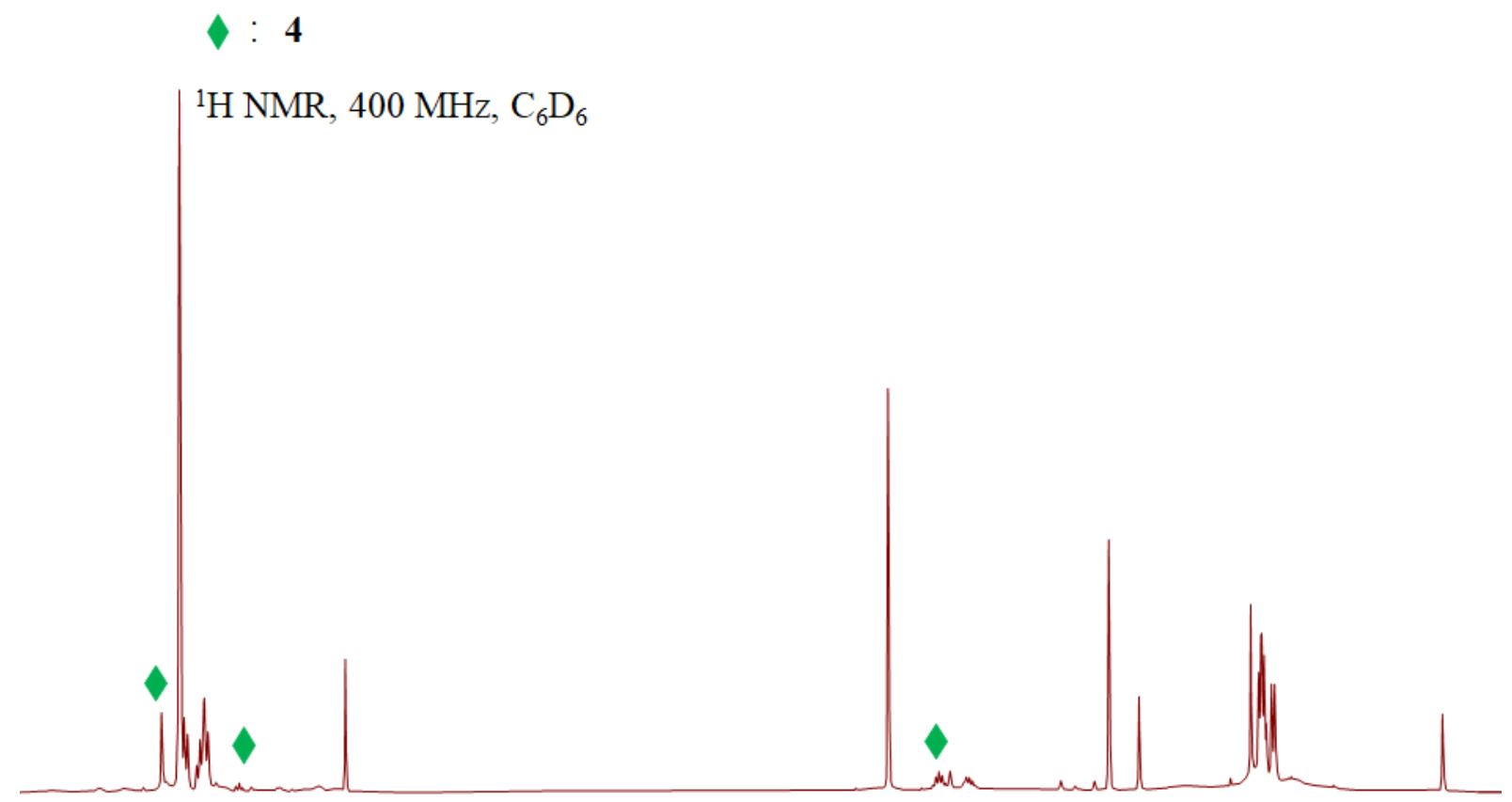

\begin{tabular}{llllllllllllllllll}
\hline .0 & 7.5 & 7.0 & 6.5 & 6.0 & 5.5 & 5.0 & 4.5 & $\begin{array}{l}4.0 \\
\mathrm{f} 1 \mathrm{(ppm})\end{array}$ & 3.5 & 3.0 & 2.5 & 2.0 & 1.5 & 1.0 & 0.5 & 0.
\end{tabular}

Fig. S57. The ${ }^{1} \mathrm{H}$ NMR spectrum of the mixture of the reaction of 1 with one equiv. of 4-(tert-butyl)-2,6-dimethylaniline in $1 \mathrm{~h}$. 

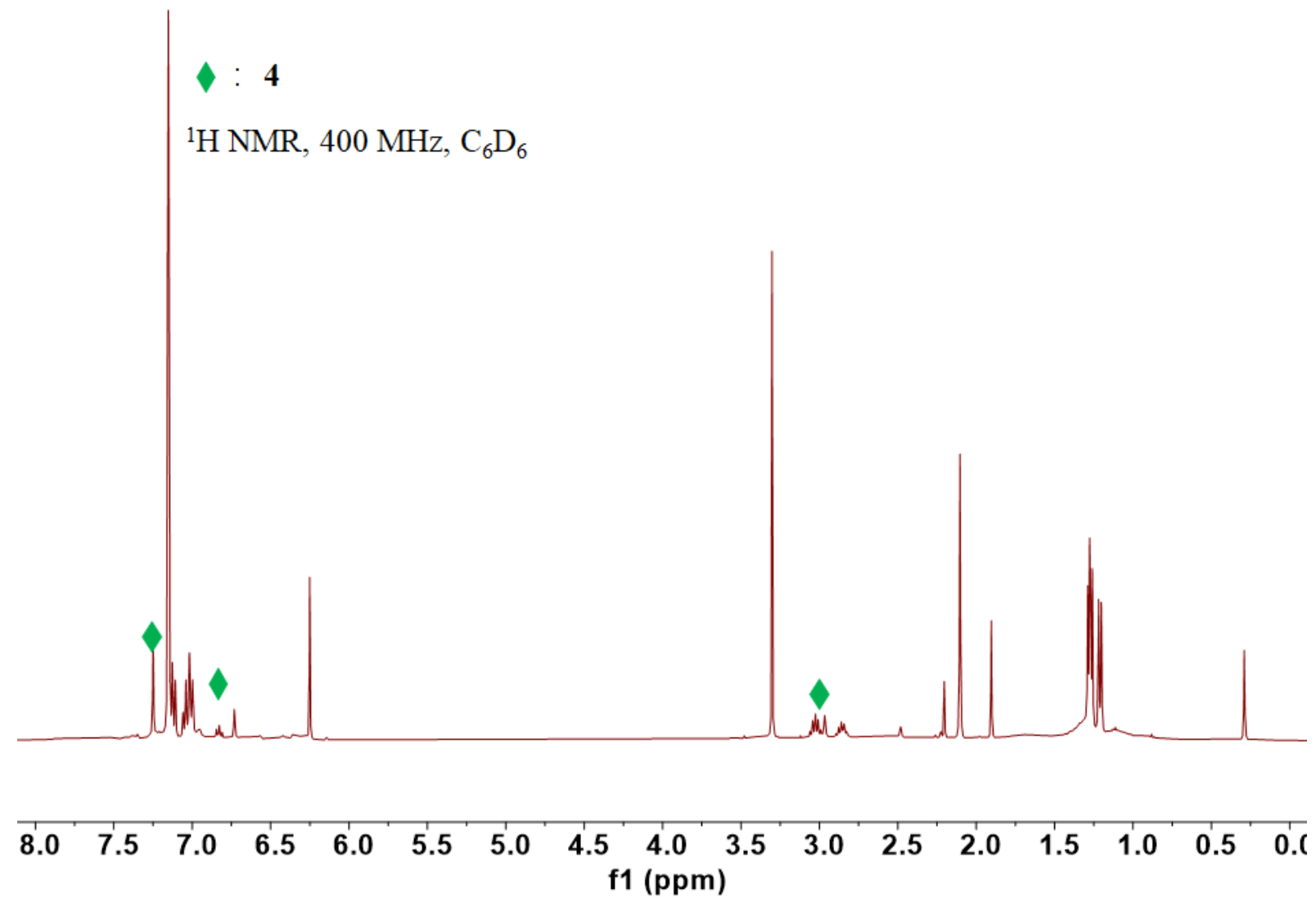

Fig. S58. The ${ }^{1} \mathrm{H}$ NMR spectrum of the mixture of the reaction of 1 with one equiv. of 2,4,6-trimethylaniline in $1 \mathrm{~h}$. 


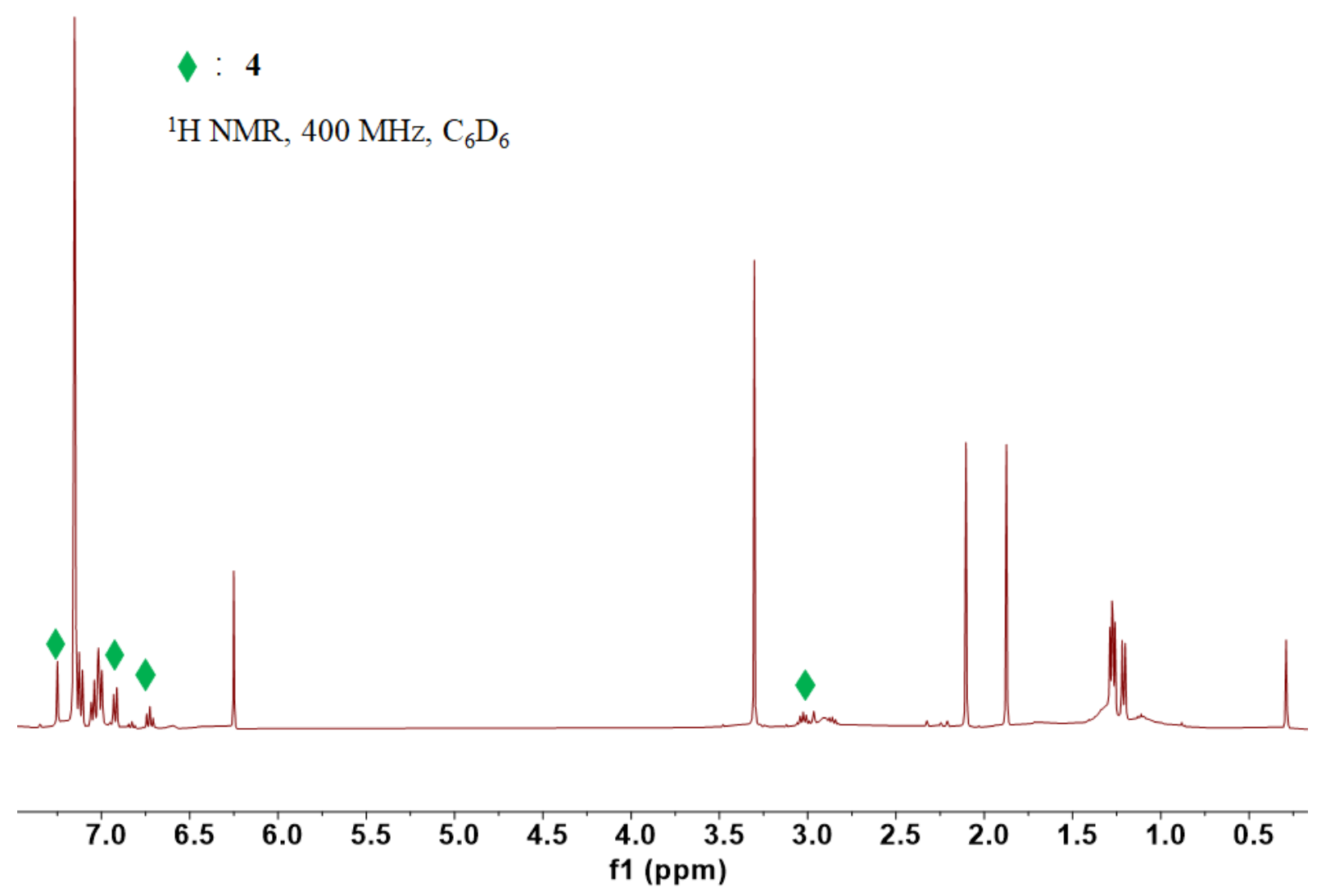

Fig. S59. The ${ }^{1} \mathrm{H}$ NMR spectrum of the mixture of the reaction of 1 with one equiv. of 2,6-dimethylaniline in $1 \mathrm{~h}$. 

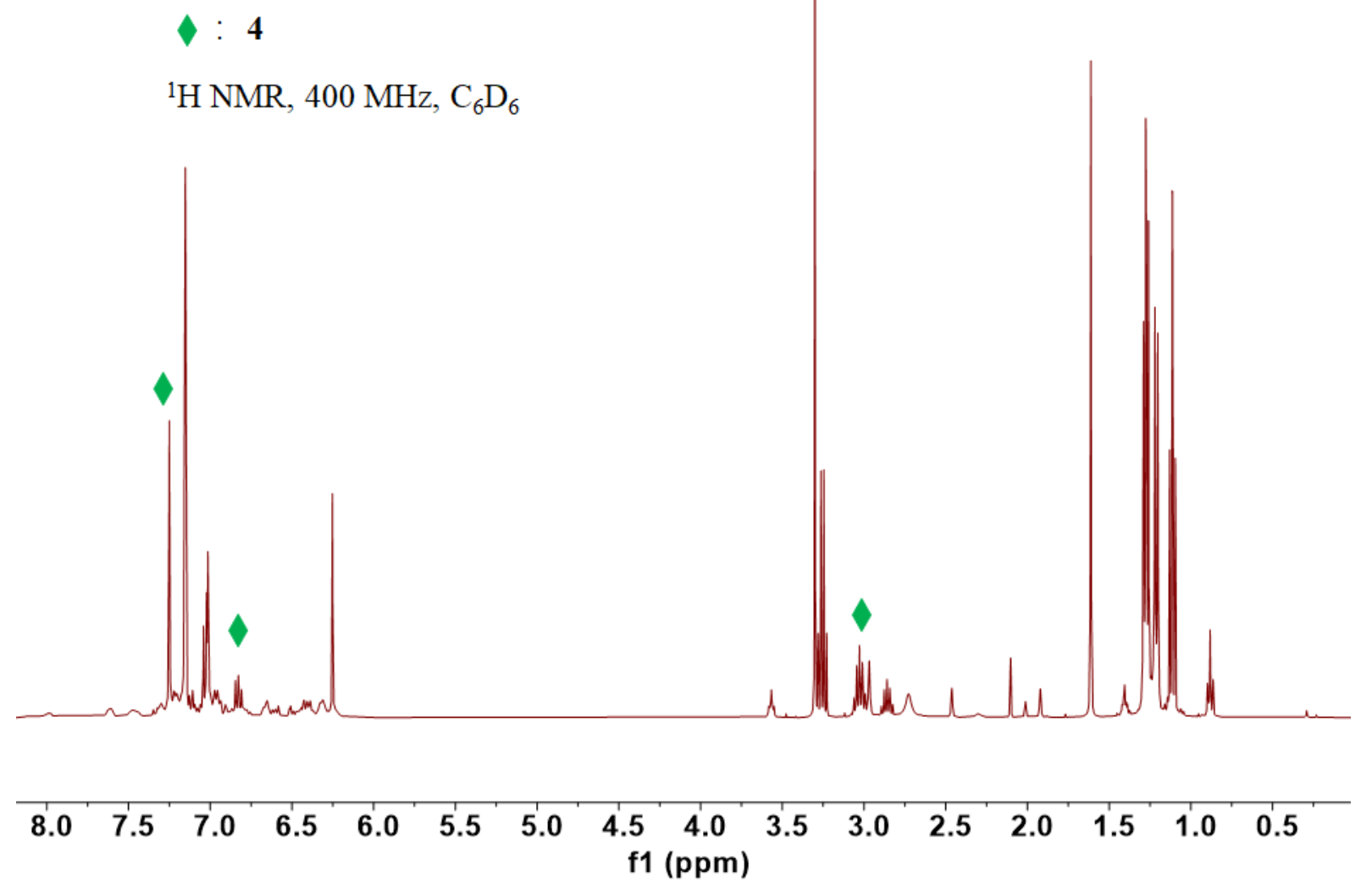

Fig. S60. The ${ }^{1} \mathrm{H}$ NMR spectrum of the mixture of the reaction of 1 with one equiv. of 4-bromo-2,6-dimethylaniline in $1 \mathrm{~h}$. 

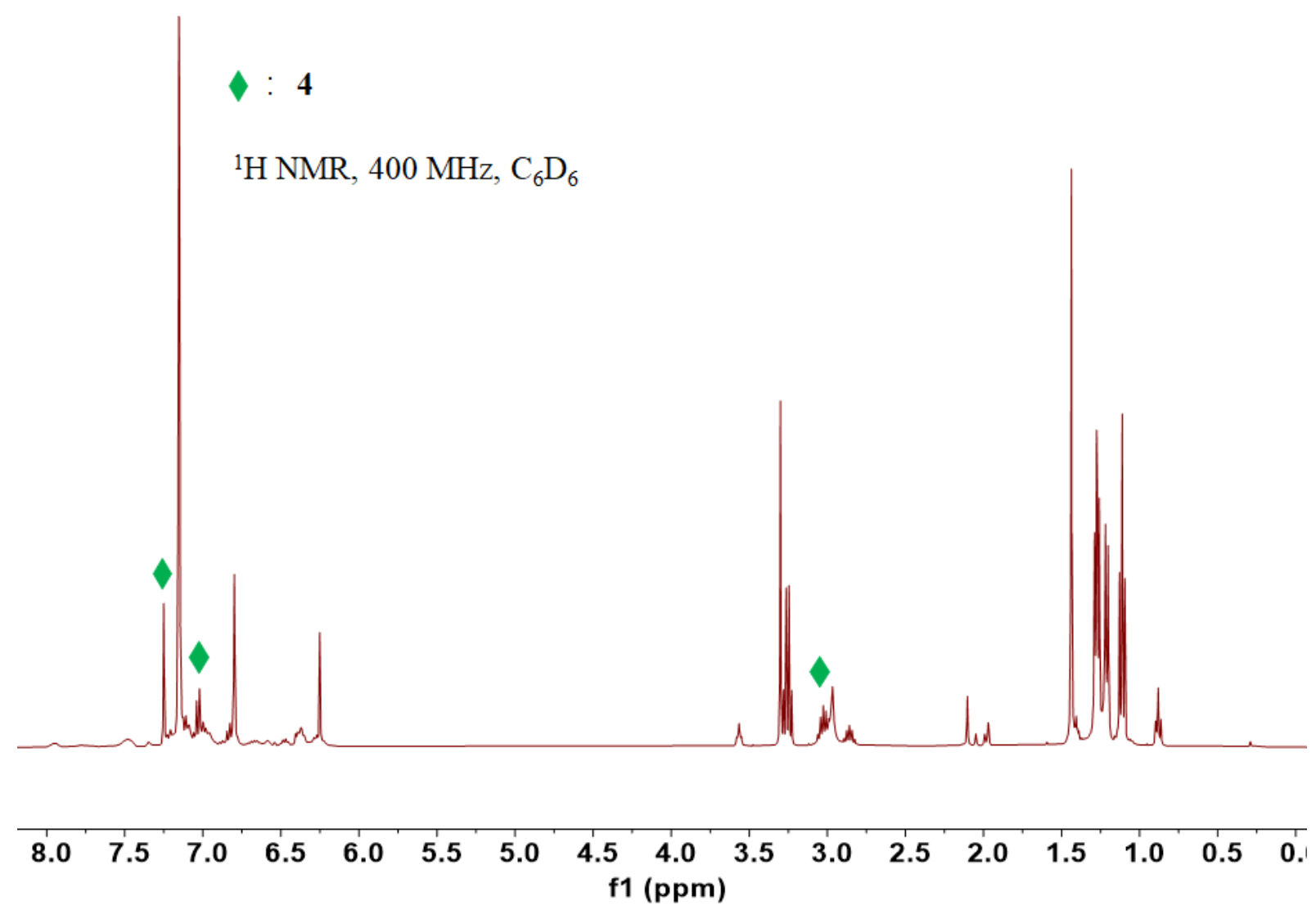

Fig. S61. The ${ }^{1} \mathrm{H}$ NMR spectrum of the mixture of the reaction of 1 with one equiv. of 4-amino-3,5-dimethylbenzonitrile in $1 \mathrm{~h}$. 


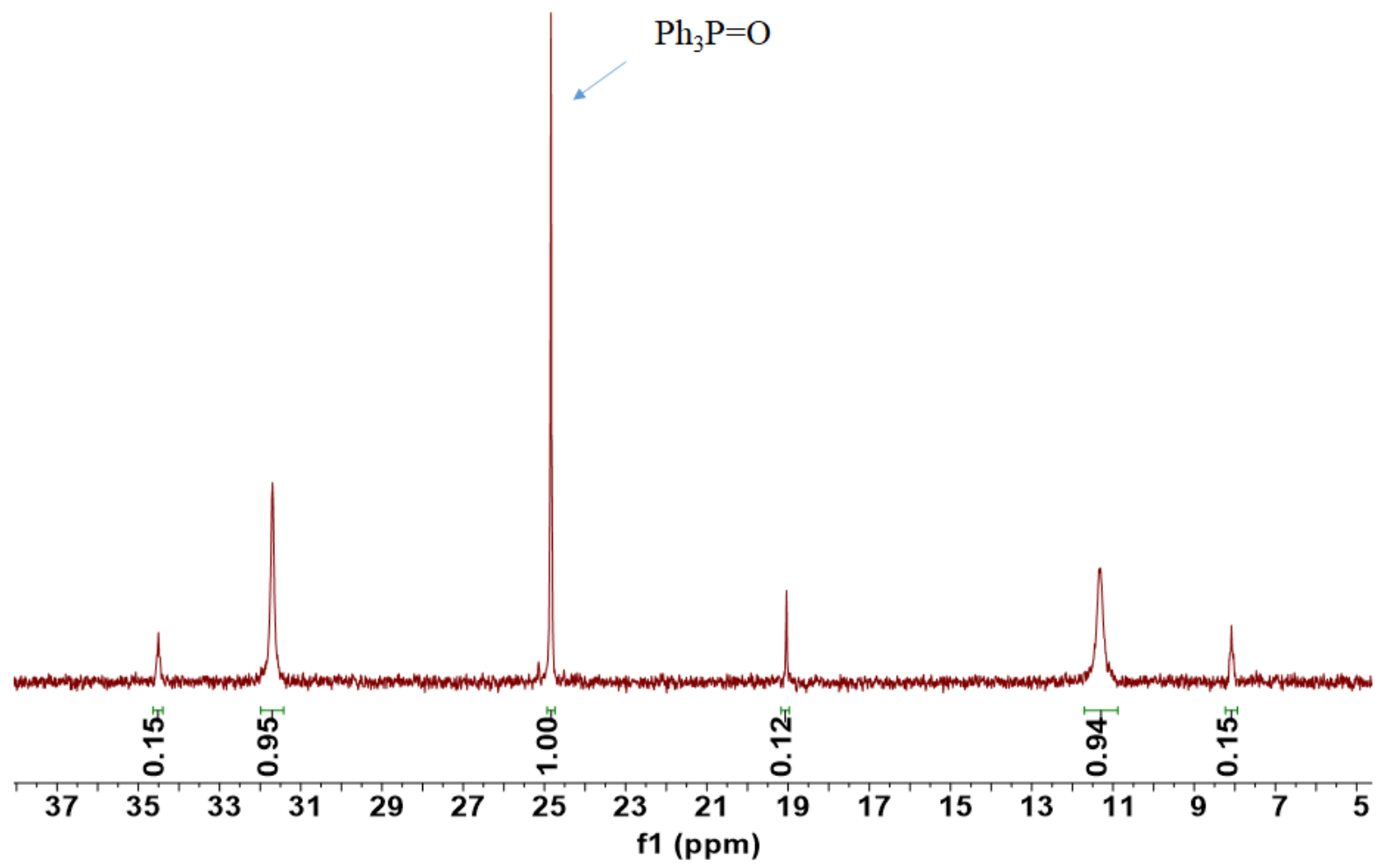

Fig. S62. The ${ }^{31} \mathrm{P}$ NMR spectrum of the mixture of the reaction of $\mathbf{1}$ with one equiv. of 2,6-dimethylaniline. The spectrum indicates the total yield of diamagnetic phosphine-containing species reaches $71 \%$. 


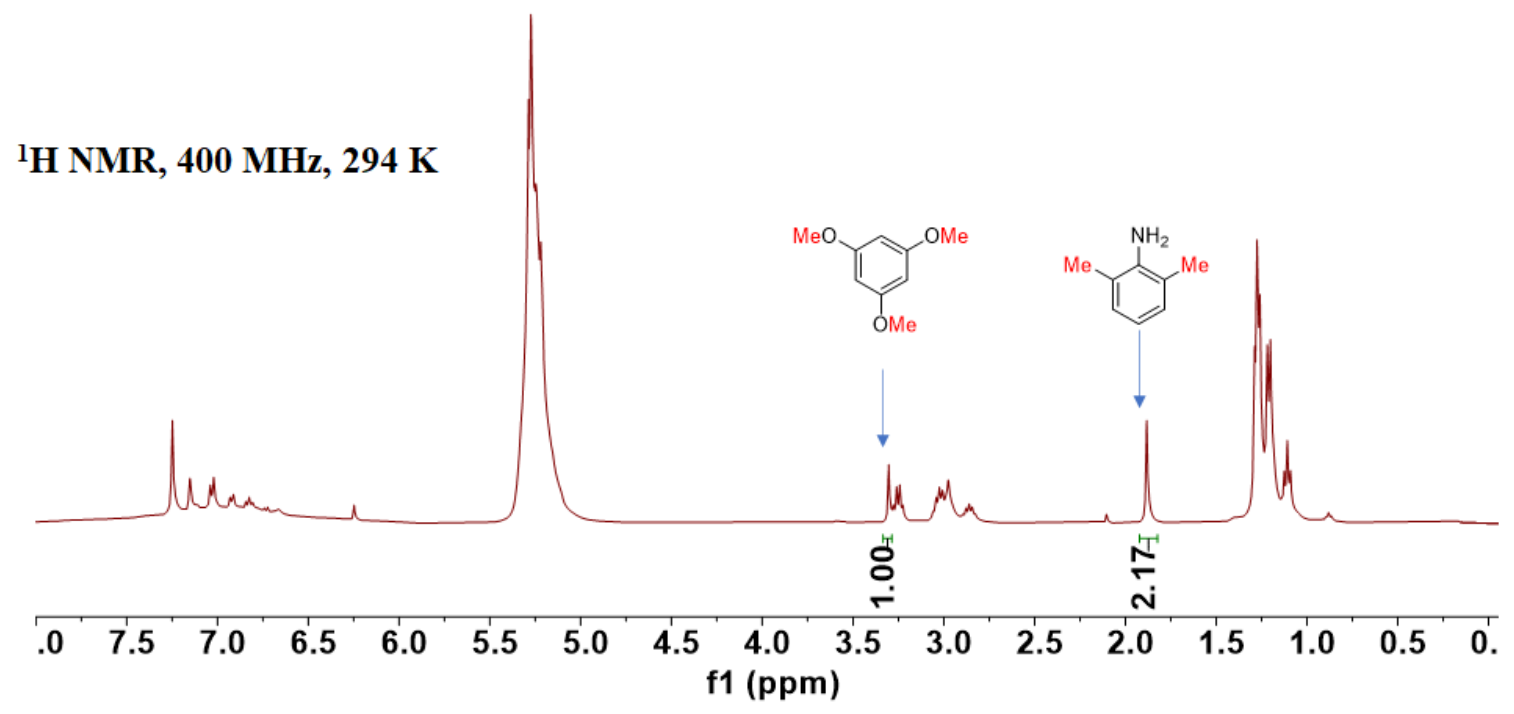

Fig. S63. The ${ }^{1} H$ NMR spectrum of the mixture of the reaction of 1 with one equiv. of 2,6-dimethylaniline after quenched with water. The spectrum clearly shows the regeneration of 2,6-dimethylaniline. 
Isotope Kinetic Effect of the Reactions 1 with 2,6-dimethylaniline and $\boldsymbol{N}, \boldsymbol{N}$ '-dideuterium-2,6-dimethylaniline. To a J-Young tube were added $\mathbf{1}$ (35 mg, $0.028 \mathrm{mmol}$ ), 1,3,5-trimethoxybenzene $\left(0.10 \mathrm{M}\right.$ in $\left.\mathrm{C}_{6} \mathrm{D}_{6}, 60 \mu \mathrm{L}\right), 2,6$-dimethylaniline $(3.5 \mathrm{mg}, 0.028 \mathrm{mmol})$ or $N, N$ '-dideuterium-2,6-dimethylaniline $(3.5 \mathrm{mg}, 0.028 \mathrm{mmol})$. Then the reaction mixture was diluted with $\mathrm{C}_{6} \mathrm{D}_{6}$ to $500 \mu \mathrm{L}$. Monitoring the increase of the ${ }^{1} \mathrm{H}$ NMR signal of 4 at $\delta=3.08-2.99 \mathrm{ppm}$ versus time gave the kinetic profile shown in Fig. 5.

Substituent Effects of the Reactions of 1 with para-substituted 2,6-dimethylanilines. The study was conducted with general procedure as follows: To a J-Young tube were added 1 (35 mg, $0.028 \mathrm{mmol})$, 1,3,5-trimethoxybenzene $\left(0.10 \mathrm{M}\right.$ in $\left.\mathrm{C}_{6} \mathrm{D}_{6}, 60 \mu \mathrm{L}\right)$, and a para-substituted 2,6-dimethylaniline $\left(0.10 \mathrm{M}\right.$ in $\left.\mathrm{C}_{6} \mathrm{D}_{6}, 280 \mu \mathrm{L}\right)$. Then the reaction mixture was diluted with $\mathrm{C}_{6} \mathrm{D}_{6}$ to $500 \mu \mathrm{L}$. The yields of 4 versus time was followed by the increase of the ${ }^{1} \mathrm{H}$ NMR signal at $\delta=$ 3.08-2.99 ppm. The initial rates in the first 10 minutes were used (Fig. S64). The Hammett plot with para-substituted 2,6-dimethylanilines is shown in Fig. 5. 


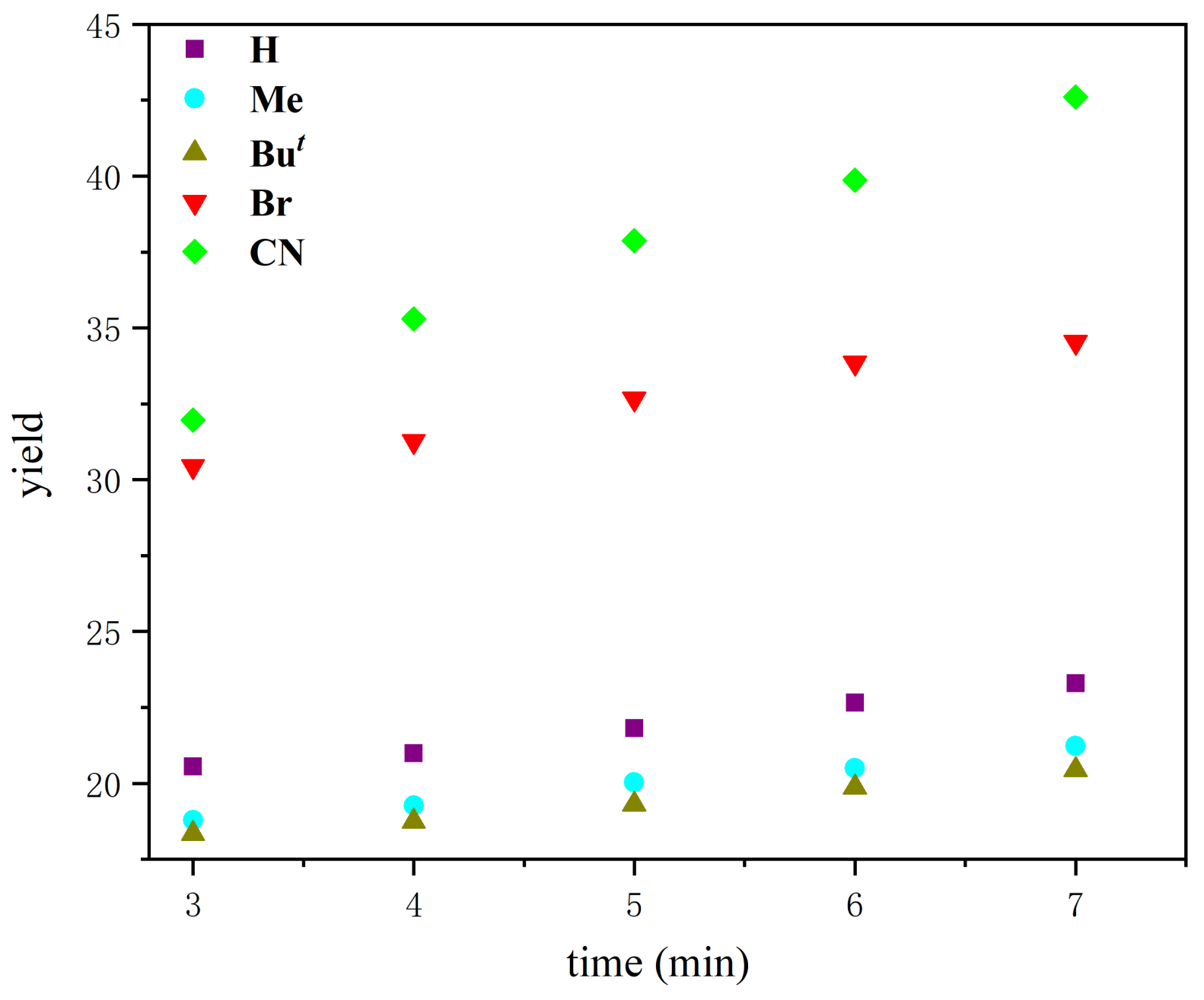

Fig. S64. The plot of the yields of $\mathbf{4}$ vs time in the reactions of $\mathbf{1}$ with different anilines. 
Reactions of 1 with $\boldsymbol{n}$-butyl amine and $\boldsymbol{n}$-octyl amine. These reactions were conducted with general procedure as follows: To a J-Young tube were added 1 (50 mg, $0.04 \mathrm{mmol}$ ), 1,3,5-trimethoxybenzene $(2.8 \mathrm{mg}, 0.02 \mathrm{mmol})$ and $n$-butyl amine $(3 \mathrm{mg}, 0.04 \mathrm{mmol})$. The production of 4 stopped in $1 \mathrm{~h}$, and the ${ }^{1} \mathrm{H}$ NMR yield of 4 reached 94\%. The other J-Young tube were added 1 (50 mg, $0.04 \mathrm{mmol}), 1,3,5$-trimethoxybenzene (3.2 $\mathrm{mg}, 0.02 \mathrm{mmol})$ and $n$-octyl amine (5.3 $\mathrm{mg}, 0.04$ mmol). The production of 4 stopped in $1 \mathrm{~h}$, and the ${ }^{1} \mathrm{H}$ NMR yield of 4 is found to be $91 \%$. 
${ }^{1} \mathrm{H}$ NMR, $\mathrm{C}_{6} \mathrm{D}_{6}, 400 \mathrm{MHz}$

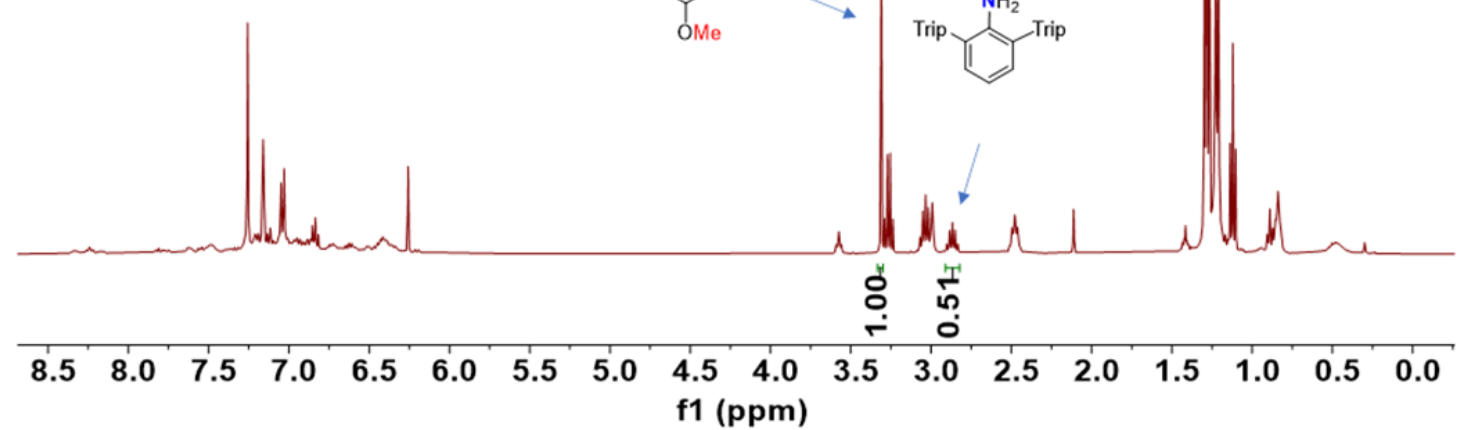

Fig. S65. The ${ }^{1} \mathrm{H}$ NMR spectrum of the mixture of the reaction of 1 with one equiv. of $n$-butyl amine in $1 \mathrm{~h}$. 
${ }^{1} \mathrm{H}$ NMR, $\mathrm{C}_{6} \mathrm{D}_{6}, 400 \mathrm{MHz}$

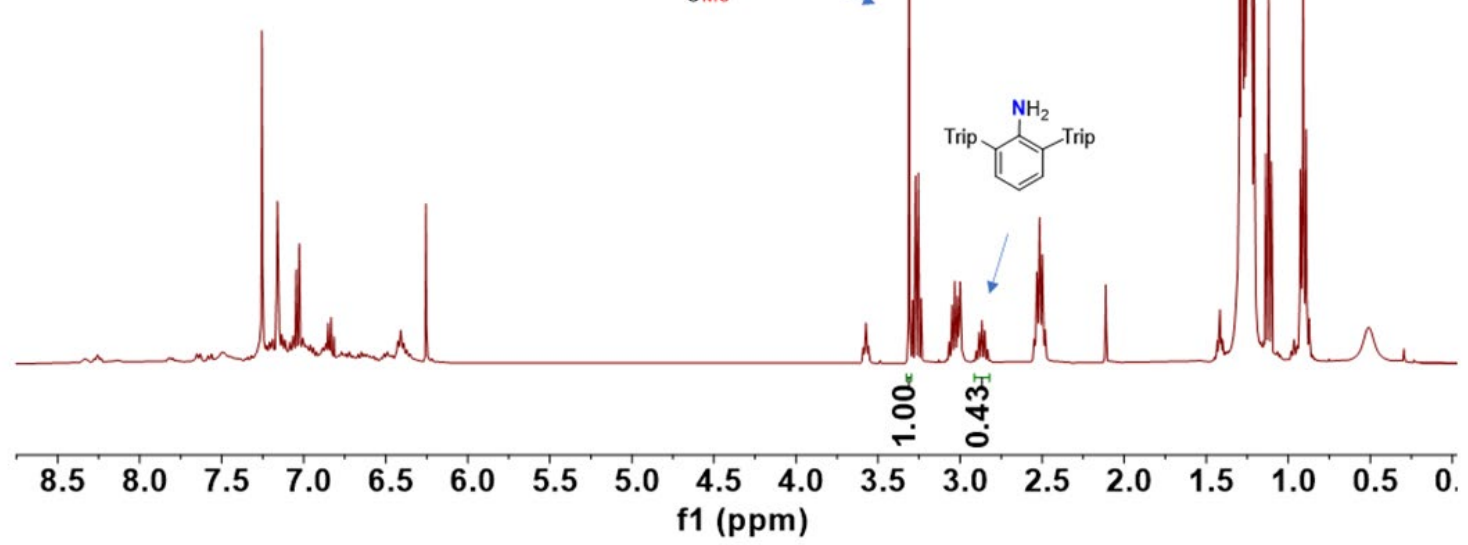

Fig. S66. The ${ }^{1} \mathrm{H}$ NMR spectrum of the mixture of the reaction of 1 with one equiv. of $n$-octyl amine in $1 \mathrm{~h}$. 
Preparation of [(BINAP)Pd(OAc) 2$]$ (6). To a solution of $\mathrm{Pd}(\mathrm{OAc})_{2}(200 \mathrm{mg}, 0.89 \mathrm{mmol})$ in THF $(20 \mathrm{~mL})$ was added BINAP $(552 \mathrm{mg}, 0.89 \mathrm{mmol})$ at room temperature. The color of the solution changed from red to yellow. After stirring for $2 \mathrm{~h}$, the yellow precipitate was collected by filtration. The resultant yellow solid was then washed with THF $(3 \times 2 \mathrm{~mL})$ and dried under vacuum, which leaves [(BINAP)Pd(OAc) $)_{2}$ (6) as a yellow powder $(653 \mathrm{mg}, 87 \%)$. Single crystals of 6 • $\mathrm{CH}_{2} \mathrm{Cl}_{2}$ suitable for $\mathrm{X}$-ray diffraction were grown by diffusion of pentane into a concentrated $\mathrm{CH}_{2} \mathrm{Cl}_{2}$ solution of 6 at room temperature for days. For 6: Anal. Calcd for $\mathrm{C}_{48} \mathrm{H}_{38} \mathrm{P}_{2} \mathrm{PdO}_{4} \cdot \mathrm{CH}_{2} \mathrm{Cl}_{2}: \mathrm{C}, 63.14$; H, 4.33; Found: C, 63.43; H, 4.52. Absorption spectrum (THF): $\lambda_{\max }, \mathrm{nm}\left(\varepsilon, \mathrm{M}^{-1} \mathrm{~cm}^{-1}\right)=320(5400)$, 350 (3200). IR (KBr, cm $\left.{ }^{-1}\right): v=3051(\mathrm{w}), 1607$ (s), $1584(\mathrm{~s}), 1500$ (s), $1481(\mathrm{w}), 1435$ (m), 1366 (s), $1315(\mathrm{~s}), 1222(\mathrm{w}), 1118(\mathrm{w}), 1159(\mathrm{w}), 1096(\mathrm{w}), 996(\mathrm{w}), 918(\mathrm{w}), 871(\mathrm{w}), 745$ (s), $695(\mathrm{~s}), 673$ (s), 609 (w), 525 (m), 503 (s), 477 (w), 438 (w). ${ }^{1} \mathrm{H}$ NMR (400 MHz, $\left.\mathrm{CDCl}_{3}, 293 \mathrm{~K}\right): \delta 7.88$ (s, 4H), $7.77(\mathrm{~s}, 4 \mathrm{H}), 7.59-7.52(\mathrm{~m}, 4 \mathrm{H}), 7.49(\mathrm{~s}, 8 \mathrm{H}), 7.37-7.29(\mathrm{~m}, 2 \mathrm{H}), 7.05-6.97(\mathrm{~m}, 2 \mathrm{H})$, 6.78-6.72 (m, 2H), $6.68(\mathrm{~s}, 4 \mathrm{H}), 6.52(\mathrm{~d}, J=8.7 \mathrm{~Hz}, 2 \mathrm{H}), 1.33(\mathrm{~s}, 6 \mathrm{H}) .{ }^{13} \mathrm{C} \mathrm{NMR}\left(101 \mathrm{MHz}, \mathrm{CDCl}_{3}, 293 \mathrm{~K}\right): \delta$ (ppm) 176.87, 138.94, 135.40, 135.17, 134.05, 132.87, 130.93, 129.95, 129.09, 128.16, 128.11, $128.05,127.65,127.45,126.75,126.49,126.20,122.80,122.21,23.02 .{ }^{31} \mathrm{P} \mathrm{NMR}\left(162 \mathrm{MHz}, \mathrm{CDCl}_{3}\right.$, $293 \mathrm{~K}): \delta(\mathrm{ppm}) 25.42$. 


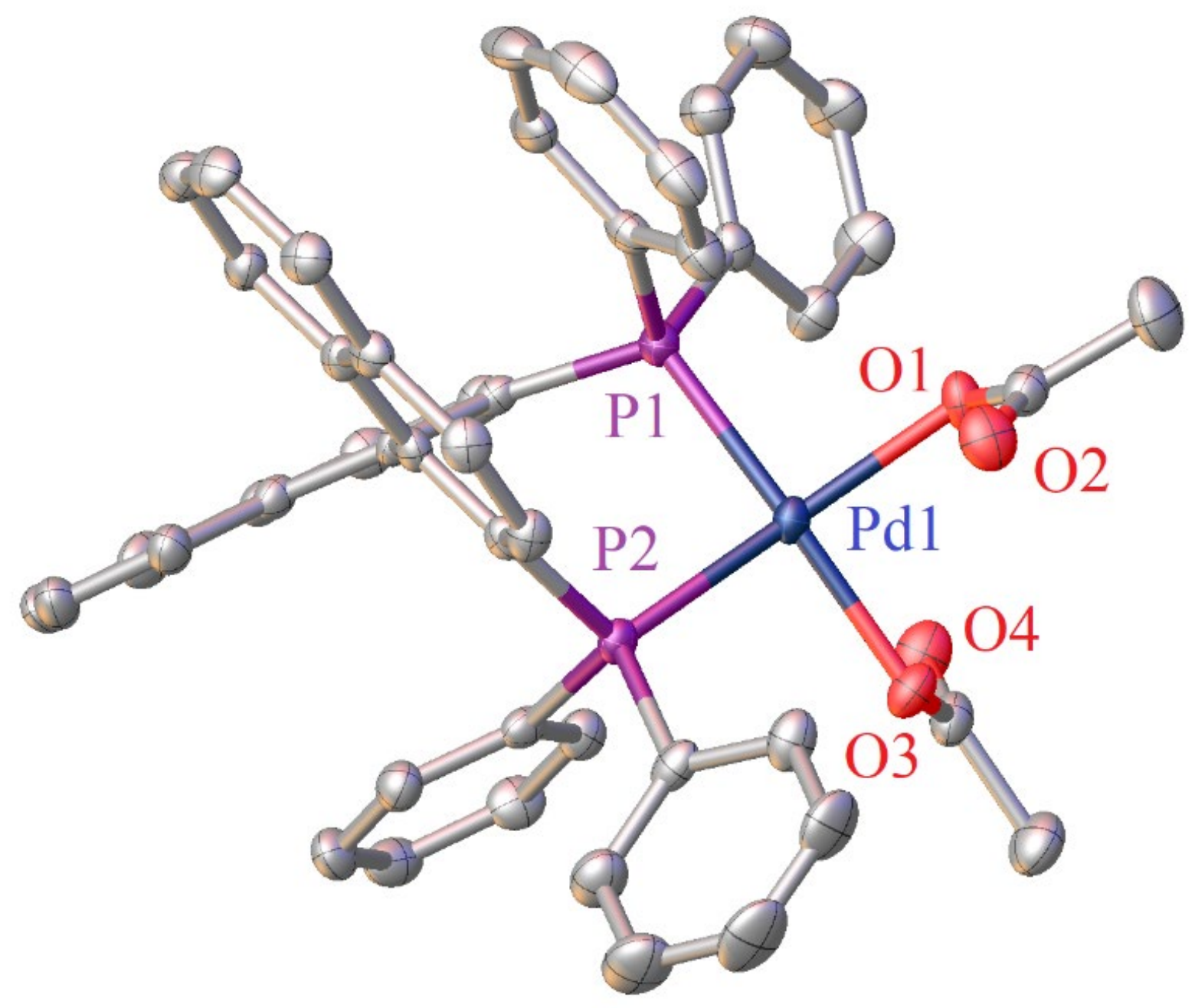

Fig. S67. Molecular structure of $\mathbf{6}$, showing $30 \%$ probability ellipsoids and the partial atoms numbering scheme. Selected distances $(\AA)$ and angles (deg): Pd1-P1 2.2415(8), Pd1-P2 2.2358(8), Pd1-O1 2.096(2), Pd1-O3 2.085(2), O1-Pd1-O3 89.68(9), O1-Pd-P1 90.47(7), O1-Pd-P2 168.73(6), P1-Pd-P2 91.78(3). 

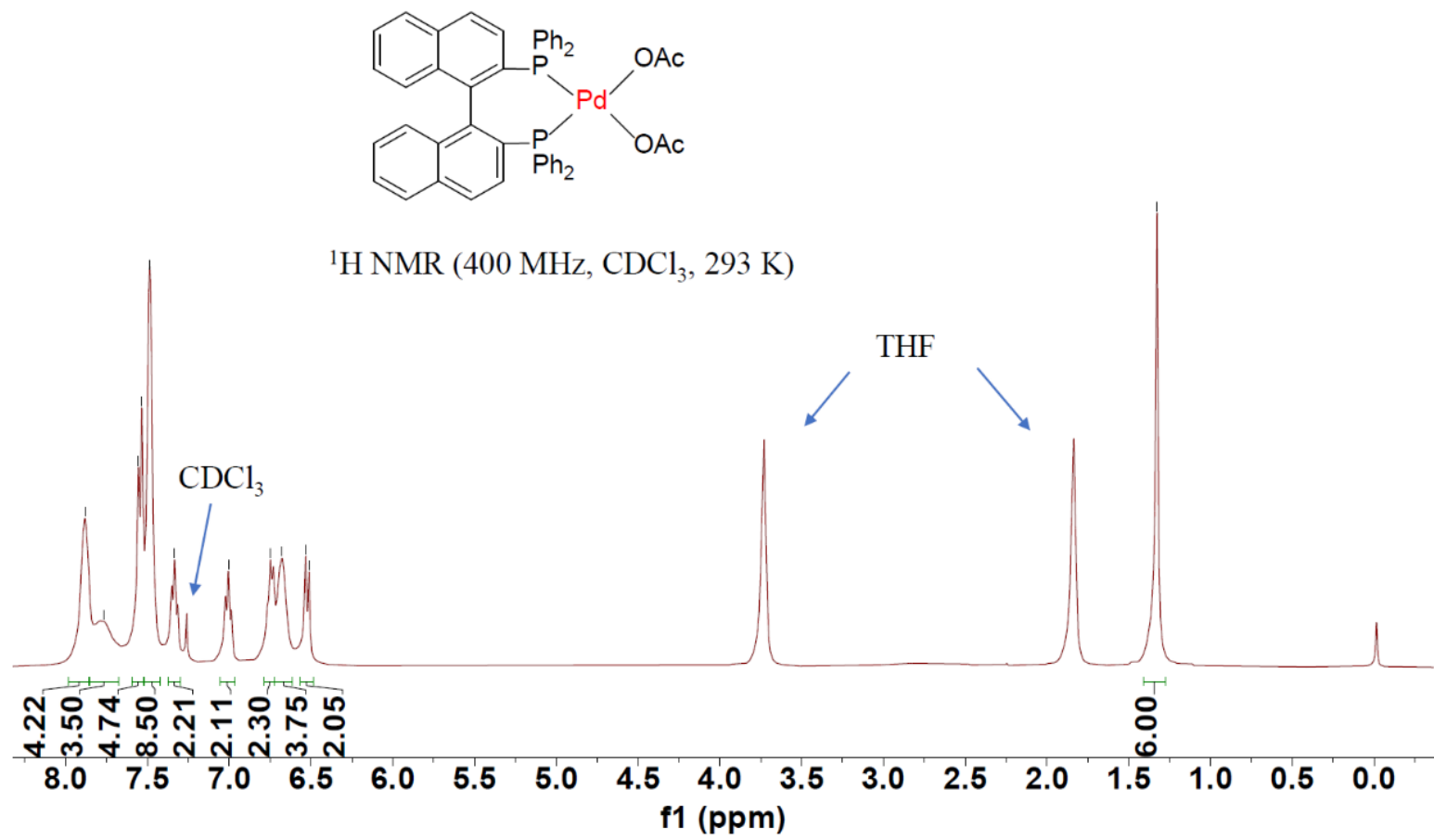

Fig. S68. ${ }^{1} \mathrm{H}$ NMR spectrum of 6 . 


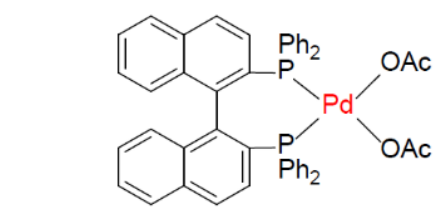

${ }^{13} \mathrm{C}$ NMR (101 MHz, $\left.\mathrm{CDCl}_{3}, 293 \mathrm{~K}\right)$
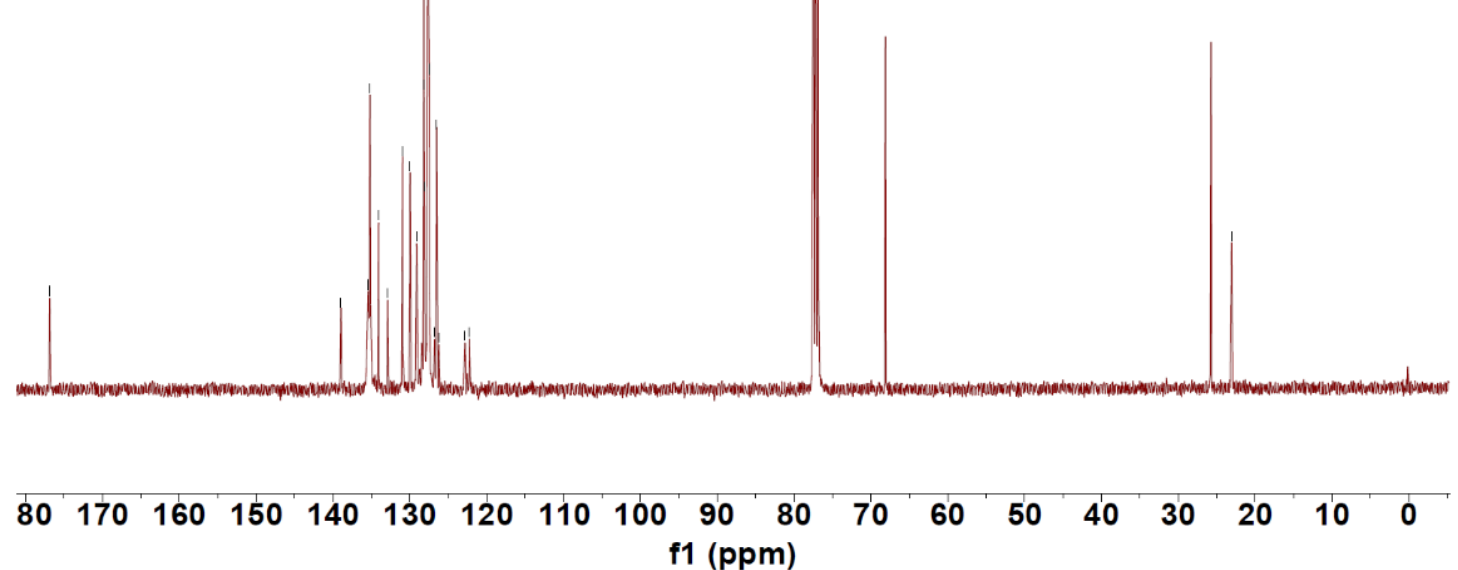

Fig. S69. ${ }^{13} \mathrm{C}$ NMR spectrum of 6 . 


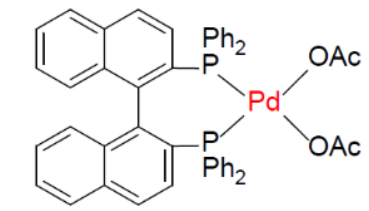

${ }^{31} \mathrm{P}$ NMR (162 MHz, $\left.\mathrm{CDCl}_{3}, 293 \mathrm{~K}\right)$

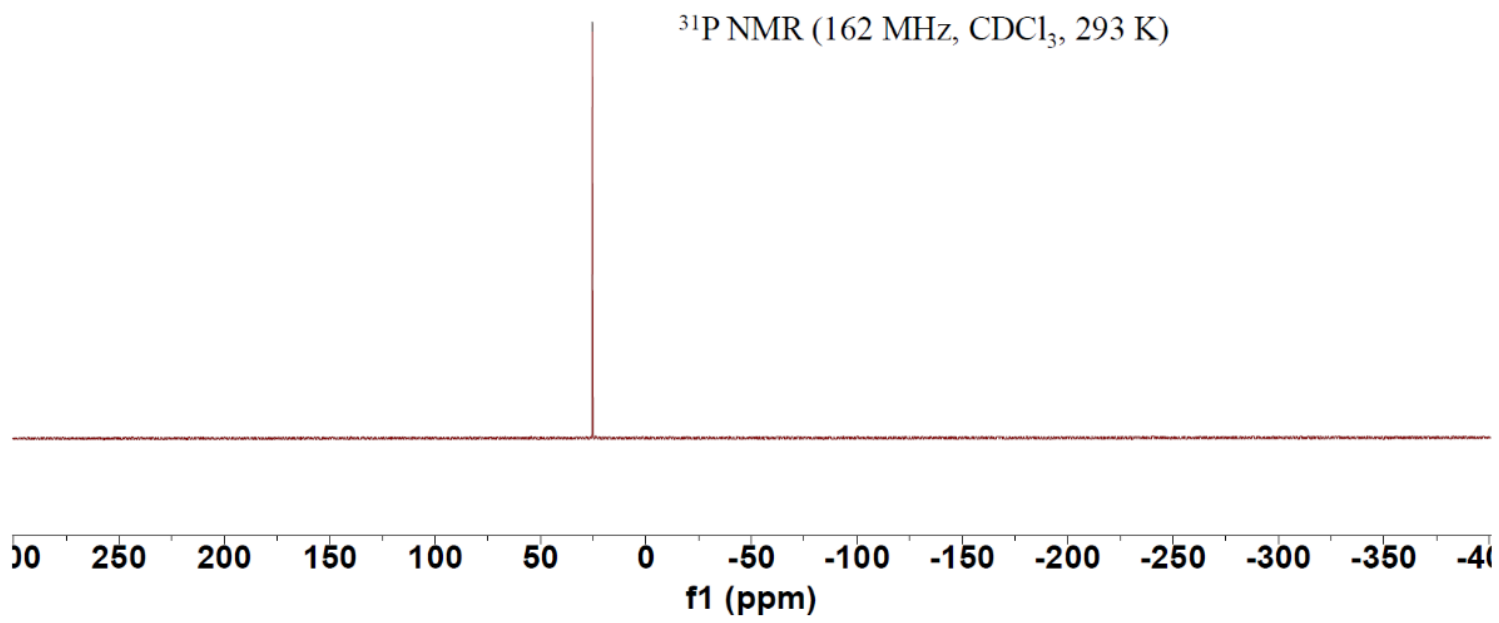

Fig. S70. ${ }^{31} \mathrm{P}$ NMR spectrum of 6 . 


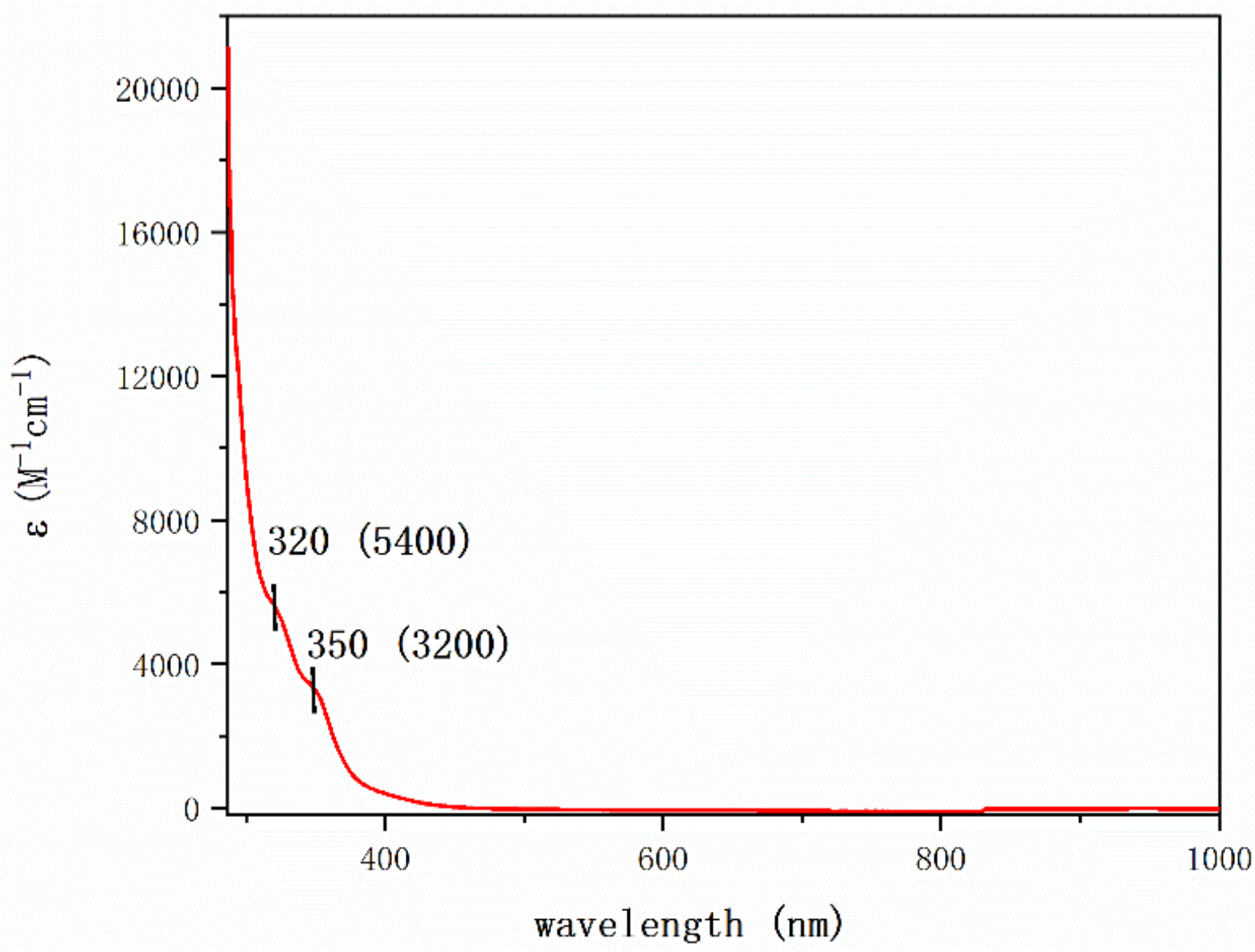

Fig. S71. UV-vis absorption spectrum in DCM of 6 recorded at room temperature. 


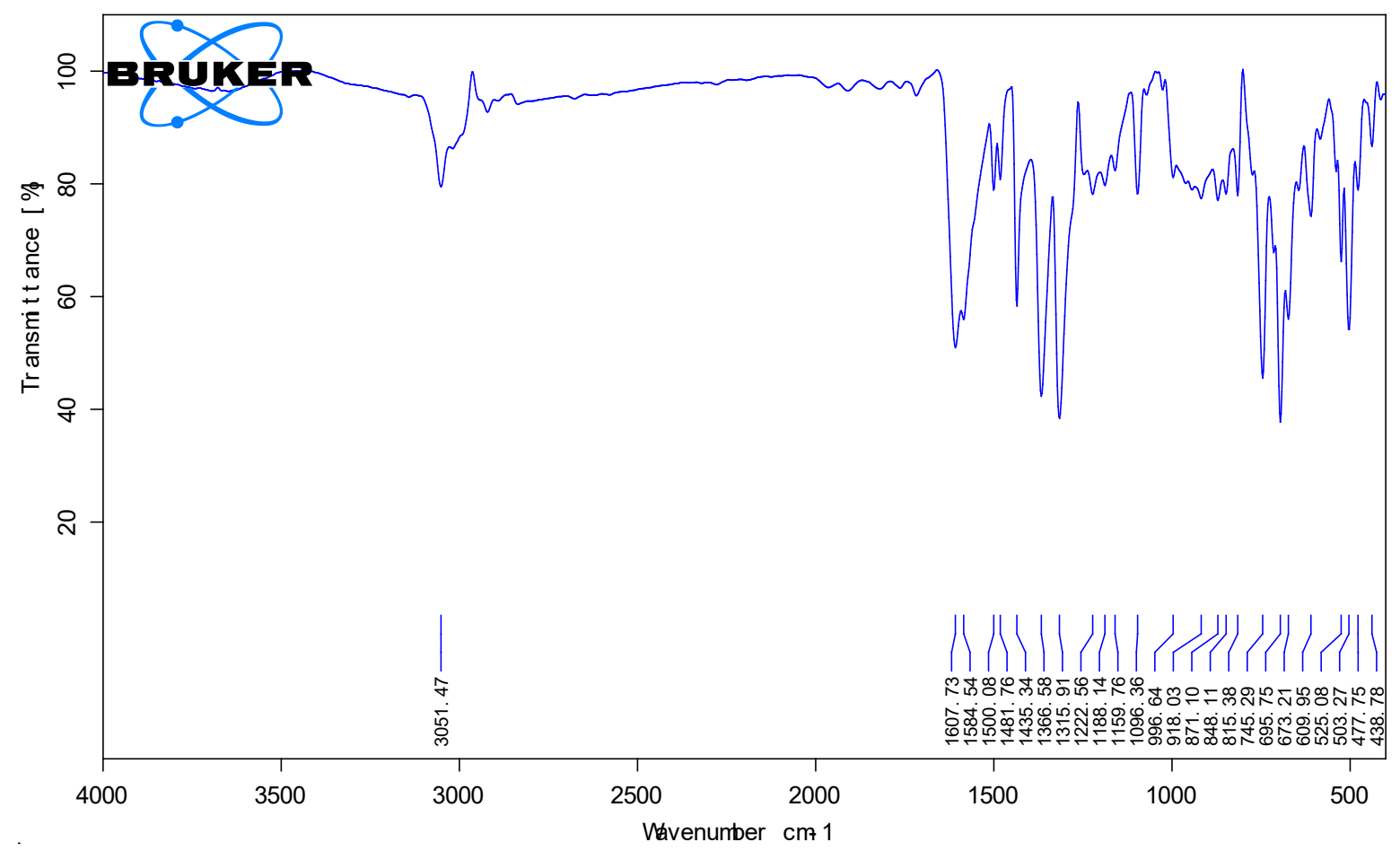

Fig. S72. IR spectrum of 6 . 


\section{Details for single-crystal X-ray diffraction study.}

Diffraction-quality crystals were obtained from recrystallizations in $\mathrm{Et}_{2} \mathrm{O}$ at $-30{ }^{\circ} \mathrm{C}$ (1), $n$-hexane at room temperature (2), DCM/n-pentane at room temperature $\left(6 \cdot \mathrm{CH}_{2} \mathrm{Cl}_{2}\right)$, toluene at -30 ${ }^{\circ} \mathrm{C}(7)$, toluene $/ n$-hexane at room temperature $\left(\mathbf{8} \bullet 0.5 n\right.$-hexane) and toluene $/ n$-pentane at $-30{ }^{\circ} \mathrm{C}(\mathbf{9})$. Crystals were coated with Paratone-N oil and mounted on a Bruker APEX-II CCD-based diffractometer or a Bruker D8 Venture diffractometer equipped with an Oxford low-temperature apparatus. Cell parameters were retrieved with SMART software and refined using SAINT software on all reflections. Data integration was performed with SAINT, which corrects for Lorentz polarization and decay. Absorption corrections were applied using SADABS(58). Space groups were assigned unambiguously by analysis of symmetry and systematic absences determined by XPREP. All structures were solved and refined using SHELXTL (59). Metal and first coordination sphere atoms were located from direct-methods E-maps. Non-hydrogen atoms were found in alternating difference Fourier synthesis and least-squares refinement cycles and during final cycles were refined anisotropically. Table S2 summarizes the crystal data and summary of data collection and refinement for the complexes. CCDC 2059309-2059313 and 2070924 contain the supplementary crystallographic data for complexes $1,2,6 \cdot \mathrm{CH}_{2} \mathrm{Cl}_{2}, 7, \mathbf{8} \bullet 0.5 n$-hexane and $\mathbf{9}$. These data can be obtained free of charge from The Cambridge Crystallographic Data Centre via www.ccdc.cam.ac.uk/data_request/cif. 
Table S2. Crystal data and summary of data collection and refinement for $\mathbf{1 , 2}, \mathbf{6} \cdot \mathrm{CH}_{2} \mathrm{Cl}_{2}, \mathbf{7 ,} \mathbf{8} \bullet 0.5 n$-hexane, and 9.

\begin{tabular}{|c|c|c|c|c|c|c|}
\hline & $\mathbf{1}(170 \mathrm{~K})$ & $2(170 \mathrm{~K})$ & $\mathbf{6} \cdot \mathrm{CH}_{2} \mathrm{Cl}_{2}(170 \mathrm{~K})$ & $7(170 \mathrm{~K})$ & $\begin{array}{c}8 \bullet 0.5 n \text {-hexane } \\
(170 \mathrm{~K})\end{array}$ & $9(193 \mathrm{~K})$ \\
\hline formula & $\mathrm{C}_{80} \mathrm{H}_{82} \mathrm{NP}_{2} \mathrm{Pd}$ & $\mathrm{C}_{72} \mathrm{H}_{100} \mathrm{~N}_{2}$ & $\mathrm{C}_{49} \mathrm{H}_{40} \mathrm{Cl}_{2} \mathrm{O}_{4} \mathrm{P}_{2} \mathrm{Pd}$ & $\mathrm{C}_{62} \mathrm{H}_{50} \mathrm{~N}_{2} \mathrm{P}_{2} \mathrm{Pd}$ & $\mathrm{C}_{57} \mathrm{H}_{45} \mathrm{~F}_{6} \mathrm{P}_{2} \mathrm{Pd}$ & $\mathrm{C}_{59} \mathrm{H}_{54} \mathrm{OP}_{2} \mathrm{Pd}$ \\
\hline crystal size (mm) & $0.08 \times 0.06 \times 0.05$ & $0.08 \times 0.06 \times 0.06$ & $0.08 \times 0.06 \times 0.05$ & $0.08 \times 0.05 \times 0.03$ & $0.1 \times 0.09 \times 0.01$ & $0.17 \times 0.14 \times 0.11$ \\
\hline crystal system & Triclinic & Monoclinic & Monoclinic & Orthorhombic & Monoclinic & Tetragonal \\
\hline space group & $\mathrm{P}-1$ & $\mathrm{P} 21 / \mathrm{n}$ & $\mathrm{P} 21 / \mathrm{n}$ & $\mathrm{P} \operatorname{ccn}$ & P $21 / c$ & I 41 \\
\hline$a, \AA$ & $16.0516(3)$ & $11.9371(2)$ & $11.9235(6)$ & $9.8868(2)$ & $14.7215(3)$ & $35.6442(11)$ \\
\hline$c, \AA$ & $23.0650(4)$ & $29.9062(5)$ & $16.1565(8)$ & $23.7699(6)$ & $26.9307(5)$ & $17.0827(6)$ \\
\hline$\alpha, \operatorname{deg}$ & $110.5920(10)$ & 90 & 90 & 90 & 90 & 90 \\
\hline$\beta, \operatorname{deg}$ & $93.5900(10)$ & $95.9090(10)$ & $94.297(2)$ & 90 & $102.2910(10)$ & 90 \\
\hline$\gamma, \operatorname{deg}$ & $96.2250(10)$ & 90 & 90 & 90 & 90 & 90 \\
\hline$V, \AA^{3}$ & $7015.2(2)$ & $6476.89(19)$ & $4229.0(4)$ & $4865.8(2)$ & $4667.30(15)$ & $21703.7(15)$ \\
\hline Z & 4 & 4 & 4 & 4 & 4 & 16 \\
\hline$\mu, \mathrm{mm}^{-1}$ & 1.903 & 0.274 & 3.835 & 2.666 & 2.898 & 0.437 \\
\hline$F(000)$ & 2580 & 2184 & 1904 & 2048 & 2068 & 7872 \\
\hline no. of obsd reflns & 85654 & 69949 & 31691 & 30005 & 50206 & 52901 \\
\hline $\begin{array}{l}\text { no. of params } \\
\text { refnd }\end{array}$ & 1567 & 696 & 525 & 305 & 596 & 1156 \\
\hline goodness of fit & 0.996 & 1.031 & 1.100 & 1.057 & 1.024 & 0.997 \\
\hline $\mathrm{R} 1$ & 0.0415 & 0.0768 & 0.0387 & 0.0437 & 0.0441 & 0.0372 \\
\hline$w \mathrm{R} 2$ & 0.0923 & 0.1854 & 0.1055 & 0.1207 & 0.0987 & 0.0779 \\
\hline $\mathrm{CCDC}$ & 2059309 & 2059310 & 2070924 & 2059311 & 2059312 & 2059313 \\
\hline
\end{tabular}




\section{Details for EPR spectroscopy.}

$9 \mathrm{GHz}$ (X-band) continuous wave (CW) EPR spectrum was collected on a Bruker EMX plus 6/1 spectrometer equipped with an Oxford Instrument ESR900 liquid He cryostat using an Oxford ITC 503 temperature controller. The spectrum was collected with the following experimental parameters: microwave frequency, $9.6 \mathrm{GHz}$; microwave power, $0.3 \mathrm{~mW}$; modulation amplitude, 10 G; time constant, $20.48 \mathrm{~ms}$; 4 scans; temperature, $70 \mathrm{~K}$. EPR spectrum in toluene solution was obtained with the following experimental parameters: microwave frequency, $9.4 \mathrm{GHz}$; microwave power, $0.15 \mathrm{~mW}$; modulation amplitude, $1 \mathrm{G}$; $1 \mathrm{scan}$; temperature $295 \mathrm{~K}$. $34 \mathrm{GHz}$ (Q-band) electron spin echo(ESE) detected EPR spectrum was collected using an EN5107D2 resonator. The spectrum was acquired using a pulse sequence, $\pi / 2-\tau-\pi$-echo, with a pulse length $t_{\pi / 2}=32 \mathrm{~ns}, t_{\pi}=64 \mathrm{~ns}$ and $\tau=$ 200 ns; temperature, 20 K. 94 GHz (W-band) CW EPR spectrum was obtained on a Bruker Elexsys E680 spectrometer with a cylindrical high Q-resonator $($ EN680-1021H) and cyrogenic temperatures were achieved with an Oxford CF-935 cryostat and Oxford MercuryiTC temperature controller. The spectrum was obtained with the following experimental parameters: microwave frequency, 93.9 GHz; microwave power, $0.05 \mathrm{~mW}$; modulation amplitude, $10 \mathrm{G}$; time constant, $81.92 \mathrm{~ms}$; temperature, $82 \mathrm{~K}$. The simulations of the EPR spectra were performed by EasySpin (60). 


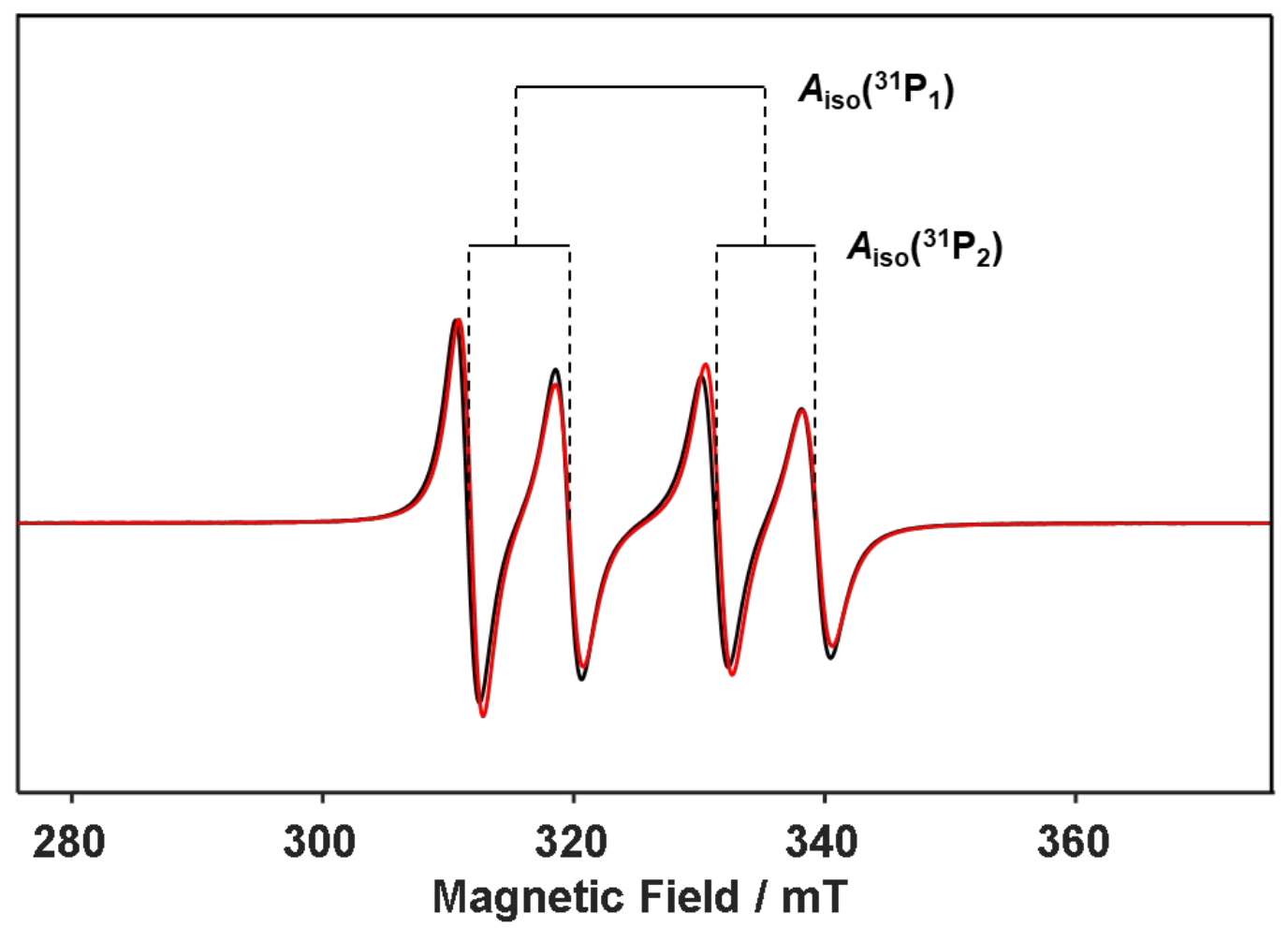

Fig. S73. Solution EPR spectrum of 1(black line) and simulations (red line) 


\section{Details for X-ray absorption spectroscopy.}

Data Collection. All data were measured at the Stanford Synchrotron Radiation Lightsource (SSRL) under ring conditions of $3.0 \mathrm{GeV}$ and $500 \mathrm{~mA}$. Samples were prepared in an inert-atmosphere glovebox where they were ground to a fine powder with $\mathrm{BN}$ to a final concentration of 5 weight $\% \mathrm{Pd}$. For Pd K-edge measurements, the powder was pressed into $1 \mathrm{~mm}$ aluminum spacers and sealed with $37 \mu \mathrm{m}$ Kapton tape. For Pd L-edge measurements, the powder was pressed into $1 \mathrm{~mm}$ aluminum spacers with a $38 \mu \mathrm{m}$ low-S Mylar tape backing and sealed with polyfilm.

Pd K-edge measurements were carried out at beamline 9-3 equipped with a 16-pole, 2-Tesla wiggler source. A double $\mathrm{Si}(220)$ crystal was used as a monochromator. Samples were maintained at $10 \mathrm{~K}$ in a liquid $\mathrm{He}$ cryostat. Spectra were measured in fluorescence mode using a passivated implanted planar silicon (PIPS) detector placed at a $90^{\circ}$ angle to the sample. Soller slits fitted with a Ni filter were included to attenuate inelastic scattering. A Pd foil and a third ionization chamber upstream of the sample were used for internal energy calibration. Two scans were measured and averaged for each compound.

Pd L 2,3-edge measurements were collected on beamline 4-3 equipped with a 20-pole, 2-Tesla wiggler source. Spectra were collected on samples in a He atmosphere at room temperature using fluorescence mode with a Lytle detector. Intensity was normalized with respect to the incident beam using a He-filled ion chamber upstream of the sample. Two scans were measured and averaged for each compound.

Data Processing. Raw Pd K- and L-edge measurements were averaged and normalized using SIXPACK (61) and processed using Igor 6.37. Energies of the palladium K-edges were calibrated by setting the inflection point of a Pd foil scan to $24350.3 \mathrm{eV}$. Background was removed by applying a linear normalization to the pre-edge region below $24300 \mathrm{eV}$. The edge-jump was normalized to unit intensity by applying a quadratic normalization to the post-edge region above $24410 \mathrm{eV}$. Rising-edge energies were determined by the first maximum in the first derivative after Savitzsky-Golay smoothing was applied in Igor.

Pd L-edge energies were calibrated by setting the inflection point of the $\mathrm{L}_{3}$-edge of a $\mathrm{Pd}$ foil scan to $3173.3 \mathrm{eV}$. Background was removed by applying a linear fit to the pre-edge region below 
$3158 \mathrm{eV}$ and subtracting it from the entire spectrum. Normalization was achieved using the $\mathrm{L}_{2}$-edge, where the post-edge region was fit to a quadratic in the region between $3358 \mathrm{eV}$ and $3608 \mathrm{eV}$ and normalized to unit intensity. The edge jumps were removed in PyMCA (62) with a statistics-sensitive non-linear iterative peak-clipping (SNIP) algorithm (63), using a background width of $21 . \mathrm{L}_{3}$ and $\mathrm{L}_{2}$ peak areas were obtained separately using the multiple peak-fitting feature in Igor (Figs. S74 and S75). To minimize error, a mixture of Voigt and Gaussian peaks was used. Only the first peak corresponding to the mainline was used to calculate the area. 


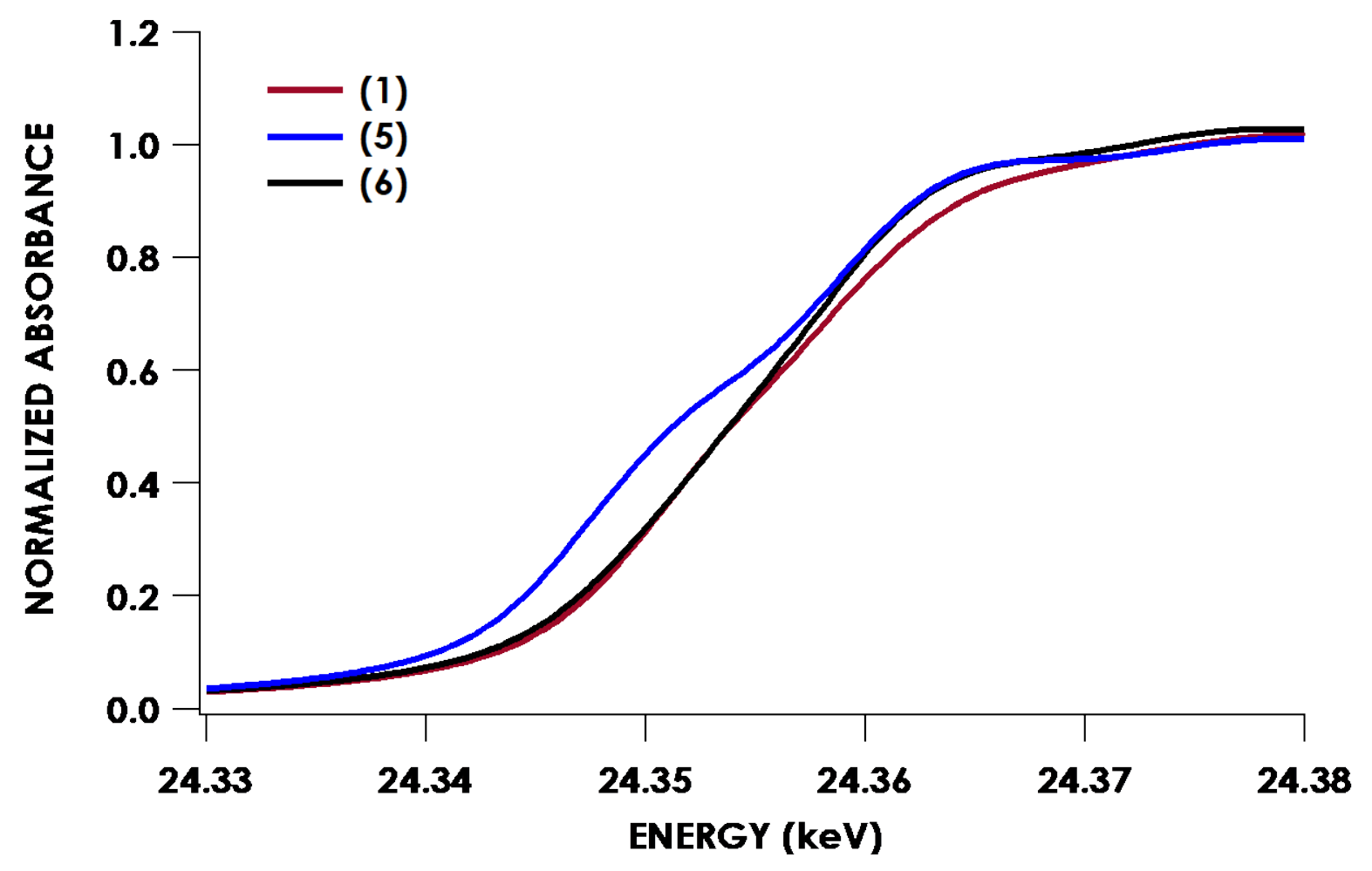

Fig. S74. Overlay of experimental $\mathrm{Pd}$ K-edge XAS spectra of $\mathrm{Pd}^{0}(\mathrm{NHC})_{2}$ (5, blue), (BINAP)Pd ${ }^{\mathrm{I}}\left(\mathrm{NHAr}^{\mathrm{Tri}}\right)$ (1, red), and (BINAP)Pd ${ }^{\mathrm{II}}(\mathrm{OAc})_{2}(\mathbf{6}$, black). 


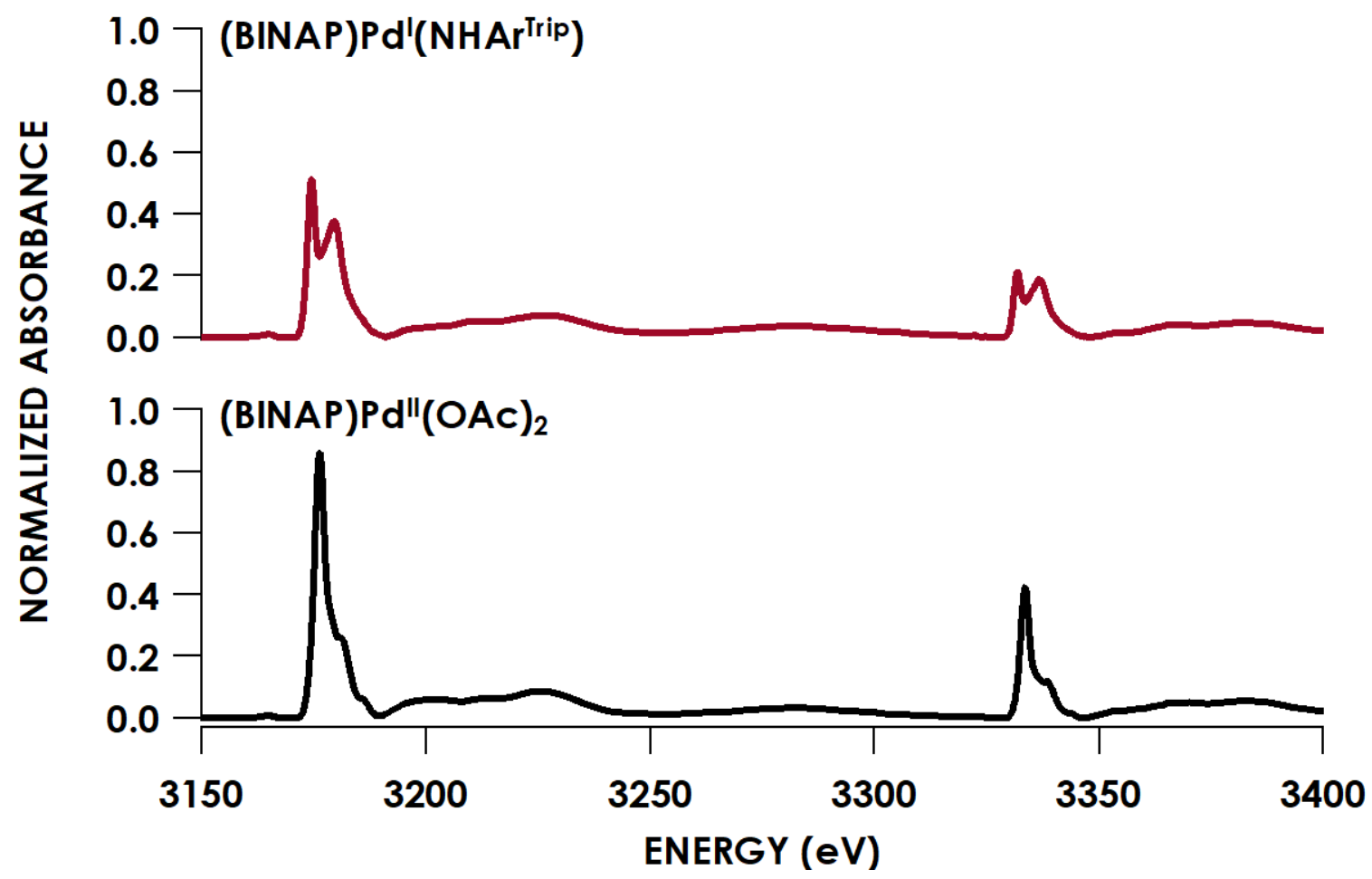

Fig. S75. Experimental L2,3-edges of (BINAP)Pd ${ }^{\mathrm{I}}\left(\mathrm{NHAr}^{\mathrm{Trip}}\right)$ (1) and (BINAP)Pd ${ }^{\mathrm{II}}(\mathrm{OAc})_{2}(\mathbf{6})$. Spectra were normalized to unit intensity in the $\mathrm{L}_{2}$ post-edge region and the edge jumps were removed. 

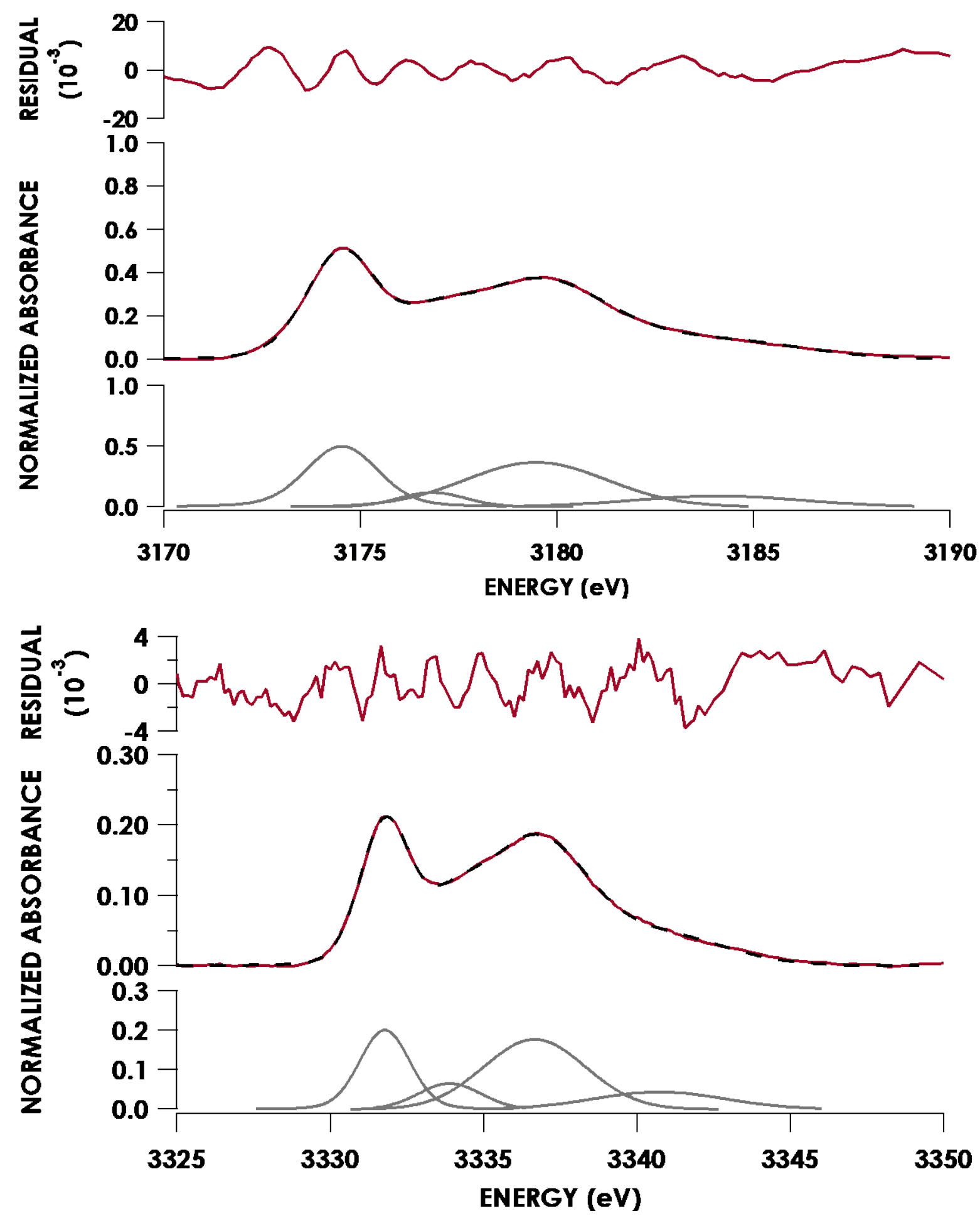

Fig. S76. Peak-fit of the experimental $\mathrm{L}_{3}$-edge (left) and $\mathrm{L}_{2}$-edge (right) of (BINAP)Pd $\mathrm{P}^{\mathrm{I}}\left(\mathrm{NHAr}^{\text {Trip }}\right)$ (1). The overall fit is represented as a black dashed line and the individual peaks are shown in grey. 

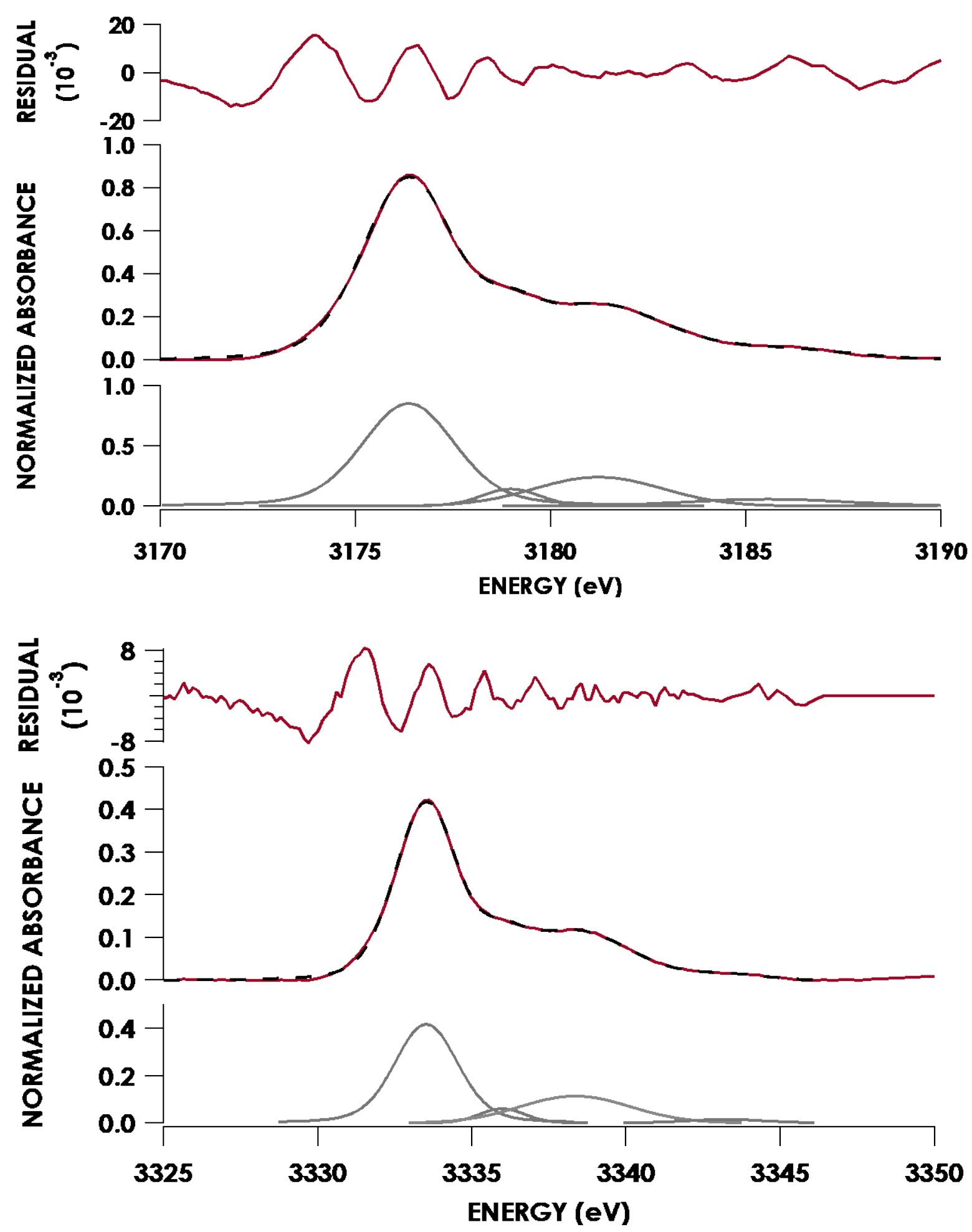

Fig. S77. Peak-fit of the experimental $\mathrm{L}_{3}$-edge (left) and $\mathrm{L}_{2}$-edge (right) of (BINAP)Pd ${ }^{\mathrm{II}}(\mathrm{OAc})_{2}(6)$. The overall fit is represented as a black dashed line and the individual peaks are shown in grey. 


\section{Computational Details.}

DFT and TDDFT calculations were performed using ORCA version 4.2 (64). The molecular structures of $\mathbf{1}$ and $\mathbf{8}$ obtained from single-crystal X-ray diffraction study was used directly for SCF calculations without further structure optimization. Single-point energies were calculated using crystallographic coordinates and the B3LYP functional (65-68). The RIJCOSX (69) approximation with auxiliary basis sets built using the ORCA AUTOAUX method (70) was employed to accelerate the calculations. The SARC-ZORA (71) basis set was used for palladium and the ZORA-def2-TZVP(-f) basis set (72) was used for all other atoms. Special integration accuracy (ORCA Grid7) was used for palladium and phosphorus, while ORCA Grid4 was used for all other atoms. The zeroth-order regular approximation (ZORA) (73) for relativistic effects and the atom-pairwise dispersion correction with Becke-Johnson damping $(44,74)$ were included. Solvation was modeled with the conductor-like polarizable continuum model (CPCM) (75) in an infinite dielectric. The UV/vis absorption spectrum of $\mathbf{1}$ was calculated using the aforementioned single-point DFT calculation as a starting point. 50 roots were calculated for the UV/vis absorption spectrum. Pd L-edge XAS spectra were calculated using TDDFT with 50 root excitations and restricting donor orbitals to the Pd $2 p$ orbitals and acceptor orbitals to the first 20 empty orbitals. Spectra were plotted using a linewidth broadening of $1 \mathrm{eV}$. Calculated energies were shifted by the average of the requisite shifts for the $\mathrm{L}_{3}$ pre-edge and TDDFT calculated pre-edge of $\mathbf{1}$ and $\mathbf{6}$.

For bonding analysis, the geometries were optimized without symmetry constraint within the DFT (density functional theory) framework using the B3LYP functional $(76,77)$ in combination with the Grimme Dispersion corrections with the Becke-Johnson damping function D3(BJ) (74) and the Ahlrichs def2-SVP basis function (78). Geometry optimization for the mononuclear Pd(I) Amido Complex 1 was conducted at B3LYP/def2-SVP level, which agree with the experimental structure very well (see Fig. S82.). These calculations were performed using Gaussian 16 A03 software (79).

Energy decomposition analysis (EDA) was performed at the B3LYP/TZ2P(50) level using the ADF2019.01 software (80). In the EDA scheme, the interaction energy $\left(\Delta E_{\text {int }}\right)$ has been decomposed into four terms as,

$$
\Delta E_{\text {int }}=\Delta E_{\text {Pauli }}+\Delta E_{\text {elstat }}+\Delta E_{\text {orb }}+\Delta E_{\text {disp }}
$$


where, $\Delta E_{\text {elstat }}$ corresponds to the classical electrostatic energy between those fragments and it is generally attractive in nature. The next attractive term is orbital interaction energy, $\Delta E_{\text {orb }}$, which arises from the charge transfer and mixing of the occupied and unoccupied orbitals on the fragments and polarization effects. The $\Delta E_{\text {disp }}$ represents the dispersion energy correction towards the total attraction energy. The only repulsive contribution is the Pauli interaction energy $\left(\Delta E_{P a u l i}\right)$ and it is originated from the repulsion between the occupied orbitals of the interacting fragments.

The EDA-NOCV calculation combines the energy and charge decomposition schemes and divide the deformation density, $\Delta \rho(r)$, associated with the bond formation into different components $(\sigma, \pi, \delta)$ of a chemical bond. From the mathematical point of view, each NOCV, $\psi_{\mathrm{i}}$ is defined as an eigenvector of the deformation density matrix in the basis of fragment orbitals.

$$
\Delta \mathrm{P}_{\psi \mathrm{i}}=v_{\mathrm{i}} \psi_{\mathrm{i}}
$$

In EDA-NOCV, $\triangle$ Eorb is given by the following equation,

$$
\Delta \mathrm{E}_{\mathrm{orb}}=\sum_{\mathrm{k}} \Delta \mathrm{E}_{\mathrm{k}}^{\mathrm{orb}}=\sum_{\mathrm{k}=1}^{\mathrm{N} / 2} v_{\mathrm{k}}\left[-\mathrm{F}_{-\mathrm{k}}^{\mathrm{TS}}+\mathrm{F}_{\mathrm{k}}^{\mathrm{TS}}\right]
$$

where, $-\mathrm{F}_{-\mathrm{k}}^{\mathrm{TS}}$ and $\mathrm{F}_{\mathrm{k}}^{\mathrm{TS}}$ are diagonal Kohn-Sham matrix elements corresponding to NOCVs with the eigenvalues $-v_{\mathrm{k}}$ and $v_{\mathrm{k}}$, respectively. The $\Delta \mathrm{E}_{\mathrm{k}}^{\text {orb }}$ terms are assigned to a particular type of bond by visual inspection of the shape of the deformation density, $\Delta \rho_{\mathrm{k}}$. The EDA-NOCV scheme thus provides both qualitative $\left(\Delta \rho_{\text {orb }}\right)$ and quantitative $\left(\Delta \mathrm{E}_{\text {orb }}\right)$ information about the strength of orbital interactions in chemical bonds. More details on the EDA-NOCV method and its application to the analysis of the chemical bond can be found in recent reviews articles (81-83). Table S3 compiles all the calculated interaction energies of each term. Figs. S83-S86 show the main components of orbital contribution. 

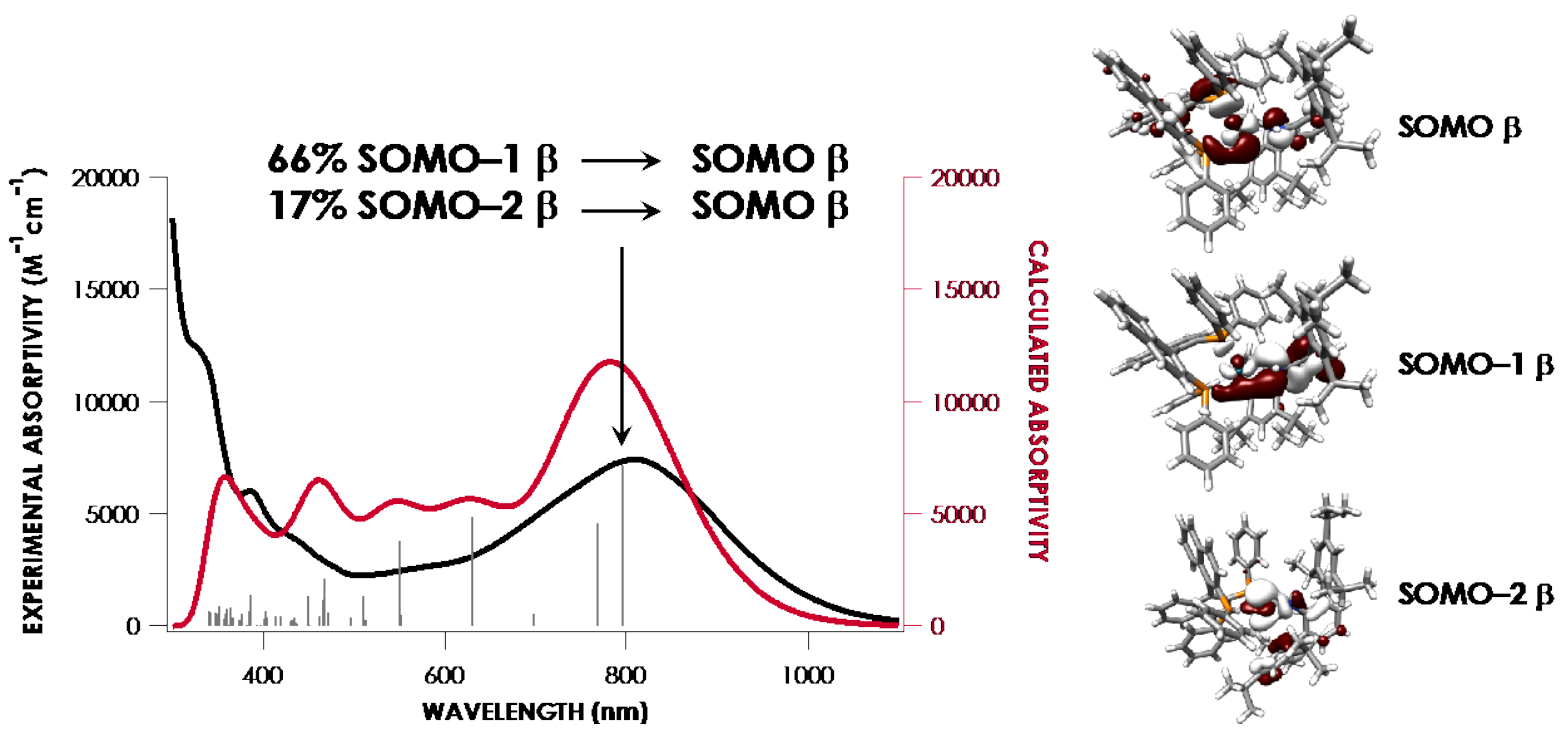

Fig. S78. Experimental (black) and TDDFT-calculated (red, B3LYP, SARC-ZORA on Pd, ZORA-def2-TZVP(-f) on all other atoms) UV/vis absorption spectra of $\mathbf{1}$. Individual transitions are indicated as grey sticks. The major ( $>5 \%$ weight) excitations giving rise to the ca. $800 \mathrm{~nm}$ charge transfer band are given, with relevant orbitals printed to the right at an isovalue of $0.03 \mathrm{au}$. 

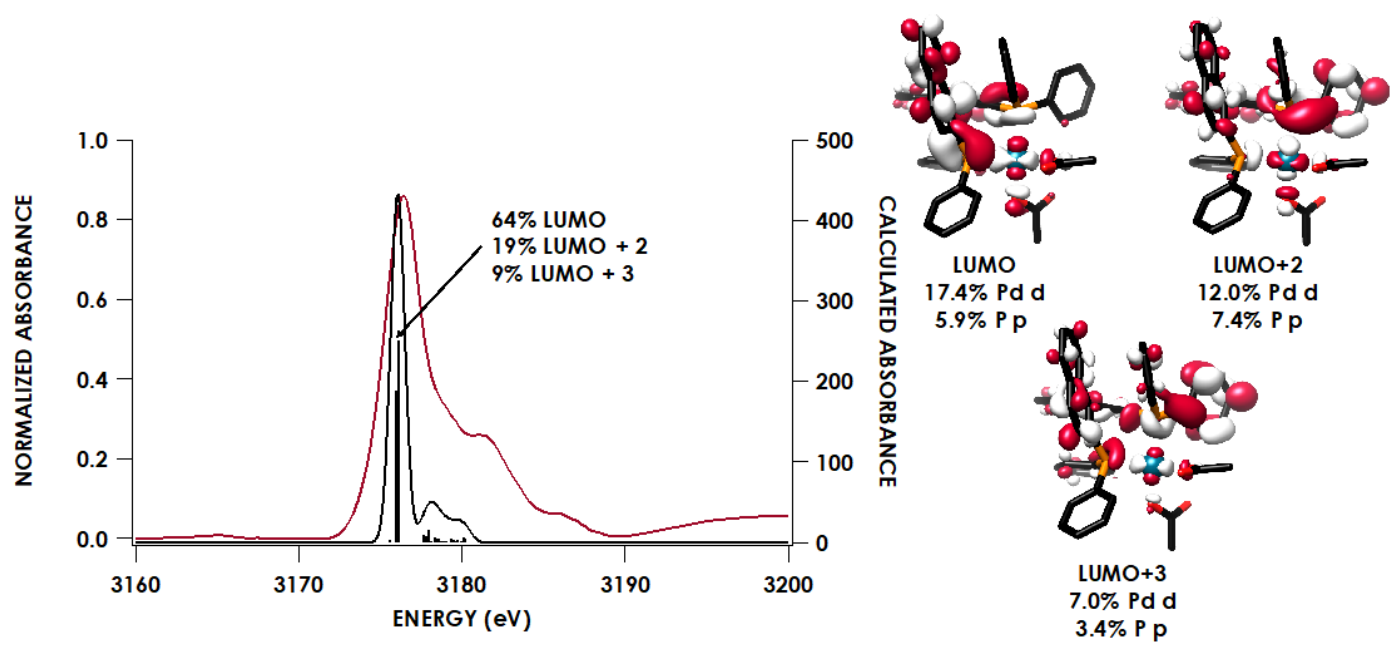

Fig. S79. Experimental (red) and TDDFT calculated (black) Pd $\mathrm{L}_{3}$-edge XAS spectra of (BINAP)Pd ${ }^{\mathrm{II}}(\mathrm{OAc})_{2}(6)$. The B3LYP functional and SARC-ZORA basis set was used for Pd, with ZORA-def2-TZVP(-f) used for all other atoms. Contributions of individual orbitals were obtained from Löwdin population analysis of the QROs. Orbitals are plotted at an isovalue of 0.03 au with hydrogen atoms removed for clarity. 


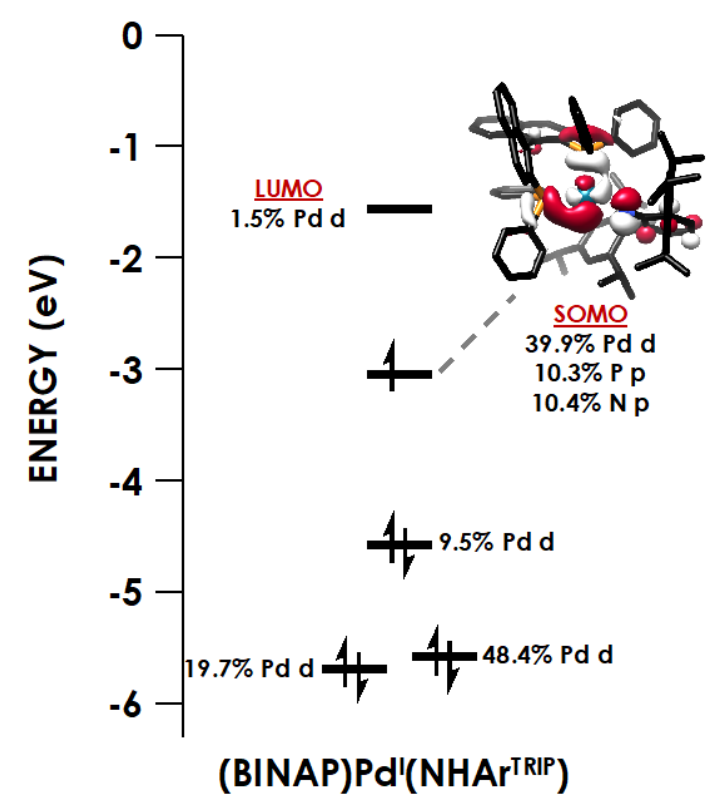

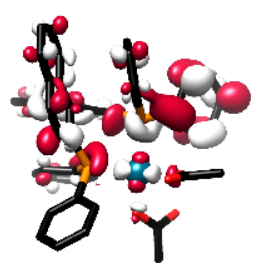

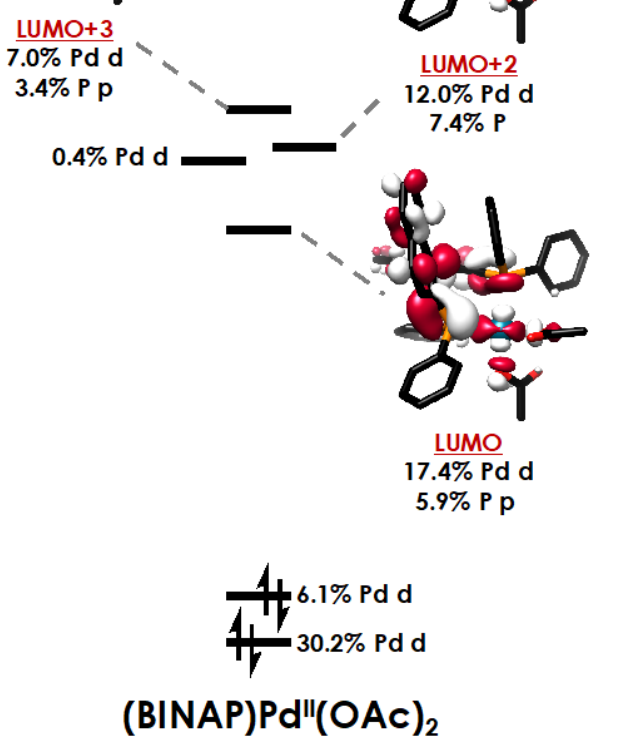

Fig. S80. Frontier MO diagram of $\left[(\mathrm{BINAP}) \mathrm{Pd}^{\mathrm{I}}\left(\mathrm{NHAr}^{\mathrm{Trip}}\right)\right]$ (1) and [(BINAP)Pd $\left.(\mathrm{OAc})_{2}\right]$ (6). Energies were obtained from the QROs (calculated using the B3LYP level of theory with the SARC-ZORA basis set on Pd and ZORA-def2-TZVP(-f) on all other atoms). Acceptor orbitals in the calculated $\mathrm{L}_{3}$-edge mainline are labeled in red. Orbitals are plotted at an isovalue of 0.03 au with hydrogen atoms removed for clarity. 


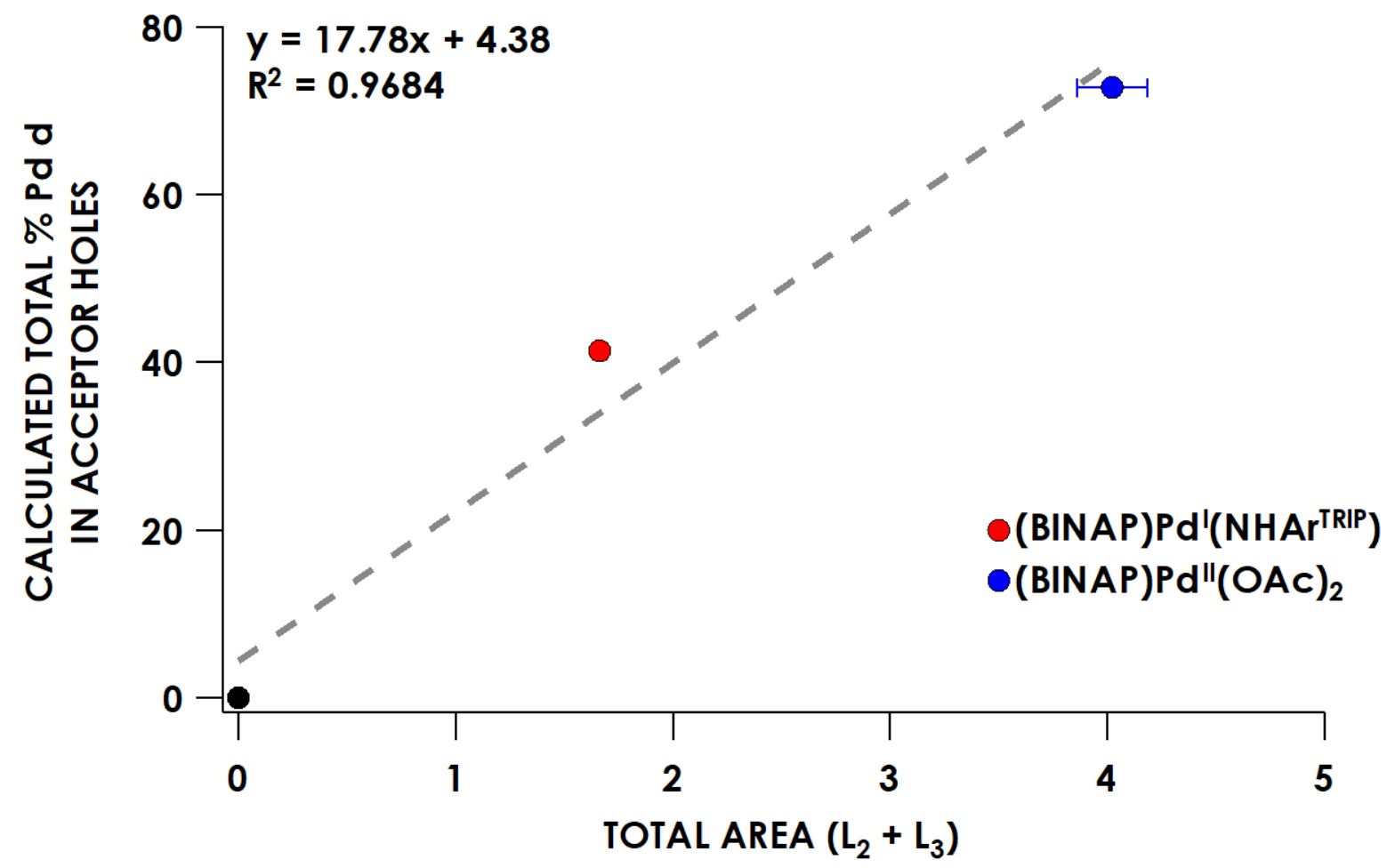

Fig. S81. Correlation between the total area of the $\mathrm{L}_{2,3}$-edge mainlines of [(BINAP) $\mathrm{Pd}^{\mathrm{I}}\left(\mathrm{NHAr}^{\mathrm{Trip}}\right)$ ] (1) and [(BINAP) $\left.\mathrm{Pd}^{\mathrm{II}}(\mathrm{OAc})_{2}\right](\mathbf{6})$ and the calculated Pd d character per hole of all acceptor orbitals. Error in the slope is estimated at 3.21 and error in the intercept is estimated at 8.07. 


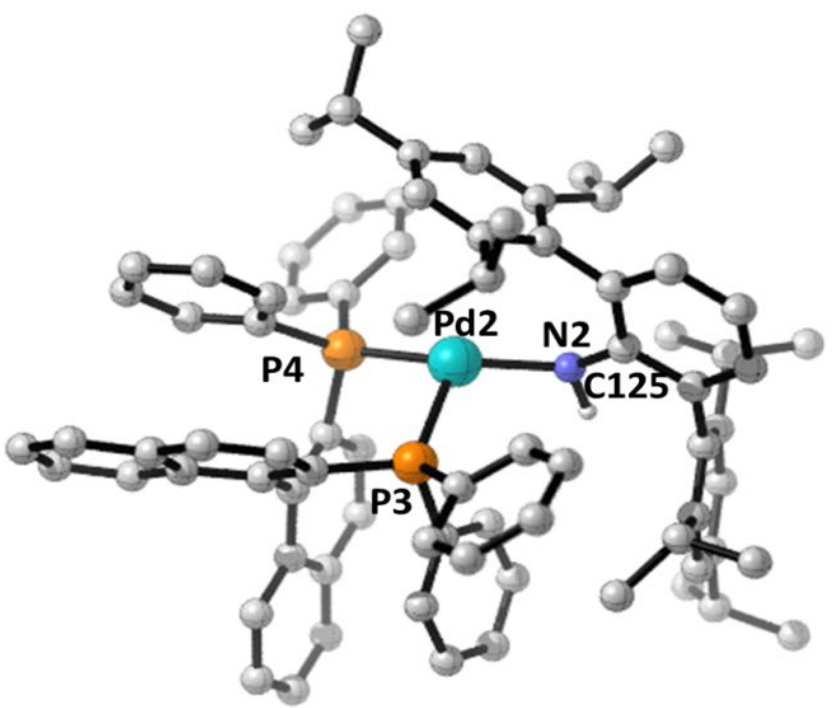

$$
\begin{array}{r}
\mathrm{Pd} 2-\mathrm{P} 3=2.383[2.321] \\
\mathrm{Pd} 2-\mathrm{P} 4=2.374[2.284] \\
\mathrm{Pd} 2-\mathrm{N} 2=2.083[2.063] \\
\mathrm{N} 2-\mathrm{C} 125=1.368[1.371] \\
\angle \mathrm{Pd} 2-\mathrm{N} 2-\mathrm{C} 125=143.0[140.0] \\
\angle \mathrm{P} 4-\mathrm{Pd} 2-\mathrm{N} 2=143.9[149.5] \\
\angle \mathrm{P} 3-\mathrm{Pd} 2-\mathrm{P} 4=93.4[92.1] \\
\angle \mathrm{P} 3-\mathrm{Pd} 2-\mathrm{N} 2=119.8[114.4]
\end{array}
$$

Fig. S82. Optimized structure of the Mononuclear Pd(I) Amido Complex 1 at the B3LYP/def2-SVP or level of theory. Key bond distances $(\AA)$, and bond angles $\left(^{\circ}\right)$ are given in angstroms and degrees, respectively. The corresponding experimental values are given in the bracket. Color code: $\mathrm{Pd}$, light green; P, orange; N, blue; C, gray. Hydrogen atoms have been omitted for clarity. 


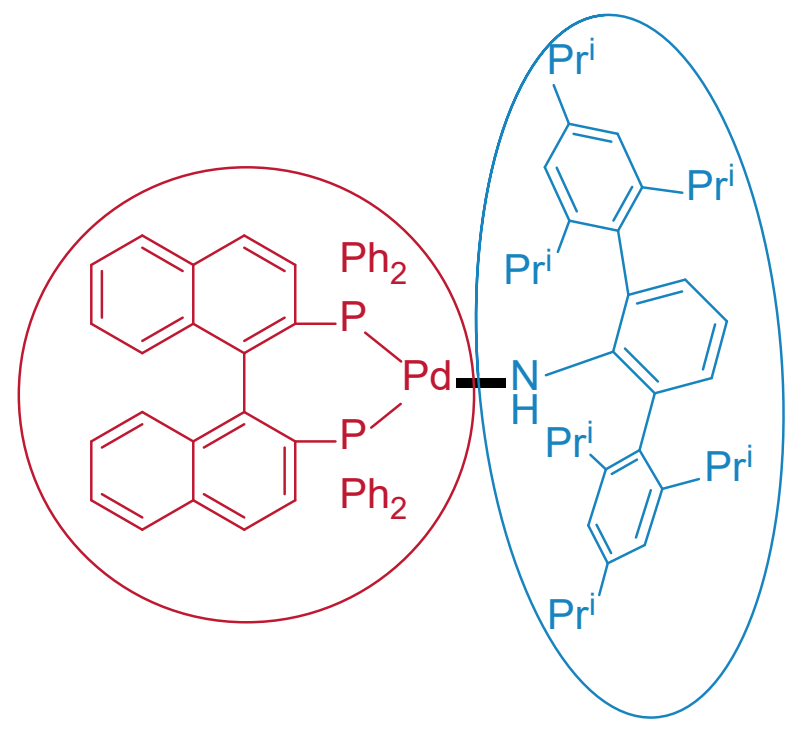

Table S3. EDA-NOCV results of [(BINAP)Pd(NHAr $\left.\left.{ }^{\text {Trip }}\right)\right]$ (1) at the $\mathrm{B} 3 \mathrm{LYP}+(\mathrm{D} 3 \mathrm{BJ}) / \mathrm{TZ2P} / / \mathrm{B} 3 \mathrm{LYP} /$ def2-SVP level of theory. Fragments are given in singlet (S) or doublet (D) electronic states. Energy values are given in $\mathrm{kcal} / \mathrm{mol}$.

\begin{tabular}{|c|c|c|c|}
\hline Fragments & $\begin{array}{l}{\left[(\mathrm{BINAP}) \mathrm{Pd}^{0}\right](\mathrm{S})} \\
+\mathrm{NHAr}^{\text {Trip }}(\mathrm{D}) \\
\end{array}$ & $\begin{array}{l}{\left[(\mathrm{BINAP}) \mathrm{Pd}^{\mathrm{I}}\right]^{+}(\mathrm{D})} \\
+\left[\mathrm{NHAr}^{\text {Trip }}\right]^{-}(\mathrm{S})\end{array}$ & $\begin{array}{l}{\left[(\mathrm{BINAP}) \mathrm{Pd}^{\mathrm{I}}\right]^{-}(\mathrm{D})} \\
+\left[\mathrm{NHAr}^{\text {Trip }}\right]^{+}(\mathrm{S}) \\
\end{array}$ \\
\hline$\Delta \mathrm{E}_{\text {int }}$ & -72.4 & -139.0 & -221.8 \\
\hline$\Delta$ EPauli & 123.1 & 129.5 & 126.0 \\
\hline$\Delta \mathrm{E}_{\mathrm{disp}}^{[\mathrm{a}]}$ & $-31.3(16.0 \%)$ & $-31.3(11.7 \%)$ & $-31.3(9.0 \%)$ \\
\hline$\Delta \mathrm{E}_{\text {elstat }}{ }^{[\mathrm{a}]}$ & $-92.3(47.2 \%)$ & $-163.5(60.9 \%)$ & $-125.3(36.0 \%)$ \\
\hline$\Delta \mathrm{E}_{\text {orb }}^{[\mathrm{a}]}$ & $-72.0(36.8 \%)$ & $-73.7(27.4 \%)$ & $-191.3(55.0 \%)$ \\
\hline$\Delta \mathrm{E}_{\text {orb1 }}[\mathrm{b}]$ & $-43.2(59.9 \%)$ & $-23.8(32.3 \%)$ & \\
\hline$\Delta \mathrm{E}_{\mathrm{orb} 2}{ }^{[\mathrm{b}]}$ & $-16.9(23.5 \%)$ & $-23.2(31.5 \%)$ & \\
\hline$\Delta \mathrm{E}_{\text {rest }}$ & $-11.9(16.6 \%)$ & $-26.7(36.2 \%)$ & \\
\hline$\Delta \mathrm{E}_{\text {prep }}$ & 21.5 & 17.7 & \\
\hline$\Delta \mathrm{E}=-\mathrm{D}_{\mathrm{e}}$ & -50.9 & -121.3 & \\
\hline
\end{tabular}

${ }^{\text {a }}$ The values in parentheses give the percentage contribution to the total attractive interactions $\Delta \mathrm{E}_{\text {elstat }}+\Delta \mathrm{E}_{\text {orb }}+\Delta \mathrm{E}_{\text {disp. }}$.

${ }^{b}$ The values in parentheses give the percentage contribution to the total orbital interactions $\Delta \mathrm{E}_{\text {orb. }}$ 


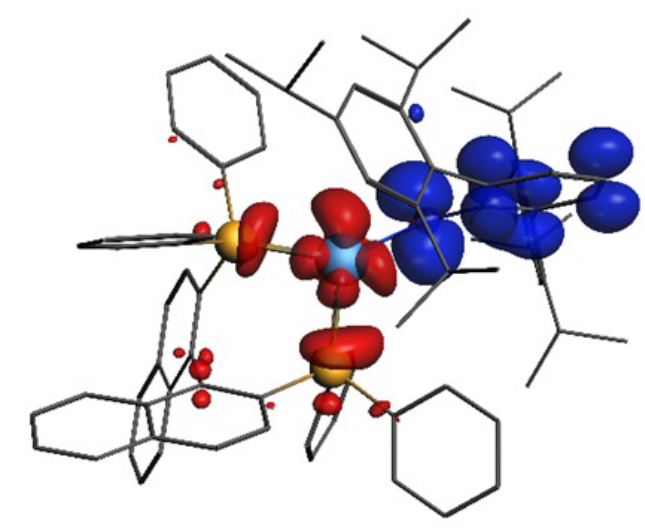

$$
\begin{gathered}
\Delta \mathrm{E}_{\text {orb }(1)}=\Delta \mathrm{E}_{\text {orb }(1 \beta)}=-43.2 \mathrm{kcal} / \mathrm{mol} \\
v= \pm 0.832
\end{gathered}
$$

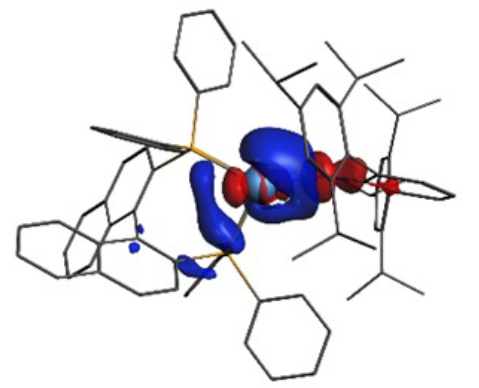

$\Delta \mathrm{E}_{\text {orb }(1 \mathrm{\alpha})}=-8.8 \mathrm{kcal} / \mathrm{mol}$ $v= \pm 0.227$

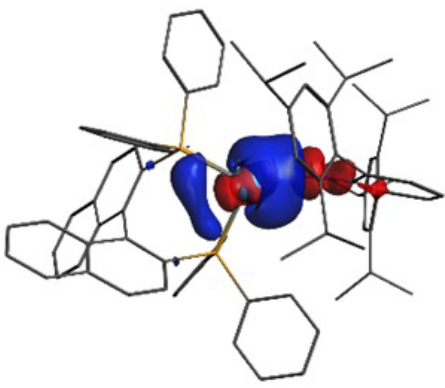

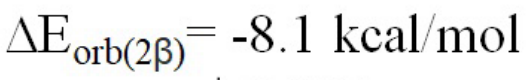
$v= \pm 0.204$

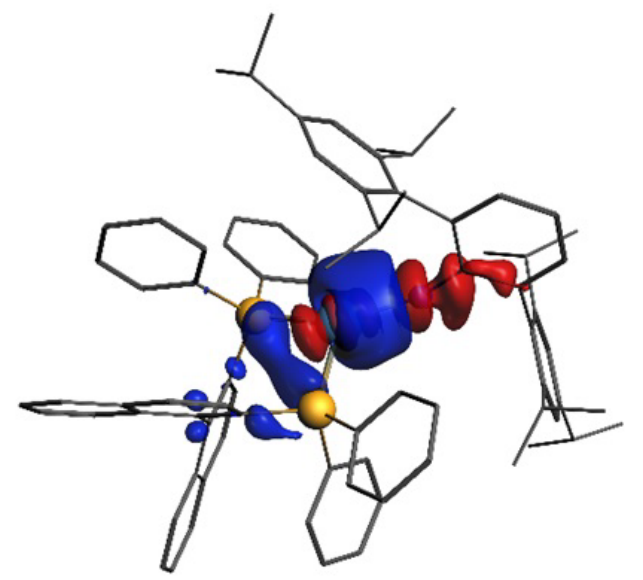

$$
\begin{gathered}
\Delta \mathrm{E}_{\mathrm{orb}(2)}=\Delta \mathrm{E}_{\mathrm{orb}(1 \alpha)}+\Delta \mathrm{E}_{\text {orb }(2 \beta)}=-16.9 \mathrm{kcal} / \mathrm{mol} \\
v= \pm 0.431
\end{gathered}
$$

Fig. S83. Plot of deformation densities $\Delta \rho$ of the pairwise orbital interactions between the $\left[(\mathrm{BINAP}) \mathrm{Pd}^{0}\right](\mathrm{S})+\mathrm{NHAr}^{\text {Trip }}(\mathrm{D})$ two fragments in their neutral states in [(BINAP)Pd(NHAr $\left.\left.{ }^{\text {Trip }}\right)\right](\mathbf{1})$ together with the associated interaction energies $\Delta \mathrm{E}_{\text {orb }}($ in $\mathrm{kcal} / \mathrm{mol})$. The eigenvalues $v$ are a measure for the relative amount of charge transfer. The direction of the charge flow is from red to blue. 


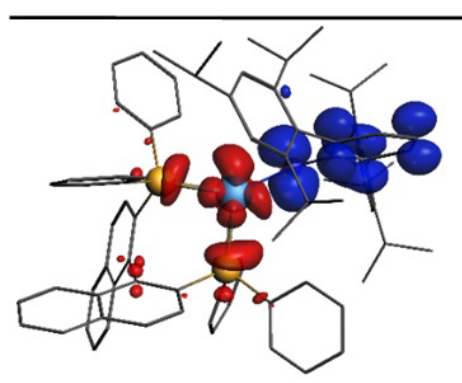

$\Delta \mathrm{E}_{\text {orb(1) }}=-43.2 \mathrm{kcal} / \mathrm{mol}$ $v= \pm 0.832$

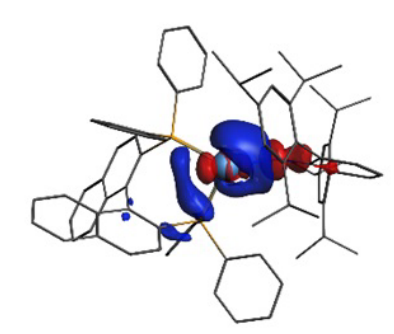

$\Delta \mathrm{E}_{\text {orb }(1 \mathrm{\alpha})}=-8.8 \mathrm{kcal} / \mathrm{mol}$

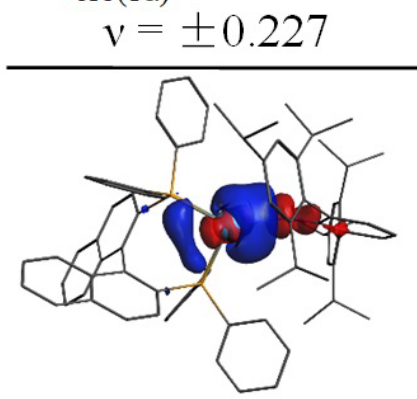

$\Delta \mathrm{E}_{\mathrm{orb}(2 \beta)}=-8.1 \mathrm{kcal} / \mathrm{mol}$ $v= \pm 0.204$

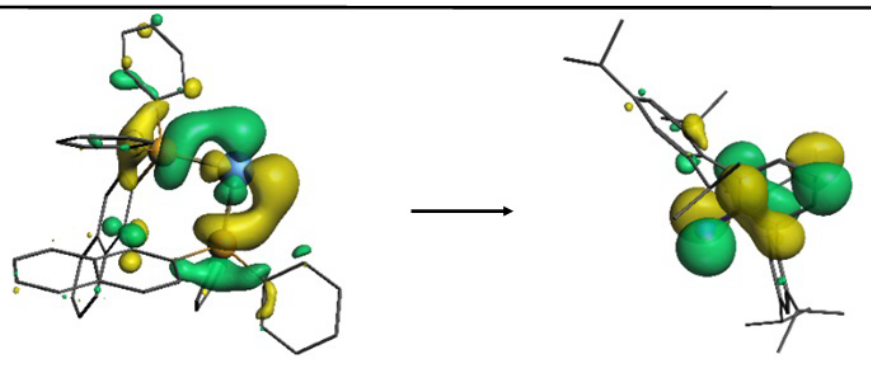

Frag 1-114A-HOMO $(-0.708)$

Frag2-100A-SOMO $(0.725)$

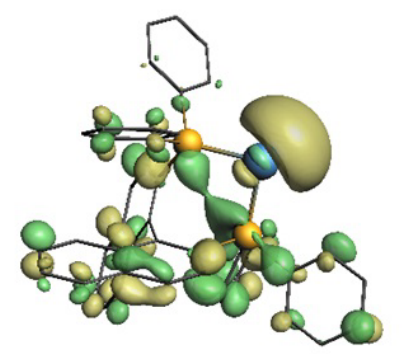

Frag1-117A-LUMO+2 $(0.012)$

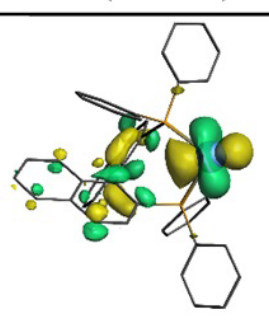

Frag1-110A-HOMO-4 $(-0.005)$

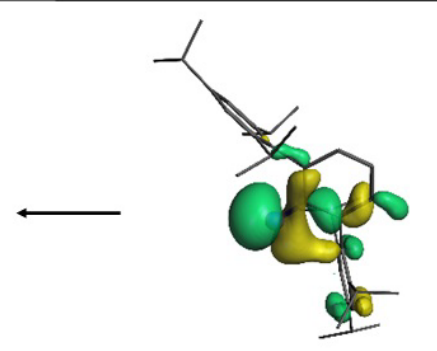

Frag2-94A-HOMO-5

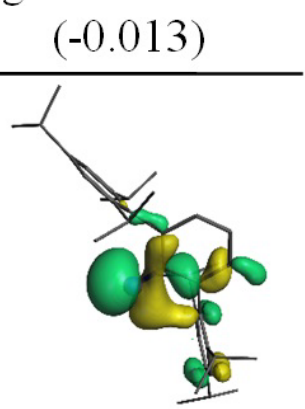

Frag2-94A-HOMO-5 $(-0.004)$

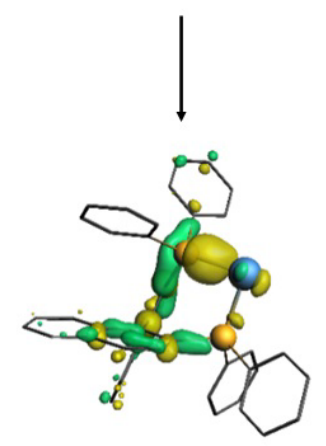

Frag1-94A-HOMO-20

$(0.004)$

Fig. S84. Shape of the most important interacting MOs of the $\left[\left(\mathrm{BINAP} \mathrm{Pd}^{0}\right](\mathrm{S})+\mathrm{NHAr}^{\text {Trip }}(\mathrm{D})\right.$ two fragments in their neutral states in [(BINAP)Pd(NHAr $\left.\left.{ }^{\text {Trip }}\right)\right](\mathbf{1})$, plot of deformation densities $\Delta \rho$ of the pairwise orbital interactions and the associated interaction energies $\left(\Delta \mathrm{E}_{\text {orb }}\right)$ between fragments. The numbers in bracket are SFO contribution. The direction of the charge flow is red to blue. 


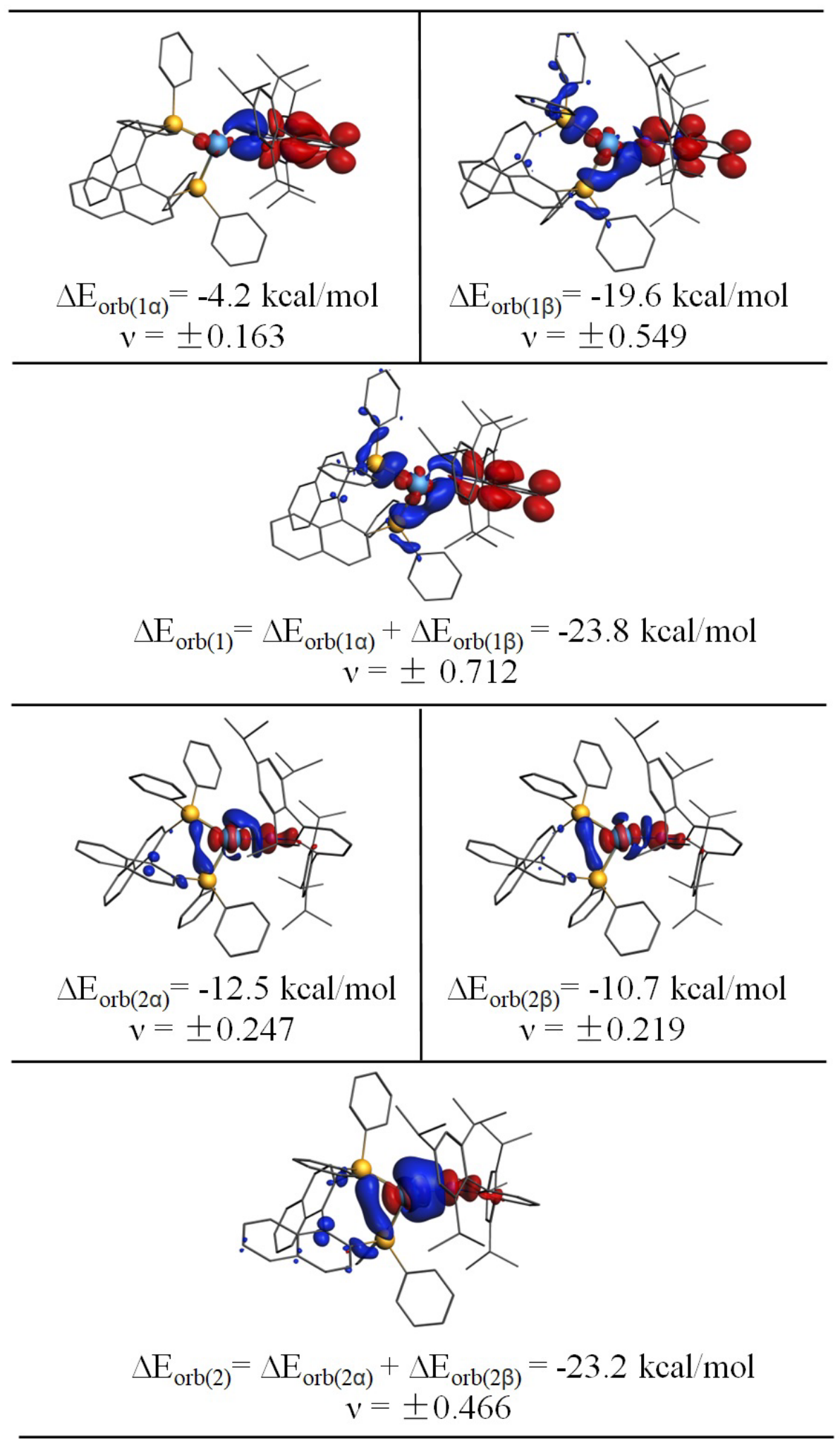

Fig. S85. Plot of deformation densities $\Delta \rho$ of the pairwise orbital interactions between the $\left[(\mathrm{BINAP}) \mathrm{Pd}^{\mathrm{I}}\right]^{+}(\mathrm{D})+\left[\mathrm{NHAr}^{\text {Trip }}\right]^{-}(\mathrm{S})$ two fragments in [(BINAP)Pd(NHAr $\left.\left.{ }^{\text {Trip }}\right)\right](\mathbf{1})$ together with the associated interaction energies $\Delta \mathrm{E}_{\text {orb }}$ (in $\mathrm{kcal} / \mathrm{mol}$ ). The eigenvalues $v$ are a measure for the relative amount of charge transfer. The direction of the charge flow is from red to blue. 


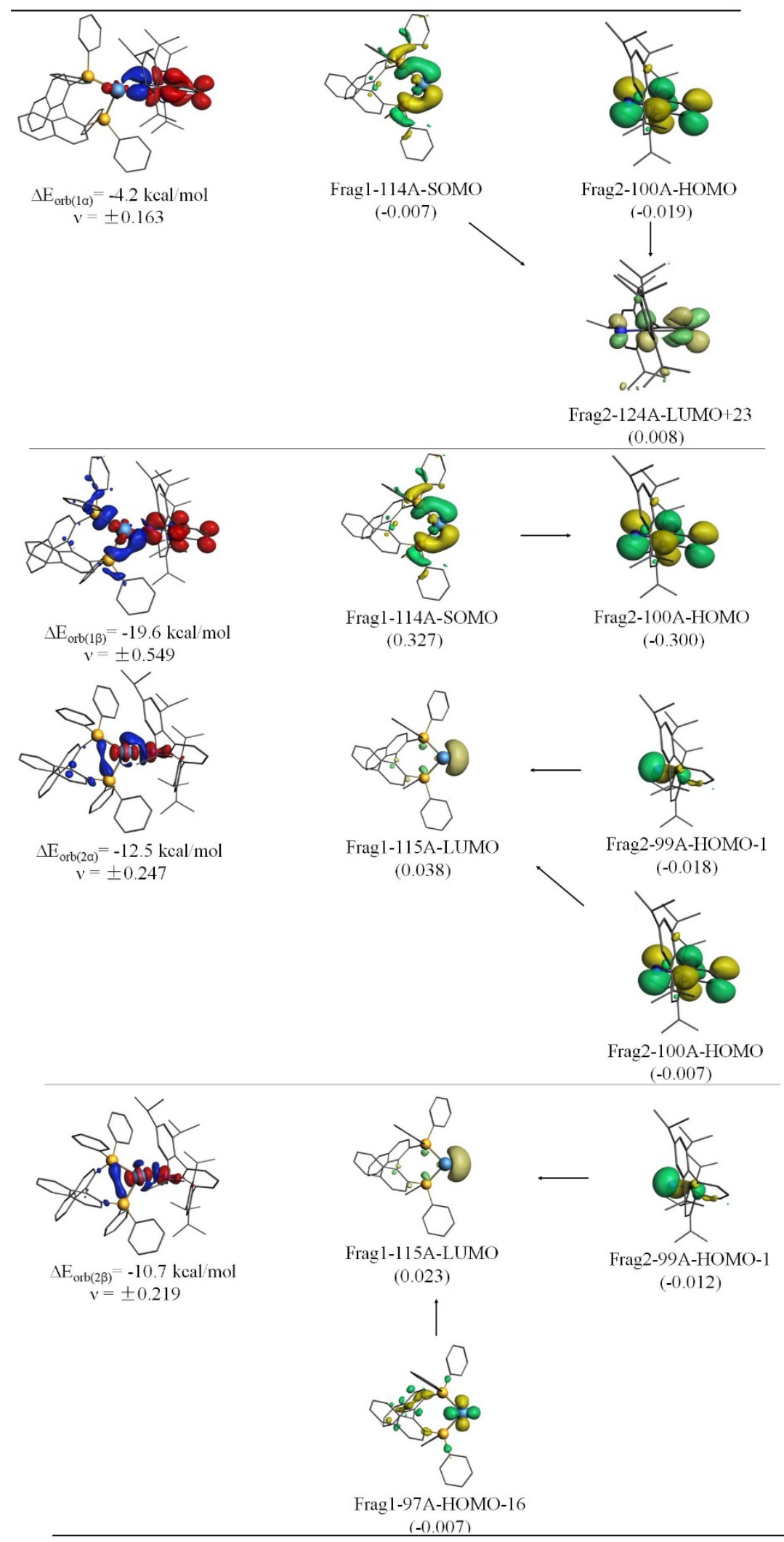

Fig. S86. Shape of the most important interacting MOs of the $\left[(\mathrm{BINAP}) \mathrm{Pd}^{\mathrm{I}}\right]^{+}(\mathrm{D})+\left[\mathrm{NHAr}^{\mathrm{Trip}}\right]^{-}(\mathrm{S})$ two fragments in [(BINAP)Pd(NHAr $\left.\left.{ }^{\text {Trip }}\right)\right]$ (1), plot of deformation densities $\Delta \rho$ of the pairwise orbital interactions and the associated interaction energies $\left(\Delta \mathrm{E}_{\text {orb }}\right)$ between fragments. The numbers in bracket are SFO contribution. The direction of the charge flow is red to blue. 


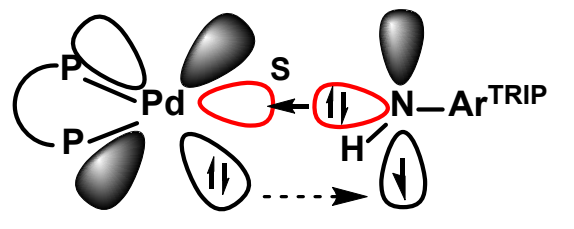

$\left[(\mathrm{BINAP}) \mathrm{Pd}^{0}\right](\mathrm{S})+\left[\mathrm{NHAr}{ }^{\mathrm{TRIP}}\right](\mathrm{D})$

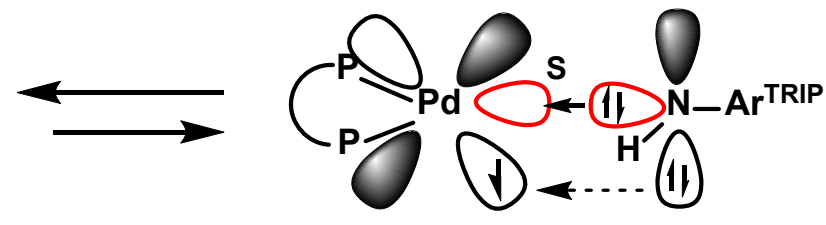

$\left[(\mathrm{BINAP}) \mathrm{Pd}^{\prime}\right]^{+}(\mathrm{D})+\left[\mathrm{NHAr}^{\mathrm{TRIP}}\right]^{-}(\mathrm{S})$

(a)

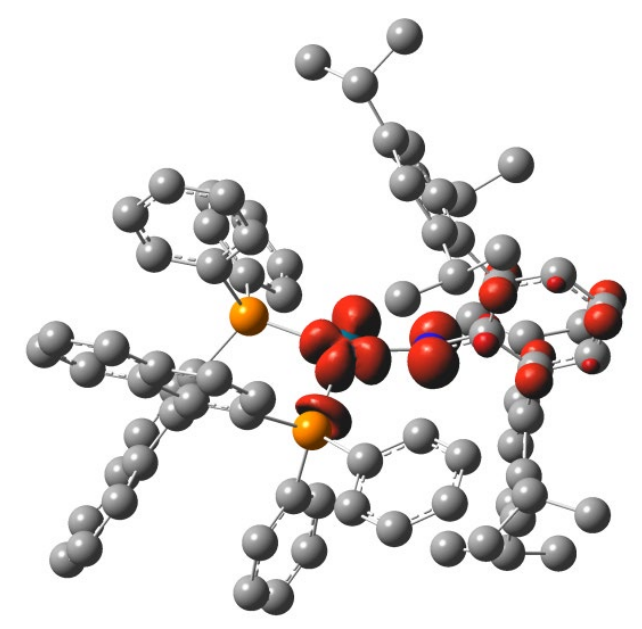

$\rho^{\alpha}{ }_{P d}=0.418$

$\rho^{\alpha}=0.197$

(b)

Fig. S87. Schematic representation of electronic resonance about $\mathrm{Pd}$ and $\mathrm{N}$ in the [(BINAP)Pd(NHAr $\left.\left.{ }^{\text {TRIP }}\right)\right]$ (a) ; Plot of the spin density of the [(BINAP)Pd(NHAr $\left.\left.{ }^{\text {TRIP }}\right)\right]$ at the B3LYP/def2-SVP level (b). 


\section{Data S1. (separate file)}

Type or paste caption here.

Cartesian coordinates $(\AA)$ and energies(in hartree) at the B3LYP/def2-SVP level Mononuclear Pd(I) Amido Complex 1

Energy $=-3960.9591951$

$\begin{array}{lccc}\mathrm{Pd} & 0.069792 & 0.207118 & -0.119940 \\ \mathrm{P} & -1.001160 & -1.337644 & 1.344525 \\ \mathrm{P} & -1.821271 & 0.386506 & -1.543461 \\ \mathrm{~N} & 2.135137 & 0.463824 & -0.023177 \\ \mathrm{H} & 2.525738 & -0.419250 & -0.355818 \\ \mathrm{C} & -2.806938 & -0.973459 & 1.569408 \\ \mathrm{C} & -3.761502 & -1.150721 & 0.556675 \\ \mathrm{C} & -3.456057 & -1.843998 & -0.745562 \\ \mathrm{C} & -2.720189 & -1.236130 & -1.774576 \\ \mathrm{C} & -3.131448 & 1.619684 & -1.149131 \\ \mathrm{C} & -2.813783 & 2.650928 & -0.250642 \\ \mathrm{H} & -1.821806 & 2.687875 & 0.206747 \\ \mathrm{C} & -3.760470 & 3.631969 & 0.060852 \\ \mathrm{H} & -3.500792 & 4.424324 & 0.766488 \\ \mathrm{C} & -5.028862 & 3.596885 & -0.524337 \\ \mathrm{H} & -5.768640 & 4.363040 & -0.278131 \\ \mathrm{C} & -5.352293 & 2.574237 & -1.422019 \\ \mathrm{H} & -6.345706 & 2.535999 & -1.875804 \\ \mathrm{C} & -4.411265 & 1.589372 & -1.730086 \\ \mathrm{H} & -4.679030 & 0.786835 & -2.420885 \\ \mathrm{C} & -1.292513 & 0.839623 & -3.266501 \\ \mathrm{C} & -0.059243 & 0.335263 & -3.719746 \\ \mathrm{H} & 0.545706 & -0.283837 & -3.051463 \\ \mathrm{C} & 0.407807 & 0.629273 & -5.002425 \\ \mathrm{H} & 1.366774 & 0.223845 & -5.334583 \\ \mathrm{C} & -0.338053 & 1.457875 & -5.846974 \\ \mathrm{H} & 0.031952 & 1.700864 & -6.846350 \\ \mathrm{C} & -1.551661 & 1.985565 & -5.398939 \\ \mathrm{H} & -2.135161 & 2.645189 & -6.046632 \\ \mathrm{C} & -2.029056 & 1.676739 & -4.120700 \\ \mathrm{H} & -2.977810 & 2.101953 & -3.791239 \\ \mathrm{C} & -2.531126 & -1.936010 & -3.002859 \\ \mathrm{H} & -1.966913 & -1.462884 & -3.805534 \\ \mathrm{C} & -3.047108 & -3.192537 & -3.208083 \\ \mathrm{H} & -2.888846 & -3.700526 & -4.163284\end{array}$




\begin{tabular}{|c|c|c|c|}
\hline $\mathrm{C}$ & -3.792384 & -3.845067 & -2.193939 \\
\hline $\mathrm{C}$ & -4.005347 & -3.163867 & -0.949893 \\
\hline $\mathrm{C}$ & -4.763806 & -3.843074 & 0.050309 \\
\hline $\mathrm{H}$ & -4.941967 & -3.353457 & 1.007427 \\
\hline $\mathrm{C}$ & -5.277238 & -5.104634 & -0.167865 \\
\hline $\mathrm{H}$ & -5.855664 & -5.596595 & 0.618427 \\
\hline $\mathrm{C}$ & -5.062037 & -5.768601 & -1.400488 \\
\hline $\mathrm{H}$ & -5.474376 & -6.767743 & -1.562064 \\
\hline $\mathrm{C}$ & -4.331916 & -5.147346 & -2.389736 \\
\hline $\mathrm{H}$ & -4.155161 & -5.645926 & -3.346697 \\
\hline $\mathrm{C}$ & -5.113902 & -0.686601 & 0.767639 \\
\hline $\mathrm{C}$ & -5.463287 & -0.029366 & 1.994129 \\
\hline $\mathrm{C}$ & -4.457515 & 0.161341 & 2.976173 \\
\hline $\mathrm{H}$ & -4.712910 & 0.673896 & 3.907523 \\
\hline $\mathrm{C}$ & -3.178467 & -0.291164 & 2.767957 \\
\hline $\mathrm{H}$ & -2.428724 & -0.125226 & 3.540928 \\
\hline $\mathrm{C}$ & -6.797195 & 0.418373 & 2.203403 \\
\hline $\mathrm{H}$ & -7.037251 & 0.916387 & 3.146785 \\
\hline $\mathrm{C}$ & -7.768101 & 0.229044 & 1.244114 \\
\hline $\mathrm{H}$ & -8.791025 & 0.572822 & 1.416841 \\
\hline $\mathrm{C}$ & -7.432249 & -0.412568 & 0.027531 \\
\hline $\mathrm{H}$ & -8.199484 & -0.559711 & -0.737039 \\
\hline $\mathrm{C}$ & -6.145126 & -0.851703 & -0.204873 \\
\hline $\mathrm{H}$ & -5.912608 & -1.337826 & -1.151631 \\
\hline $\mathrm{C}$ & -0.341974 & -1.429082 & 3.080420 \\
\hline $\mathrm{C}$ & -0.866116 & -2.284520 & 4.067977 \\
\hline $\mathrm{H}$ & -1.716436 & -2.930836 & 3.844377 \\
\hline $\mathrm{C}$ & -0.314918 & -2.311250 & 5.349772 \\
\hline $\mathrm{H}$ & -0.735514 & -2.978840 & 6.106394 \\
\hline $\mathrm{C}$ & 0.771884 & -1.486500 & 5.666353 \\
\hline $\mathrm{H}$ & 1.201270 & -1.507942 & 6.671425 \\
\hline $\mathrm{C}$ & 1.304789 & -0.641123 & 4.692041 \\
\hline $\mathrm{H}$ & 2.157100 & 0.001906 & 4.925287 \\
\hline $\mathrm{C}$ & 0.751920 & -0.614847 & 3.405845 \\
\hline $\mathrm{H}$ & 1.175660 & 0.039073 & 2.640510 \\
\hline $\mathrm{C}$ & -0.848112 & -3.097617 & 0.793227 \\
\hline $\mathrm{C}$ & 0.191826 & -3.413024 & -0.097211 \\
\hline $\mathrm{H}$ & 0.819713 & -2.610885 & -0.492667 \\
\hline $\mathrm{C}$ & 0.427179 & -4.737364 & -0.479295 \\
\hline $\mathrm{H}$ & 1.243191 & -4.962855 & -1.170365 \\
\hline $\mathrm{C}$ & -0.377595 & -5.763843 & 0.020624 \\
\hline $\mathrm{H}$ & -0.196252 & -6.799633 & -0.277736 \\
\hline $\mathrm{C}$ & -1.421800 & -5.459890 & 0.972000 \\
\hline $\mathrm{H}$ & -2.064619 & -6.255649 & 1.284504 \\
\hline
\end{tabular}




\begin{tabular}{|c|c|c|c|}
\hline $\mathrm{C}$ & -1.655316 & -4.137724 & 1.283765 \\
\hline $\mathrm{H}$ & -2.484549 & -3.918383 & 1.958365 \\
\hline $\mathrm{C}$ & 3.124415 & 1.122334 & 0.654670 \\
\hline $\mathrm{C}$ & 4.406762 & 0.487898 & 0.859785 \\
\hline $\mathrm{C}$ & 4.722092 & -0.846039 & 0.230629 \\
\hline $\mathrm{C}$ & 4.644323 & -2.051523 & 0.974363 \\
\hline $\mathrm{C}$ & 5.013647 & -3.259192 & 0.361819 \\
\hline $\mathrm{H}$ & 4.960278 & -4.185552 & 0.939613 \\
\hline $\mathrm{C}$ & 5.453298 & -3.326612 & -0.962937 \\
\hline $\mathrm{C}$ & 5.520879 & -2.128795 & -1.683363 \\
\hline $\mathrm{H}$ & 5.870517 & -2.149749 & -2.719129 \\
\hline $\mathrm{C}$ & 5.170072 & -0.895618 & -1.117959 \\
\hline $\mathrm{C}$ & 5.330919 & 0.368149 & -1.963046 \\
\hline $\mathrm{H}$ & 4.910597 & 1.205397 & -1.389409 \\
\hline $\mathrm{C}$ & 6.817294 & 0.692599 & -2.199563 \\
\hline $\mathrm{H}$ & 7.356858 & 0.801602 & -1.245924 \\
\hline $\mathrm{H}$ & 6.926242 & 1.636072 & -2.759958 \\
\hline $\mathrm{H}$ & 7.317798 & -0.101386 & -2.778710 \\
\hline $\mathrm{C}$ & 4.558449 & 0.295618 & -3.290723 \\
\hline $\mathrm{H}$ & 4.942749 & -0.499505 & -3.950872 \\
\hline $\mathrm{H}$ & 4.646156 & 1.247590 & -3.839362 \\
\hline $\mathrm{H}$ & 3.487846 & 0.106482 & -3.116091 \\
\hline $\mathrm{C}$ & 5.842681 & -4.660342 & -1.589434 \\
\hline $\mathrm{H}$ & 5.718836 & -5.427335 & -0.804896 \\
\hline $\mathrm{C}$ & 4.911312 & -5.043344 & -2.752756 \\
\hline $\mathrm{H}$ & 3.858288 & -5.065686 & -2.429683 \\
\hline $\mathrm{H}$ & 5.167055 & -6.039460 & -3.150657 \\
\hline $\mathrm{H}$ & 4.989159 & -4.323036 & -3.583803 \\
\hline $\mathrm{C}$ & 7.317504 & -4.688272 & -2.026134 \\
\hline $\mathrm{H}$ & 7.514633 & -3.956425 & -2.826726 \\
\hline $\mathrm{H}$ & 7.593631 & -5.683701 & -2.411860 \\
\hline $\mathrm{H}$ & 7.987433 & -4.450304 & -1.185147 \\
\hline $\mathrm{C}$ & 4.208966 & -2.068569 & 2.438832 \\
\hline $\mathrm{H}$ & 3.683758 & -1.120741 & 2.630805 \\
\hline $\mathrm{C}$ & 3.234094 & -3.210947 & 2.766756 \\
\hline $\mathrm{H}$ & 2.374585 & -3.222666 & 2.079827 \\
\hline $\mathrm{H}$ & 2.843854 & -3.096814 & 3.789943 \\
\hline $\mathrm{H}$ & 3.721336 & -4.198234 & 2.712865 \\
\hline $\mathrm{C}$ & 5.426593 & -2.115009 & 3.381667 \\
\hline $\mathrm{H}$ & 6.011012 & -3.037481 & 3.226508 \\
\hline $\mathrm{H}$ & 5.103815 & -2.094854 & 4.436106 \\
\hline $\mathrm{H}$ & 6.099464 & -1.260358 & 3.218124 \\
\hline $\mathrm{C}$ & 5.407502 & 1.134030 & 1.588488 \\
\hline $\mathrm{H}$ & 6.368537 & 0.629759 & 1.722167 \\
\hline
\end{tabular}




\begin{tabular}{|c|c|c|c|}
\hline $\mathrm{C}$ & 5.212369 & 2.411330 & 2.121075 \\
\hline $\mathrm{H}$ & 6.002454 & 2.906429 & 2.690199 \\
\hline $\mathrm{C}$ & 4.005344 & 3.063533 & 1.863588 \\
\hline $\mathrm{H}$ & 3.869095 & 4.091287 & 2.210189 \\
\hline $\mathrm{C}$ & 2.965596 & 2.470492 & 1.131986 \\
\hline $\mathrm{C}$ & 1.802793 & 3.369730 & 0.793712 \\
\hline $\mathrm{C}$ & 0.879410 & 3.781471 & 1.788116 \\
\hline $\mathrm{C}$ & -0.047615 & 4.794179 & 1.492022 \\
\hline $\mathrm{H}$ & -0.743945 & 5.119349 & 2.271195 \\
\hline $\mathrm{C}$ & -0.101783 & 5.422661 & 0.245327 \\
\hline $\mathrm{C}$ & 0.792915 & 4.98000 & -0.735512 \\
\hline $\mathrm{H}$ & 0.773286 & 5.448914 & -1.720276 \\
\hline $\mathrm{C}$ & 1.739548 & 3.976590 & -0.491452 \\
\hline $\mathrm{C}$ & 2.745078 & 3.631341 & -1.589952 \\
\hline $\mathrm{H}$ & 3.110879 & 2.616701 & -1.385811 \\
\hline $\mathrm{C}$ & 2.132122 & 3.605132 & -2.998125 \\
\hline $\mathrm{H}$ & 1.238477 & 2.964997 & -3.038769 \\
\hline $\mathrm{H}$ & 2.863824 & 3.209193 & -3.720820 \\
\hline $\mathrm{H}$ & 1.848160 & 4.610254 & -3.351014 \\
\hline $\mathrm{C}$ & 3.955441 & 4.584088 & -1.543751 \\
\hline $\mathrm{H}$ & 3.644812 & 5.623832 & -1.742080 \\
\hline $\mathrm{H}$ & 4.702401 & 4.304901 & -2.306119 \\
\hline $\mathrm{H}$ & 4.450564 & 4.560681 & -0.561652 \\
\hline $\mathrm{C}$ & -1.052817 & 6.592134 & 0.011157 \\
\hline $\mathrm{H}$ & -1.873595 & 6.484939 & 0.743428 \\
\hline $\mathrm{C}$ & -0.351964 & 7.931290 & 0.312538 \\
\hline $\mathrm{H}$ & 0.054471 & 7.949217 & 1.335713 \\
\hline $\mathrm{H}$ & -1.051429 & 8.777612 & 0.206275 \\
\hline $\mathrm{H}$ & 0.488505 & 8.097170 & -0.381693 \\
\hline $\mathrm{C}$ & -1.685411 & 6.610511 & -1.387813 \\
\hline $\mathrm{H}$ & -0.935129 & 6.804169 & -2.171607 \\
\hline $\mathrm{H}$ & -2.439549 & 7.411406 & -1.458791 \\
\hline $\mathrm{H}$ & -2.178515 & 5.654810 & -1.621986 \\
\hline $\mathrm{C}$ & 0.869665 & 3.182254 & 3.194385 \\
\hline $\mathrm{H}$ & 1.558842 & 2.324911 & 3.187400 \\
\hline $\mathrm{C}$ & 1.389197 & 4.175195 & 4.250655 \\
\hline $\mathrm{H}$ & 1.402772 & 3.709659 & 5.250521 \\
\hline $\mathrm{H}$ & 0.747164 & 5.069916 & 4.308217 \\
\hline $\mathrm{H}$ & 2.411200 & 4.512579 & 4.022486 \\
\hline $\mathrm{C}$ & -0.520158 & 2.655479 & 3.590198 \\
\hline $\mathrm{H}$ & -1.251032 & 3.472895 & 3.703468 \\
\hline $\mathrm{H}$ & -0.472198 & 2.121315 & 4.552893 \\
\hline $\mathrm{H}$ & -0.911585 & 1.958212 & 2.834362 \\
\hline
\end{tabular}

